Christian Lininger

\title{
Consumption-Based Approaches in International Climate Policy
}

\section{Doctoral Thesis}

\author{
to be awarded the degree of \\ Doctor of Social and Economic Sciences (Dr. rer.soc.oec.) \\ at the University of Graz, Austria
}

Ao.Univ.-Prof. Dr. Karl W. Steininger (first supervisor)

Department of Economics and Wegener Center for Climate and Global Change, University of Graz

Ao.Univ.-Prof. Dr. Karl Farmer (second supervisor)

Department of Economics, University of Graz

Graz, May 2014 

Author's Declaration

Unless otherwise indicated in the text or references, or acknowledged above, this thesis is entirely the product of my own scholarly work. Any inaccuracies of fact or faults in reasoning are my own and accordingly I take full responsibility. This thesis has not been submitted either in whole or part, for a degree at this or any other university or institution. This is to certify that the printed version is equivalent to the submitted electronic one.

Graz, May 2014

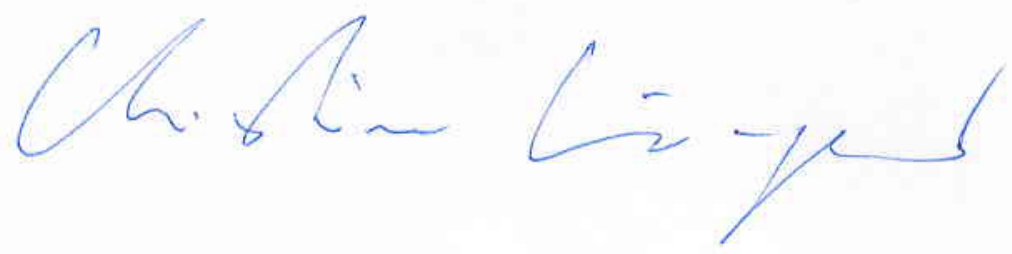





\section{Abstract}

International climate policy is currently characterized by bottom-up, unilateral approaches to emissions abatement. Some authors suggest that the global effectiveness of unilateral policies can be improved by switching from the current system of a production-based to a consumption-based policy orientation, i.e. by not targeting the emissions discharged on the territory of the country that abates, but the emissions embodied in the goods it consumes. This study analyzes whether industrialized countries by adopting this approach can indeed increase policy effectiveness - defined in terms of environmental effectiveness, cost-effectiveness, and carbon leakage. First, the findings of two literature strands that both relate to this subject, but that have for some years existed side by side with only little exchange of ideas, are compared - the literature on emissions embodied in trade and the literature on border carbon adjustments. Then a stylized analytical model is developed to examine the effects of changing the policy orientation in more detail. Finally, recommendations for the practical design of effective consumption-based policies are formulated. This study finds that the relative effectiveness of the two policy variants cannot be decided in general, but depends on (i) demand, trade, and production parameters and (ii) the design of the policy instrument used to change the policy base. In particular, to be more effective than a production-based one, a consumption-based policy should not curb the exports of emerging economies, but cause a switch to a cleaner production-technology in these countries. This however requires some cooperation between abating and nonabating countries. Thus, a switch to a consumption orientation is not a policy tool whereby industrialized countries can unilaterally improve the effectiveness of abatement policies - rather it should be seen as an intermediate step on the way from unilateral to fully multilateral approaches to mitigation. 


\section{Zusammenfassung}

Die internationale Klimapolitik ist derzeit von unilateralen Ansätzen zur Emissionsreduktion geprägt. Manche Wissenschaftler argumentieren, die Industrieländer könnten die globale Effektivität solcher Ansätze erhöhen, indem sie in ihrer Klimapolitik nicht auf die auf ihrem Territorium in der Produktion freigesetzten Emissionen abzielen, sondern auf jene Emissionen, die in den von ihnen konsumierten Gütern „enthalten“ sind. Diese Studie untersucht derartige konsumorientierte PolitikAnsätze anhand der Effektivitäts-Kriterien Umwelt-Effektivität, Kosten-Effektivität und „Carbon Leakage“. Erster Schritt ist eine Gegenüberstellung zweier Forschungsströmungen, zwischen denen es bisher nur wenig Austausch an Ideen gegeben hat: der Literatur zu „Border Carbon Adjustments“ und jener zu „Emissions embodied in Trade“. Mithilfe eines theoretischen ökonomischen Modells werden dann die Auswirkungen produktions- und konsumorientierter Ansätze im Detail verglichen. Abschließend werden Vorschläge für die praktische Gestaltung einer konsumorientierten Klimapolitik erarbeitet. Zentrales Ergebnis dieser Studie ist, dass keiner der beiden Ansätze unter allen Bedingungen der effektivere ist. Die relative Effektivität von produktions- und konsumorientierten Politikvarianten hängt vielmehr (i) von Nachfrage-, Handels- und Produktionsparametern und (ii) der Ausgestaltung der verwendeten Politikinstrumente ab. Um effektiver zu sein, sollte eine konsumbasierte Politik unter anderem nicht die Exporte von Schwellenländern mindern, sondern in diesen Ländern einen Umstieg auf „saubere“ Produtktionstechnologien fördern. Dies erfordert aber ein Mindestmaß an Kooperation zwischen Ländern, die Klimapolitik betreiben und jenen, die dies nicht tun. Konsumorientierte Politik ist daher kein Ansatz, durch den Industrieländer unilateral eine höhere Politik-Effektivität erreichen können vielmehr sollte sie als Zwischenschritt auf dem Weg zu einer vollends multilateralen Klimapolitik gesehen werden. 


\section{Acknowledgements}

Working as a radio correspondent at the UN climate conferences in Copenhagen, Cancun, and Durban, I gained first-hand insights into the fight of many European countries for a comprehensive legally binding international climate treaty - and of their huge disappointment about what they saw as much too slow a progress towards that goal. I always had a great interest in environmental economics; and the experience at these UN conferences contributed to my motivation to explore the question whether there existed alternatives to climate policies based on a global treaty - approaches by which ambitious industrialized countries could improve the effectiveness of their climate policies even in case it was impossible to agree on the intended treaty in the near future. My superiors at the radio department of the Austrian Broadcasting Corporation let me to take time off to pursue doctoral studies at the University of Graz; and Professor Karl W. Steininger of the Department of Economics and the Wegener Center for Climate and Global Change of the University of Graz offered me to participate in the research project "RESPONSE" - a project that focused on options for European climate policy in a situation without a global top-down climate architecture. Most of the research for this thesis was performed in the course of this project. It was Professor Steininger who - as my first supervisor - suggested taking a deeper look into consumption-based approaches to climate policy, a field that turned out to be an extremely rewarding subject for economic research. I am deeply indebted to Professor Steininger for supporting my work by offering numerous valuable suggestions and engaging in lively discussions on the subject of my thesis - and for always encouraging me to follow through the planned research project. Very special thanks also go to my second supervisor, Professor Karl Farmer, also of the Department of Economics of the University of Graz. From the very beginning Professor Farmer guided me through the difficulties of developing the analytical model used in this study; he always took the time to look at my writing and to advise me on possible ways forward whenever I got stuck with the mathematical argument. The project "RESPONSE" was financed by the Austrian Climate Research Programme ACRP of the Austrian Climate and Energy Fund. This study tremendously benefited from the research of the group within the "RESPONSE" team focusing on consumption-based climate policies - Karl W. Steininer, Susanne Droege, Lukas Meyer, Dominic Roser, and Luke Tomlinson - and also from extensive discussions with all other team members: Birgit Bednar-Friedl, Barbara Buchner, Thomas Schinko, Andreas Tuerk and Alexa Zellentin. Completing this study would not have been possible without the help of all these people. Any remaining errors are mine alone. 



\section{Contents}

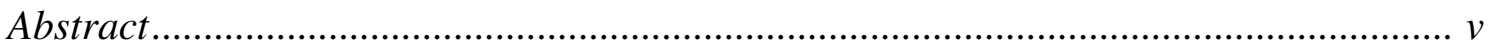

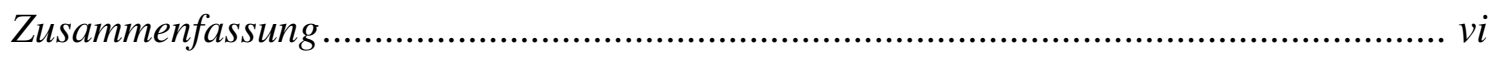

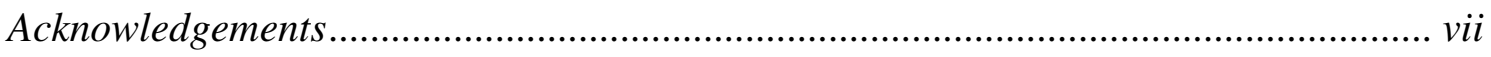

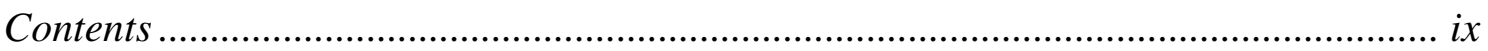

List of Figures/List of Tables ................................................................................. xiii

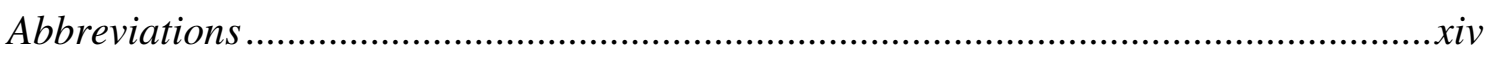

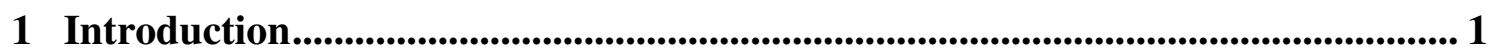

1.1 Production-based vs. consumption-based policy orientation ............................... 2

1.2 Consumption-based approaches and policy effectiveness ................................ 3

1.3 Two strands of literature - and a controversial political debate ......................... 5

1.4 Methodology, structure, and research objectives ............................................ 8

1.4.1 A common perspective on hitherto separate literature strands................... 8

1.4.2 Theoretical analysis .......................................................................... 9

1.4.3 Policy design and the practicability of consumption-based policies.......... 11

PART I - The Economic, Political, and Legal Background ................... 13

2 Consumption as a Base for Emission Accounting and as a Policy Base ............. 15

2.1 Production- and consumption-based emission inventories ............................... 15

2.1.1 Emission accounting concepts......................................................... 15

2.1.2 Determining a country's consumption-based emissions ........................... 19

2.2 Consumption-based emissions as a policy base .............................................. 20

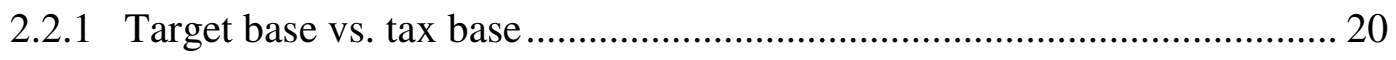

2.2.2 The tax base - production vs. consumption ............................................ 23

2.2.3 Implementing a consumption-based policy ........................................... 24

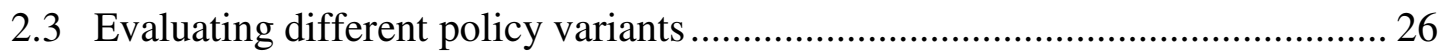

2.3.1 Criteria to evaluate a policy's effectiveness ........................................... 27

2.3.2 Carbon leakage ................................................................................. 28

(Policy-induced carbon leakage 28, Consumption-induced carbon leakage 31)

2.3.3 Criteria to evaluate the relative performance of different regions ............. 32

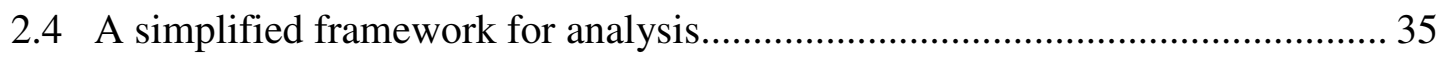

3 The Political and Legal Background to the Discussion about Consumption-Based Policies ............................................................................ 39

3.1 Border carbon adjustments - a politically controversial idea ........................... 39

3.2 Consumption-based policies and world trade law ......................................... 43 
4 Unilateral Climate Policies - the Theoretical Economic Background .49

4.1 Optimal unilateral abatement policies ............................................................49

4.2 Analysis of carbon leakage and possible counter-measures................................51

4.3 Macroeconomic effects not depicted in simple model .....................................54

5 Quantitative studies of carbon leakage and the effects of border adjustments..57

5.1 Quantitative estimates of carbon leakage .......................................................58

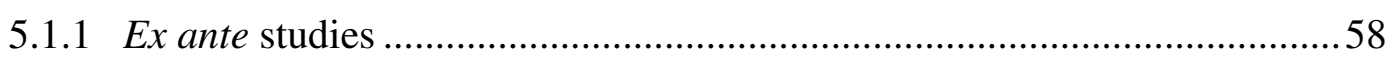

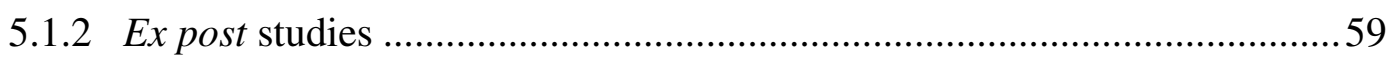

5.1.3 Apportioning overall leakage - which channels are relevant? ..................60 60

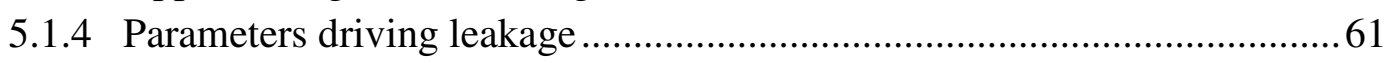

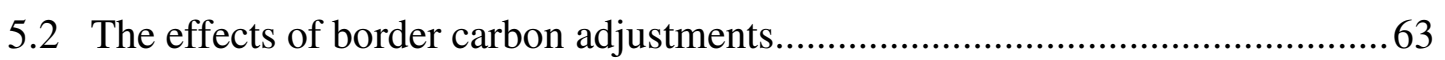

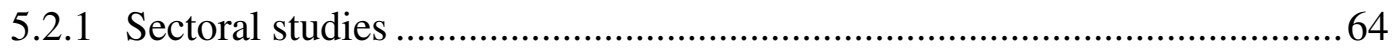

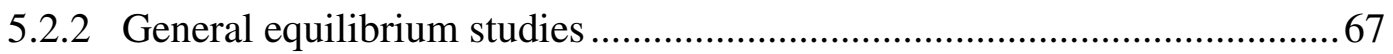

(Leakage channels 68, Model structure 68, Import tariffs vs.

full carbon adjustments 69, Calculating the carbon content 71,

Producer response 73)

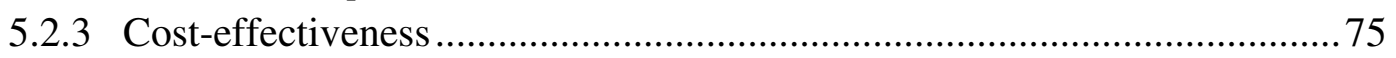

5.2.4 International distribution of the "burden" of the policy …......................... 76

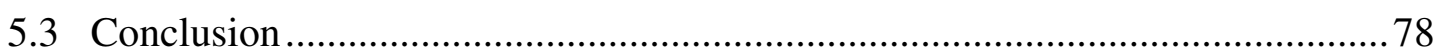

6 Literature on Emissions Embodied in Trade ...............................................................881

6.1 Trends in emission transfers via international trade ....................................... 82

6.2 Policy proposals focusing on environmental effectiveness .............................. 85

6.2.1 Leakage and the share of global emissions targeted by climate policy ...... 85

6.2.2 Comparative advantage and technology diffusion................................... 88

6.3 "Responsibility" for emissions and the question of justice ...............................90

6.3.1 Definitions and basic concepts ............................................................ 91

6.3.2 Attributing "responsibility for emissions" - a literature review .................99

6.3.3 Contribution of the research project "RESPONSE" ................................ 95

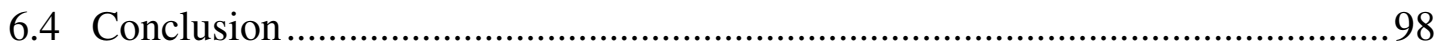

PART II - Theoretical Analysis .............................................................. 101

7 Evaluating a Shift to a Consumption-Based Climate Policy

- Objectives and Analytical Tools............................................................................... 103

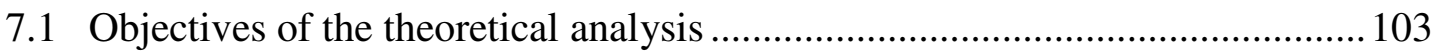

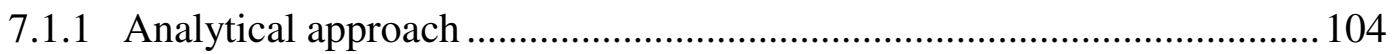

7.1.2 Coalition size, parameters, tax design - which factors are decisive? ....... 107

7.2 Partial equilibrium climate policy model ...................................................... 108

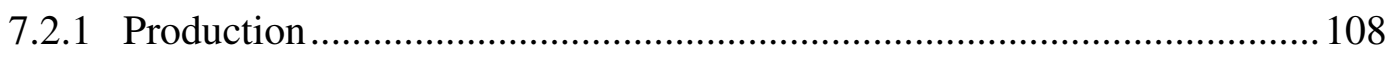


7.2.2 Emissions 111

7.2.3 Demand and goods market equilibrium 112

8 Effects of Policy Transmission via Non-Energy Markets ................................... 115

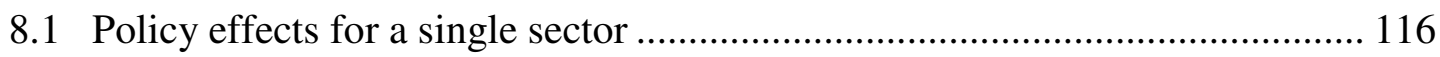

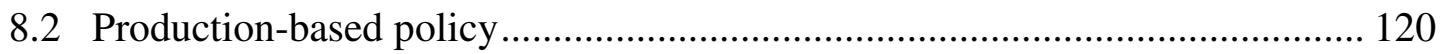

8.2.1 Global emission reduction and carbon leakage .................................... 120

8.2.2 Effects of a production-based policy on competitiveness ...................... 124

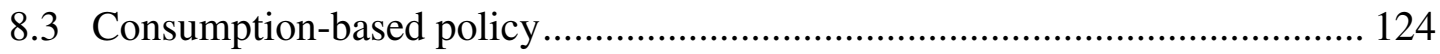

8.3.1 Global emission reduction and carbon leakage .................................... 124

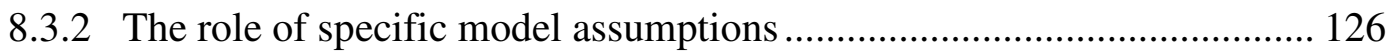

8.3.3 Effects of a consumption-based policy on competitiveness.................... 128

8.3.4 Border tax design and producer response........................................... 128

8.4 Policy evaluation in terms of environmental effectiveness............................ 131

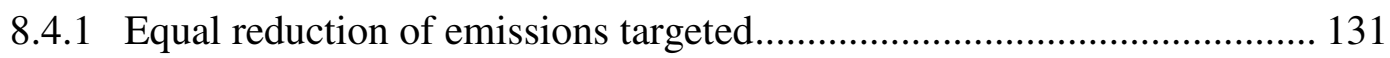

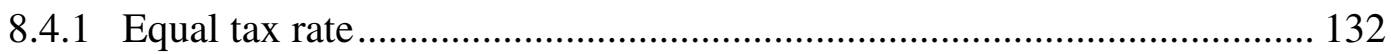

8.5 Switching the tax base, but not the target base .............................................. 136

8.6 Policy with import tax, but without export rebate ........................................ 138

8.6.1 Environmental effectiveness of "import-tax-only" policy ....................... 138

8.6.2 Impact of an "import-tax-only" policy on competitiveness ..................... 142

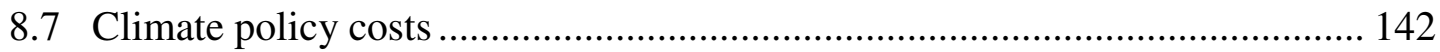

8.7.1 Policy evaluation in terms of cost-effectiveness .................................. 143

8.7.2 Welfare effects of an emission tax ..................................................... 147

8.7.3 Distributional impacts of the different policy variants............................ 150

8.7.4 Costs vs. competitiveness effects as measures of the "policy burden" ... 154

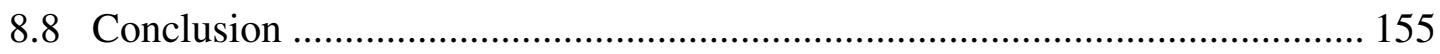

Appendix A: Relationships between the price elasticities of demand of the representative consumers of the model...................................... 161

Appendix B: Relationships between elasticities following from the Cournot aggregation condition

9 Policy Transmission through Energy Markets, Income Effects, and Technological Spillovers................................................................................ 165

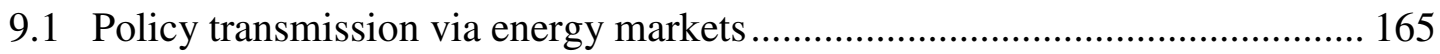

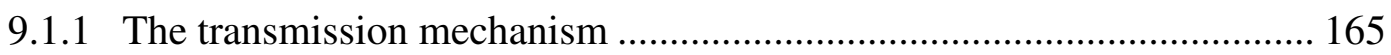

9.1.2 Energy market effects and global emission reduction............................ 168

9.1.3 Comparing the policy variants in terms of environmental effectiveness . 169

9.1.4 Practical implications of the impact of the fuel market on emissions...... 173

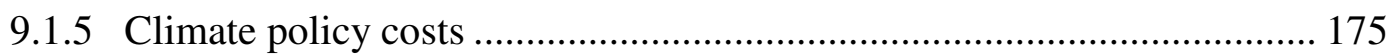

9.2 Abatement via income effects and its distributional implications ................... 176

9.2.1 Distributional effects of climate policy ............................................... 176 


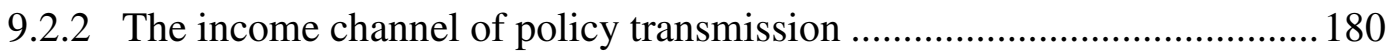

9.3 Policy transmission through technological spillovers ..................................... 181

9.4 Limitations to an analysis relying on simplified models ................................. 181

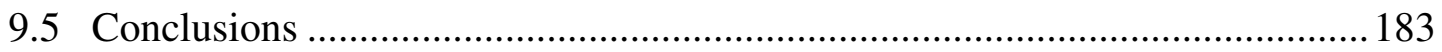

\section{PART III - Implementing Consumption-Based Policy Approaches... 185}

10 Design Options for Consumption-Based Policy Approaches

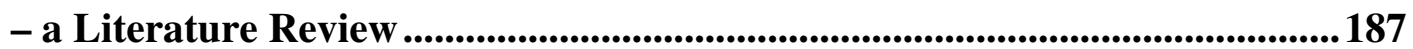

10.1 Making border carbon adjustments politically acceptable ............................ 188

10.1.1 Objectives of border adjustments and their legitimacy ........................ 188

10.1.2 Border carbon adjustments as a win-win scenario? ................................. 190

10.1.3 Export taxes - a feasible alternative to import tariffs? ........................... 192

10.1.4 Compensating developing countries for income losses ....................... 193

10.1.5 A multilateral approach to the introduction of border adjustments ........ 195

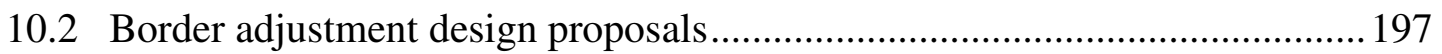

10.2.1 The proposal of Ismer and Neuhoff ...................................................... 197

10.2.2 The proposal of Monjon and Quirion .................................................... 198

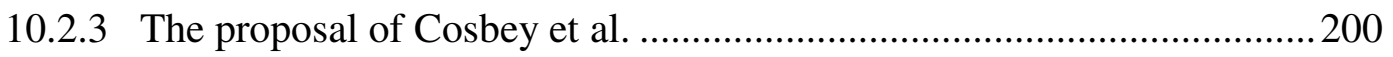

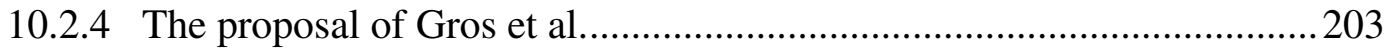

10.2.5 Relying on benchmarks and taxing only basic commodities.................205

\section{Consumption-Based Climate Policy in Practice:}

Abatement Potentials Difficult to Exploit ......................................................207

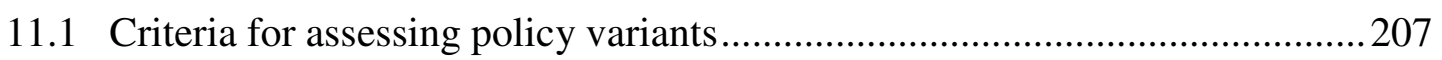

11.2 Conditions favoring the effectiveness of consumption approaches ..............209

11.3 Designing an effective and just consumption-based policy .........................209

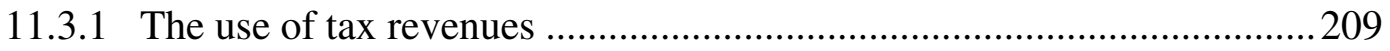

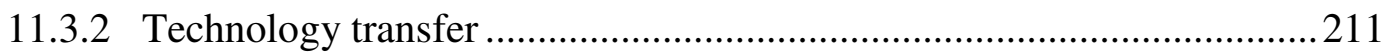

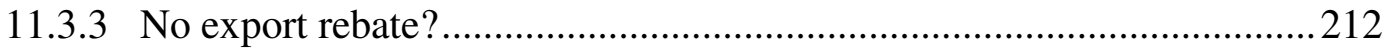

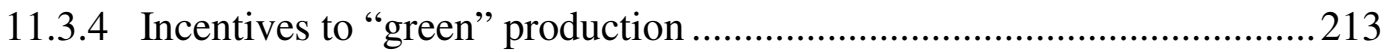

11.4 Policy implementation in the short run: border adjustments .......................213

11.5 Policy implementation in the long run: carbon added scheme ......................2.218

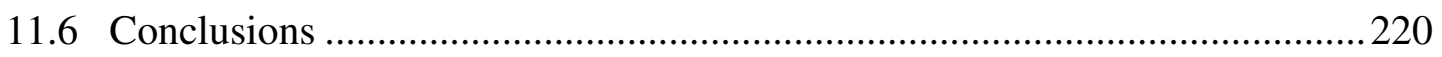

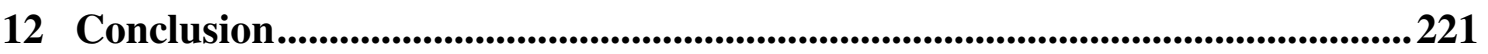

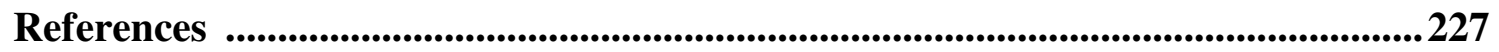




\section{List of Figures}

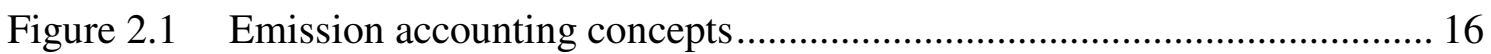

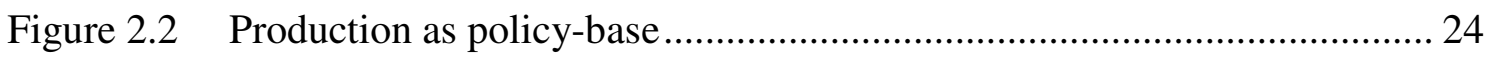

Figure 2.3 Consumption as policy-base ............................................................ 24

Figure 2.4 Production and consumption as policy base - simplified framework ....... 36

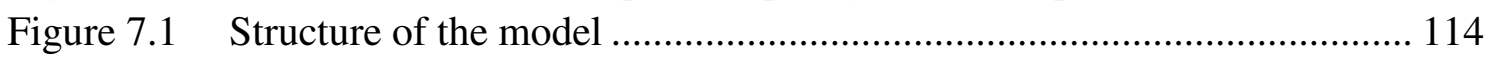

Figure 8.1a Cost-effectiveness of policies causing an equal emissions reduction ..... 144

Figure $8.1 \mathrm{~b}$ Cost-effectiveness of policies with the same tax rate............................ 145

\section{List of Tables}

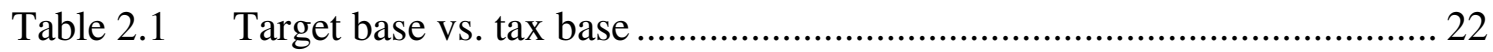

Table 8.1 Comparison of climate policies with different tax bases......................... 156

Table 8.2 Parameter values and environmental effectiveness of policy variants .... 157 


\section{Abbreviations}

Annex I Parties Countries that commited to emissions reduction under the UNFCCC

Annex B Parties Countries that commited to emissions reduction under the Kyoto

Protocoll

BAT Best available technology

BCA Border carbon adjustment

BEET Balance of emissions embodied in trade

CBDR Common but differentiated responsibility (a UNFCCC principle)

CDM Clean Development Mechanism (of the Kyoto Protocoll)

CE marking "Communauté Européenne" marking - indicates a product's

compliance with EU legislation

CES Constant elasticity of substitution

CGE Computable general equilibrium

$\mathrm{CO}_{2} \quad$ Carbon dioxide

COP Conference of the Parties to the UNFCCC

EEE Emissions embodied in exports

EEI Emissions embodied in imports

EET Emissions embodied in trade

EMF Energy Modelling Forum

ETS Emissions Trading System (of the EU)

GATT General Agreement on Tariffs and Trade

GDP Gross Domestic Product

GE General equilibrium

GHG Greenhouse gas

Gt Gigatonne

IPCC Intergovernmental Panel on Climate Change

ISO International Organization for Standardization

LDC Least developed country

LIC Low-income country

MAC Marginal abatement costs

MFN Most-favoured nation treatment (a WTO principle)

NAFTA North American Free Trade Agreement

OECD Organisation for Economic Co-operation and Development

PE Partial equilibrium

SCM Agreement on Subsidies and Countervailing Measures

UN United Nations

UNEP United Nations Environment Programme

UNFCCC United Nations Framework Convention on Climate Change

VAT Value-added tax

WBGU Wissenschaftlicher Beirat der Bundesregierung - Globale Umweltveränderungen (German Advisory Council on Global Change)

WTO World Trade Organization 


\section{CHAPTER 1}

\section{Introduction}

While the need to swiftly and effectively address climate change is becoming ever more urgent, international climate policy is still characterized by a lack of a worldwide coordinated emissions abatement strategy. In 2009 the Copenhagen Climate Conference failed to agree on a binding international climate treaty. The subsequent UN Climate Conference in Durban in December 2011 anew formulated the objective to work out an international agreement, but that treaty - if ever signed - is supposed to enter into force not before 2020. Thus, at least in the short to medium term, global climate policy will be characterized not by a top-down approach, but by what is termed bottom-up or hybrid climate architectures, i.e. unilateral actions and voluntary coalitions of certain countries. To date, such unilateral measures - and also the pledges of individual countries to take further abatement actions in the future - do not add up to what would be required in order not to overshoot the internationally agreed $2^{\circ}$ global warming threshold: the United Nations Environment Programme (UNEP 2013) estimates that the implementation of current pledges would imply a global temperature increase of $3{ }^{\circ} \mathrm{C}$ to $4^{\circ} \mathrm{C}$ to the end of the century compared to the preindustrial period; and the recently completed first volume of the $5^{\text {th }}$ Assessment Report of the IPCC (2013) predicts a mean temperature increase to the end of the century of about $2.4^{\circ} \mathrm{C}$ even for the secondmost optimistic of four greenhouse gas (GHG) concentration scenarios studied.

Thus the current situation is characterized by an urgent need to step up action against climate change, but the constraint that, realistically, in the short run such action will only be possible through unilateral initiatives. The challenge therefore is inter alia to increase the effectiveness of unilateral approaches to climate policy. One way to possibly accomplish that goal suggested in the academic literature is a change from the current system of a production-based to a consumption-based policy orientation. Such a policy would not target the emissions discharged on the territory of the country that abates, but the emissions embodied in the goods it consumes. If industrialized countries adopted this approach, they could bring the large and increasing amount of emissions embodied in imports from emerging economies into the scope of the policy. This, it has been suggested, might improve the efficiency, the cost-effectiveness, and the environmental effectiveness of the policy as well as reduce carbon leakage.

This study will review the literature on consumption-oriented climate policy approaches (and policy approaches that are at least partly consumption-oriented). Employing an analytical model, it will then examine to what extent such approaches can indeed enhance the effectiveness of unilateral abatement policies and what consequences they have for other criteria important in practical policy formulation such as the global distribution of the cost of the policy or its effect on the competitiveness of 
individual countries. Finally, drawing on the results of the literature review and the model-based analysis, this study will discuss the question how consumption-based policies could be designed in practice and whether design options exist that help to realize the possible advantages of consumption-based approaches while minimizing their possible disadvantages.

\subsection{Production-based vs. consumption-based policy orientation}

Currently, virtually all countries apply their climate policy to the emissions directly discharged on their territory. For emissions set free in the production of goods and services, this means counting the emissions at the point of production of these goods, irrespective of where and by whom the goods are later consumed. Emissions counted following this principle are therefore often referred to as a country's "production-based emissions inventory" (e.g. Peters and Hertwich 2008a). Territorial or production-based emissions ${ }^{1}$ accounting is also the GHG accounting principle employed by the UNFCCC (1998a; b) in the Kyoto Protocol. However, it is not the only possible accounting principle: Alternatively, one might record emissions at the point where goods and services are consumed. All emissions that occur in any location worldwide in the course of the production of these goods would then be attributed to this consumption. This is termed "consumption-based accounting", and the emissions base thus determined can also be used as base for unilateral climate policy: for example, a tax could be levied on the emissions "embodied" in every good sold for consumption.

Note that for the world as a whole both emissions measures - the production-based and the consumption-based one - are equal: They record exactly the same emissions, just at different points. For an individual country, however, the two measures typically diverge. This is due to the fact that emissions embodied in imports are "brought" into the country. When the imported goods are consumed in that country, these emissions will be recorded as part of the country's consumption-based emissions inventory, but as these goods where produced in a different part of the world - they are not counted as part of the country's production-based emissions inventory. The opposite holds true for goods exported: the emissions set free in their production are recorded in the exporting country's production-based emissions inventory but not in its consumption-based one. Thus, the difference between a policy using production and one using consumption as its base is that the first policy targets the country's exports and the second the country's imports. Both policies, of course, also include the country's domestic production for domestic consumption within their bases.

1 For an explanation of the difference between the terms "territorial" and "production-based" emissions accounting see Footnote 4. 


\subsection{Consumption-based approaches and policy effectiveness}

The adoption of consumption-based emissions abatement policies has been advocated out of a number of different motivations - this study will however analyse only one of these motivations in greater detail, the argument that a consumption-oriented policy, pursued by a coalition of industrialized countries (e.g. by the EU or by a broader coalition of, say, all OECD countries), has the potential to be more effective than the current production-based approach. Various indicators for the effectiveness of a climate policy will be used, for example cost-effectiveness, environmental effectiveness, or carbon leakage. In the academic literature on unilateral climate policy, different reasons are given (or in some cases at least suggested) why a consumption-based approach should - according to one of these indicators - indeed be more effective:

- With current worldwide production and trade patterns, a consumption-based policy by industrialized countries includes a larger share of global emissions than a production-based policy. This result is mainly due to the far higher carbon-intensity of the exports of emerging economies compared to the exports of most industrialized countries (e.g. Davies and Caldeira 2010). Peters and Hertwich (2008b) argue that one of the advantages of a consumption-based approach in such a situation is that commitments of developing countries are less important in achieving a global emissions reduction goal. While Peters and Hertwich do not discuss it in these terms, one can use this argument also to draw conclusions on the cost-effectiveness of a consumption-based policy: if, as it is usually assumed, marginal abatement costs rise with the quantity of emissions abated, then to reach a given absolute abatement target it is cheaper to abate a smaller percentage from a larger emissions base then to abate a larger percentage from a smaller emissions base. Therefore, enlarging the emissions base by switching to a consumption-based approach may increase the cost-effectiveness of the policy. Note also that for industrialized countries the gap between production- and consumption-based emissions has rapidly grown wider within the last two decades (e.g. Peters et al. 2011) - thus this argument is constantly gaining in importance.

- Global cost-effectiveness also requires that emissions be abated in those countries where it is cheapest to do so (Weyant and Hill 1999). This is sometimes termed "where-flexibility". Obviously, marginal abatement costs are high in countries that have already partly decarbonised their economy (like many industrialized countries), but effectively zero in countries without a climate policy - like some developing and emerging economies. Thus abatement in developing and emerging economies should be more cost-effective (Barrett 1998; Stern 2007). Here, this well-known argument will be taken one step further: even if developing countries do not follow a climate policy themselves, industrialized countries might still be able to exploit some of these low-cost abatement opportunities. By pursuing a consumption-based policy they can bring the export sector of developing and emerging economies into the scope of 
the policy. According to this line of reasoning, overall costs will be lower for a consumption-based as compared to a production-based policy.

- The introduction of a production-based policy raises the costs and thus the prices of goods produced in abating countries. Consumers (demanding final products) and producers (demanding intermediate products) thus have an incentive to substitute the now relatively cheaper goods from non-abating countries for the more expensive ones that are subject to the policy. Thus, production and as a consequence emissions in non-abating countries will rise and in this way counteract the emissions reduction in abating countries. This effect is known as carbon leakage (more exactly, carbon leakage through the "competitiveness channel"): instead of being reduced on a global level, emissions are just shifted across borders (to non-abating countries). The larger such carbon leakage, the smaller is the global emissions reduction achieved by the abatement policy and thus the smaller its environmental effectiveness. If, on the other hand, by means of a consumption based-policy, imports of abating countries are also subject to the policy (and their prices thus also raised), while exports from abating countries are exempted from the policy, then such leakage effects will be avoided. A consumption-based policy may therefore be environmentally more effective. This is the probably best-known argument in support of consumptionbased policy approaches, suggested in numerous studies (e.g. Peters and Hertwich 2008b).

- A related argument can be made as regards the effects of a climate policy on competitiveness: the cost increase caused by the abatement policy also lowers the competitiveness of the industry of abating countries. Firms in abating countries are therefore typically opposed to stringent unilateral abatement measures, and their resistance may make it politically impossible for governments to commit themselves to such measures. If, however, the competitiveness of the domestic industry could be protected, this would allow countries to unilaterally pursue a more ambitious climate policy. One way to protect the industry's competitiveness is a switch to a consumption-based policy - this would, as is often argued, "level the playing field between domestic and foreign producers." Note that this argument is not about protecting the domestic industry as an end in itself, but about overcoming political opposition to an ambitious climate policy (Grubb 2011; Cosbey et al. 2012).

These four arguments may appear convincing at first sight - still, as will become clear in the course of this study, they only hold under certain assumptions and in certain circumstances. Thus, it is far from clear how useful they are for developing climate policies that work in a real-world setting, i.e. whether it is indeed possible to improve the effectiveness of the existing global climate policy framework by switching the accounting base. Most of this study will be devoted to a detailed analysis of this question.

Various authors have, however, suggested to instead of attempting to formulate climate policies within the current global policy framework to rather completely reform 
this framework. For example, the German Advisory Council on Global Change (WBGU) has proposed an alternative way to allocate abatement obligations between individual countries. Instead of agreeing on percentage emissions reductions relative to the status-quo or to some reference scenario the Advisory Council suggests to proceed as follows: in a first step, the "GHG disposal space" in the atmosphere would have to be established that remained if the global temperature increase were limited to $2^{\circ}$. In a second step, this disposal space would then be distributed in the form of "emissions budgets" among individual countries (WBGU 2009). As Droege (2011) remarks, the debate on an equitable division of these emission rights is related to the question of consumption-based policy approaches. The proposed "emission budgets" could refer either to production-based, or alternatively to consumption-based emissions. Thus, if indeed a switch to a new system for the allocation of abatement obligations is considered, then the choice between a production- and a consumption-based system should be based on a clear understanding of the different consequences of these two systems. The debate on such a reform therefore provides additional impetus for studying the effects of consumption-based policies.

\subsection{Two strands of literature - and a controversial political debate}

In recent years, a switch to a consumption-based policy orientation has been explicitly or implicitly discussed by two lines of the economic literature. These discussions have revolved not only around policy-effectiveness arguments (listed in the previous section), but also around a number of other criteria deemed important: In one of the two literature strands, the literature on emissions embodied in trade, many authors argue that it is "fairer" to make countries partly or wholly responsible for the emissions triggered by their domestic consumption, rather than just their production-based emissions (Kondo et al. 1998; Munksgaard and Pedersen 2001; Ferng 2003; Bastianoni et al. 2004; Peters and Hertwich 2006; Lenzen et al. 2007). A second core field of research of this strand of literature are emissions "transfers" between countries by means of international trade. Virtually all studies on this subject reveal a common characteristic: emissions embodied in goods are exported mainly from emerging economies to consumers in developed countries, and these inter-country carbon flows are rapidly growing over time (e.g. Davis and Caldeira 2010; Peters et al. 2011). This is seen as a worrying development for the environment, as ever more of the goods consumed in countries with binding mitigation targets (which however limit only emissions in production, but not in consumption) are produced in countries without such targets (Peters and Hertwich 2008a). Even though the literature on emissions embodied in trade does not suppose that these trends in emission transfer are caused by current (production-oriented) climate policy, some authors suggest basing international climate policy on consumption-based accounting as a countermeasure (Peters and Hertwich 2008a; b; Nakano et al. 2009; Wiedmann 2009).

The second line of literature, the literature on carbon border adjustments, indirectly also discusses switching to a consumption-based approach - although in that strand of literature it is usually not termed that way. Carbon border adjustments work as 
follows: the region that abates bases its policy on production-based emissions accounting, but supplements that policy by import taxes ${ }^{2}$ and export rebates. The import taxes are levied on the carbon-content of products originating from countries not following an equally stringent climate policy, and the export subsidies are granted to domestic producers for the carbon content of exports to countries with a less stringent policy. If such import taxes and export rebates are applied to all products according to their true carbon content and if the carbon price charged or rebated equals the domestic carbon price, the measures represent a full switch to a consumption-based policy approach; or, to use the language of the literature on international taxation, a switch from an origin basis to a destination basis in the carbon tax system.

The literature on carbon border adjustments, however, usually does not assume such a "full switch" - the adjustments are typically not envisioned for all goods, but only for the products of carbon-intensive industries, and often they are also not based on a precise calculation of the carbon content of these goods. The reason is that in this strand of literature the objective of the border adjustments is defined more narrowly: the adjustments are not introduced for fairness reasons or out of a principled believe that the carbon price applied to different products must always be the same, but as one of a number of possible measures to achieve some practical policy goals - to protect industries deemed at risk of losses in competitiveness or to (at least somewhat) stem carbon leakage triggered by unilateral climate policy. Protecting the competitiveness of certain industries - if pursued as an aim in itself and not as a means to overcome political opposition to a more stringent climate policy - is, of course, not an environmental objective. Competitiveness issues will therefore not be analyzed in-depth in this study. A basic understanding of competitiveness concerns - as discussed in the border adjustment literature - will however help to grasp the political controversies triggered by the pursuit of unilateral climate policies.

At any rate, the scenarios studied in the literature on border carbon adjustments do not qualify as examples of a "pure" consumption-based policy. But as we will see in the course of this study, it is questionable whether a "pure" consumption-based policy can actually be implemented in a real-world setting; and secondly, also the analysis of a "less-than-full" switch to consumption-based accounting will provide valuable insights into the consequences of switches of the policy base.

The question whether border carbon adjustments indeed help to protect the competitiveness of industries at risk and to stem carbon leakage is studied in this strand of literature by quantitative sectoral as well as computable general equilibrium (CGE) models. The results diverge vastly - they range from findings that border measures are effective in curbing both leakage and competitiveness losses to results that they can fulfil neither objective (see Chapter 5 for a review of these studies and the respective

2 There exist other forms of border adjustments apart from taxes - see Section 2.2.3. The expression "taxes" is only used - without loss of generality - to keep the discussion simple. 
references). One reason for the huge variety in results may be that the studies start from quite different assumptions on the size of the abating coalition, the range of products included, the way how the border adjustments are calculated, and the question whether the adjustments consist only of an import tariff, or also of an export rebate. At any rate, currently there is still no consensus in this strand of literature on the question whether and if so, under what conditions - the introduction of border carbon adjustments can be recommended. One recent study comparing 12 simulation models not only assesses the effects of border measures on carbon leakage and competitiveness, but also on costeffectiveness. This study finds that the improvements in terms of cost-effectiveness are only modest, but that, on the other hand, the border measures shift the economic burden of emissions reduction to non-abating countries (Boehringer et al. 2012a).

Apart from these two strands of the recent economic literature there exists an older theoretic literature on unilateral climate policy measures (Markusen 1975; Hoel 1996). These contributions find that border adjustments can improve the efficiency of a unilateral policy, but that typically the most efficient outcome is not achieved by a "full" adjustment that completely changes the accounting base, but rather by a policy that combines the taxation of production with the taxation of consumption - and that typically also applies different carbon tax rates to different economic sectors. To see why, note that a policy that combines taxing production and consumption includes more sectors of the global economy than either a "pure" production-based or a "pure" consumption-based policy. But bringing additional sectors into the scope of the policy and having the possibility to freely set the carbon tax rate in these sectors (which may be positive or negative) as well as to adjust the carbon tax rates in all other sectors clearly enlarges the set of choices available to design an efficient policy. Thus such a policy can never be less efficient and will typically be more efficient that either of the two "pure" policy variants.

Notwithstanding the ambiguity of findings on their effectiveness, the idea of carbon border adjustments has triggered an intense and often controversial political debate. In Europe, such measures have repeatedly been called for by industry representatives as well as some politicians, for example the former French president Nicholas Sarkozy. In the U.S., the introduction of a cap-and-trade regime was discussed in 2009. There, provisions for border adjustments were included in all proposed congressional bills. In the end, the Senate did not approve any of these bills - and the plans for the cap-and-trade system were abandoned (Clapp, 2010). Still, many authors (e.g. Van Asselt and Brewer 2010) expect that the debate on border measures will not be over. Van Asselt and Brewer also note that - especially in the U.S. - the calls for border measures are mainly motivated by competitiveness arguments, and not by environmental concerns.

The response to these proposals from the countries possibly targeted by the measures - emerging economies - was immediate and fierce: they asked the UNFCCC to ban border carbon adjustments (Khor and Jhamtani 2009). For emerging economies, gains in the relative competitiveness of industrialized countries correspond to losses in the competitiveness of their industry. Additionally, emerging economies also fear 
general welfare losses through border adjustments - as, for example, predicted by the model comparison study mentioned above (Boehringer 2012a). How intense the controversy can become, can be seen from the vehement reaction from emerging economies as well as industrialized countries to the EU's recent decision to introduce an aviation emissions levy (which has some similarities to a border carbon tax).

Border carbon adjustments are not the only way to change the emissions accounting base to a consumption-orientation - this study will also discuss a different proposal for switching to a consumption-based policy as well as measures to alleviate negative distributional impacts on developing and emerging economies. Still, given the "long-standing negative experience in developing countries with trade talks" and the absence of "trust" in the motives of industrialized countries (Droege 2011, 1197), the introduction of consumption-based policy approaches will remain a controversial idea.

\subsection{Methodology, structure, and research objectives}

The objections in developing and emerging economies to border carbon adjustments (and therefore, presumably, to every form of consumption-oriented policy) make it all the more important to examine whether consumption-based approaches can indeed further environmental objectives - or whether they are only another form of "protectionism," (Droege 2011, 1197), as often claimed by these countries. As discussed in the previous section, the academic literature has so far not given a final and unanimous answer to this question. This study aims to further contribute to the respective discussion. As opposed to much of the existing literature, the discussion will however not be framed in the tradition of only one of the literature strands introduced in the previous section; rather the aim is to draw from the findings and arguments of all of these traditions in order to compare the different approaches and to make best use of all of the current knowledge in this field of research. The study is structured into three parts, of which each pursues quite distinct research objectives.

\subsubsection{A common perspective on hitherto separate literature strands}

The first part of the study introduces the central concepts needed for the following analysis - it provides the economic, the political, and the legal background - and it reviews the literature on consumption-based abatement policies, in particular the two literature strands mentioned above, the literature on emissions embodied in trade and the literature on border carbon adjustments. One might argue that a literature review only seldom reveals new facts or arguments - but in the field of the economics of unilateral climate policy this might be different: the two literature strands have for some years existed side by side - but only seldom has it been attempted to compare their arguments, their findings, or their policy recommendations (Steininger et al. (2014) is one of the few exceptions). This study, in contrast, aims to jointly critically review the literature from the two strands, to examine where these strands produce comparable results, and where they diverge. To give a few examples:

- The concept of carbon leakage is central to the literature on border carbon adjustments. But if one regards these adjustments not as being just an "add-on" 
to a production-based policy, but as bringing about a switch of the policy base to a consumption-orientation, one realizes that the standard concept of leakage cannot be used for a policy with border adjustments (or at least it has to be interpreted completely differently) - for consumption-based policies, carbon leakage must be calculated by a different formula.

- Many authors writing in the tradition of the literature on emissions embodied in trade see a consumption-based approach as "fairer" than a production-based one. But a comparison to the literature on border adjustments shows that these authors apparently envision formulating only the abatement targets in terms of consumption. But they do not take the additional step to examine how these targets can be implemented. If they are implemented by a switch to a consumption-based policy, then - as the literature on border adjustments finds the distributional impacts of changing the reference point for the mitigation targets might actually be reversed - and the claim that consumption-based approaches are "fairer" becomes debatable.

- Much of the literature on emissions embodied in trade is written by noneconomists. This study will provide an economist's perspective on the findings of this literature strand. For example, some authors contributing to the literature on emissions embodied in trade discuss schemes to change the distributional impacts of a policy in terms of the question, to which economic actor a climate policy instrument is applied. Tax incidence theory, however, tells us that tax burdens (or the burdens imposed by some other climate policy instrument) are passed on and that one cannot determine the distributional effects of a policy by asking on whom the tax is levied.

\subsubsection{Theoretical analysis}

The second part of this study is the central analytical part: a production-based policy will be compared to a consumption-based one and assessed according to various criteria - first of all, the "effectiveness" criteria already listed above. But as a policy that is to be actually implemented must also meet other requirements than just being effective, additionally the distributional consequences of the adoption of the different policy variants and their impact on competitiveness will be examined. The analysis will be organized along four so-called "carbon leakage channels" discussed in the literature: Policy transmission in non-energy markets (the "competitiveness channel") and in energy markets (the "fossil fuel channel") will be examined by means of an analytical partial equilibrium (PE) model. Policy transmission through income effects (the "income leakage channel") or through technological spillovers, however, does not lend itself to a representation in a PE setting - these two channels will therefore be discussed without resorting to a formal presentation. Finally, the question will be asked which possible effects may have been ignored by confining the analysis to a PE setting - and not using a general equilibrium (GE) model.

As mentioned in Section 1.3, the quantitative literature on border adjustments has produced vastly different results on the effectiveness of such measures. These findings - 
and some other arguments discussed in the course of this study - suggest that a consumption-based policy will not be either more effective or less effective than a production-based one under all circumstances: rather its effectiveness appears to depend on parameters characterizing markets, trade relationships, production technologies, and the exact design of the policy instrument applied. The analytical part of this study will therefore examine which parameter and policy design constellations enhance the effectiveness of consumption-based approaches, and which have the opposite effect.

The choice of research methodology - using an analytical PE model - is motivated as follows: Quantitative border carbon adjustment models have produced a wide variety of different results, and the researchers developing and employing these models have drawn quite different conclusions on the desirability of implementing border adjustments. What currently appears to be most conducive in this field of research is to gain a clear understanding why the findings diverge so much. There exist, of course, several methods to examine this question. The present study aims to address it by means of developing a better understanding of the basic mechanisms at work in this field of economics. These mechanisms can be best revealed in small models with only few sectors that depict economic relationships in a rather "stylized" fashion. Thus, it is not the objective of this study to produce exact quantitative estimates that apply to a very specific setting, but to examine in which settings (in terms of parameter values and instrument design options) consumption-based policy approaches prove effective.

Earlier theoretical studies of unilateral environmental policy (e.g. Markusen 1975) mostly use simple GE models of the Heckscher-Ohlin-Samuelson type. Such models include factor-price and income effects - impacts not represented in a PE analysis. Nonetheless, for the present study it was decided to employ a PE model: in a PE setting, it is easier to - in addition to final goods markets - also include a fossil fuel market and to assume less than perfect substitutability between domestic and foreign goods, two characteristics that according to the CGE literature on carbon leakage may be decisive for the results to be obtained. The model developed includes two regions, four final goods markets, and a global fossil fuel market. It is characterized by two features that distinguish it from models used in other studies:

- It includes, as already mentioned, a fossil fuel market. Thus it allows the examination of the interrelationship between effects in goods and in energy markets and thus also the study of carbon leakage through the energy market channel. To the knowledge of the author, currently no studies exist on climate policy that combine goods and fuel markets in this way in a single stylized analytical model.

- It allows producers in non-abating countries to react to the introduction of border measures by adopting a less carbon intensive technology in the production of export goods. This is achieved by means of two characteristics of the model: (i) the import border tariff is a true emissions tax - and not, as according to Winchester (2011) is the case in many CGE studies, an output tax, and (ii) producers can differentiate their production technology across destination markets, i.e. they can produce exports with a different input mix than goods 
destined for the home market. As will become clear in the course of this study, the question whether developing and emerging economies react to the introduction of a consumption-based policy by "greening" their production technology is decisive for the effectiveness of such a policy.

\subsubsection{Policy design and the practicability of consumption-based policies}

The third - and last - part of this study poses the question whether it is possible to design consumption-based policy approaches that are also effective in a "real-world" setting - and if so, how exactly these policies must be designed. First, the question what characterizes a politically feasible policy proposal is discussed. Then, three proposals on a "partial" and one on a "full" switch to consumption-based accounting made in recent years will be reviewed. Finally, drawing on this review, on the review of the literature on emissions embodied in trade and the literature on border adjustments in the first part of this study, and on the results of the theoretical analysis in the second part, the requirements on a practicable policy design are discussed. In addition to the criteria for policy effectiveness, which are the main focus of this study, a policy supposed to be feasible must meet a number of other criteria. In this study the following additional criteria will be employed: the policy should not increase the burdens on developing and emerging economies, it should meet the criterion of "perceived fairness" (discussed in Chapter 11), stand a reasonable chance not to be immediately challenged in the dispute settlement system of the World Trade Organization (WTO), and its implementation should be practicable. A number of design recommendations will be developed that guarantee that these criteria are fulfilled. Compared to design proposals for consumption-based approaches previously made in the literature, this study additionally aims to shed light onto the following issues:

- The impact of the policy on the international income distribution and possible negative feedbacks of income losses on environmental effectiveness.

- The question how a policy can incentivize a "greening" of production methods in emerging and developing countries. It will be argued that the answer to this question may prove decisive for the effectiveness of the policy.

- The question whether there exist policy design options that cannot be implemented in the short run, but that might be fruitful in the medium to long term.

The discussion of different options for practical policy design will finally allow us to give a more informed answer to the central question of this study: Will the adoption of consumption-based policy approaches by industrialized countries indeed help to overcome at least some of the problems of current international climate policy - or are consumption-based policies a concept that works only in the idealized setting of theoretical models relying on specific assumptions, but that is of little use in practical policy making? 

PART I

The Economic,

Political, and Legal

Background 



\section{CHAPTER 2}

\section{Consumption as a Base for Emission Accounting and as a Policy Base}

This chapter introduces some basic concepts that will be used throughout this study: first, the exact difference between production-based and consumption-based emission accounting will be explained, then the question will be examined how a country's consumption-based emission inventory can be used as a base for climate policy, and finally, various criteria to assess different climate policy variants will be discussed. In the course of this discussion we will also see that one of the most common policy effectiveness indicators - carbon leakage - in its standard definition is actually tailored only to a production-based policy. To serve as a meaningful indicator also for a consumption-based policy, the formulas defining carbon leakage have to be adjusted. Additionally, it will be argued that when formulating abatement policies it is crucial to distinguish between the base the emission reduction targets refer to and the base the policy instrument is applied to - a distinction usually not made in the literature.

\subsection{Production- and consumption-based emission inventories}

\subsubsection{Emission accounting concepts}

After the UN climate conferences in Copenhagen and Cancun in 2009 and 2010, around 90 countries have offered various GHG mitigation pledges. ${ }^{3}$ If these countries abide by their pledges, a multitude of national climate policies with quite different levels of stringency will exist side by side. Here, no attempt will be made to model this realworld complexity. Rather, the simplest of possible settings is used to analyze the consequences of a switch of the GHG accounting system: a world, where one region (the policy-region, called "Home" in the following) pursues a GHG abatement policy, whereas the rest of the world (the non-policy region, called "Foreign" in the following) does not. In a highly stylized representation of current international circumstances, it will be assumed that the policy region Home comprises industrialized countries, whereas the non-policy region Foreign consists of developing and emerging economies.

In a first step, this simplified framework will be used to demonstrate the difference between production-based and consumption-based emission accounting. Region Home

3 See UNFCCC (2011a), for an overview of the mitigation pledges of developed countries, and UNFCCC (2011b) for an overview of the mitigation pledges of developing countries. 
produces goods for domestic consumption as well as for export, denoted $H$ and $X 1$, respectively (see Figure 2.1). The sum of $H$ and $X 1$ is Home's output. Region Foreign produces goods for its domestic consumption $(F)$, and also goods it exports (termed $M 1$, as these goods are imports seen from the perspective of Home). Thus, Foreign's output is the sum of $F$ and $M 1$.

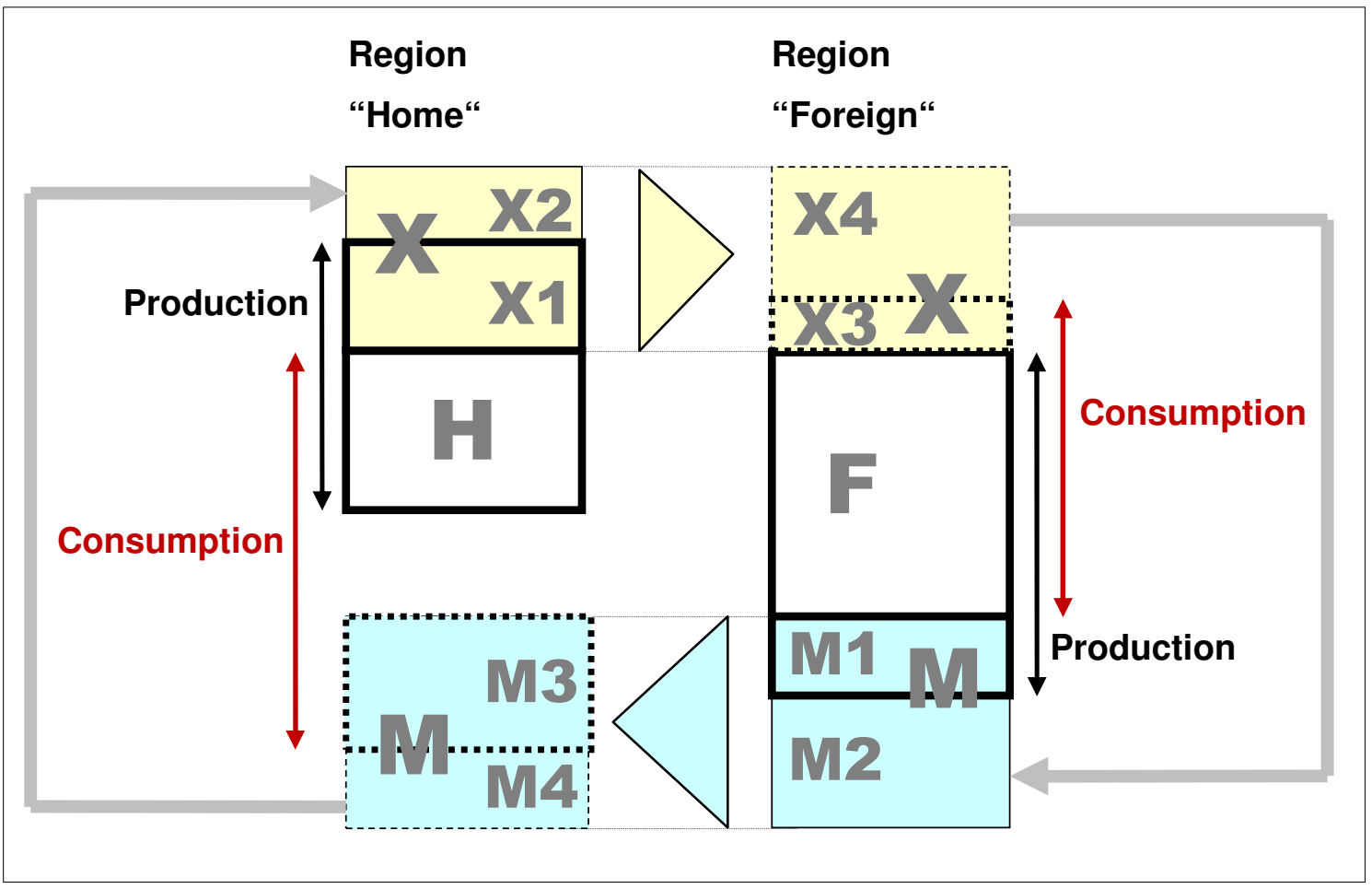

Figure 2.1 Emission accounting concepts

(see the main text for details)

Let now $E_{H}$ be the GHG emissions discharged by producing $H, E_{X I}$ those discharged by producing $X 1, E_{F}$ those discharged by producing $F$, and $E_{M 1}$ those discharged by producing $M 1$. Then, Home's production-based emissions inventory $E_{1}{ }^{P B}$ and Foreign's production-based emissions inventory $E_{2}{ }^{P B}$ are defined as follows (variables and parameters relating to region Home will in the following be marked by the subscript 1 , those relating to Foreign by the subscript 2):

$$
\begin{aligned}
& E_{1}^{P B}=E_{H}+E_{X 1}, \\
& E_{2}^{P B}=E_{F}+E_{M 1} .
\end{aligned}
$$


$E_{1}{ }^{P B}$ includes all emissions set free to produce Home's output, and $E_{2}{ }^{P B}$ includes those set free to produce Foreign's output. ${ }^{4}$

Next, consider the consumption-based emissions inventory of the two regions. At the outset, two terminological issues shall be clarified: First, note that in the term "consumption-based emissions" the word "consumption" is used in a different sense than in national income accounting: it refers not only to private consumption, but also to investment and to government consumption, i.e. to all forms of domestic final demand. Second, the literature on consumption-based emission accounting uses the term "embodied emissions" - it, for example, discusses "emissions embodied in imports" or "emissions embodied in exports." This, however, does not mean that these emissions are in some way "physically contained" in the imports or exports examined. Rather, the emissions embodied in some good are defined as the emissions set free at all different steps of the production process of that good, from raw materials extraction trough to final assembly and ultimately the final sale of the product (Peters and Hertwich 2008b). Thus, the emissions embodied in a product also contain the emissions embodied in intermediate goods used in the production of that good; and in the intermediate goods used to produce these intermediate goods etc. The supply chain of many manufactured goods extends across many individual countries; therefore, to determine the emissions embodied in some good, one needs to add up the emissions discharged to produce that good in all of those countries. In the simplified setting employed in this study, there are, however, only two regions. Thus, every good is either produced in Home, or in Foreign, or in both Home and Foreign.

The reason why a country's consumption-based emissions inventory typically differs from its production-based one is international trade: the goods a country consumes are not all the same as the ones it produces, and so in general also the emissions embodied in these goods will not be the same. Figure 2.1 shows the trade flows: Imports $M$ bring additional goods to Home, but not all of them find their way

4 This study follows Peters (2008) and Peters and Hertwich (2008a; b) in its definition of the productionbased emissions inventory. As Peters and Hertwich point out, their definition is close, but it is not the same as the one employed by the UNFCCC in the Kyoto Protocol (UNFCCC 1998a; b). The Protocol refers to the definition given by the Intergovernmental Panel on Climate Change (IPCC): "national inventories should include greenhouse gas emissions and removals taking place within national (including administered) territories and offshore areas over which the country has jurisdiction" (IPCC 1997). Thus, a country's geographic and not its economic definition is used. The approach may therefore be termed "territorial" emissions accounting. The problem with it, Peters and Hertwich argue, is that emissions from international transportation are not assigned to any country and that the geographic approach differs from the way how quantities like GDP are calculated in national economic accounts. They therefore suggest employing the same allocation rules for emissions as for economic activities in national accounts, i.e. not to count emissions occurring within national territories, but emissions from institutional units resident in the economy. For the topics discussed in this study, however, the difference between the two definitions is inconsequential and will therefore not be elaborated. 
into final consumption. The reason is that imports (according to the term as used in trade statistics) contain (a) final goods as well as (b) intermediate goods. The intermediate goods can be used to produce either (b1) domestic final goods or (b2) exports (Peters 2008). Only (a) and (b1) are part of Home's final demand - they are termed $M 3$ in Figure 2.1. The quantity (b2), on the other hand, constitutes trough-trade: imports used to produce exports. It is termed $M 4$ in Figure 2.1, and it equals $X 2$ - the part of Home's exports $X$, which stems from trough-trade. The remainder of $X$ is $X 1$, which - as explained above - are exports produced domestically. We can now determine Home's final demand: it consists of $H$, goods produced domestically for domestic consumption, plus $M 3$, the part of imports that is not re-exported. The emissions embodied in Home's final demand constitute $E_{1}{ }^{C B}$, Home's consumptionbased emissions inventory. $E_{2}{ }^{C B}$, Foreign's consumption-based emissions inventory, is calculated in a similar manner:

$$
\begin{aligned}
& E_{1}^{C B}=E_{H}+E_{M 3}, \\
& E_{2}^{C B}=E_{F}+E_{X 3} .
\end{aligned}
$$

Thus, the consumption-based inventory measures the emissions caused by a country's final demand, no matter where the production to meet this demand takes place. ${ }^{5}$

The relationship between a country's production-based and its consumption-based emissions inventory can be stated in various ways:

$$
E_{1}^{C B}=E_{1}^{P B}-E_{X 1}+E_{M 3}=E_{1}^{P B}-E_{X}+E_{M} .
$$

The second equality holds true because the terms related to through-trade cancel out. Of course, a similar relationship applies to region Foreign. Thus, the difference between the production-based and the consumption-based emissions inventory can be calculated as the difference between emissions embodied in exports and emissions embodied in imports. This difference is usually termed the "balance of emissions embodied in trade" (Peters and Hertwich 2008a) or simply the " $\mathrm{CO}_{2}$ trade balance" (Munksgaard and Pedersen 2001). We shall label it $E^{T B}$ :

5 Emissions discharged not during production but during the final use of goods (like emissions from the use of private cars or from heating private homes) should be included in the production-based as well as in the consumption-based emissions inventory of the country where these emissions are set free. This can be motivated as follows: activities like heating a private home can be seen as production - the production of a pleasant room climate - and consumption - enjoying that room climate - occurring at the same time. 


$$
E^{T B}=E_{1}^{P B}-E_{1}^{C B}=E_{X}-E_{M} .
$$

One more equality can be demonstrated easily within this two-region framework: We already know that $E_{X 2}=E_{M 4}$ and $E_{X 4}=E_{M 2}$. From this we obtain $E_{X 1}+E_{M 1}=E_{X 3}+$ $E_{M 3}$, which in turn can be used to show that global production-based emissions $E^{P B}$ equal global consumption-based emissions $E^{C B}$ :

$$
\begin{aligned}
& E^{P B}=E_{1}^{P B}+E_{2}^{P B}=E_{H}+E_{X 1}+E_{F}+E_{M 1}, \\
& E^{C B}=E_{1}^{C B}+E_{2}^{C B}=E_{H}+E_{M 3}+E_{F}+E_{X 3}=E_{H}+E_{X 1}+E_{F}+E_{M 1}=E^{P B} .
\end{aligned}
$$

This is as it should be: both emissions measures refer to the very same emissions - they are just measured at different points along the supply chain.

\subsubsection{Determining a country's consumption-based emissions}

Determining a country's production-based emissions inventory (or more exactly: its territorial emissions inventory, see Footnote 4) is a well-established procedure: it is done by all industrialized countries at least once a year, inter alia to meet their emission reporting requirements under the Kyoto Protocol. Establishing the emissions embodied in an individual good or the consumption-based emissions inventory of a whole country is however a more difficult task: consumption-based emissions cannot simply be "measured at the chimney" where they are set free. Currently, two approaches are used to determine embodied emissions, which both have certain advantages and disadvantages (Ismer and Neuhoff 2007): in the bottom-up approach, production processes and the emissions associated with them are assessed for individual products (or narrowly defined product categories). The emissions measure thus determined is sometimes termed the "carbon footprint" of a product. It is the same quantity as the emissions embodied in that product defined above (Hertwich and Peters 2009). This method requires a lot of information (often from suppliers of intermediate products spread across the globe), it is time-consuming, but it can deliver exact results on the carbon content of individual products. If this carbon content were added up for all goods that make up the final demand of a country, theoretically, the country's consumptionbased emissions inventory could be established (which, in analogy, is sometimes termed the "carbon footprint" of that country).

But this would be a tedious procedure, and therefore for determining consumptionbased emissions for a whole country, in practice rather the second approach mentioned above is employed, the top-down approach. This approach has been refined starting in the late 1990s in what has become known as the literature on emissions embodied in trade (see Chapter 6). It is based on environmentally extended input-output analysis. Simply put, such an analysis does not establish the carbon content of individual goods, 
but works with sector averages. For every sector it is determined, how many inputs from other sectors directly or indirectly (via a longer supply chain) are required to produce one unit of output of the sector examined. These data are combined with data on the aggregate emissions discharged by every sector (or alternatively its energy consumption) in order to provide the amount of emissions embodied in the output of the sector studied. Lenzen et al. (2004) give an overview of different types of such international input-output models: The simplest type, autonomous trade models, assumes that imported commodities are produced with the same technology and production structure (and thus the same emissions) as domestic goods. The second type of models, unidirectional trade models trace imports one step back to the region producing them. Every such producing region is characterized by its own technology and production structure (and thus its own emission intensities). Finally, the most sophisticated type of models, multidirectional trade models, traces back the whole supply chain of imports, often involving many different regions (each with its own technology and production structure).

All these types of models have in recent years been used to estimate consumptionbased emissions inventories for most countries and regions of the world - see Chapter 6 . They are an excellent tool to depict the interconnectedness of production between different regions in today's globalized economy. Still, one should not forget that these models work with aggregate or average data relating to whole sectors. Any individual good may be produced using a supply chain or a technology that is quite different from that sector average. Thus, also the emissions embodied in that good will typically differ from the values characterizing the whole sector. The top-down approach to the estimation of consumption-based emissions is therefore a method suitable for determining the emissions inventories of whole countries or regions, but it will provide less accurate data for individual goods. This contrast with the bottom-up approach, which can give more precise data for individual goods, but is a tedious and timeconsuming procedure if applied on a larger scale.

\subsection{Consumption-based emissions as a policy base}

Leaving the practical problems of determining consumption-based emissions aside for the moment, let us examine the formulation of a consumption-oriented policy. Basically, just as a country's production-based emission inventory can be used as a base for an abatement policy, also its consumption-based emissions inventory can be used as a policy base, i.e. policy targets and policy instruments can be tied to the country's consumption-based emissions. These two options will in the following be referred to as "production-based policy" and "consumption-based policy."

\subsubsection{Target base vs. tax base}

Steininger at al. (2012) observe that the question of the policy base of a certain policy actually consists of two questions: the "target base question", i.e. the question whether we should interpret an emissions reduction target as a target to lessen a country's production-based emissions inventory or its consumption-based emissions inventory. 
Similarly, if not targets, but "emission-budgets" (see Section 1.2) are used to define the stringency of an abatement policy, these budgets might also either refer to a country's production- or its consumption-based emissions inventory. The second question is the "tax base question", i.e. the question whether the base of an emission tax should be a country's production- or its consumption-based emissions inventory. ${ }^{6}$ A change of the target base from production to consumption has quite different effects from a change of the tax base from production to consumption. This so far has not been discussed in the literature in any detail. But as a clear understanding of this difference is essential when comparing production- to consumption-based policy approaches, the main arguments shall be outlined here.

Simplifying a bit, a change of only the target base affects the distribution of the costs of an abatement policy between different countries or regions, but it will not affect the effectiveness of the policy. Consider, as an example, the following scenario: A global conference agrees that every country reduce its emissions by 20 percent. This agreed target is defined in terms of production-based emissions. At some point, however, it is decided to redefine it in terms of consumption-based emissions. What consequences does that switch of the target base have, for example, for the EU? To answer this question, one has to determine what the percentage target means for the

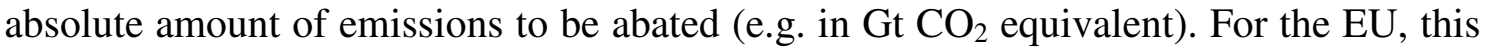
absolute amount is larger if the 20 percent reduction target refers to emissions in consumption than if it refers to emissions in production, as the EU's consumption-based emissions inventory is larger than her production-based one (see Section 6.1). Thus, for the EU a switch to a consumption-based policy means an increase in the absolute abatement requirement and as a consequence also an increase in the cost of the abatement policy. Countries or regions that have a larger production-based than consumption-based emissions inventory will, on the other hand, experience a reduction of the costs of the policy due to the switch of the target base. Thus, overall, this switch redistributes the policy costs between regions. ${ }^{7}$

6 "Instrument base" would be a more comprehensive term than "tax base", as a climate policy cannot only be pursued by means of an emission tax, but also through quantity instruments like, for example, a cap-and-trade scheme. Still, here mostly the term "tax base" will be employed - simply because it is a term that is also used in other fields of economics and that is therefore well-established. But note that all the results discussed in this study equally apply when instead of a tax a different policy instrument is used.

7 The claim that a change of the target base does not influence the effectiveness of the policy is a simplification. As described in the main text, the choice of target base influences the international distribution of the costs of the policy and thus the international income distribution. Insofar as this income distribution has an influence on policy effectiveness, effectiveness is not independent of the choice of target base. On this question, see also the discussion of the "income leakage channel" in Section 9.2. Secondly, if the target base, but not the tax base is switched, typically in every region at least an adjustment of the stringency of the policy will be needed to meet the altered target. Now, if the effectiveness of the policy is related to its stringency, then the choice of target base may have an effect on policy effectiveness. But all these effects are rather indirect - and will not be discussed here in more detail. 
As opposed to a switch of only the target base, a switch of only the tax base will influence both the distribution of the costs of the policy between regions and the environmental effectiveness as well as the cost-effectiveness of the policy. The direction and size of these distributional and effectiveness effects are the central questions of this study. As we will see in the following chapters, conclusions on these effects cannot be drawn without knowing the values of all relevant parameters. Still, as regards distributional consequences, for a scenario where only industrialized countries abate, these countries will in many cases be able to reduce the costs incurred by them by a switch to a consumption tax base. Now, if both the target base and the tax base are switched at the same time, both from production to consumption, then there will be two counteracting effects on costs (and thus income or welfare) of industrialized countries: the switch of the target base increases costs (recall the example above of the effects of such a switch on the EU), but the switch of the tax base decreases costs - the overall effect will again depend on parameter values.

This study will mostly analyze exactly such a scenario where the target base and the tax base are switched at the same time. Peters and Hertwich (2008b) examine a similar setting. But, as Table 2.1 shows, the different strands of the literature mostly discuss quite different scenarios:

Table 2.1 Target base vs. tax base

\begin{tabular}{|c|c|c|c|}
\hline & \multicolumn{2}{|c|}{$\begin{array}{c}\text { Target base } \\
\text { (affects burden sharing) }\end{array}$} \\
\hline & & $\begin{array}{l}\text { Production- } \\
\text { based }\end{array}$ & $\begin{array}{l}\text { Consumption- } \\
\text { based }\end{array}$ \\
\hline \multirow{2}{*}{$\begin{array}{l}\text { Tax base } \\
\text { (affects } \\
\text { burden sharing, } \\
\text { policy } \\
\text { effectiveness) }\end{array}$} & $\begin{array}{l}\text { Production- } \\
\text { based }\end{array}$ & $\begin{array}{c}\text { Current UNFCCC system } \\
\text { (Kyoto Protocol) }\end{array}$ & $\begin{array}{c}\text { Most of literature } \\
\text { on emissions embodied } \\
\text { in trade }\end{array}$ \\
\hline & $\begin{array}{l}\text { Consumption- } \\
\text { based }\end{array}$ & $\begin{array}{l}\text { Literature on border } \\
\text { carbon adjustments }\end{array}$ & $\begin{array}{ll} & \text { Peters and Hertwich } \\
(2008 b) \\
\text { This study }\end{array}$ \\
\hline
\end{tabular}

The literature on border carbon adjustments typically assumes a (partly) switch of the tax base by means of the adjustments towards a consumption-orientation (see Section 1.3). But the target base is typically not altered - it is assumed that the (industrialized) countries introducing the border measures continue to pursue targets defined in terms of production-based emission as, for example, the targets of the Kyoto Protocol. Such a policy may seem inconsistent - should it not be easier to meet a given target if the tax base matched the target base? Note, however, that the literature on border adjustments 
typically does not assume a "full" switch of the tax base. And additionally, the aim of the introduction of the border measures is often not to improve the effectiveness of the policy, but to protect the domestic industry of the country introducing the measures.

The other strand of literature discussed in this study, the literature on emissions embodied in trade, typically does not draw a distinction between changes in the target base and changes in the tax base. However, many of the proposals on assigning "responsibility for emissions" seem to actually discuss just a switch of the target base without a corresponding switch of the tax base - see Section 6.3.1.

\subsubsection{The tax base - production vs. consumption}

Tax incidence analysis tells us that under the assumption of flexible prices the effects of a tax do not depend on the question on which economic agent a tax is levied, but only on the tax base. For example, to cite a standard textbook example, a uniform sales tax is equivalent to a uniform income tax as both have the same tax base. It is true that the two taxes are collected from different economic agents, but the tax burden is passed on and - after all price adjustments have taken place - the tax burden borne by each economic agent is the same for the two taxes. These principles, of course, also hold for emission taxes (or any other policy instrument used for abatement policy). Thus, from the fact that the production-based and the consumption-based emissions inventories are equal on a global scale (see Equation 2.7) it follows immediately that if the world were to follow a uniform abatement policy (i.e. apply a uniform tax rate - or carbon price - to all emissions), it would not make any difference whether productionbased or consumption-based emission were taxed: the tax base is the same in both cases - all emission world-wide.

In the remainder of this study, however, situations will be examined where just one region abates and the other does not - in that case, the policy bases of a production- and a consumption-based policy will differ. And, to repeat the central point, it is this difference in policy bases that is the cause of differences in effectiveness and distributional impacts of the two policies - and not the fact that one tax is collected from producers, while the other one might be collected, for example, directly from consumers or at the border between the regions.

In Figure 2.2 the policy-base for a policy in Home targeting production-based emissions is highlighted. One can see that also Foreign is affected by this policy: part of its imports (the part that does not constitute through-trade for Home) are subject to the policy (and will therefore usually become more expensive). 


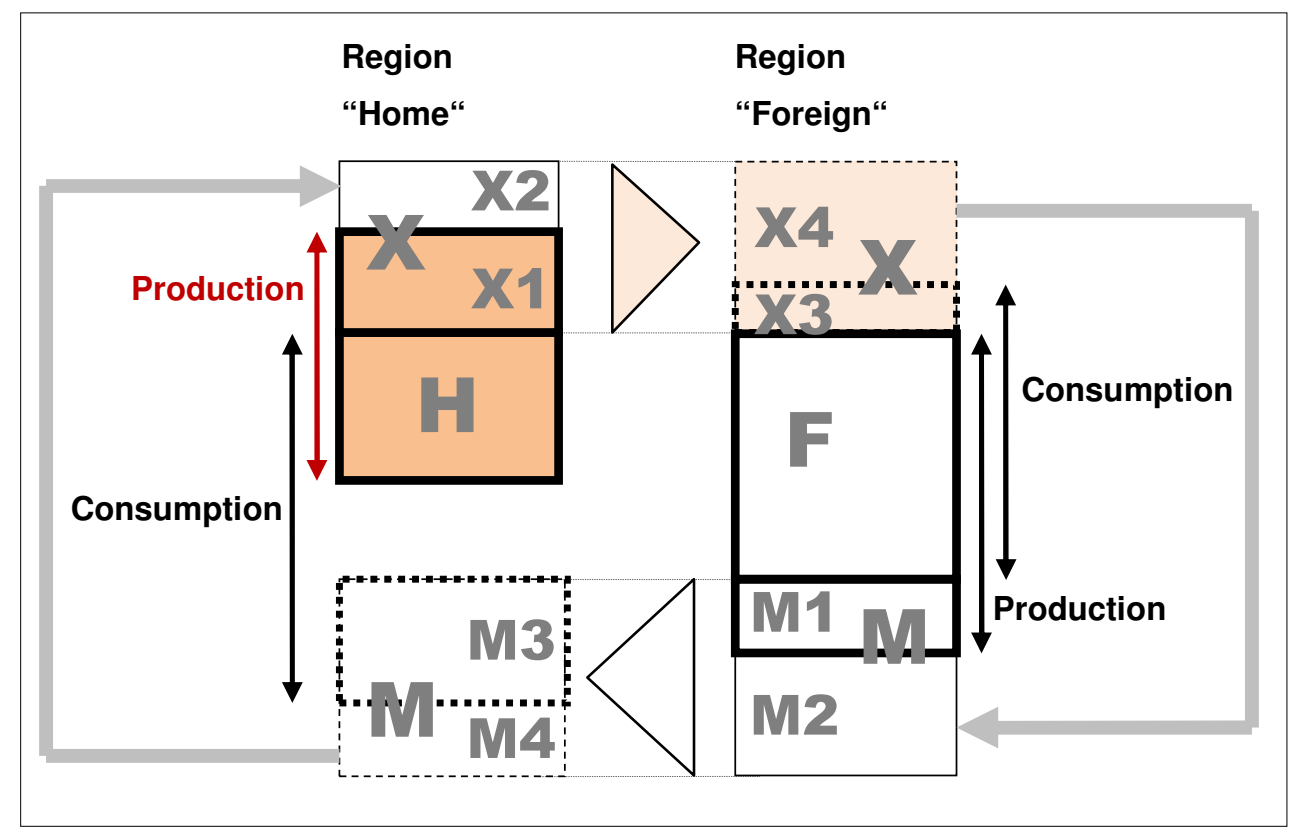

Figure 2.2 Production as policy-base

In Figure 2.3 Home follows a policy targeting consumption-based emissions. Now, the policy also affects Foreign's export production; or more precisely that part of export production which will not become through-trade in region Home.

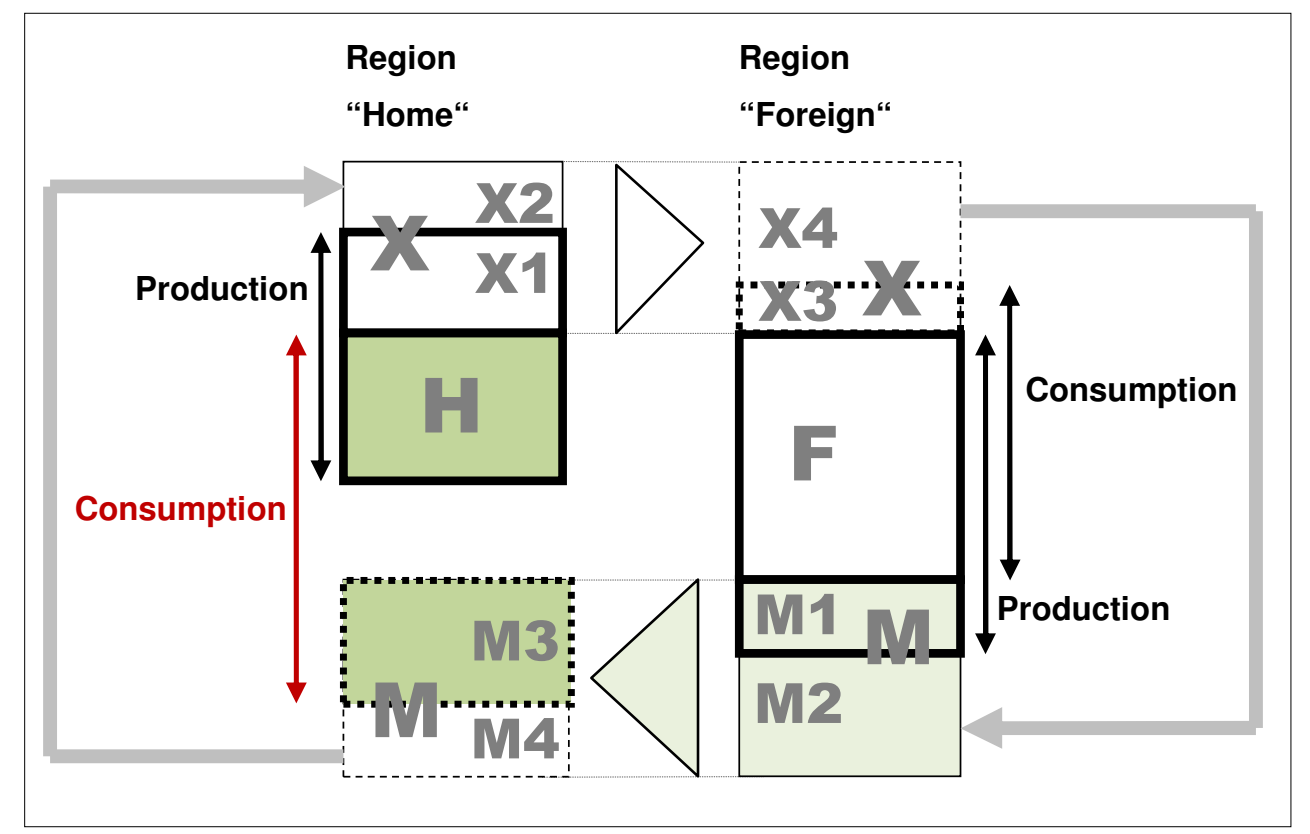

Figure 2.3 Consumption as policy-base

\subsubsection{Implementing a consumption-based policy}

Most countries currently abating their GHG emissions follow some form of a production-based policy. In practical terms, this means imposing the carbon price (e.g. a 
tax or the costs of emissions permits) on those firms that actually discharge the GHGs. Consumption-based policies are currently not followed by any country on a wider scale. The academic literature however discusses several options how they might eventually be introduced (see e.g. Droege 2011, Droege et al. 2009).

The only one of these options that could be realized relatively quickly appear to be border carbon adjustments. Border adjustments usually start with a mitigation policy that uses production as the policy-base. Then, in the case of full adjustment, all imports are taxed at the border for the emissions associated with their production (i.e. the emission embodied in these goods) in the same way as domestic goods, and exporters receive a tax rebate on exports for the full amount of emissions taxes paid. In this way, the tax base is being changed from production to consumption (through-trade is not taxed as import taxes and export rebates cancel out). Border adjustments cannot only be imposed for emission taxes - also equivalent measures exist for quantity-based policy instruments, for example importers may be required to purchase emission allowances for the emissions embodied in imports. In this study, border adjustments will however in order to keep the argument simple and without loss of generality - be discussed in the form of taxes.

There exists a vast literature on border carbon adjustments (see Chapter 5). Most of the adjustments discussed in that literature however do not qualify as "full adjustments," i.e. they will not bring about a full switch of the tax base from a production-based to a consumption-based one: For example, they either do not extend to both imports and exports; or they include only energy-intensive, but not all sectors of the economies studied; or they only encompass direct emissions or direct emissions plus indirect emission from electricity, but not all emissions discharged along the complete international value added chain for all products; or they only count combustion emissions, but disregard process-related emissions; or they apply a carbon price that differs from the one that prevails domestically. In this study, on the other hand, we examine the effects of a "full switch" of the policy base towards consumption.

It is however not clear whether such a "full switch" can indeed be achieved by means of border adjustments. The discussion in Section 2.1.2 has already shown that establishing the emissions embodied in a good is a tedious procedure that requires a lot of information on production processes and supply chains in foreign countries. It is far from clear whether this information can indeed be available "at the border." Several methods to calculate border taxes are discussed in the literature (see Chapter 10) - but most of these methods will not bring about a full switch of the tax base. Still, even though it is thus doubtful whether border carbon adjustments are indeed an appropriate means to introduce a consumption-based policy in real-world situations, the idea of such adjustments can serve as a convenient "tool" in theoretical discussions: phrasing one's arguments in terms of border adjustments can sometimes help to envision the effects of a policy notwithstanding the fact that the policy, if ever implemented, might actually be pursued through other policy instruments.

A second option how a switch to a consumption-based tax base might be accomplished is discussed by Droege et al. (2009) and Droege (2011). It is termed 
"carbon-added proposal" and has certain similarities to a value added tax (VAT): for every good, the emissions discharged are recorded at every step of the value added chain the good passes through. The emissions measures of the individual steps are added and passed on with the good whenever it is sold. At every production step, their sum gives the emissions already embodied in the good at the step; at the end of the production chain, the "carbon footprint" (or the overall embodied emissions) of the good will be obtained. In that way, for all goods, no matter whether they are intermediate or final goods, information on their carbon content will be available.

Under the „carbon-added proposal" governments can use this information to tax any good according to its embodied carbon. They are free to decide for or against applying such a tax; all they are required to do is to safeguard a correct recording of emissions. An emerging economy might, for example, decide to apply the emissions tax only to its exports, but not to its domestic consumption (this would amount to an export tax as discussed in Section 10.1.3). An industrialized country, on the other hand, might decide to apply the tax to all goods. Similar to value added taxation, where VAT is charged on the basis of total sales, but companies can offset their tax dues against the tax paid by others at earlier stages of the production chain, the carbon added tax would also be calculated according to the total carbon embodied in the goods under question, but again it would be possible to offset the tax dues against tax already paid. For a company importing some good from an emerging economy that means that this company would have to pay tax on all emissions embodied in that good if no previous tax had been collected in the exporting country. There would thus be a "border tax." If, on the other hand, an emissions tax had already been paid in the exporting country, the importer would be able to reduce her tax dues by the amount of that tax.

The introduction of such a "carbon added" scheme would require the cooperation of (nearly) all countries - a credible system of emissions monitoring and recording would have to be established on a global scale. Thus, such a scheme cannot be introduced quickly; rather, building it is a long-term project. But once established, a "carbon added" scheme would have the advantage that it would enable a "full switch" to consumption-based accounting - the reason being that accurate information on the emissions embodied in every good would be available.

\subsection{Evaluating different policy variants}

Evaluating different climate policies is by its very nature a normative exercise - one has to decide which criteria to use to determine whether one policy variant performs "better" than another one (Venmans 2012). A great number of different criteria are mentioned in the literature, and of these, different authors employ different ones. Some guidance on criteria choice is provided by the $4^{\text {th }}$ assessment report of the IPCC (2007): It lists environmental effectiveness, cost-effectiveness, distributional considerations, and institutional feasibility as principal criteria. As stated in the introduction, this study will concentrate on the question of policy effectiveness. Policy effectiveness as such is not a very precise term - but it is probably best operationalized by either of the first two criteria in the list above, environmental effectiveness or cost-effectiveness. Still, as this 
study also intends to provide proposals for climate policies that can actually be implemented, it does not suffice to concentrate on effectiveness alone - we also need to discuss those criteria that dominate the political debate. Thus, also the other two criteria recommended by the IPCC will be used - we will come back to distributional questions at various points in this study; the criterion of political feasibility will be considered at length in Chapter 10. Additionally, two other criteria that are often used in the academic literature as well as in the public debate will be introduced: carbon leakage and competitiveness. But to begin this overview of policy evaluation criteria, a criterion that is almost exclusively employed in theoretical models will be briefly discussed, the criterion of economic efficiency.

\subsubsection{Criteria to evaluate a policy's effectiveness}

Some of the theoretical models that will be discussed in Chapter 4 employ the criterion of economic efficiency to compare different policies. Efficiency is the most comprehensive of the criteria reviewed in this subsection - it not only assesses the effectiveness of reaching a given environmental goal, but also the process of selecting this goal, i.e. it helps to identify, for example, the "optimal level" of emissions reduction. To that end, however different environmental outcomes must be valued, which is a difficult and controversial exercise. Therefore, economic efficiency is a criterion well suited for purely theoretical analyses; in studies closer to real-world circumstances most researchers however prefer to avoid valuing environmental outcomes and employ other criteria such as environmental effectiveness or costeffectiveness.

Cost-effectiveness is a criterion that evaluates both costs and benefits of a policy, but does not require a valuation of environmental outcomes. This is achieved by either comparing policies with the same environmental outcome (i.e. the same benefits). Then the policy with the lowest costs is the most cost-effective one. Or, alternatively policies involving the same costs are compared - then the one with the best environmental outcome (i.e. the largest benefits) is the most cost-effective one. Determining, which environmental outcome is best, can be done by just ranking the outcomes on an ordinal scale - a valuation of the outcomes is not required.

As climate change is triggered by the global concentration of GHGs, the environmental effect of a climate policy - the benefits of the policy - must also be measured on a global scale. In this study, benefits will be represented by the reduction in $\mathrm{CO}_{2}$ emissions; and it is thus the global reduction of these emissions that counts and not the reduction of the emissions in a single country or a group of countries - even if the policy is pursued unilaterally. ${ }^{8}$ Equally, also the costs will always be defined on a

8 This study thus discusses just one of the GHGs, $\mathrm{CO}_{2}$ - albeit the currently most important one in terms of its contribution to global warming. Also, to simplify the analysis, benefits are defined in terms of the "intermediate goal" of global emission reduction, and not in terms of a reduction of global GHG concentrations or even of climate change impacts avoided. 
global scale, i.e. we are interested in the question whether a policy is desirable for the world as a whole, and not just for one region. Policy makers, in contrast, are typically rather interested in the costs incurred by their region or country when introducing the policy. However, a policy with minimal global cost also permits to achieve minimal cost for the region introducing the policy for given costs to the rest of the world. This argument, of course, assumes that it is possible to redistribute costs between world regions. We will come back to the question of redistribution when discussing proposals for a future climate policy.

Environmental effectiveness, as opposed to cost-effectiveness, is a criterion that looks only at the benefit side of a policy: the IPCC (2007) defines it as the extent to which a policy meets its intended environmental objective. As stated above, in this study the environmental objective is given by the reduction of global $\mathrm{CO}_{2}$ emissions. As no information on the costs of the policies examined is required, environmental effectiveness may be a criterion that is more convenient to apply in practical circumstances than cost-effectiveness; this convenience, however, comes at a price: the informative value of a comparison of just the environmental effectiveness of two policies is, of course, smaller. Economists therefore - whenever possible - typically prefer to analyze the cost-effectiveness of a policy, and not its environmental effectiveness.

Furthermore, for a comparison of environmental effectiveness to be meaningful, the two policies being compared have to be similar at least regarding some of their aspects: this study will in the following compare policies that either (i) achieve the same emission reduction in the region that abates or that (ii) apply the same carbon price. As we will see in Section 8.7.1, option (ii) can actually be interpreted as a simple costeffectiveness analysis.

\subsubsection{Carbon leakage}

Carbon leakage is a criterion that is widely used in the academic literature and that has also found its way into the public discussion. Loosely speaking, it describes an effect that may occur if not all regions of the world abate: then emissions may not be reduced on a global scale, but just shifted from abating to non-abating regions. Two main versions of the concept of carbon leakage exist: first, "policy-induced" or "strong" carbon leakage, and second, "consumption-induced" or "weak" carbon leakage (Peters and Hertwich 2008a; Droege 2011).

\section{Policy-induced carbon leakage}

In this study, mostly the first variant will be discussed, policy-induced leakage. As the name already indicates, it measures an effect directly triggered by climate policy, or more precisely, an unintended global effect of unilateral climate policy - a possible increase in emissions in the non-policy region caused by the introduction of the 
abatement policy in the policy-region. ${ }^{9}$ In its most simple form, this can be stated in absolute terms, i.e. in tons or megatons of $\mathrm{CO}_{2}$ of additional emissions in the non-policy region. In our two-region framework, if Home introduces a policy using emissions in production as the policy-base, then this policy-base consists of all emissions discharged in the production of $H+X 1$, i.e. all emissions set free in production taking place inside the policy region. The emission discharged in production taking place in the non policyregion, on the other hand, are those set free in the production of $F+M 1$. The absolute policy-induced leakage for a policy targeting production, $L^{P B}$, then equals

$$
L^{P B}=\Delta E_{F}+\Delta E_{M 1}
$$

$\Delta$ denotes the change in a variable compared to a reference state with no abatement policy. Absolute leakage therefore is a measure of the (unintended) "side-effect" of the policy, an increase of emissions in the non-policy region, in absolute terms.

However, more common than this absolute leakage measure is a relative measure the leakage ratio (denoted here by the lower-case letter $l$ ). It is defined as the increase of emissions in the non-policy region divided by the reduction in the policy region:

$$
l^{P B}=\frac{\Delta E_{F}+\Delta E_{M 1}}{-\left(\Delta E_{H}+\Delta E_{X 1}\right)} .
$$

Thus the leakage ratio sets the undesired effect of the policy - the increase of emissions in the non-policy region - in relation to the desired effect, the reduction of emissions in the policy-region.

Note that policy-induced leakage thus measures one aspect of the global environmental effectiveness of a policy: if a reduction of emissions in the policy region is accompanied by an increase of emissions in the non-policy region, then clearly the global reduction in emissions is smaller than the reduction in the policy region - the effectiveness of the policy is thus reduced by the unintended effect in the non-policy region. Thus, leakage is an unwanted phenomenon, reducing the global effectiveness of a unilateral climate policy.

Still, carbon leakage cannot be used as a measure of the overall effectiveness of a climate policy: the overall effectiveness depends on the impact of the policy in both the

9 The IPCC defines carbon leakage as "the part of emission reductions in Annex B countries that may be offset by an increase of the emissions in the non-constrained countries above their baseline levels" (IPCC 2007, 811). This definition refers to the split of countries into abating and non-abating ones as introduced by the Kyoto Protocol. But obviously, the concept of carbon leakage can also be used for other coalitions of abating countries. 
non-policy and the policy region - but carbon leakage only assesses impacts in the nonpolicy region. To give an example: assume policy $A$ leads to a little less leakage than policy $B$. But policy $B$ is much better in lowering emissions in the policy region than policy $A$. Taken together, policy $B$ causes a larger reduction in global emissions and is therefore the environmentally more effective one, even though it performs worse as regards leakage. In one specific setting it is however indeed possible to infer the environmental effectiveness of a policy directly from its leakage ratio: if one compares two policies that bring about an equal emissions reduction in the policy region, then the policy involving less leakage leads to a larger reduction in global emissions and is therefore the environmentally more effective one.

When analyzing a policy with consumption instead of production as its policy base, the split-up of the impacts of the policy into intended and unintended effects changes: A consumption-based policy followed by region Home targets emissions embodied in goods $H+M 3$. Thus emissions embodied in $H+M 3$ constitute the policy base $-\mathrm{a}$ "consumption policy-base" - and the intended effect of the policy is a reduction of exactly these emissions. The unintended effect of the policy, on the other hand, is a possible increase of emissions not targeted, i.e. of emissions outside the "consumption policy-base" - and these are the emissions embodied in goods $F+X 3$. Now, if one wants to use carbon leakage again as a measure of the unintended effects of the policy (and thus of the loss of effectiveness associated with these unintended effects), the leakage formula has to be adapted accordingly. Absolute leakage and the leakage ratio for a policy with consumption as the base are then defined as follows:

$$
\begin{gathered}
L^{C B}=\Delta E_{F}+\Delta E_{X 3}, \\
l^{C B}=\frac{\Delta E_{F}+\Delta E_{X 3}}{-\left(\Delta E_{H}+\Delta E_{M 3}\right)} .
\end{gathered}
$$

When comparing policies, one therefore has to decide whether to calculate leakage with the "production formulas" (2.8) and (2.9) or with the "consumption formulas" (2.10) and (2.11). The choice between these formulas should be guided by the objective a country pursues with its climate policy, and not by the base of the actual policy followed, i.e. the emissions reduction target that a country wants to reach defines what is an "intended" and what an "unintended" effect: assume, for example, that a country, bound under the current UNFCCC system by mitigation targets referring to emissions in production, decides to introduce border carbon adjustments to protect its domestic industry. The border adjustments in effect represent a (partial) switch to a consumptionbased policy. Now the country is interested in the question whether leakage under its former production-based or its new consumption-based policy is larger. In this case, the country should calculate leakage for both policies with the "production formulas" (2.8) and (2.9), as with both policies it aims to reach a mitigation target stated in terms of production. This also is the scenario usually assumed in the CGE literature on border 
carbon adjustments (see e.g. Boehringer et al. 2010a; 2012a; Burniaux et al. 2010; Fischer and Fox 2012). Note, however, that a leakage measure calculated in this way provides information only on the question how well the policy performs in achieving the country's internationally agreed mitigation target, but not on whether the policy also helps to reduce global emissions. Thus, carbon leakage in that case is no longer an indicator of the global effectiveness of the policy. This is an important point that so far has not been discussed in the literature on border carbon adjustments.

The situation, however, changes if a country examines the effects of changing both the tax and the target base - either because a switch of the global accounting system is considered or because the country is interested in how by pursuing a unilateral policy it best furthers mitigation efforts at the global level. Then, leakage for the productionbased policy should be determined by formulas (2.8) and (2.9), and leakage for the consumption-based policy by formulas (2.10) and (2.11). For much of the remainder of this study, exactly such a setting will be analyzed: a switch of both the target and the tax base. Then, by applying the correct leakage formulas, one can compare the unintended effects of the two policies as seen from a global perspective.

\section{Consumption-induced carbon leakage}

The second leakage concept, "consumption-induced" or "weak" carbon leakage is defined as the emissions embodied in imports of the abating region from the nonabating region. ${ }^{10}$ In terms of the two-region framework introduced in this chapter, consumption-induced leakage thus equals $E_{M}$ (or alternatively $E_{M 3}$, if one subtracts imports that are re-exported). In other words, it is the amount of emissions discharged in the non-policy region in order to produce goods that are consumed in the policy-region. Note that as opposed to the definition of policy-induced leakage the definition of consumption-induced leakage does not assume any specific cause why a certain amount of emissions is embodied in the imports of the abating region; in particular, the definition does not require that weak carbon leakage is triggered by the introduction of a climate policy (it can be, but it need not be). Therefore, weak carbon leakage is not an indicator of the effectiveness of a certain policy. Some authors writing on emissions embodied in trade (see e.g. Peters and Hertwich 2006; 2008a; b) however regard a high or increasing level of consumption-induced leakage as an indicator of a situation that is deemed (at least implicitly) problematic for the environment or for international climate policy, the reason being that production to meet the consumption demand of countries with binding mitigation targets takes place in countries without binding mitigation

10 The concept of "weak" carbon leakage was introduced by Peters and Hertwich (2008a). They frame their definition in terms of countries that have reduction targets under the Kyoto Protocol (Annex B countries) and countries that do not. But, of course, this definition can be generalized to any split-up of countries into a group that abates and another one that does not. 
policies (Peters and Hertwich, 2008a). ${ }^{11}$ Chapter 6 will discuss empirical findings on the amount of and trends in weak carbon leakage. At this point, just note that a high level of weak leakage may indeed be a sign of a situation problematic for the environment, but it need not be. It is, for example, problematic if abating countries "outsource" their production to non-abating countries which then produce the same goods with a more carbon-intensive technology. But in general, differing carbon trade balances (and high levels of "weak" carbon leakage) may (and typically will) also exist in situations that are economically efficient and where there are no external effects harming the environment.

\subsubsection{Criteria to evaluate the relative performance of different regions}

The policy evaluation criteria discussed so far assess climate policies or trends in the distribution of emissions between regions from a global perspective, i.e. they ask the question, what is to the advantage of the world as a whole, and not only to the advantage of certain countries. In practical policy making, however, the question of distribution, i.e. the question who gains and who loses if a specific policy is implemented, is often more important. When analyzing practical proposal for policies to be implemented, such distributional questions therefore cannot be neglected. This study however limits the discussion of these questions to distributional effects between countries or between groups of countries; the distributional consequences of climate policies within countries, for example between producers and consumers, will be mentioned at some points, but not analyzed in detail.

Two different criteria will be employed in the examination of distributional effects: the first is the international distribution of the costs of the different policy variants. As the analysis is performed on the aggregate (i.e. national or global) level, costs from emission abatement can be best thought of as welfare losses. Thus we will examine the (relative) effects of the policy on the welfare of countries or coalitions of countries. Section 8.7 will provide a more detailed explanation what exactly constitutes the cost of pursuing a climate policy.

The second criterion used to evaluate the relative effects of climate policy on individual countries or regions is competitiveness. As will be discussed in Chapter 3, the problem of a possible loss of competitiveness of the country introducing the policy is at the center of the political debate on unilateral climate policy - compared to this debate, the question of the environmental effectiveness of a unilateral policy or of carbon

11 One might argue that a concept using the net amount of emissions embodied in foreign trade like the $\mathrm{CO}_{2}$ trade balance is a better indicator of possible environmental effects of emissions "transfers" through international trade than a concept like "weak" carbon leakage that includes only imports, but disregards exports. But Peters and Hertwich (2006), who have contributed significantly to the development of the literature on emissions embodied in trade, object: They argue that the $\mathrm{CO}_{2}$ trade balance mostly reflects the emissions intensity of the resource endowment of a country, but that they are rather interested in something else, the possibility that countries reduce their emissions by decreasing domestic production while increasing imports. 
leakage triggered by it is often relegated to second place; sometimes the term "carbon leakage" is even used - not entirely correctly - as a synonym for a loss of competitiveness.

However, as Alexeeva-Talebi et al. $(2007,2)$ observe, "the concept of competitiveness has proven hard to define and susceptible for ambiguities." The main reason for this is that it is often seen as a quite comprehensive concept - but if it is measured by certain indicators, they will typically not encompass all one has in mind when using the term "competitiveness." Here, a rather pragmatic approach will be adopted: the model used in the analytical part of this study is not suited to examine all aspects of the concept of competitiveness. Therefore, one aspect will be chosen; and then a measure appropriate to gauge this aspect will be developed.

Alexeeva-Talebi et al. (2007) review much of the recent theoretical literature on competitiveness. They suggest differentiating between competitiveness at the firm, at the sectoral, and at the national level. This study concentrates on the sectoral and on the national level. At the sectoral level, Alexeeva-Talebi et al. argue that competitiveness resides in (i) the "ability to sell" and (ii) the "ability to earn". For the "ability to earn", for example, the profitability of an industry may be used as an indicator. The model of this study, however, analyzes a long-run competitive equilibrium, where firms to not make any profits. The model therefore cannot be used to analyze the "ability to earn" instead, the focus is on the "ability to sell". Quirion $(2010,108)$ defines the ability to sell at the sectoral level as "the capacity (...) of a sector of a given country or region to increase its market share, both domestically and abroad." Alexeeva-Talebei et al. (2007) discuss some complex indicators of this capacity that either compare the performance of one domestic sector to that of all other domestic sectors or to the performance of the same industry in other countries. Most CGE studies however make use of simpler indicators like changes in output, in exports, in imports, or in net exports (i.e. in exports minus imports) - see Chapter 5. All of these indicators - the complex as well as the simple ones - measure different components of the "ability to sell". All in all, there are four such components: (i) the ability to sell by home sectors at domestic markets, (ii) the ability to sell by home sectors at foreign markets, (iii) the ability to sell by foreign sectors at domestic markets, and (iv) the ability to sell by foreign sectors at foreign markets (Alexeeva-Talebi et al. 2007).

At the national level, according to Alexeeva-Talebi (2007) competitiveness needs to be defined somewhat differently. In addition to the "ability to earn" and the "ability to sell" one may also consider the "ability to attract" - referring to the economy's capacity to attract factors of production - and the "ability to adjust" - referring to the capability of an economy to adapt to new circumstances. Discussing these last two "abilities" is however beyond the scope of this study. The "ability to earn" is defined differently at the national level than at the sectoral level: while on the sectoral level it usually relates to only one type of income, profits, at the national level it includes income in general. In the analytical part of this study, the effects of climate policies on "welfare derived from consumption" will be compared. For small changes in income, the difference between using either income or "welfare derived from consumption" as a 
metric is however typically quite small (Boehringer et al, 2012a). Thus, one can interpret results referring to changes in "welfare derived from consumption" triggered by climate policy as actually also signifying changes in competitiveness defined as "ability to earn". As regards the "ability to sell", the indicators recommended by Alexeeva-Talebi et al. (2007) for use at the national level are different from those suggested for the sectoral level - they include the current account, the terms of trade, the real exchange rate, and the world market share of the exports of the country under question. CGE studies examining the effects of climate policy on competitiveness at the national level or at the level of a whole region - see Chapter 5 - typically report changes to the terms of trade or the same measures also used at the sectoral level, i.e. changes to output, imports, exports, or net exports (which equal the current account).

The use of output as an indicator of competitiveness is debatable. Fischer and Fox $(2012,203)$ suggest that one should rather rely on the change in net exports: "Arguably, this metric is more appropriate for climate concerns, because it does not include the lost production associated with reduced consumption at home." A reduction of the consumption of carbon-intensive products at home is, of course, one of the main aims of a domestic climate policy - even though at the same time it reduces competitiveness in the sense of the "ability to sell by home sectors at domestic markets." This study will follow the recommendation of Fischer and Fox and will also employ the change in net exports as its indicator of the competitiveness effects of different climate policies. This indicator can be used at the sectoral level as well as when examining the effects on competitiveness for a whole region. One however still must decide whether to measure net exports in physical units or in value units. Fischer and Fox (2012) in a study on different anti-leakage measures (which will be reviewed in detail in Chapter 4) use physical units, while many CGE models report value units.

For the purpose of this study, however, the use of physical units is more appropriate. Consider in particular exports: taxing emissions discharged in their production will typically raise their price and thus lower the quantity demanded and produced. Whether the overall effect on the value of exports is positive or negative cannot be determined without knowing the specific values of the parameters of the demand and supply functions. At any rate, the change in the value of exports informs us only about the competitiveness effect on the economy as a whole, but not on the competitiveness effect on the industrial sector under question - or, if the analysis is not sectoral but national, on the competitiveness effect on the production side of the economy. The reason is that the economy as a whole also receives the revenues of the emissions tax, the producers on the other hand - whether those of just one sector or of the whole economy - do not receive these revenues and therefore do not experience any advantage from the price increase triggered by the introduction of the tax. In this study, however, the competitiveness measure employed is meant to serve as an indicator of effects that pertain to the production side of the economy (and not to the economy as a whole) and thus, the value of (net) exports is not an appropriate measure. Instead, a competitiveness measure that captures only changes to the physical quantity of (net) exports, but not to the prices of exports and imports will be employed. As imports and exports are different goods, it is however not possible to directly add up their physical 
quantities. Therefore to determine the quantity that will in the following be labeled "net exports", the physical quantities of exports and imports will be weighted with the prices these goods have in the reference state with no policy. These prices - the weights - are assumed to be fixed. Thus, when the change in "net exports" triggered by the policy is determined, this change is due only to a change in the physical quantities of imports of exports, but not to their prices. Formally, let $X 1_{i}$ and $M 3_{j}$ be the physical quantities of export goods $i$ and import goods $j$, respectively, and $\bar{p}_{X 1_{i}}$ and $\bar{p}_{M 3_{j}}$ their prices in a situation without any climate policy. Net exports $N$ are defined by

$$
N=\sum_{i} X 1_{i} \bar{p}_{X 1_{i}}-\sum_{j} M 3_{j} \bar{p}_{M 3_{j}},
$$

and the change in net exports caused by the introduction of a climate policy is given by

$$
\Delta N=\sum_{i} \Delta X 1_{i} \bar{p}_{X 1_{i}}-\sum_{j} \Delta M 3_{j} \bar{p}_{M 3_{j}}
$$

\subsection{A simplified framework for analysis}

In the analytical part of this study, the framework introduced in this chapter will be further simplified: only final, but no intermediate goods are assumed to be manufactured and traded. This implies that there will be no trough-trade in the two regions - all imports find their way into final demand in Home, and all exports find their way into final demand in Foreign. Of course, as compared to real-world circumstances, this is a substantial simplification; actually, currently more intermediate than final goods are globally traded - but this simplification allows depicting our tworegion framework by a small model that is analytically tractable. Figure 2.4 visualizes the policy-bases of a production- and a consumption-based policy according to this simplified framework. 

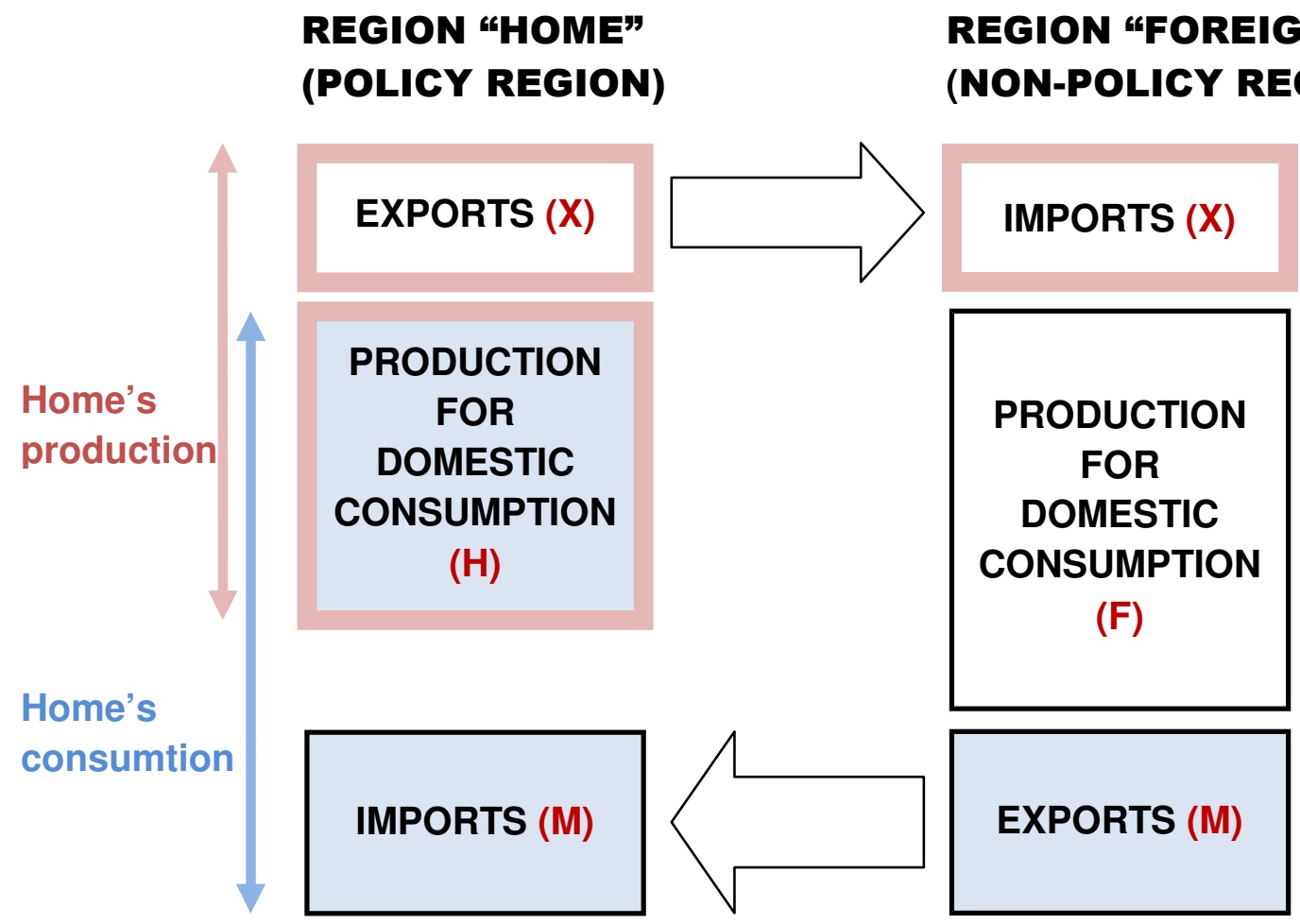

REGION "FOREIGN"

(NON-POLICY REGION)

IMPORTS (X)

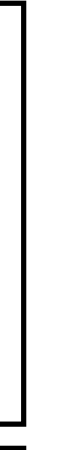




$$
\begin{aligned}
& L^{P B}=\Delta E_{F}+\Delta E_{M} \quad \text { and } \\
& l^{P B}=\frac{\Delta E_{F}+\Delta E_{M}}{-\left(\Delta E_{H}+\Delta E_{X}\right)} .
\end{aligned}
$$

For a consumption-based policy, absolute leakage and the leakage ratio within the simplified framework are defined as follows:

$$
\begin{aligned}
& L^{C B}=\Delta E_{F}+\Delta E_{X} \quad \text { and } \\
& l^{C B}=\frac{\Delta E_{F}+\Delta E_{X}}{-\left(\Delta E_{H}+\Delta E_{M}\right)} .
\end{aligned}
$$

Finally, the change in net exports simplifies to:

$$
\Delta N=\sum_{i} \Delta X_{i} \bar{p}_{X_{i}}-\sum_{j} \Delta M_{j} \bar{p}_{M_{j}}
$$

"Net exports" defined in this way will be used as the measure of competitiveness in the analytical part of this study in Chapter 8 . 



\section{CHAPTER 3}

\section{The Political and Legal Background to the Discussion about Consumption-Based Policies}

\subsection{Border carbon adjustments - a politically controversial idea}

Since its very beginnings international climate policy has been characterized by different levels of efforts of different countries - and as a consequence differences in the (explicit or implicit) carbon price in these countries. The first global climate treaty that set legally binding targets for emission reduction, the Kyoto Protocol (UNFCCC 1998), foresaw these targets only for developed countries. At the international climate conference in Copenhagen in 2009, plans to agree on a legally binding follow-up agreement to the Kyoto Protocol however collapsed. Instead, a non-binding political accord, the Copenhagen Accord (UNFCCC 2010), was adopted. It introduced what became to be known as "pledge-and-review" system, a climate policy architecture where individual countries voluntarily state by how much they plan to reduce their emissions. For countries and groups of countries that were committed to an ambitious climate policy, the failure of the Copenhagen conference came as a huge disappointment; fears grew that, without a global agreement in place, international climate policy would become ever more fragmented and that carbon prices in different countries would drift apart even further. The UN climate conference in Durban in 2011, however, again envisioned work on an international climate treaty, and the recent UN conferences in Doha and in Warsaw in 2012 and 2013 affirmed that goal (UNFCCC 2011c; 2012; 2013). Still, that treaty - if ever signed - will not enter into force before 2020. Thus at least in the short to medium term global climate policy will be dominated by unilateral actions of single countries - and a wide array of different carbon prices.

But even if a new global climate treaty is indeed eventually agreed upon, it will most probably still stipulate differences in the efforts required of different countries and thus cause differences in carbon prices. As Droege (2011) points out, such a difference in carbon prices is a direct consequence the UNFCCC principle of "common but differentiated responsibilities" (CBDR $)^{12}$ - which, put briefly, requires a larger

12 Theoretically, the principle of CBDR can also be met by other means than by having carbon prices differ. For example, a global carbon market - leading to a single carbon price - could be established and the different treatment of developed and developing countries mandated by the CBDR principle could be achieved through direct income transfers between countries. Still, the current international political discussion on mitigation policies is dominated by approaches that would lead to differing carbon prices. 
abatement effort from industrialised countries than from developing and emerging economies. Thus, unequal carbon prices can be expected to prevail - probably with a larger spread as long as there is no global climate treaty, but still involving substantial differences also with a new climate agreement.

Fears soon emerged that differences in abatement efforts, and thus differences in carbon prices, might be detrimental to the economy of countries forging ahead with their climate policy - or might undermine that very climate policy. The basis for such fears was discussed in the literature on carbon leakage; and the literature on border carbon adjustments examined one of the possible countermeasures. This discussion did not remain a purely academic one - it was soon taken up by politicians and also became known to the general public. This is in contrast to the results of the literature on emissions embodied in trade. The finding of this strand of literature that industrialized countries, while abating at home, were importing ever larger quantities of embedded carbon from emerging economies was sometimes mentioned in newspaper and magazine articles or blogs - sometimes with graphic titles like "The cost of trade - rich countries are outsourcing their carbon-dioxide emissions" (Economist 2011). Still, these results - and the sometimes recommended countermeasure of a switch to a consumption-oriented policy - never became the subject of such a heated political and public debate as the idea that unilateral climate policy might have negative consequences for the countries pursuing that policy. Thus, also the terms used in the literature on emissions embodied in trade such as "consumption-based emissions accounting" never became known to the wider public. Instead, the political debate revolved around the arguments discussed in the literature on policy-induced leakage and the proposal to introduce border carbon adjustments. To understand that debate, note that the adoption of border adjustments can serve quite different purposes:

- To preserve the competitiveness of the industry in abating countries. - This argument has become known as "levelling the playing field" between domestic and foreign producers (Clapp 2010). The idea is the following: taxing emissions embodied in imports at the same level as those in domestic products equalizes the carbon price between these two categories of products in the domestic market and thus prevents a loss of competitiveness of domestic producers caused by the introduction of an abatement policy. Equally, in foreign markets the playing field between domestic exporters and foreign producers "can be levelled", i.e. the carbon price can be equalized, by granting a export carbon rebate to domestic exporters, i.e. exempting their products from the climate policy.

- To increase the efficiency, the environmental effectiveness, or the global costeffectiveness of a climate policy or to prevent carbon leakage. - As opposed to the competitiveness argument, which is concerned with the relative economic advantage of the abating region, this argument focuses on the global environmental effects of the policy. Whether this argument actually holds is the main research question of this study. Reasons why it may hold were given in the introduction: preserving competitiveness might also curb carbon leakage (by 
removing the cost-advantage of "dirty" products). Additionally, a policy supplemented with border carbon adjustments may be environmentally more effective or more cost-effective due to the large amount of carbon embodied in imports and the low costs of abatement in the industries producing these imports.

- To sanction countries not participating in an international abatement regime. This is an argument from game theory: trade restrictions applied to nonparticipants may increase participation and compliance with an international (climate) regime, inter alia because they deter free-riding behaviour (e.g. Barrett and Stavins 2003). Such a use of border measures as sanctions, of course, depends on the presumption that these measures will impose costs on the countries targeted.

- To prevent an increase in "weak carbon leakage", i.e. of carbon imports of abating from non-abating countries. This is an argument from the literature on emissions embodied in trade (e.g. Peters and Hertwich 2008a; b). As mentioned above, the arguments of this strand of literature were mainly used in the academic debate, but rarely in the political discussion. Note that the literature on emissions embodied in trade does not claim that climate policy is the cause of "weak carbon leakage". Still, a climate policy coupled with border carbon adjustments can - by means of changing the policy base to emissions in consumption - reduce "weak carbon leakage."

The idea of an introduction of border measures has been supported by, among others, two well-known, Nobel prize-winning economists: Joseph Stiglitz (2007, 177) has suggested that the EU react to the U.S. decision not to ratify the Kyoto Protocol with such measures: "[T]he countries of Europe and elsewhere could impose countervailing duties to make up for the subsidies that American producers, using energy intensive technologies, implicitly receive when they degrade the global environment without paying the costs." And Paul Krugman (2009) - writing on the idea that the U.S. themselves employ border measures - argues that this is "a matter of levelling the playing field, not protectionism." Both Stiglitz and Krugman thus recommend border measures on the grounds that they avert competitiveness losses of abating countries although Krugman also stresses that the measures prevent "an inefficient outcome even from a world point of view."

As Van Asselt and Brewer (2010) observe, the border adjustment debate in the U.S. is in general motivated mostly by fears of a loss of competitiveness - and as a consequence a loss of jobs - and not so much by environmental concerns. Also, the argument to prevent free riding by countries like China and India, i.e. the "sanctioning argument," is sometimes heard. Actually, already the U.S. decision not to sign the Kyoto Protocol was based on the competitiveness argument: Former U.S. President George W. Bush argued that "[f]or America, complying with those mandates would have a negative economic impact, with layoffs of workers and price increases for consumers" (White House 2001). As opposed to Bush, his successor in the White House, Barack Obama, has promised to take action against climate change. Soon after 
his inauguration, the introduction of a federal cap-and-trade system was envisioned. But even though Obama himself opposed border adjustments, provisions for such measures were included in the climate bills discussed in the U.S. Senate and the House of Representatives. The House in 2009 finally passed the "American Clean Energy and Security Act" (Waxman-Markey 2009), which foresaw the introduction of a cap-andtrade system. Apart from provisions to grant free emission allowances to certain energyand/or trade-intensive industries this bill also required importers in certain sectors to purchase emission allowances, i.e. a form of border adjustments. This provision, however, would not have entered into force before 2020. The corresponding proposal in the Senate, the Kerry-Lieberman (2010) bill, also included provisions for border carbon adjustments. This bill was however never passed. In consequence, the plans to introduce a cap-and-trade system were shelved; and currently the Obama administration pursues its climate policy not through federal legislation, but through "rulemaking" by federal agencies like the Environmental Protection Agency based on existing legal authority (World Resources Institute 2010). Still, as Van Asselt and Brewer (2010, 47) note, "the debate on border measures in the US is far from over": any new cap-and-trade legislation can be expected to include some provision to preserve U.S. competitiveness - and this provision may well be some form of border adjustment.

In Europe, the former French president, Nicholas Sarkozy, repeatedly argued that "[w]e need to impose a carbon tax at [Europe's] borders" and announced that he "will lead that battle" (Hollinger 2009). But not all EU countries share that conviction. Van Asselt and Brewer $(2010,49)$ list, for example, Germany as heavily opposed to border adjustments and the U.K. and the Netherlands as sceptical; the European Commission and the European Parliament view border measures "as a possible option, but only if international negotiations fail." Also, as Van Asselt and Brewer note, the arguments used in the European debate differ from those used in the U.S: whereas in the U.S. the emphasis is on safeguarding competitiveness, in the EU the problem has mainly been framed in terms of carbon leakage, i.e. as an environmental concern. In the end, the measures adopted to prevent a loss of competitiveness due to the introduction of the EU Emission Trading Scheme (ETS) were not border carbon adjustments, but the free allocation of emission allowances to industries at risk. Some authors (e.g. Droege and Cooper, 2010) suggest that in fact more industries have been categorized as being at risk than in fact are at risk, i.e. the EU anti-leakage policies are overly generous. As concerns border carbon adjustment, the EU directive revising the ETS (European Parliament and the Council of the EU, 2009) mentions them only briefly as a possible alternative to the free allocation of permits and requires that such measures, if introduced, must conform to the principles of the UNFCCC and obligations under the WTO agreement. But no other details are given - indicating that, at least for the moment, not plans exist to actually implement border measures. Van Asselt and Brewer $(2010,48)$ interpret this as "a clear indication of the sensitivity of the issue." Thus, in Europe the political pressures to adopt border adjustments are not as strong as in the U.S. Still, the debate on such measures cannot be expected to die down completely - at least, as long as the EU continues to seek an ambitious climate policy. 
The main reason why border carbon adjustments are such a politically sensitive issue is that they are heavily opposed by developing and emerging economies (see e.g. Voituriez and Wang 2011 for the Chinese position). Typically, these countries fear that border measures will cause harm to their industry. As Droege $(2011,1193)$ observes, plans of industrialized nations to make use of such measures are sometimes characterized as "green protectionism" or "eco-imperialisms." India, along with the "Group of 77 and China," has already called on the UNFCCC to ban the introduction of border carbon adjustments by industrialized countries (Khor and Jhamtani 2009). As Houser et al. (2008) and Cosbey et al. (2012) stress, border measures will prove especially divisive, if they are not used to purse environmental objectives, but as "sanctions": such punitive measures would undermine international trust and therefore might impair efforts to achieve a multilateral climate agreement. In the extreme, border measures used as sanctions might even ignite a trade war.

To summarize, as long as carbon prices between individual countries differ, there is a motivation for countries with relatively high carbon prices to introduce carbon border adjustments - not only for environmental reasons, but also to protect the competitiveness of their industry. Equally, as long as the use of border adjustments allows one country to achieve welfare gains at the expense of other countries, such a policy will remain controversial. This study will not examine whether border measures can indeed be used as "sanctions", nor will it devote much room to the discussion of competitiveness issues. As already stated in the Introduction, the central question to be analyzed is the environmental effect of the introduction of a consumption-based policy (by means of border adjustments or otherwise). Still, if it proves true that such a policy switch puts developing and emerging economies at a disadvantage, its implementation will be controversial - even if it is motivated by environmental concerns. The political feasibility of the introduction of a consumption-based policy thus also depends on its international distributional consequences. These will be analysed in Chapters 8 to 11 . First, in the next section, a different question shall be discussed that may also affect the political acceptability of a switch of the policy base: the question, whether such a switch conforms to international trade law.

\subsection{Consumption-based policies and world trade law}

To change the orientation of climate policy from the current production-based to a consumption-based system, governments will have to rely on measures regulated under international trade law. This holds true irrespective of whether the policies are implemented by means of a "simple" form of border carbon adjustments or by a "carbon added" regulation as discussed in Section 2.2.3: most design options for a "carbon added" system will also involve at least some tax adjustment at the border; and all kinds of such border adjustments must comply with the provisions of the various agreements under the World Trade Organisation (WTO). Possible legal problems can, however, be avoided if the introduction of the consumption-oriented policy is based on a global agreement: then, if the chosen form of border adjustments contradicts WTO regulations, the parties to this agreement may decide to forego their WTO rights to 
challenge the agreement (Sampson 1998); they may adopt a protocol under the UNFCCC that would override WTO rules or pass a UNFCCC COP resolution, which would not be legally binding, but constitute persuasive authority on WTO panels (Hoerner and Muller 1996); or they may work directly through the WTO and amend the relevant WTO regulations (Van Asselt and Biermann 2007).

The situation is different if a single country or a group of countries decides to unilaterally introduce border adjustment measures. Then this country faces the risk that the WTO compatibility of the measures will be challenged by other countries. Some designs of border adjustments are allowed under WTO rules - adjustments for value added tax (VAT), for example, are common; other designs, however, are definitely prohibited. Still, as climate change mitigation policies have never been discussed in the dispute settlement system of the WTO, the exact line of demarcation between allowed and prohibited measures is unclear; on many important questions legal scholars remain divided. There are several recent reviews of the legal arguments. ${ }^{13}$ Here, however, the focus is not on the legal details. The aim of this section is to provide a brief overview of design options for a consumption-based policy that keep the risk of legal challenges within the WTO rather low. For countries planning to introduce consumption-oriented policies, in most circumstances it seems wise to rely on such "low risk" designs: thereby they will not only avoid possible retaliatory measures or even a "trade war". Also, a reliable legal environment will stabilize the expectations of producers and will thus help to achieve the environmental goals of the policy.

Under WTO law, border adjustments for imports are treated differently from the ones for exports, and adjustments for a carbon tax are treated differently from adjustments for a permit system (Fischer and Fox 2012). Regulations for imports mostly rely on the General Agreement on Tariffs and Trade (GATT); for exports additionally the Agreement on Subsidies and Countervailing Measures (SCM) applies.

Basically, there are two ways to justify border measures for imports under GATT rules: Either they conform to the core non-discrimination principles of Article I and III plus some rules specific to border tax adjustments in Article II and III; or, if these provisions are violated, border measures can still be justified by the general exception clause of Article XX. If one seeks justification using the first route, the following criteria have to be met: GATT Article III:2 requires that member states must not discriminate between domestic products and "like" imports - this is the so-called national treatment principle. And there also must not be any discrimination between "like" imports originating from different trade partners (giving them equally "most favoured-nation" (MFN) status, GATT Article I:1). One of the key questions is how the

13 See e.g. Ismer and Neuhoff (2007) or WTO/UNEP (2009) for in-depth discussions; or Cosbey et al. (2012), Droege et al. (2009), Fischer and Fox (2012) for shorter summaries. Van Asselt and Biermann (2007) analyze border measures the EU could adopt to support her emissions trading system. The following paragraphs of the main text are mainly based on these sources. 
term "like" should be interpreted. Many authors agree that GATT rules do not permit to differentiate between products which are similar in all respects except for their method of production, i.e. the use of a very carbon intensive production technology does not make a good "unlike" another good that has been produced employing a "clean" technology (e.g. Cosbey et al. 2012, Ismer and Neuhoff 2007). Thus, Ismer and Neuhoff $(2007,147)$ argue, the border adjustment must be the same for all products sharing the same physical qualities, and in order to fulfil the non-discrimination requirements, it also must not be higher than "the lowest charge incurred by any domestic producer." This requirement can be made operational by calculating the level of the import adjustment using the emissions intensity of the best available technology (BAT). Ismer and Neuhoff recommend this approach; still, from an economic perspective, this proposal is unsatisfactory: Imports are indeed allowed to be taxed at the border, but as "clean" imports are taxed at the same rate as "dirty" imports, the border measure may be environmentally not very effective.

In contrast, Cosbey et al. (2012) argue that - as a differentiation between carbonintense and low-carbon goods is not possible if one adheres to the non-discrimination clauses - one should chose the second route: justify import adjustments by making use of Article XX of the GATT, the article allowing "general exceptions" from the principles of non-discrimination. Justifying a policy under the exception clause is a twotier process (WTO/UNEP 2009): First, at least one of ten possible reasons for gaining an exception must be applicable to the policy. For climate policy, especially two of these ten provisions appear to be relevant: paragraph (b) allows measures "necessary to protect human, animal or plant life or health"; and paragraph (g) permits measures "relating to the conservation of exhaustible of natural resources." Second, the suggested border measures must also satisfy the requirements of the "chapeau" (the introductory paragraph) of Article XX: it must not constitute "a means of arbitrary or unjustifiable discrimination between countries where the same conditions prevail" or a "disguised restriction on international trade."

Article XX thus also clearly constrains the forms of border adjustments that are allowed: In particular, import border adjustment must only be used to achieve an environmental objective, e.g. to prevent leakage. Preserving the competitiveness of the domestic industry or "punishing" or "trying to coerce" other countries are not legitimate objectives - even if the reason for the "punishment" is that these countries resist to sign an international climate agreement (Cosbey et al. 2012). Also, border adjustments must not be implemented at short notice: attempts at negotiating a multilateral solution must precede their introduction. Cosbey et al. suggest that these requirements can be fulfilled by the following form of import adjustment: a tax at the level of average emissions intensity in the implementing country for direct emissions and at the level of the average emissions intensity of the exporting country for indirect emissions stemming from electricity production plus the possibility for exporters to prove that they produce with lower carbon intensity and that therefore a lower tax rate should be applied. Cosbey et al. base this recommendation not on legal arguments alone - they also take into account issues of data availability and the ease of practical implementation. Their proposal is closer to what would be called for by the criterion of environmental 
effectiveness than the proposal of Ismer and Neuhoff (2007) discussed above. Still, this discussion shows that in order to meet the requirements of world trade law when designing carbon import adjustments, one must compromise on economic and environmental objectives.

The justification of export rebates under international trade law is even more difficult than the justification of import taxes. One problem is that under SCM rules adjustments are only allowed for indirect taxes. Whether a carbon tax legally qualifies as indirect tax is, however, debatable (WTO/UNEP 2009, Ismer and Neuhoff 2007) according to Cosbey et al. (2012) carbon taxes fall into a grey zone between direct and indirect taxes. Also, it is unclear whether the exemptions of GATT Article XX can be applied (Ismer and Neuhoff 2007): as export rebates in fact exempt the export industry of the abating country from the climate policy, it may prove difficult to argue that they further an environmental objective. Theoretically, indirect taxes on goods and services that are "consumed" in the production of the exported good can be rebated (Fischer and Fox 2012). For example, a gasoline tax could qualify for such a rebate. Cosbey et al. $(2012,17)$, citing Hoerner and Muller (1996), however note that there "does seem to be a 'gentlemen's agreement' (i.e., without legal force) within the WTO not to rebate taxes levied on inputs that are consumed in the production process." Actually, many of the proposals for border tax adjustments made by policy-makers to date do not include export rebates (see the previous section). One reason for this may be their unclear legal status. Cosbey et al. (2012) also recommend formulating a policy without export rebates. Ismer and Neuhoff (2007), on the other hand, do propose applying an export rebate: they argue it should be calculated in the same way as the import levy they propose, i.e. using the carbon intensity of the best available technology.

Finally, if the domestic climate policy relies not on a carbon tax, but on a permit system like the EU's ETS, further complications may arise. Pauwelyn (2007) argues that using a border tax to adjust a cap-and-trade system may cause legal problems especially if it is applied to exports. Justification of a tax on imports may be easier, but its legality is also not assured. Alternatively, one might introduce import border adjustments for a cap-and-trade system not by a tax, but by requiring importers to buy emissions allowances just like domestic firms. Brewer (2010) argues that such a design could more easily be justified as allowable under Article XX of the GATT. Ultimately, the legal status of the use of border adjustment measures in conjunction with cap-andtrade system is however even less clear than that of border adjustments for carbon taxes.

Summarizing, the only way to switch the orientation of climate-policy to a consumption-based system that is legally definitely unproblematic seems to be the conclusion of an international agreement. Any unilateral imposition of border adjustment measures means treading legally uncharted territory. If one is nonetheless prepared to proceed unilaterally, some design options for border adjustments, however, exist that appear to be legally relatively "safe": these involve implementing only import adjustments, but no export rebates; additionally, the level of these adjustments would not fully differentiate between "clean" and "dirty" products. Thus, the legally permissible designs for border adjustments fall short of what would be called for by 
environmental criteria. Still, to be able to claim an exception under Article XX of the GATT, the border measures must pursue an environmental objective. Of course, as Cosbey et al. (2012) point out, there are few policies that follow only one single motivation - nonetheless, objectives such as preventing leakage have to be at the centre of the proposed policy. This provides an additional motivation for the main research question of this analysis - the question whether a switch to a consumption-based policy orientation will indeed make the policy environmentally more effective. 



\section{CHAPTER 4}

\section{Unilateral Climate Policies - the Theoretical Economic Background}

From an economic perspective, the cause of climate change - the unrestricted emission of greenhouse gases - is a market failure in the form of an externality. The remedy traditionally recommended by economists is the internalization of this external effect, i.e. pricing emissions at their social cost. This is the efficient solution to the problem of the externality, often also termed the "first best" solution. The discussion on tax incidence in Section 2.2.2 has shown that if indeed such a "first best" solution can be implemented, i.e. if all GHG emissions world-wide are priced equally, and if additionally all markets are perfectly competitive, the effect of the "internalization policy" does not depend on whether it is applied to production-based or consumptionbased emissions. This result is independent of the instrument chosen to bring about the "internalization" - it could be an emission tax, or just as well a quantity instrument. If the "internalization policy" however cannot be implemented globally but, for example, only in one country or a coalition of countries, it will not be possible to achieve a "first best" solution. Under these circumstances, also the equivalence between the effects of a production- and a consumption-based policy will break down, as now the "instrument bases" of the two policies are different. Both policies are only "second best" solutions, both are less efficient than the "first best" solution - but typically they are not equally efficient.

\subsection{Optimal unilateral abatement policies}

Markussen (1975) was among the first economists to compare the efficiency of different systems of environmental taxation in unilaterally correcting a global externality. $\mathrm{He}$ employs a simple two-country, two-good general equilibrium model. In this model, production results in a fixed level of pollution per unit of output. Welfare in one of the two countries, the "domestic country," depends on consumption as well as on the global level of pollution. The country has three policy instruments at its disposal: a production tax, a consumption tax, and border adjustments (tariffs or subsidies). It will use these instruments to influence the global level of pollution. Now, Markusen derives results for the welfare optimum of the domestic country (but not the global welfare optimum). He shows that this optimum can be achieved by any combination of two of the three policy instruments, e.g. by combining either a production tax or a consumption tax with border adjustments (or by combining a production and a consumption tax). Note that in this setting neither a policy with production as its base nor one with consumption at its base alone suffices to reach the welfare optimum - both policies need to be combined with border adjustments, and these adjustments are not "full adjustments" (in the sense as 
discussed in Section 2.2.3, i.e. adjustments that achieve a complete switch of the policy base).

The "mechanism" in that type of model, by which a country influences the level of emissions in a foreign country, is the following: the tax imposed by the domestic country influences the world price of the polluting good, and this price in turn has an effect on foreign production and thus foreign pollution. Note that for this mechanism to work the country using it must have some "monopoly power" in international trade, i.e. it must be able to influence international prices. If the domestic country has no monopoly power and is limited to use just one of the three instruments, it should use a production tax. Thereby it can reach the (national) welfare optimum. By a consumption tax, on the other hand, in this setting the country cannot influence world prices and therefore neither can it influence domestic nor foreign production. Thus, the optimal consumption tax is zero. Finally, if the country is limited to use just one of the three instruments but has monopoly power, it is - as Markusen shows - not possible to rank these three "second-best" instruments in terms of welfare.

Hoel (1996) extends Markusen's results to a more general $n$-country, $n$-good setting. He finds that a unilaterally abating coalition of countries can achieve its welfare optimum by combining a domestic uniform carbon tax on emissions in production with border adjustments. Both Markusen and Hoel derive expressions for the optimal border tariff (or subsidy) that share the following characteristics: they consist of a term that represents the terms-of-trade effect and an (additive) second term that represents the effect of the border tax on foreign emissions. The terms-of-trade term is simply the optimal tariff formula known from international trade theory: a country that has some monopoly power in international trade can in general improve its welfare by taxing its imports. It therefore has a motive for imposing border taxes irrespective of any effect these taxes may have on emissions. The foreign emissions term represents the price effect on foreign emissions described in the previous paragraph. According to Hoel, for each good this term is proportional to (i) the domestic carbon tax and to (ii) the marginal effect that a reduction of net imports of that good has on total foreign emissions.

If one analyses not the welfare of the abating coalition (like Hoel) but global welfare, the terms of trade term vanishes. Thus, in that case the optimal border tax depends only on the foreign emissions term (Boehringer et al. 2012b). The globally welfare maximizing border carbon tax therefore is proportional to but not the same as the domestic carbon tax: the border tax is higher the larger its effect is on foreign emissions reduction, and this effect is in general different for different goods. Also, in Hoel's model this effect does not only depend on emissions embodied in the good examined, but also on emissions embodied in other foreign goods. This is due to the fact that the production of these other goods may increase and replace the production of the good examined, if the international price of this good is lowered by means of the import tax. Low-carbon goods should therefore not be taxed at the border, but in some cases even subsidized, as an increased foreign production of these goods will crowd out the more emissions-intensive production of other foreign goods. Summarizing the principal 
point, from a global perspective it is in general not optimal to apply the same carbon price used in the taxation of domestic products also in the calculation of border taxes.

More recently, Gros (2009) and Gros and Egenhoger (2011) have also analyzed the welfare effects of carbon border taxes. In contrast to Markusen and Hoel, Gros and Egenhofer determine global welfare, and not just the welfare of the country abating. They employ a simple, one-good, two-country partial equilibrium model. Production of the good leads to $\mathrm{CO}_{2}$ emissions at a fixed per- unit rate. These emissions lower global welfare. The good examined is imported by the country following the climate policy; and the type of border adjustment studied consists only of an import tax (but not an export rebate, as there is no export good in this model). The main finding of the analysis is that the introduction of the border tax increases global welfare if there is insufficient carbon pricing abroad. In the welfare optimum, the domestic carbon tax and the carbon border tax are, however, not equal to the social cost of the externality, and they are also not equal to each other: the domestic tax is higher, and the border tariff is lower than the social cost of $\mathrm{CO}_{2}$ emissions. Thus, the imposition of the optimal border tariff will not completely "level the playing field" (as is sometimes demanded by industry representatives - see Chapter 3) for domestic and foreign producers. In general, the optimal level of the border tariff depends on many parameters such as the carbon intensity abroad, the relative sizes of the production bases in the two countries, and the elasticities of demand and supply of the good examined.

Summarizing, the studies discussed in this section find that the optimal unilateral policy to correct a global externality actually is neither a policy with just production nor one with just consumption as its base, but a policy combining either of the two approaches with "less than full" border adjustments. This study will compare the two "pure" policy variants, the production-based and the consumption-based one, as well as examine one variant of a "combined" policy - a policy that applies a uniform carbon tax to the production of the abating region plus its imports. A policy that applies different carbon tax rates to different economic sectors - the approach found to be the most efficient one by Hoel (1996) - is however extremely difficult to practically implement and will therefore not be examined in this study.

\subsection{Analysis of carbon leakage and possible counter-measures}

With the ratification of the Kyoto Protocol and the introduction of the ETS in the EU, the research focus has in recent years shifted from questions of the "efficiency of unilateral climate policies" in general to a specific form of inefficiency - to carbon leakage. Carbon leakage is caused by follow-on effects of the introduction of a climate policy (again, it might be easiest to think of an emissions tax) in the non-policy region. In general, an emissions tax will affect (i) the prices (and quantities demanded) of the goods taxed, but also the prices (and quantities) of substitutes for these goods (and through further follow-on effects also the prices and quantities of most other goods); (ii) the prices and quantities demanded of inputs into production, especially of those either causing emissions (e.g. fossil fuels) or necessary to abate emissions, but more generally also the prices (and quantities) of more basic inputs like capital; and (iii) the income (or 
the welfare) of all economic agents. If these effects lead to a change in emissions in the non-policy region, this change in emissions is termed carbon leakage (to be more specific: "strong" or "policy-induced" carbon leakage). The literature on carbon leakage has categorized the most important ones of these leakage effects according to the "economic mechanisms" that cause them. These mechanisms have become known as "leakage channels" (Felder and Rutherford 1993). Not all authors distinguish between the same "leakage channels" (for an overview see e.g. Reinaud 2008a; Droege et al. 2009; Quirion 2010) - but at least two such channels, the competitiveness and the energy market channel, are differentiated in virtually all studies on this subject. This study in addition to these two channels also discusses a leakage channel known as the technology spillovers channel and a channel that may be termed income channel. The "economic mechanisms" on which these four channels are based are the following:

- Competitiveness channel (or "non-energy markets channel", "production cost channel"): the goods produced in the policy-region are subject to the policy, for example a tax, and therefore become more expensive. In the policy as well as the non-policy region, consumers buying final goods and producers buying intermediate goods substitute cheaper, non-taxed goods produced in the nonpolicy region for the now more expensive goods produced in the policy region. Production in the non-policy region expands (in the short run within existing plants, i.e. only production and trade flows are affected; in the long run also additional plants might be built, i.e. also investment is affected ${ }^{14}$ ), and thus emissions in the non-policy region grow, which is carbon leakage.

- Energy market (or: fuel price) leakage channel: Most emissions stem from the burning of fossil fuels. Climate policy leads to a drop in the demand for fossil fuels, which (in case we are studying a globally traded type of fuel like oil) leads to a drop of the world market price of fuel, which in turn causes increased demand for fuel (and thus more emissions) in the non-policy region.

- Income leakage channel: climate policy due to the direct costs of the policy and through terms-of-trade effects changes the income distribution between individual countries or groups of countries (see Sections 8.7 and 9.2 for details). This affects consumption (and in turn production) patterns, which then affects emissions and leads to (positive or negative) leakage. Most studies of leakage, however, do not list this effect as a separate "channel" - the studies by Burniaux

14 The movement of plants to regions without carbon pricing is also known as the "pollution haven hypothesis" (Copeland and Taylor, 1994). It says that higher-income countries tend to have tighter environmental regulations. But as production costs usually rise with the level of regulation, lowerincome countries will have a cost advantage in "dirty" production. Heavy polluting industries will therefore migrate to these countries, which will then become a "pollution haven." 
and Oliveira Martins (2012) and Gerlagh and Kuik (2007) are some of the exceptions.

- Technology spillovers channel: in the policy region, climate policy creates an incentive to develop "green technologies", and these then "spill over" to the non-policy region and cause a reduction of emissions - negative leakage - there. This channel differs from the other ones insofar as it rests on dynamic incentive effects - and not on comparative-static general equilibrium effects. ${ }^{15}$

The analytical part of this study not only examines carbon leakage, but more generally the environmental effectiveness of a policy, i.e. not only the effects of the policy on emission in the non-policy region, but also those in the policy region. Still, the analysis is structured by splitting up the policy effects according to the four leakage channels introduced above - they constitute a very convenient structuring tool. But note that the interpretation of the channels is a little different if all policy effects and not only leakage is analyzed. Consider, for example, the first of the channels, the non-energy market channel: it then not only includes the unintended side-effect of the policy, "competitiveness leakage" in the non-policy region, but also the main intended direct effect - a reduction of emissions in the policy region.

Another conceptual framework to break down policy effects on emissions has been suggested by Grossman and Krueger (1991). They actually did not study a change in climate policy, but the environmental impact of trade opening - more specifically of the conclusion of the North American Free Trade Agreement (NAFTA). Their framework can however also be helpful when comparing different climate policies - and will at some points be mentioned in this study. Grossman and Krueger break down policy impacts into three "effects": (i) the scale effect - the change in emissions due to increased or decreased economic activity; (ii) the composition effect - the change in emissions due to a change in the relative size of the various sectors of an economy; and (iii) the technique effect - the change in emissions due to the adoption of a less (or more) carbon-intensive production technology.

The problem of carbon leakage under unilateral climate policy - but probably even more the fear of a loss of competitiveness - has also motivated the study of possible counter-measures. Apart from the introduction of border carbon adjustments the following options have been suggested: the free allocation of emission permits to industries at risk (which effectively exempts them form the climate policy), direct subsidies to producers (which, for example, compensate them for the cost of the

15 The four leakage channels introduced here are not the only mechanisms for carbon leakage discussed in the literature: Quirion (2010), for example, analyzes a further effect that may work in energy as well as non-energy markets, which he terms the "international cleaner goods channel". It works as follows: climate policy also raises the prices of "green goods" (e.g. bio-fuels) and thus also causes leakage. For example, if the EU imports bio-fuels from Brazil because of a stringent climate policy in the EU, this could raise the price of these fuels and have the effect that Brazilians run more cars on gasoline instead of bio-fuels, which leads to carbon leakage. 
introduction of low-carbon technology), and international sectoral agreements (which could, for example, impose technological standards on foreign competitors of the domestic industry) - see, for example, Neuhoff (2008), Droege et al. (2009), or Droege and Cooper (2010) for an overview.

The effect of such measures - and in particular border adjustments - was mostly examined with CGE models. On the other hand, only few studies exist that employ analytical models to compare anti-leakage measures. One of these few studies was carried out by Fischer and Fox (2012). They develop a two-country, two-good partial equilibrium model. Climate policy is introduced by a domestic carbon tax, which is then complemented with an import tax and an export subsidy. The policy affects productionand consumption-levels in abating- and non-abating countries as well as the carbon intensity of production in the abating (but not the non-abating) region. Fischer and Fox interpret their findings as relating not to an economy as a whole, but to individual carbon-intensive sectors. The central result is that border carbon adjustments support competitiveness. The effect on global emissions is however less clear-cut: whether a policy with or without border adjustments leads to a larger reduction in global emissions depends on the relative carbon intensities in the two countries studied, on elasticities of substitution, and on consumption volumes. The model by Fischer and Fox will serve as the starting point for the model to be developed in this study.

\subsection{Macroeconomic effects not depicted in simple models}

A number of recent papers draw attention to macroeconomic effects of unilateral climate policies that are not depicted in standard models. Lockwood and Whalley $(2008,1)$ criticize that the present debate on border tax adjustments "seems to overlook and older literature" which was written at the time of the adoption of the value added tax in the EU in the early 1960's. This literature finds that (under a number of restrictive conditions) a change from an origin to a destination principle in taxation does not have any real effects, but only changes price or wage levels or the exchange rate between the region applying the tax and the rest of the world (see e.g. Grossman 1980). A change from origin to destination taxation is the same as a change from a production tax to a consumption tax. The result on the neutrality of such a change, however, only holds if all goods are taxed uniformly. A carbon tax, in contrast, applies different tax rates to goods that have different carbon content. Still, Lockwood and Whalley $(2008,4)$ contend that "in the current debate there seems to be a misconception between the price level effects and relative price effects" stemming from a border tax adjustment. They argue that the price level effect "could likely have little or no impact on trade flows, and even offer no offset to either leakage or competitive disadvantage" (Lockwood and Whalley 2008, 17). Even if one does not agree with the implicit claim of Lockwood and Whalley that the price level effect of border carbon adjustments will be quantitatively more important than the relative price effect and that a carbon tax can thus be analyzed in the same way as value added tax, there are a few lessons one can draw from this debate: First, to have real effects, a carbon tax should as close as possible be tied to the true carbon content of all goods and not be based on a uniform benchmark. Second, the 
literature on origin and destination taxation also stresses the fact that the border adjustment on imports and exports should be symmetric in order to avoid distortions. Following these arguments, a border adjustment that consists only of an import tax (as suggested in US congressional bills and also favored by many scholars on legal arguments - see Chapter 3) would thus be inefficient.

Criticism of the possible application of carbon border adjustments from another angle has been expressed by Jakob and Marschinski (2013). Using a Laspeyres index decomposition method, they partition the net flows of embodied emissions of six large countries into four factors, which they assume to represent different determinants of these carbon flows. The factors are the trade balance, the economy-wide energy intensity, the economy-wide carbon intensity of energy, and trade specialization. Trade specialization is determined by comparing the factor content of a country's exports with the average factor content of its total production, i.e. a country is specialized in the production of carbon-intensive goods only if the carbon content of its exports is higher than the carbon content of its total production.

Applying this decomposition method, Jakob and Marschinsky find that, for example, in bilateral trade between the U.S. and China, 45 percent of carbon flows can be attributed to the large trade deficit of the U.S., further substantial shares are due to the high energy-intensity of production and the high carbon-intensity of energy in China. Only about 20 percent, Jakob and Marschinsky find, can be attributed to China's specialization in carbon-intensive exports. For the trade between China and Western Europe, the authors obtain qualitatively similar results - although the trade deficit is not as important. Jacob and Marschinski conclude that it would be wrong to interprete large international carbon flows as indication that countries like China specialize in "dirty" production. They also contend that a carbon "tariff leads to a reduction of carbon leakage only if the country against which it is applied is specialized in the production of relatively carbon intensive goods" (Jakob and Marschinski 2013, 22). Jakob and Marschinski provide no explanation why they assume such a limited effect of carbon tariffs. One might object that a well-designed tariff should also help to reduce some of the emissions that Jakob and Marschinski attribute to other factors, for example, it should incentivize "dirty" producers to use "cleaner" fuels and to reduce the carbonintensity of their production.

Jakob and Marschinski however additionally argue that carbon border tariffs will not only have only limited effects on global emissions, they might even have negative ones, i.e. increase instead of reduce global emissions. This might happen as countries targeted by border tariffs on their exports might react with import substitution. One reason for such a reaction is the mutual dependence between imports and exports. Typically, countries face limits to the size of their trade deficit. Thus, if export revenues of emerging economies drop because emissions embodied in these exports are taxed, these economies will also have to scale back their imports. As a reaction, they may be forced to produce goods they used to import from industrialized countries themselves, yet most likely with higher carbon intensity. Thus, theoretically, a drop in export revenues can cause carbon leakage. If this effect is quantitatively important, it may 
constitute a powerful argument against the introduction of consumption-based policies. This issue will be taken up again in Chapter 9. 


\section{CHAPTER 5}

\section{Quantitative studies of carbon leakage and the effects of border adjustments}

The discussion of the preceding chapters suggests that a production-based unilateral climate policy may lead to carbon leakage and may be less efficient than a consumption-based approach. But so far we have not posed the question whether these findings point to a mere theoretical possibility - or whether such effects are actually quantitatively significant in real-world situations. As we have seen, a switch of the orientation of climate policy to a consumption base is a legally and practically challenging endeavour - and will definitely also involve costs. Thus, only if the difference between the two policy options is not negligible in terms of environmental effectiveness or cost-effectiveness, such a switch seems worth considering. But is it "non-negligible"? To date, our knowledge on the correct answer to this question is still limited - the quantitative effects of the introduction of a consumption-based policy as such have never been examined. But in the literature on carbon leakage and border carbon adjustments numerous quantitative studies were produced that investigate related questions - and we will have to rely on the findings of these studies if we want to gain at least a rough idea of the possible quantitative effects of a switch of the policy base.

More precisely, the literature on (policy-induced) carbon leakage assesses the quantitative impacts of the introduction of production-based policies, and the literature on border carbon adjustments studies an at least partial switch to a consumptionorientation of the policy. Such "partial" adjustments may fall short of a "full" switch of the policy base along several dimensions - see Section 2.2.3. Still, also looking at such "incomplete" adjustments is of interest: First, at least some of the scenarios examined in recent quantitative studies come reasonably close to a "full" switch to a consumptionbased policy orientation; and second, as we will see in chapters 10 and 11, in practical terms it is quite difficult to actually implement a policy that achieves a full switch of the policy base. Thus, even though the theoretical arguments in this study always refer to such a full switch, a "partial" switch may actually be all that can be realized by a realworld policy.

First, before we look at border carbon adjustments in detail, the first section of this chapter will however give an overview of studies that aim to quantify the problems border adjustments are meant to correct, i.e. either possible losses in competitiveness or reduced environmental effectiveness due to carbon leakage. Note, that the "policy effectiveness discussion" in the literature is often framed exclusively around the criterion of carbon leakage - even though, as discussed in Chapter 2, carbon leakage is a less than perfect proxy for more informative policy assessment criteria such as environmental effectiveness or cost-effectiveness. 


\subsection{Quantitative estimates of carbon leakage}

\subsubsection{Ex ante studies}

In recent years, the ratification of the Kyoto Protocol on the one hand and the introduction of emissions trading in the EU on the other hand have created interest in carbon leakage and effects on competitiveness of a climate policy that is not pursued globally. The first commitment period of the Kyoto Protocol has however only ended a short while ago - at the end of 2012 - and the EU ETS has only in the beginning of 2013 entered its third phase with substantial auctioning of emissions allowances. Ex post data on these two climate policy endeavours are therefore still scarce and most studies so far rely on ex ante analyses: they use simulation models either for individual sectors or for economies as a whole to predict the impacts of climate policy.

Economy-wide estimates are mostly performed with CGE models. A survey of 18 such models by Gerlagh and Kuik (2007) shows leakage rates between 2 and 21 percent, with one outlier of 115 percent. In general, however, the magnitude of carbon leakage declines with the size of the abating coalition. A study by the OECD (2009) reports a leakage rate of 12 percent if the European Union alone cuts its emissions by 50 percent; but leakage would drop to the virtually negligible amount of less than 2 percent if all Annex I countries acted together. As Burniaux and Oliveira Martins (2012, 475) point out, in CGE models such as the one employed by the OECD "the relationship between country coverage and carbon leakage is nonlinear with small increases in the size of the coalition leading to substantial reductions in leakage."

There is however broad agreement among economists that most of the leakage reported for countries as a whole stems from just a few trade- and energy-intensive sectors (Droege et al. 2009, Reinaud 2008a): iron and steel, cement, aluminium, paper and pulp, refineries and a few other chemical subsectors. Reinaud (2008a) reviews recent partial-equilibrium studies of these sectors - the reported leakage rates range from 0.5 to 73 percent; in one study they are as high as 70 percent even at a quite moderate carbon price of 20 Euro per tonne of $\mathrm{CO}_{2}$. Quirion (2010), however, advises against taking such ex ante estimates at face value. He points out the striking divergence of the findings of different studies on the same sector: for example, a study by the Boston Consulting Group (2008) reports that at a carbon price of $€ 25 / \mathrm{CO}_{2}$ as much as 80 percent of the European production of clinker, an intermediate product in the manufacturing of cement, would be replaced by imports. In contrast, a study by Demailly and Quirion (2006) on the same sector finds a rise of the import ratio of clinker from 3 to only 8 percent at a carbon price of $€ 20 / t \mathrm{CO}_{2}$. Quirion (2010) attributes the divergence between the results of the two studies to different assumptions on capacity constraints and the market structure in clinker production. This example may serve as a warning that as long as there are only few ex post studies available our understanding of carbon leakage under real world circumstances remains limited.

But even if the impact of climate policy on certain economic sectors is substantial, the consequences for economies as a whole may still be moderate: Hourcade et al. (2008), for example, show that in the UK the sectors where a $\mathrm{CO}_{2}$ price of $€ 20 / \mathrm{t}$ leads to 
an increase in costs of more than 4 percent only account for a little more than 1 percent of GDP. Quirion (2010) states that the situation seems to be similar in most developed countries. Only in countries with a higher-than-average share of heavy industry, such as for example Germany, the GDP share of such sectors reaches 2 percent (Graichen et al. 2008).

\subsubsection{Ex post studies}

While thus ex ante studies typically report at least some carbon leakage, only few ex post studies were able to detect significant effects of climate policy on leakage or competitiveness. However, the overall number of ex post analyses dealing with GHG abatement is not very large - most of the earlier studies of the effects of environmental policy focus on other pollutants. Jaffe et al. $(1995,157)$, in an extensive review of such studies on the "pollution haven effect", conclude that "overall, there is relatively little evidence to support the hypothesis that environmental regulations have had a large adverse effect on competitiveness, however that elusive term is defined." On the other hand, according to Jaffe et al. (1995, 159), "there is also little or no evidence supporting the [opposite] hypothesis that environmental regulation stimulates innovation and improved international competitiveness." As Karp $(2011,406)$ points out, more recent studies employing more sophisticated econometric methods such as instrumental variables however produce more conclusive results - the studies suggest "that the pollution haven effect is real and possibly large enough to be important."

Surveys that focus explicitly on GHGs - and not just on the pollution haven effect for other pollutants - can be found in Quirion (2010) and Venmans (2012). Venmans reviews 4 studies on the first period of the EU ETS and one study on carbon taxes in the EU and concludes that they do not reveal a significant effect of the ETS on competitiveness. He however argues that the three years oft he first ETS period (2005 to 2007) were characterized by over-allocation of emission allowances as well as increasing steel, aluminium, cement, and petroleum world prices, and additionally an economic upturn. Furthermore, as leakage according to Venmans $(2012,5501)$ is closely linked to long-term investment decisions, it "is difficult to detect over the short time frame of the first three years of the ETS." Quirion $(2010,113)$ also reviews two of the ETS studies surveyed by Venmans plus a different study on environmental tax reforms (Miltner and Salmons 2007) in Europe and a World Bank (2007) study on the evolution of exports and imports in energy-intensive industries in the OECD: "Neither study shows clear evidence of a loss in competitiveness due to carbon taxes," he summarizes. But Quirion $(2010,113)$ also qualifies this conclusion by pointing out "that in every country, GHG-intensive sectors have benefited from exemptions, lower taxes or rebates, precisely in order to mitigate the possibly adverse competitiveness impacts."

Another problem in drawing definitive conclusions on competitiveness and leakage is highlighted in a study on the aluminium industry by Reinaud (2008b) - one of the studies reviewed by Venmans and Quirion: Reinaud reports that in the three years after the beginning of the EU ETS three European smelters closed. But there had been aluminium production growth outside the EU also before the introduction of the ETS. As Reinaud $(2008 \mathrm{~b}, 4)$ argues, it is difficult to establish the counterfactual in times 
when global production patterns change rapidly, i.e. it is not clear whether the closures are due to the introduction of carbon pricing or whether they would have happened in any case.

There is however one recent study that does provide evidence of carbon leakage: Aichele and Felbermayr (2012) claim to have been the first authors to make an econometric ex post analysis of the Kyoto Protocol. They use an instrumental variables estimation strategy to evaluate the effects the ratification of the binding Kyoto commitments has had on the ratifying countries' production-based and consumptionbased emissions. Their results are quite surprising: a commitment under Kyoto indeed leads to a reduction in production based-emission of 7 percent, but it does not cause any reduction of a country's consumption-based emissions. Aichele and Felbermayr (2012, 336) conclude that "carbon leakage due to the Protocol's incomplete coverage has therefore neutralized emission savings." In other words, the leakage rate is 100 percent - not just for certain sectors, but on average for all Annex I countries. This result by far exceeds the prediction of nearly all ex ante studies - see above. Further econometric research will be required to explain these discrepancies. The central question will be how good various econometric methods fare in "extracting" that part of the growth of consumption-based emission in industrialized countries that is indeed due to climate policy, and not just to the general trend of rising consumption-based emissions (discussed in Section 6.1).

\subsubsection{Apportioning overall leakage - which channels are relevant?}

For an analysis of the relative importance of the individual leakage channels, we again have to rely on ex ante models. Out of these, sectoral models often include a lot of detail on the distinct production steps of the industry studied, but they typically only examine one of the leakage channels: the non-energy market channel. CGE studies, on the other hand, usually in addition also model leakage through the energy market and the income leakage channel. Very often in such models, the income channel is however not separated analytically from the energy and the non-energy market channel - its effects are therefore included in the effects reported for the other two leakage channels.

To determine the relative importance of these two channels, Gerlagh and Kuik (2007) perform a meta-study of 17 individual CGE studies. Applying regression analyses, they find that the global energy market is the dominant transmission channel for carbon leakage. This result is consistent with the findings of some individual analyses (e.g. Boehringer et al. 2010a; b). Kuik and Hofkes (2010), however, report a contrarian finding: they estimate that for the case of the EU proceeding unilaterally, leakage through the non-energy market channel is more than 4 times larger than leakage through the fuel price channel. The discrepancies between these studies may be due to the fact that in the typical CGE model the relative importance of the two channels is actually determined by the size of the coalition that abates (the "policy region"): in smaller coalitions, the competitiveness component, i.e. the effects in non-energy markets, dominates; large coalitions, on the other hand, also have a larger influence on world fuel prices - now the leakage effect through energy markets is the dominant one (Burniaux et al. 2010). 
The third leakage channel, the income channel, is discussed by only few authors. Burniaux and Oliveira Martins $(2012,478)$ mention income losses of energy-exporting economies caused by climate policy, which "would tend to create negative leakages." Nonetheless, Burniaux and Oliveira Martins argue that "this is likely to be a secondorder effect, at least over a medium time-horizon." In a similar vein, Gerlagh and Kuik (2007, 3), consider income effects to be "typically negligible" compared to the other channels. But neither of these authors actually presents a quantitative estimate of these supposedly "negligible" effects. Furthermore, their arguments refer to current climate policy and rather small emissions reduction targets. By contrast, any mitigation policy actually capable of limiting global warming to 2 degrees will involve a "substantial redistribution of wealth" (Edenhofer et al., 2010, 69); thus there seems to be potential for this to eventually also cause a substantial change in leakage through the income channel.

Finally, least of all is known about the size of the technology spillovers channel, which apart from possibly the income channel is the only channel that should lead to "negative leakage". Quirion (2010) gives the following example of how this channel works: Denmark, Germany, and Spain followed ambitious climate policies and, in particular, supported wind power by feed-in tariffs. This induced rapid technological progress in this industry, which reduced the costs of wind power. The technological advances spilled over to China and lead to a rapid spread of wind power there - which may have reduced emissions in China. Droege et al. $(2009,20)$ however caution that "the causal relationship between domestic carbon pricing, technological change abroad and foreign emissions levels is still weak." To date, only few quantitative studies exist. Barker et al. (2007) employ a dynamic econometric model of 27 European countries to study the effects of environmental tax reforms between 1995 and 2005. They conclude that "carbon leakage is very small and in some cases even negative, due to technological spillovers" (Barker et al. 2007, 6281). Gerlagh and Kuik (2007) are among the few authors that attempt to separate spillover effects from the other leakage channels. They model technological change as an increase in the "ease" of substituting between energy and other inputs, driven by the level of the carbon price. Using a static CGE model, they find that if 20 to 30 percent of the predicted input substitution were due to such technological change and not to the "traditional" form of substitution between existing technologies and if this technological knowledge could freely spill over between countries, then carbon leakage would become zero or even negative. Gerlagh and Kuik $(2007,18)$ thus tentatively conclude that "moderate levels of technological spillover" suffice to produce negative leakage rates. Quirion $(2010,115)$ reviews these findings; he rates them as "interesting," but still "fragile."

\subsubsection{Parameters driving leakage}

Burniaux and Oliveira Martins (2012) aim to attribute overall leakage not only to the different leakage channels, but in great detail explore the individual factors driving leakage. They develop a stylized two-country, two-goods CGE model incorporating three types of fossil fuels as well as internationally mobile capital to perform an extensive multidimensional sensitivity analysis. One of their main findings is that the 
most critical parameter for the size of leakage is the supply elasticity of coal: if this elasticity is low, every emissions reduction in the policy region will be met by an increase of emissions in the non-policy region of almost identical size; leakage will thus be large and it will be virtually impossible to reduce emissions by unilateral climate policy.

In addition, also the shape of the production function matters: high inter-factor and inter-fuel substitution elasticities generate large carbon leakages. As regards the interfuel substitution elasticity between carbon-intensive coal and less carbon-intensive oil, if this elasticity is low and (as typically assumed) coal supply is more price elastic than oil supply, then the demand effect dominates: abatement in the policy-region reduces the oil price more than the coal price, and this induces the non-policy region to consume relatively more oil instead of carbon-intensive coal, generating even negative marginal leakage rates. The picture is different for high inter-fuel substitution elasticities: in that case, the substitution effect dominates. Abatement in the policy region reduces the coal price, but drives up the world oil price, which in turn induces the non-policy region to consume more coal, thereby increasing the carbon emissions there, i.e. causing leakage.

In a similar manner, also for the inter-factor elasticity of substitution between energy and other factors of production it is possible to produce different results depending on the values assumed for the other elasticities. The central case of Burniaux and Oliveira Martins is the following: the higher the inter-factor elasticity of substitution, the larger the shift in the policy region from energy towards the other factors of production. This increased demand raises the price of these other factors; this in turn raises the price of the export good of the policy-region. The non-policy region therefore demands less of the foreign good and shifts towards domestic production, demanding more of the most elastic input, which is coal. This raises emissions in the non-policy region. Thus a higher inter-factor elasticity of substitution leads to higher leakage rates.

The parameters characterizing non-energy markets - the (Armington) trade elasticities and the degree of capital mobility - are however not very decisive for the amount of leakage, Burniaux and Oliveira Martins report. As regards capital flows, their results actually contrast with some of the arguments made in the debate on the possible losses of competitiveness in some energy-intensive economic sectors. As mentioned above, this debate warns of possible capital outflows out of abating countries as energyintensive industries might relocate to countries with a less stringent climate policy. Burniaux and Oliveira Martins, by contrast, find that abatement policy also triggers capital inflows. These - except in a case where the Armington trade elasticities are very large - in fact dominate the capital outflows due to losses in competitiveness. The inflows are caused by the following mechanism: Abatement in the policy region leads to a substitution towards the use of more capital. This additional demand drives up the rate of return on capital and triggers a net capital inflow into the policy region.

Also the finding of Burniaux and Oliveira Martins that the degree of substitutability between domestic and foreign goods (represented by the Armington elasticities) is not decisive for the leakage rate contrasts with the typical conclusion 
drawn in the CGE literature: "The model-based result depends crucially on the formulation of international trade," Boehringer et al. (1998, 17), for example, stress in an analysis of abatement strategies for the EU, and in a similar vein Bernard and Vielle (2009, S283), also examining climate policies for the EU, conclude that "the so-called 'Armington elasticity' is crucial to the size of [carbon leakage], and very few studies and econometric estimates are available to general equilibrium modelers." In general, of course, the ease of substitution between domestic and foreign goods will be especially relevant for leakage in models that have most of the leakage occur through the competitiveness channel (this again will typically be the case if the abating coalition is comparatively small - unilateral policy of the EU is such a case). On the other hand, in models where most of the leakage occurs in energy markets, the fuel supply and the inter-fuel substitution elasticities are comparatively more important.

Regarding the modeling of international trade, Babiker (2005) demonstrates that it is easily possible to produce extreme results if the typical assumptions of the CGE literature of less than perfect substitutability of domestic and imported goods - and some other typical assumptions like constant returns to scale technologies and perfect competition - are discarded. In a setting with increasing returns to scale and homogeneity of traded products he obtains leakage rates reaching 130 percent (i.e. abatement in the policy region actually causes an increase of global emissions); in a setting that also assumes homogeneity of traded products, but constant returns to scale the leakage ratio still amounts to around 60 percent.

Babiker's study is a reminder that the results of all simulation models heavily depend on the assumptions made and that - as the quote from Bernard and Vielle cited above shows - there is often not enough empirical evidence available to determine whether these assumptions reflect real-world circumstances. The findings of Burniaux and Oliveira Martins, on the other hand, point to another important regularity: often, it will not suffice to study the impacts of one parameter or variable at a time - the interplay of the various parameters in climate policy models is often complicated and only their simultaneous analysis will reveal which of their sometimes countervailing effects dominates. Overall, the leakage literature has by now identified certain parameters that might qualify as "drivers" of leakage, but as yet there is no unanimity which of these parameters are the most important ones.

\subsection{The effects of border carbon adjustments}

As border carbon adjustments have never actually been implemented, all our knowledge of their effects is based on ex ante analysis. In the leakage literature, border adjustments are usually studied as one of a number of possible counter-measures to limit leakage and losses in competitiveness, the other such measures being free allocation of emissions permits and direct subsidies to affected industries (see Section 4.2). There is however no unanimity whether border adjustments indeed help to reach these objectives. 


\subsubsection{Sectoral studies}

Again, the effects of border measures have been examined in sectoral as well as general equilibrium studies. Sectoral studies focus on leakage through only one of the various channels, leakage brought about by policy transmission in non-energy markets (i.e. the competitiveness leakage channel); they, as mentioned above, however typically provide more detail on the individual steps of production and the market structure of the sectors examined than larger general equilibrium analyses. One recent sectoral study was made by Monjon and Quirion (2009; 2011): they develop a quantitative partial equilibrium model to examine four sectors: the three leakage-prone basic industry sectors steel, aluminium, and cement (including also the "sub-sector" producing clinker, an important intermediate product needed to make cement), and furthermore the electricity sector, which produces a major input for the other 3 sectors. For the EU ETS, they find that the introduction of "full" border carbon adjustment would be an effective way to curb leakage: in the clinker sub-sector, for example, the leakage ratio would drop from a value of 16 percent for a scenario where the EU reduces emissions by 14.3 percent to a value of 5 percent if full border adjustments are applied. In the steel sector the effect of border adjustments is even stronger: the leakage ratio drops from 39 to -26 percent. Thus in this sector - and also in the aluminium sector - border adjustments even produce negative leakage, i.e. a drop of emissions outside the EU - possibly accompanied also by less emission reduction within the EU than under an abatement policy without border measures (see also Droege et al. 2009 for details on these results).

The "mechanisms" driving the impact of border adjustments in the model of Monjon and Quirion - including the result of "negative leakage" in some sectors - are quite typical for partial equilibrium climate policy models and will therefore briefly be explained here. Basically, two main mechanisms are at work, one describing the effect of the import tariff, and the other one giving the effect of the export rebate. First, on the import side, the extension of carbon pricing to imports into the EU reduces EU demand for these products. Hence production and also emissions in the rest of the world decrease, meaning leakage is reduced. But apart from this income effect of demand for the products under question there may also be a substitution effect: if the industry in the rest of the world is more carbon intensive than in the EU, applying the same carbon price to both the EU's domestic production and to imports into the EU will give the "cleaner" EU industry a relative cost advantage. Thus, "cleaner" EU products will be substituted for more "dirty" products from the rest of world, which increases production and emissions in the EU and further reduces production and emissions abroad. For the rest of the world, therefore, both the income and the substitution effect triggered by the border measures work to reduce emissions, i.e. both effects reduce leakage - and if these effects are stronger than the substitution effect triggered by the introduction of the original policy without border adjustments (i.e. stronger than the "pollution haven effect"), they produce "negative leakage". For the EU, on the other hand, the substitution effect triggered by the import tariff diminishes the domestic emissions reduction. In the extreme, the emissions reduction in the EU might even become negative, i.e. an abatement policy accompanied by border measures may lead to more emissions being discharged in the EU. But whether the import tariff indeed causes a 
substitution effect depends not only on possible differences in the carbon intensity of production in the EU and abroad, but also on the question, whether this difference is reflected in different carbon prices for EU products and imported products. Thus, only if the carbon import tax actually reflects true embodied emission - or at least a close proxy thereof - substitution in the direction of the cleaner product will be triggered. Monjon and Quirion (2009; 2011) demonstrate this by comparing different methods to calculate the size of the border adjustments. Apart from these effects of the import tariff, of course, also the export rebate will have an impact: Basically, such a rebate means that the export production of the EU is exempt from the climate policy. The EU's export industry will therefore produce and emit more than in a scenario with abatement policy, but without border measures - or produce and emit the same if compared to a scenario without any abatement policy.

Monjon and Quirion $(2009 ; 2011)$ also compare border adjustments to the free allocation of emissions allowances (in the form of output-based rebating, i.e. the amount of free allowances a firm receives is determined ex post by the level of the firm's output) as an alternative measure to curb leakage and losses in competitiveness. As concerns competitiveness, they find that the free allocation of allowances is more effective in avoiding production losses. But that comes at a price: the reduction of global emissions is smaller under a policy of output-based rebating as such a policy exempts all trade-intensive and leakage-exposed sectors from climate policy. Monjon and Quirion (2011) therefore see output-based allowance allocation only as a transitory solution to the problems of international climate policy. As concerns carbon leakage, the results are reversed: border carbon adjustments are typically more effective than the free allocation of allowances. Note, however, that - as discussed in section 2.3.2 - a decline of the leakage ratio brought about by border measures does not necessarily signify an increase in environmental effectiveness: as discussed above, the anti-leakage policies studied by Monjon and Quirion also lead to a rise of production and thereby emissions inside the EU, which (partly) neutralizes the drop of emissions outside the EU. Other studies show that this counteracting effect can be quite strong: Bednar-Friedl et al. (2012a) study the consequences of anti-leakage policies pursued by the EU for Austria in a general equilibrium setting. They find that a border carbon adjustment in the form of an export rebate (without an import tax) is effective in reducing carbon leakage but has no effect on global environmental effectiveness at all: the increase of emissions in Austria exactly counterbalances the reduction of emissions outside Austria.

Another recent analysis of sectoral leakage rates was performed by Fischer and Fox (2012) in the study already briefly reviewed in Section 4.2. The authors study unilateral mitigation policy followed alternatively by three different economies: the United States, Canada, and the European Union. Using a CGE model, they obtain values for elasticities and other parameters, which they then plug into a more simple sectoral partial equilibrium model (which was discussed in detail in Section 4.2). Within this partial equilibrium model they calculate estimates of (marginal) competitiveness and environmental effectiveness effects of border measures (and other anti-leakage policies) for individual sectors. One of their main findings is that border measures are always 
effective in supporting competitiveness (measured by the change in net exports as a share of domestic production).

The results on the question whether border measures also help to reduce global emissions are however not as clear-cut. As mentioned in Section 4.2, within the partial equilibrium model of Fischer and Fox this question cannot be answered in general - the answer depends on the parameter values specific to the sectors and countries analyzed. Fischer and Fox study 3 different economies with 7 sectors each. Overall, in the central scenario examined, border adjustments do indeed help to increase environmental effectiveness in the vast majority of sectors. But there are exceptions: In the US as well as in Canada, for example, in the chemicals sector the introduction of border carbon adjustments actually increases global emissions (as compared to a unilateral policy without border adjustments). The reason is that in both countries the chemicals sector produces with an emissions intensity that is larger than the one in the rest of the world. Thus, the border adjustments actually protect a sector that does not contribute to the global effectiveness of the policy. This result demonstrates how crucial differences in the emissions intensity between abating and non-abating countries are for improvements in environmental effectiveness.

Also, a sensitivity analysis performed by Fischer and Fox (2012) demonstrates that the results on environmental effectiveness are actually quite susceptible to a change of the parameter values. If one assumes, for example, that the own-price elasticity of exports from the policy region is actually twice as large as in the central scenario (in which the parameter estimates obtained from the CGE model were used), the implementation of border adjustments causes a rise instead of a fall of global emissions in many sectors. A high own-price elasticity of a good, of course, means that that the demand for this good reacts strongly to carbon pricing - for such a good carbon pricing is therefore a very effective policy tool. If such a good is taken out of the scope of the policy by an export rebate, thus a very effective abatement option is lost, making the policy on average less effective. By a similar argument, doubling the own-price elasticity of imports would make the border adjustments more effective. Fischer and Fox warn that their highly aggregated data may not adequately represent the quite narrow set of sectors indeed at risk of leakage. Parameter estimates therefore have to be treated with some caution, and cases where border adjustments actually decrease global environmental effectiveness can therefore not be excluded - even though according to the analyses of Fischer and Fox such cases are rather the exception that the rule. At any rate, in nearly all sectors examined, border measures are more effective than the alternative anti-leakage policy studied: output-based rebating.

Even though many model-based studies thus see border measures as the policy tool of choice to reduce carbon leakage, authors discussing the practical implementation of anti-leakage measures do not recommend their application for all sectors at risk of leakage. For example, a Carbon Trust (2010) report drawing on the results obtained by Monjon and Quirion (2009) identifies border adjustments as the most appropriate policy option only for the cement sector. But for the aluminium sector, the report recommends to support domestic smelters by an investment subsidy, which may be tied to an 
obligation to use low carbon electricity and to adopt the best technologies available. The reason why the Carbon Trust opposes border measures in this case is that the calculation of the appropriate taxes and rebates would be very complex: in aluminium production most emissions are indirect - they stem from the production of the electricity used for smelting. Equally, also for the steel sector the Carbon Trust advises against the use of border measures in the short run and instead recommends the (benchmarked) free allocation of emissions permits. In this sector, the authors of the study argue, border carbon adjustments could be introduced in the medium term. To be effective, these adjustments, however, would need to differentiate between different steel products and different production technologies, and the adjustments would need to consist of an import tax as well as a (legally more problematic) export rebate. Even though the adjustment regime - in contrast to the aluminium sector - would not require taking into account indirect emissions, it would still be quite complex. The Carbon Trust advises against unilaterally imposing such complex (and legally controversial) adjustments and recommends rather negotiating them internationally. This would require time - but in the meantime the domestic steel industry could be supported by free emissions permits. Summing up these recommendations, Droege and Cooper $(2010,51)$ note that "sector characteristics differ greatly (...). Subsequently, the nature of the risk of carbon leakage will also differ and cannot be addressed by one single policy tool." Thus, even though simple analytical models typically rank border carbon adjustments as the best antileakage policy, this ranking often does not carry over to real-world situations: due to legal, practical, or political problems with the implementation of border measures, many authors advise against their use in some economic sectors.

\subsubsection{General equilibrium studies}

As opposed to sectoral studies - which, as we have just seen, regard border adjustments as at least theoretically effective, if not always easy to implement - general equilibrium studies provide vastly diverging results: some find border carbon adjustments effective in reducing carbon leakage (e.g., Burniaux et al. 2010; Boehringer et al. 2011; Winchester et al. 2011; Bednar-Friedl et al. 2012b), or in protecting the competitiveness of the industry in the policy region (e.g. Matoo et al. 2009; Alexeeva-Talebi et al. 2010; Kuik and Hofkes 2010), or in achieving both (Manders and Veenendal 2008; Boehringer et al. 2012a). Other studies, however, report only small overall effects (Dong and Whalley 2009; McKibbin and Wilcoxen 2009), or either little success in reducing leakage (Babiker and Rutherford 2005; Peterson and Schleich 2007; Boehringer et al. 2010a; Antimiani et al. 2013), or in curbing losses in competitiveness (Burniaux et al. 2010). Note again that even if a study finds the introduction of border adjustments as being effective in reducing carbon leakage that does not per se imply that the adjustments also improve the environmental effectiveness of the policy - as noted above the increase of emissions in the policy region caused by the border adjustments may outweigh the reduction of emissions in the non-policy region. One CGE analyses that does report such an effect is the study by Dong and Whalley (2009): in all its central scenarios (carbon pricing plus border adjustments either by the EU, or 
by the US, or by both the EU and the US) the leakage rate drops, but global emissions increase.

\section{Leakage channels}

The large divergence of the results of the CGE studies listed above can be traced back to a number of various factors: First, CGE studies include not only the effects of the policy in non-energy markets (the competitiveness leakage channel), but also those in energy markets (and additionally also income effects - but those are usually not reported separately). There is general agreement that border adjustments may help to curb leakage in non-energy markets, but that - as Boeters and Bollen (2012, S181) put it - leakage in energy markets "cannot systematically be influenced by border measures." Boehringer et al. (2010a) note that import tariffs might have at least some small effect on leakage in energy markets, as foreign production is taxed. Still, in all CGE analyses the main effect of border measures is observed in non-energy markets; thus, naturally in studies where most of the carbon leakage takes place via international energy markets, border adjustments are less helpful in reducing this leakage than in studies where leakage mainly takes place in non-energy markets. Also, as all CGE studies attribute at least some portion of leakage to policy effects in energy markets the reported impact of border adjustments will be lower than in sectoral studies - which, as we have seen, do not model energy market effects.

As discussed above, which share of leakage can be attributed to effects in energymarkets and which to effects in non-energy markets, inter alia depends on the size of the coalition following the mitigation policy: if this coalition is small, Burniaux et al. (2010) argue, most leakage occurs because of losses in the international competitiveness of the coalition's products, i.e. through the non-energy market leakage channel, rather than because of a decline in world fuel prices triggered by the coalition's policy. The reverse holds true if the coalition pursuing the policy is large (as a share of the world economy). Therefore, border adjustments tend to be more effective in curbing leakage for small coalitions, for example they might be quite effective for a scenario where the EU unilaterally pursues a climate policy, but less so if all Annex I pursue the policy.

\section{Model structure}

A second reason for the divergence of the results of different CGE studies is much more difficult to identify - it relates to differences in the representation of the production chain from raw materials via intermediate products to final products and to the international trade links at these different steps in the production chain, i.e. to differences in the details of the structure of various models. For example, the model of Burniaux et al. (2010) produces the unusual result that border measures do help against leakage, but they do not curb output losses incurred by the domestic energy-intensive industries. This is - at least partly - due to the fact that the energy-intensive industries of industrialized countries heavily rely on intermediate inputs produced by energyintensive industries in emerging economies. Border measures tax these imports of intermediate products from emerging economies and thus increase the costs of production in the policy region. 
Boeters and Bollen (2012) point to another possible difference between CGE models that relates to the structure of models: in most CGE models, fuel supply is modelled by a CES production function, in which a natural resource is treated as a fixed factor. This has the consequence that the elasticity of fuel supply systematically varies with the level of fuel supply, which brings about further possible difficulties: first, as already mentioned, it seems plausible to assume that leakage rates decrease with coalition size - simply because, as Boeters an Bollen (2012, S187) put it, "the part of the world where leakage can take place is shrinking." This monotonic relationship, however, does not hold under the CES formulation of fuel supply. Second, in the CES fuel supply case, marginal leakage rates increase sharply with the strictness of the emissions reduction targets. Both of these features are model artefacts that lead to a model behaviour typically not intended by the modeller, Boeters and Bollen remark. They suppose using a function that has a constant elasticity of fuel supply instead of the typical CES formulation with a fixed factor. With this formulation, the competitiveness channel becomes relatively more important for overall leakage; and the difference between the two functional forms is largest if also the abating coalition is large. Border adjustments, on the other hand, are most effective for small coalition. Thus, the practical consequences of using one or the other formulation are not that big for border adjustments; still, in any case, border adjustments are somewhat more effective under the constant-elasticity-of-fuel-supply specification. Taken together, the examples of the model of Burniaux et al. (2010) and the critique of Boeters and Bollen (2012) demonstrate that much of the difference between individual models can be found where it is most difficult to detect at first sight - in functional forms and the intricate interrelationships assumed among the functions of the model.

\section{Import tariffs vs. full carbon adjustments}

As discussed in Chapter 3, the introduction of export rebates might be legally more problematic than the introduction of import tariffs. A further important question therefore is whether import tariffs would suffice to improve the environmental effectiveness of a policy or whether additionally export rebates are needed. The inclusion or exclusion of export rebates is a third aspect, in which the CGE studies listed in the first paragraph of this section differ. Here, those studies that compare both options - border adjustments with and without export rebates - will be briefly reviewed.

Matoo et al. (2009) examine an emissions reduction of high income countries by 17 percent. They compare a policy with only an import tariff to one with an import tariff and an export rebate. Both the tariff and the rebate are based on the emission intensity of the abating coalition. As far as environmental effectiveness is concerned, the authors find little difference between the introduction of only the tariff and of both measures: the policy leads to a reduction of global emissions of 9.3 percent without border adjustments, of 9.8 percent with the import tariff, and of 10 percent with both the import tariff and the export rebate. These figures suggest that it is mostly the import tariff that triggers additional global emissions reduction; the export rebate is not as effective. For competitiveness however, the relative importance of the effects of the two measures is reversed: the output of energy-intensive manufacturing within the climate coalition falls 
by 2.3 percent if the policy is introduced without border measures, it drops by only 1.5 percent if an import tariff is added, and it does not decline at all if both the tariff and the rebate are introduced. Note, however, that the weaker effect of the import tariff as compared to the export rebate may be due to the fact that the tariff rate is based on the emissions intensity in the abating coalition, and not on the much higher actual carbon content of the products taxed.

Boehringer et al. (2010a) compare an import tariff, an export rebate, and the combination of both measures, i.e. full border adjustment, for unilateral abatement policies of either the EU, or the US, or both. As opposed to Matoo et al. (2009) they base the import tariff on the actual embodied emissions of the imported goods, and not on the emissions intensity of similar domestic goods. For all three climate coalitions studied, the authors find that the import tariff leads to a larger reduction in global emissions than the export rebate, and that the combination of both measures causes a still larger reduction in global emissions. Boehringer et al. (2010a, 20) explain the stronger effect of the import tariff as opposed to the export rebate inter alia by the fact that the tariff "can differentiate among regions, so that production of energy-intensive goods in regions with very carbon-intensive production is particularly penalized." Of course, this form of targeted "penalizing" works only if the tariff is based on actual embodied carbon. As concerns its effect on competitiveness, for all three climate coalitions the import tariff is on average more important than the export rebate - within the coalitions, however certain sectors exist where this ranking is reversed, for example the chemicals sector in the U.S.

Alexeeva-Talebi et al. (2010) study border tax adjustments for the EU. They find that the adjustments have only rather limited environmental impacts, but that they do have substantial competitiveness effects. Furthermore, the ranking of the different forms of border adjustments is not the same for all EU states: if the import adjustments are calculated using EU emissions intensities, then the EU15 - the group of states that have been members before 2004 - would prefer the export rebate to the import tariff, whereas for the group of the 12 new EU member states the import tariff represents the more attractive option. As expected, for both groups of EU states a combination of import tariffs and export rebates reduces the negative competitiveness impacts even further than any of the measures applied alone. And if the import tariff is based on the comparatively higher average sectoral carbon content of non-EU countries, both groups of EU states would benefit more from the import tariff than the export rebate. For the EU15, the introduction of the policy accompanied by either the import tariff or both the tariff and the export rebate would even lead to an increase of output in the EU instead of a drop. The reason for this result is that the carbon intensity is far higher outside than within the EU. Imports into the EU will therefore face a higher tax than domestic products, which causes substitution towards domestic products and an increase of domestic production.

Finally, border adjustments consisting of both import tariffs and export rebates have also been contrasted to a "import-tariff-only" policy by a recent Energy Modelling Forum (EMF) comparison of 12 different CGE models - summarized by Boehringer et 
al. (2012a). The finding is that the efficiency and equity impacts of both policies are very similar. Boehringer et al. (2012a, S104f.) argue that "the main reason is that the abatement coalitions under consideration are large net importers of embodied carbon, such that export rebates play a secondary role." Again, this result rests on using country-specific carbon coefficients, and not the carbon coefficients of the abatement coalition to calculate the import tariff rate. Summing up, this kind of result appears to be typical for CGE studies of unilateral climate policy by industrialized countries: if the import tariff is based on the true carbon content of the imported good, then the import tariff tends to be quantitatively more important than the export rebate in either lowering leakage or in minimizing competitiveness losses.

\section{Calculating the carbon content}

As the preceding paragraphs have shown, the question how the size of the border tariffs and rebates is calculated critically influences their effect. A number of such calculation methods have been used in the literature - we thus have a fourth aspect, in which the CGE studies listed in the beginning of this section differ. A full switch from productionto consumption-based accounting would, of course, require that the calculation of border tariffs and rebates exactly mimics the calculation of the domestic carbon tax. As has been discussed in Chapter 3, that may however cause legal problems - and, due to the complexity of determining the amount of carbon embodied in many goods, it may also not be practicable; additionally, also political considerations might call for the use of a different formula to calculate the tariff or rebate rate (for a detailed discussion of these issues see Chapter 10). Thus, the question, which effect the use of different methods to determine the tariff and rebate rates has on leakage and competitiveness, is of huge practical importance.

Mattoo et al. (2009) compare a border tax based on the carbon content of comparable domestic products to one based on the true carbon content of imports. In their model, leakage rates are very low and thus the difference in the effects of the two options on leakage is negligible. But the choice between the two methods for calculating the border tax has huge consequences for competitiveness, trade flows, and the distribution of the tax burdens: if high income countries reduce their emissions by 17 percent and introduce a border tariff (but no export rebate) based on the carbon content of imports, this would fully address competitiveness concerns of producers in high income countries, but it would result in a decline in manufacturing exports from China by 21 percent, and from India by 16 percent. As a consequence, welfare in China would drop by 3.7 percent and in India by 1.4 percent. Mattoo et al. (2009, 3) characterize this as "a 'nuclear option' in terms of trade consequences." On the other hand, according to Mattoo et al., border adjustments based on the carbon content of domestic production (which is by far lower than the one of imports) would, especially if applied symmetrically to both exports and imports, still allow producers in high-income countries to regain most of the competitiveness lost due to the climate policy. But the trade and income consequences for emerging economies would be less serious: manufacturing exports from China and India, for example, would only decline by 1.8 and 2.1 percent, respectively. 
Kuik and Hofkes (2010) - like Mattoo et al. (2009) - also compare border adjustments based either on the emissions of similar domestic products or on the average emissions in the exporting country, but as opposed to Mattoo et al. they for both options include only direct emissions and furthermore they limit the application of border adjustments to two sectors especially at risk of leakage, steel and mineral products. For the EU pursuing a unilateral climate policy, they find that the border adjustments are especially effective in reducing leakage in the steel sector: the sectoral leakage rate drops from 35 percent without border adjustments to 29 percent with border adjustments based on EU carbon coefficients, and to 2 percent with adjustments based on foreign carbon coefficients. In the minerals sector the effects are somewhat smaller, but still substantial. For the EU economy as a whole, the border adjustments however do little to ameliorate the problem of carbon leakage: the leakage rate falls from 10.8 percent without adjustments only to 8.2 percent even if the border tax is calculated using the larger foreign emission coefficients. The reason for the only small impact of the border adjustments on the macro leakage rate is that most of the leakage in the model stems from the energy market channel - and this channel is not (or only little) affected by the border measures. Kuik and Hofkes therefore conclude that border measures - at least if calculated using foreign carbon content - are effective in protecting the competitiveness of individual sectors, but not very effective from an environmental point of view.

A very detailed assessment of the various design options for border adjustments was recently carried out by Boehringer et al. (2012b). They examine only import tariffs (no export rebates), but these are varied along three dimensions: the first is whether the tariffs are calculated taking into account only direct emissions, or direct emissions plus indirect emissions from electricity inputs, or total embodied emissions. The second dimension relates to the sectors included - only energy-intensive and trade-exposed ones or all sectors. And the third dimension differentiates between using the sectoral carbon content of the policy-region, or the average sectoral carbon content of the whole non-policy region, or the average sectoral carbon content of the region where the imported product originates (i.e. the non-policy region is further broken down into different regions with differing carbon coefficients). The analysis is performed for three different coalitions pursuing the abatement policy: the EU alone, all Annex 1 countries except Russia, and all Annex 1 countries except Russia plus China. The main result is the following: the more complex and detailed the system to determine the tariff, the more effective the border measures are in curbing leakage, and the more cost-effective is the policy on a global level. Thus it is important that the policy includes all sectors, and not just energy-intensive ones, that the tariff is calculated using the carbon content of non-coalition technologies (although there is little difference between taking nonpolicy region averages and further differentiating between the country of origin of the good examined), and that not only direct emissions, but also emissions from electricity inputs are included (further extending the emissions base by including all embodied emissions however does not make a big difference). All these differences are especially pronounced for small climate coalitions. For example, for a unilateral climate policy of the EU, the leakage rate without import tariffs is 17 percent. It falls by a small amount 
to around 16 percent, if an import tariff is introduced that is based on direct emissions within the EU, but quite substantially to around 8 percent if the tariff is based on all embodied emissions (using the carbon coefficients from the region where the good was produced). Boehringer et al. (2012b, S143) conclude "that systems more likely to comply with international law yield very little in terms carbon leakage and efficiency." Summing up the results of the three studies on tariff design just discussed, simple, easyto-calculate tariffs that might conform to WTO law might suffice to protect the competitiveness of trade-exposed sectors, but they apparently achieve little in terms of environmental effectiveness.

Another dimension of border tariff design was studied by Bednar-Friedl et al. (2012b): the question whether the inclusion of process emissions - in addition to fuel combustion emissions - is relevant when calculating border adjustment rates. Industrial process emissions are emissions set free not by burning fossil fuels, but by other chemical processes in the production of certain goods - emissions from coke conversion in steel production and from clinker production are the most important examples. Overall, only some 10 percent of global production emissions are process emissions - in many CGE studies on leakage and border carbon adjustments they are therefore neglected. Bednar-Friedl et al., however, note that process emissions are discharged predominantly in sectors that are prone to carbon leakage: for example, in the iron and steel and in the cement sector they account for roughly half of the sector's emissions. Thus, the inclusion of process emissions is important in calculating the overall leakage rate of an economy. For a unilateral emission reduction of the EU by 20 percent, Bednar-Friedl et al. find that carbon leakage in a model with combustion emissions only amounts to 29 percent, but if process emissions are included, the leakage rate increases to 38 percent. Furthermore, border carbon adjustments are found to be roughly twice as effective in reducing leakage if process emissions are correctly accounted for. This strong effect is due to the fact that the inclusion of process emissions allows a more accurate and comprehensive targeting of the sectors truly responsible for leakage.

\section{Producer response}

Closely related to the design of border measures is the question how producers in nonabating countries will react to the imposition of a border carbon adjustment. Winchester (2011) analyses four possibilities for such responses for a scenario where most industrialized countries reduce their emissions by 20 percent. In this study, the border adjustment consists of an import tariff only. It is based on fuel combustion emissions; process emissions are not accounted for. Producers are assumed to react rationally to the policy introduced - their choices are however dependent on how exactly the border tax is imposed and which technologic possibilities they posses. Winchester's approach will here be reviewed in some detail, as the analytical part of this study (see chapters 7 to 9) will examine similar possibilities of producer reaction.

In Winchester's first scenario firms regard the border tax as an output tax on their exports. As Winchester points out, this is actually a formulation adopted in many CGE studies of border adjustments. It mimics a situation, where the calculations on embodied emissions are never or rarely updated: the carbon intensity of each industry is assessed 
once; then this carbon intensity, the carbon price in the abating coalition before the introduction of border adjustments, and data on current export volumes are used to calculate the border tax amount. Thus the firm cannot lower its tax burden by adopting a cleaner production technology. In the second scenario the firm also regards the tax as an output tax on exports, but now the carbon intensity is determined endogenously in the model. This scenario is supposed to mimic the - probably not very realistic - case where embodied carbon calculations are regularly updated, but firms do not realize that they can reduce their border tax charges by reducing emissions. As opposed to the first scenario, in this scenario firms however adapt their input choice to the change in energy prices triggered by the introduction of the border adjustments.

In the other two scenarios, firms view the border adjustments not as an output tax, but as an emissions tax. They thus realize that their tax burden depends on the "cleanness" of their production. These scenarios mimic a situation where the embodied carbon measures used to compute the tax are frequently updated. Firms can change the emissions discharged in production by altering their factor employment shares: they can substitute among different energy commodities with different carbon content, and they can substitute other inputs for energy commodities. This setting is subdivided into two scenarios: one scenario - scenario number three by our overall scenario count - assumes that firms can run separate production lines for different markets, i.e. they will still employ the same technology (represented by the shape of the production function) for all markets, but they will use different input shares for production for the non-coalition domestic market and for production for exports. In that case, the border tax will motivate firms to change the input mix and thus the emissions discharged only in export production. The production lines producing for the domestic market of non-coalition countries, on the other hand, are not affected by the tax (at least not directly). Finally, the fourth scenario assumes that such a differentiation of production lines is not possible - firms have to use one production line for goods shipped to all markets. All goods of a sector in the non-abating countries are therefore produced with the same input mix and the same emission intensity. Winchester observes that in that case the border adjustments effectively apply a carbon price to all non-coalition production that equals a parameter $\alpha$ times the carbon price prevailing in coalition countries, where $\alpha$ is the share of exports to the coalition in overall non-coalition production. This means that the emission intensity in all non-coalition production, and not just in export production, is reduced by the border measures, but the size of the reduction in emissions intensity is smaller than that in scenario three (which applies only to export production).

The main results of Winchester's analysis are as follows: In the central simulation case of the study, leakage amounts to 24.8 percent for an abatement policy without border measures, to 16.3 percent in scenario one (border tariff works as export tax), to 15.7 percent in scenario two (border tariff works as export tax, but emissions intensity is endogenous), to 15.1 percent in scenario three (border tariff works as emissions tax, different production line for exports), and to 5.1 percent in scenario four (border tariff works as emissions tax, only one aggregate production line). As might be expected, leakage reduction is thus larger if not only non-coalition export volumes are reduced, but also non-coalition firms react by adjusting the carbon intensity of production, i.e. in 
scenario three and four. But what explains the big difference in leakage reduction between scenario three and four? According to Winchester it is driven by the convexity of the marginal abatement cost functions (which are implicit in the model): such a functional form implies that a small carbon price applied to a large emissions base induces a larger decrease in emissions than a large carbon price applied to a small emissions base. Another result is that the scenarios with the lowest leakage rate scenario three and especially four - are also the ones that result in the smallest increase in production in the abating coalition relative to an abatement policy without border adjustments. Winchester $(2011,10)$ stresses that this implies that "policymakers face a trade-off between leakage and competitiveness concerns." Summarizing the main conclusions, Winchester's study finds that technological possibilities and the way how the carbon content in traded goods is determined are of huge importance to the environmental effectiveness of border adjustment measures. Again, the measures are more effective, if the tax depends on the true carbon content of the goods under question. Only if producers can influence their tax charges by altering their emissions, the policy indeed incentivizes the adoption of cleaner production methods.

\subsubsection{Cost-effectiveness}

Most CGE studies of border tax adjustments examine - as we have just seen - effects on carbon leakage and competitiveness; only few, on the other hand, compare policies in terms of cost-effectiveness - even though, as was argued in Section 2.3, costeffectiveness is a criterion that has a larger informative value than carbon leakage or environmental effectiveness. Among these few exceptions are the study by Boehringer et al. (2010a) and the EMF model-comparison study (Boehringer et al. 2012a) discussed in the subsection on "import tariffs vs. full carbon adjustments" in this chapter. Both studies proceed by keeping the global emissions reduction constant across the policy scenarios compared. Then the costs in terms of welfare gains or losses in each scenario are determined - the scenario with the least costs will be the most cost-effective one.

Boehringer et al. (2010a) find that for global emissions reductions between 4 and 6.6 percent achieved through either unilateral policy of the U.S. or of the EU, or of both the U.S. and the EU, the differences in welfare effects among the policies compared are very small for the world as a whole - the global costs of a policy without adjustments, a policy with an import tariff, one with an export rebate, and one with both a tariff and a rebate differ by far less than 0.1 percent of world consumption.

The results of the EMF model-comparison study are similar: the introduction of border adjustments - an import tariff and an export rebate - in the 12 models being compared brings about global cost savings between close to zero and 18 percent with a mean value of 8.5 percent. Boehringer et al. (2012a, S102) give two reasons for this modest improvement in cost-effectiveness: first, "import tariffs applied to the industryaverage of embodied carbon do not incentivize polluters in unregulated countries to adopt less emission-intensive production techniques." Thus, again the question how the border tariffs are calculated is crucial. The second reason listed by Boehringer et al. (2012a, S102) is that "exporters in unregulated countries can to a certain extent also reroute their products from countries that levy carbon tariffs to unregulated markets." 
Also note that in the 12 models being compared the introduction of border adjustments is quite effective in reducing leakage: the leakage rate drops from a 12-model average of 12 percent to 8 percent, i.e. by a third. Thus, as Boehringer et al. (2012a, S100) remark, border carbon adjustment indeed "helps to reallocate emissions between the abating and the non-abating countries in the 'right' (cost-saving) direction." Still, even though the direction is "right", the size of the effect is - as we have just seen - rather small: A leakage reduction of a third leads to a cost reduction of only 8.5 percent.

\subsubsection{International distribution of the "burden" of the policy}

Even though the global cost-saving through the introduction of border adjustments thus appears to be small, in many - but not all - CGE models the border adjustments lead to a substantial redistribution of the burdens of the policy: the abating countries typically experience welfare gains, the non-abating countries losses. In the EMF study just discussed (Boehringer et al. 2012a) the burden sharing ratio measured in percentage GDP loss for the abating countries over the percentage GDP loss for the non-abating countries amounts to about 3:1 for the mitigation policy without border adjustments, but this ratio drops to $1: 1$, if border adjustments are introduced. Note also that the nonabating countries have to bear some of the cost of the policy even without border adjustments. According to Boehringer et al. (2012a) this is due to terms-of-trade changes - the ratio of the non-abating countries' export prices to their import prices deteriorates. Also, non-abating countries suffer from a reduction of the economic activity in abating countries caused by the introduction of the policy. These two effects in most - but not all - of the 12 models compared dominate any gains in comparative advantage the non-abating countries might experience due to carbon-pricing in the abating countries. If border adjustments are introduced, the terms-of-trade of nonabating countries worsen further. The countries that under the assumptions of the EMF study suffer the most severe welfare losses - both from the original policy and the policy including border adjustments - are oil exporting countries.

Other studies draw similar conclusions: Mattoo et al. (2009), for example, report a welfare loss for China of 3.7 percent if a policy of reducing emissions in high-income countries is accompanied by an import tariff based on embodied carbon in the imported goods. The same policy without the import tariff would lead to a welfare loss in China of only 0.2 percent. In the same vein, also Babiker and Rutherford (2005) and Boehringer et al. (2011) find strong distributional effects of border carbon adjustments. Boehringer et al. (2011), studying a 20 percent emissions reduction for the OECD countries, even report that for these countries the terms-of-trade gains are larger than the abatement costs - thus the OECD countries, on average, experience a net welfare gain from introducing a climate policy accompanied by border adjustments compared to a scenario with no climate policy.

An opposite result is, however, reported by Peterson and Schleich (2007): in their study, the introduction of border adjustments slightly increases the costs for the EU of meeting her Kyoto targets. The reason for this finding is that the border adjustments lead to an increase of the output and therefore the emissions of the sectors protected by the adjustments. In order not to exceed the EU wide Kyoto emissions limits, other 
sectors thus have to abate more. The border adjustments in that way shift the burden of abatement from protected to non-protected sectors, which drives up the abatement costs. Obviously, such an effect can indeed occur in a setting where the abating region is bound by an emissions reduction target referring to the production-based emissions of that region, but is less likely in a setting where the aim is to meet a global emissions reduction target as in the EMF model-comparison study discussed above (Boehringer et al. 2012a).

Dong and Whalley (2009) report a result where not only the abating, but also the non-abating countries experience welfare gains from the introduction of border adjustments, i.e. a result that differs from the findings of most of the other CGE studies. In the model of Dong and Whalley, welfare is not only derived from consumption, but also depends on damages from global warming. The introduction of border adjustments in their model, however, leads to a smaller global emissions reduction compared to an abatement policy without border adjustments - the welfare gains reported for nonabating countries in the scenario with border adjustments therefore cannot be due to a reduction of damages from global warming, but must be caused by changes in consumption. The likely explanation for these - compared to other models - "untypical" welfare gains is as follows: Dong and Whalley also report results for a scenario where the border adjustments consist only of an import tariff, but no export rebate. In that case the non-abating countries suffer a welfare loss. If, however, also an export rebate is applied, instead a welfare gain is reported. From this, we can conclude that the effect of the export rebate dominates the effect of the import tariff. And there is an obvious reason for the comparatively small effect of the import tariff: As opposed to the EMF comparison-study (Boehringer et al. 2012a), the model of Mattoo et al. (2009), or the model of Boehringer et al. (2011), in Dong and Whalley's (2009) model the import tariff is not based on the (comparatively larger) true carbon content of the imported goods, but on the (comparatively smaller) carbon intensity of similar goods produced in the importing country. Thus, the import tariffs in the model of Dong and Whalley are far smaller than the ones in the other studies just listed, and therefore also the welfare effect of these smaller import tariffs is smaller. At any rate, this finding suggests that the often heard assertion that developing countries will suffer welfare losses from the introduction of border adjustments by industrialized countries may not apply in all cases.

Note also that the distributional effects of the introduction of border carbon adjustments have an influence on the size of carbon leakage - through the "income leakage channel". If, as many studies find, developing and emerging countries suffer welfare (or: income) losses due to the border measures, this will reduce the demand of these countries and thus also their domestic production, thereby causing "negative leakage". To the knowledge of the author, to date no studies exist that aim to quantify this effect. Boehringer et al. $(2011,2)$ however mention such income effects and note that "part of the effectiveness of tariffs stems from the fact that they are harmful to countries subjected to them" - or to state it even more bluntly: making heavily polluting emerging economies poorer will help the environment. 


\subsection{Conclusion}

While there seems to be some agreement among economists that carbon leakage might pose a problem for a narrow set of energy-intensive and trade-exposed sectors, views on its quantitative importance for entire economies diverge. "Given the absence of historical experience with meaningful carbon restrictions, we do not have data to do the kind of empirical work used to estimate the pollution haven effect for other pollutants," Karp $(2011,416)$ observes. The task at hand is not to evaluate past policies, but to look into the future, to assess GHG abatement of an extent without precedent. That there is no unanimity about the consequences of such a policy is therefore probably only natural. Simulation models have been employed to estimate leakage rates in such a situation - but as this chapter has shown, the results heavily depend on the assumptions made and not all authors feel comfortable with the empirical basis of these assumptions. How difficult it is to say something definite about the magnitude of carbon leakage under these circumstances is reflected in another quote by Karp (2012, 23-24), who, after reviewing the empirical literature and analysing various theoretical partial- and general-equilibrium models, concludes: "My best guess is that [leakage] will be small or moderate, but neither the theoretical nor empirical basis exists for asserting this with confidence."

If, as often in the literature, the problem of carbon leakage is used as the main argument for the introduction of border carbon adjustments, then we are thus in trouble: we cannot even say for sure that carbon leakage indeed is a problem of some size; hence, we also do not know whether a "solution" for this problem is required, i.e. whether the introduction of border adjustments or a switch to a consumption-based policy orientation should even be considered. Still, one might argue that most of the studies reviewed in this chapter examine quite moderate emission reductions - usually of a size not exceeding 20 percent. The IPCC $(2007,776)$, on the other hand, argues that industrialized countries should reduce their emissions by 80 to 95 percent until 2050 if we do not want to exceed the $2^{\circ}$ global warming threshold. It does not appear implausible to assume that with such stringent abatement targets also carbon leakage will turn into a "real" problem in the not too distant future. But even if we allow for this argument and therefore accept that a "solution" for the problem of carbon leakage is required: as has been summarized in the first paragraph of Section 5.2.2, there is no agreement in the literature whether the introduction of border adjustments qualifies as such a solution that indeed helps against leakage.

What about the other arguments for a consumption-orientated policy listed in the introduction to this study? Some articles that belong to the literature on border adjustments besides carbon leakage also discuss cost-effectiveness. But, as we have seen, they conclude that the cost-difference between consumption- and productionbased policies is rather small. These studies however also provide explanations for this only small cost difference: it is due to details of the calculation of the border tariffs and the producer response triggered thereby on the one hand, and to the possibility of a redirection of trade flows to third countries on the other hand. But such arguments immediately raise a question: is it possible to design border measures in such a way as 
to avoid these problems with limited producer response and a redirection of trade flows? And could thus a sizeable cost-advantage be achieved for a consumption-oriented policy?

Actually, the main insights produced by the quantitative literature on leakage and border adjustment are not the quantitative estimates per se - these differ too much between individual studies as to allow definite conclusions. But that strand of literature has hugely contributed to point out on which parameters, on which scenario details, and on which details of border adjustment calculation and design the cost-effectiveness of a policy depends - or similarly, a reduction of the leakage rate depends. In that way, the findings of this literature strand are immensely helpful for answering one of the central research questions of this study: the question which design and scenario requirements a consumption-based policy would have to meet in order to stand a chance of improving on the environmental effectiveness and cost-effectiveness as compared to a productionbased policy.

This question will be addressed in numerous passages in the remainder of this study. Here, briefly the main findings from the quantitative border adjustment literature shall be recapped - one should however keep in mind that all these finding are tentative and that often also studies exist that come to the opposite conclusion. But in general, border adjustments seem to perform better at improving the competitiveness of the country imposing the measures than in preventing leakage. For both leakage and competitiveness, the measures are more effective for small abating coalitions, i.e. in a setting where most of the leakage occurs through the competitiveness leakage channel. To reduce leakage, the adjustments should be definitely applied to imports; an export adjustment on the other hand apparently does not have as big quantitative effects. Also, the effect to improve environmental effectiveness is larger, the larger is the emissions intensity in non-abating countries compared to the one in abating countries, the larger is the elasticity of demand for imports (from non-abating countries), the smaller is the substitutability between domestic goods and imports, the smaller is the elasticity of demand for exports, and the larger is the substitutability between exports and goods produced in non-abating countries. The calculation of the size of the tariffs is crucial: to be effective, the policy should be imposed on all sectors and not just carbon-intensive ones; the tariffs should be based on true embodied carbon (or at least a close proxy thereof), and not on the carbon-content of similar products produced in the abating coalition; and - as concerns indirect emissions - at least those from electricity production should be included. Also, process-related emissions should be counted. To provide incentives for the adoption of clean technologies, it is especially important that carbon import taxes are not based on some industry average of carbon intensity, but that each individual producer has the possibility to reduce her tax burden by switching to a "cleaner" production method. To that end, the measure of embodied emissions for each good should be frequently updated, and not fixed for long periods of time. Finally, the introduction of border adjustments leads to a huge redistribution of the burdens of the policy - in the typical setting of most studies to the disadvantage of developing and emerging economies. This improves environmental effectiveness in most CGE models, but might also lead to countervailing environmental effects (see Section 4.3), which are 
not discussed in that strand of literature. To conclude, note that all effects studied by the quantitative literature on border carbon adjustments relate to leakage through the competitiveness, the energy market, and the income channel. The impact of border adjustments on technological spillover-effects has so far not been analyzed quantitatively. 


\section{CHAPTER 6}

\section{Literature on Emissions Embodied in Trade}

The second major strand of literature that discusses consumption-based accounting and a consumption-based policy orientation is the literature on emissions embodied in trade. Emissions embodied in trade (EET) are a quite new field of research: the first articles on this topic relating to GHG emissions were written in the late 1990s. One major contribution of this strand of literature was to refine the methods by which consumption-based emissions inventories for whole countries could be estimated: the "top-down approach" to determine embodied emissions was established, an approach relying on environmentally extended input-output analysis (see Section 2.1.2 for a more detailed explanation). These relatively new methods were employed first to estimate the emissions embodied in imports (EEI) and exports (EEE) for single countries; later also models representing the whole of global trade relations were developed. All these models have produced one common "stylized fact": industrialized countries are increasingly becoming carbon importers - in the last decades they mostly managed to stabilize their production-based, but not their consumption-based emissions. The empirical findings on this - under certain conditions environmentally worrying international trend will be the subject of the first section, 6.1. Section 6.2 discusses proposals on how, under such circumstances, the environmental effectiveness of climate policy can be improved. Then, in Section 6.3, a question that has recently gained much interest in the literature on emissions embodied in trade will be discussed, the question: "Who is responsible for emissions - the producer or the consumer?" This question relates to the debate on how commitments and burdens of an abatement policy should be apportioned between countries in order to achieve a just outcome. Section 6.4 concludes.

Prior to discussing these issues in detail, however, one more general point should be briefly mentioned: the literature on emissions embodied in trade does not only discuss attributing the emissions embodied in goods to either the producer or the consumer - recently also a third, and one might argue, even a fourth option for attributing emissions has been suggested. First, note that in the life-cycle of a product there are more economic agents involved than just the producer (or rather: the many producers contributing to the supply chain of a product) and the consumer: also, at each stage of production, primary inputs are needed. Thus, the emissions embodied in a product can also be attributed to the suppliers of primary inputs (i.e. to the suppliers of the factors of production). Two different variants of this idea have been suggested in the literature: Lenzen and Murray (2010) and Marques et al. (2012) propose assigning the emissions embodied in a good or service to all inputs involved in its production in proportion to the relative costs of these inputs. Lenzen and Murray $(2010,269)$ provide the example of a road freight business: “[A] supplier of $\$ 1000$ worth of insurance 
policies to a road freight business is as responsible for the emissions of the trucks exhausts as the supplier of $\$ 1000$ worth of trucks, or the supplier of $\$ 1000$ worth of diesel." They point out that all these inputs "enable" the road freight business to operate. Therefore, they introduce the term "enabled emissions" for emissions attributed to primary inputs. Marques et al. (2012), referring to the same emissions measure, instead speak of "income-based responsibility for emission". They thereby aim to stress that the suppliers of primary factors benefit from emissions because they receive income in return. This - besides the production- and the consumption-based emissions count - third emission measure can, of course, not only be applied to individual products or businesses, but also to whole countries: the "income-based responsibility" of a country provides information on the amount of emissions "enabled" in order to generate the country's income through wages, profits, and rents.

As opposed to Lenzen and Murray (2010) and Marques et al. (2012), Davis et al. (2011) introduce a somewhat different concept (the "fourth concept" for attributing emission mentioned above): they attribute emissions not to all primary inputs, but just to the input of fossil-fuel, i.e. they trace back emissions to the country, where the fossil fuel the burning of which caused the emissions was extracted. This emission measure is termed "extraction emissions." These two additional emissions measures - "enabled emissions" and "extraction emissions" - can, of course, also be used for crafting new variants of climate policy, for example emissions could be regulated at the point of fuel extraction (Davis et al. 2011). Here, these options shall however not be discussed in detail - the focus of this analysis is consumption-based emissions measures.

\subsection{Trends in emission transfers via international trade}

Over the past decade, a number of studies have compared production-based emissions inventories of different countries to consumption-based ones - see Wiedmann et al. (2007) and Wiedmann (2009) for comprehensive reviews. Besides specific findings relating to individual countries, these studies reveal a common characteristic of international carbon transfers: emissions embodied in goods are exported mainly from emerging economies to consumers in developed countries. For example, Davis and Caldeira (2010), using 2004 trade and emissions data, find that 23 percent of global $\mathrm{CO}_{2}$ emissions are traded internationally. The largest carbon exporting countries or regions are China, Russia, the Middle East, South Africa, Ukraine, and India; and the largest importers are the U.S., Japan, the UK, Germany, France, and Italy. These carbon transfers through trade reinforce the existing global disparity in per-capita emissions: typically, countries with low production-based per-capita emissions have even lower consumption-based per-capita emissions and countries with high production-based percapita emissions have even higher consumption-based per-capita emissions. In some wealthy countries like Switzerland, Sweden, Austria, the UK, and France more than 30 percent of consumption-based emissions were imported, Davis and Caldeira find.

Furthermore, there are huge differences in the carbon intensity of trade between carbon exporters and carbon importers: The mean $\mathrm{CO}_{2}$ intensity of Russia's exports, for example, amounts to $2.43 \mathrm{~kg} \mathrm{CO}_{2} / \$$, and for China the corresponding figure is $2.18 \mathrm{~kg}$ 
$\mathrm{CO}_{2} / \$$. On the other hand, the exports of countries that are net carbon importers are much "cleaner": In Germany and the UK, the $\mathrm{CO}_{2}$ intensity of exports amounts to 0.21 $\mathrm{kg} \mathrm{CO}_{2} / \$$; and in France to only $0.17 \mathrm{~kg} \mathrm{CO}_{2} / \$$, Davis and Caldeira find. Theoretically, a high carbon intensity of a good can be due to two factors: either the choice of fuel, i.e. the use of a carbon-intensive fuel like coal in production, or a low value of the good per unit of energy required to produce it. Davies and Caldeira show that for the exports of emerging economies both of these factors contribute to the overall high carbon intensity. The second factor, the low value of the goods per energy input, of course partly stems from the fact that developing and emerging economies make different types of goods: on average, emerging economies produce more basic commodities and industrialized countries more goods that are higher-up the value-added chain. But even if one compares similar products, differences in carbon intensity are substantial. Peters and Hertwich (2006), for example, estimate for the case of Norway that one would underestimate emissions embodied in imports by a factor of 2.5 if one were to assume that imports are produced with Norwegian technology.

A further central finding of studies comparing various countries' production-based to their consumption-based emissions inventories is that the carbon flows between countries are not stable over time: the reported disparities are growing, i.e. in industrialized countries consumption-based emissions are increasing, whereas production-based ones have on average stabilized over the past two decades. Thus these countries are becoming ever larger importers of carbon. The reverse side is that emerging economies are becoming larger and larger carbon exporters. Peters et al. (2011) develop a method to obtain annual estimates for emissions embodied in trade from 1990 to 2008 from the scarce data available (global multiregional input-output tables have been calculated only for a few years - Peters et al. make use of such tables compiled for 1997, 2001, and 2004). They find, firstly, that the share of "traded emissions" in overall emissions grows: in 1990, 20 percent of global emissions were transferred between countries by means of trade in goods and services; in 2008 the figure was 26 percent of global emissions. Thus, "traded emissions" increase faster than overall global emissions - the respective annual growth rates are 4.3 percent and 2 percent. Considering not overall global trade, but only trade between developing (nonAnnex B) and developed (Annex B) countries, the changes are even more pronounced: according to Peters et al., the net emission transfers from non-Annex B to Annex B have grown from $0.4 \mathrm{Gt} \mathrm{CO}_{2}$ in 1990 to $1.6 \mathrm{Gt} \mathrm{CO}_{2}$ in 2008 . This amounts to an average annual growth rate of 17 percent. And Peters et al. point out that their method of calculation actually even underestimates the true amounts of emission transfers between developing and developed countries, as it considers only trade between two individual countries, but does not trace back the whole global supply chain of every product through multiple countries.

It is also interesting to look at the sectoral break-down of emission transfers provided by Peters et al. (2011): trade in non-energy-intensive manufactured products dominates the emission transfers between non-Annex B and Annex B countries - as Peters et al. (2011, 4) remark, "despite the policy focus on energy-intensive manufacturing." As concerns energy-intensive manufacturing, the study of Peters et al. 
reveals that trade patterns have reversed in the nearly two decades examined: in the early 1990s, developed countries were small net exporters of emissions from energyintensive manufacturing, but by now they are substantial importers.

Results for Austria fit this general pattern: : Muñoz and Steininger (2010) estimate that the carbon content of Austrian consumption was 36 percent larger than that of her production in 1997, and already 44 percent larger in 2004, and that in 2004 one third of emissions embodied in imports originated in non-Annex I countries. As Steininger et al. (2014) remark, thus even in countries with significant energy-intensive industries like Austria (or France) carbon embodied in imports far outweighs carbon embodied in exports. For countries with only a small share of basic industries, the wedge between consumption- and production-based emissions is even larger - in Switzerland, for example, the consumption-based emissions measure is twice as large as the productionbased one (Steininger et al. 2014).

As discussed in Section 2.1.1, the difference between the consumption-based emissions inventory and the production-based one equals the balance of emissions embodied in trade, and this balance is in turn closely related to the leakage-measure introduced by Peters and Hertwich (2008a) - "weak" carbon leakage. "Weak" leakage is defined as the $\mathrm{CO}_{2}$ emissions embodied in imports from non-Annex $\mathrm{B}$ countries to Annex B countries. As compared to the balance of emissions embodied in trade between these groups of countries, weak carbon leakage thus only considers imports of developed countries, but disregards exports. Peters and Hertwich (2008a) calculate leakage figures for a data set of 87 countries for the year 2001. They report two leakage measures: first, weak carbon leakage normalized with respect to the total productionbased emissions of a country or region, expressed in percentage terms; and second, weak carbon leakage normalized relative to the total emissions embodied in imports of a country or region, also expressed in percentage terms. Using the first measure, the authors find that weak leakage from the Kyoto Protocol region amounts to 10.8 percent. The reported values are larger for smaller, trade-exposed countries, for example 29.4 percent for Belgium and 21.1 percent for the Netherlands. For larger, more selfsufficient countries, on the other hand, this leakage measure is typically smaller, for example 9.6 percent for the U.S. The second leakage measure compares carbon embodied in imports from non-Annex B countries to overall carbon embodied in imports. It is typically larger for countries located far away from other Annex B countries, for example 61.7 percent for the U.S. and 68.5 percent for Japan. In contrast, for countries that border other Annex B countries and therefore mostly trade with other Annex B countries like most EU countries, the reported values are smaller, for example 33.4 percent for Germany or 17.7 percent for the Czech Republic.

For individual countries sometimes the weak carbon leakage measure favoured by Peters and Hertwich and the balance of emissions embodied in trade (BEET) reported by most other authors point in different directions: for example, for Australia, Peters and Hertwich (2008a) calculate a BEET (expressed as a percentage of production-based emissions) of 16.5 percent. Thus, Australia exports more carbon than it imports, which is untypical for industrialized countries (the reason is that Australia is a large exporter 
of natural resources). The value found for weak carbon leakage out of Australia (relative to total production-based emissions), 8.6 percent, is however more in line with the results for other large industrialised countries. For all industrialized countries taken together, however, both measures convey the same picture: the BEET is negative, i.e. there is a net flow of emissions embodied in trade from developing to industrialized countries; and weak carbon leakage is substantial, i.e. a non-negligible fraction of $\mathrm{CO}_{2}$ emissions consumed in Annex B countries is not produced there.

\subsection{Policy proposals focusing on environmental effectiveness}

Many authors writing in the field of emissions embodied in trade have suggested making use of consumption-based emissions inventories in climate policy. Most of these suggestions are motivated by one of the following two arguments: Either the current system of territorial emissions-accounting and corresponding policy design is considered as not being "fair", or it is supposed that improvements in environmental effectiveness can be achieved by relying on consumption-based emissions measures. "Fairness" will be the topic of Section 6.3. First, in this section, arguments relating to environmental effectiveness shall be discussed. Many of these arguments have been formulated by Peters and Hertwich (2006; 2008a; b).

\subsubsection{Leakage and the share of global emissions targeted by climate policy}

Firstly, Peter and Hertwich $(2008 \mathrm{~b}, 57)$ argue that using consumption-based GHG inventories may be "the key to reducing carbon leakage". They refer to their own concept of carbon leakage, i.e. "weak" carbon leakage, the emissions embodied in imports of Annex B countries from non-Annex B countries. To start with, note that the literature on emissions embodied in trade does not claim that either "weak" carbon leakage or a negative balance of emissions embodied in trade of industrialized countries is caused by abatement policy. On the contrary, Peters et al. $(2011,5)$ state that "the likely cause of the large emission transfers (...) are pre-existing policies and socioeconomic factors that are unrelated to climate policy itself." Nakano et al. (2009, 26) perform a sensitivity analysis on trade flows and find "that the recent globalisation of industrial activity has had a significant impact on the discrepancies between production- and consumption-based emission measures," i.e. with growing trade flows also the BEET of industrialized countries has increased in absolute value. And Muñoz and Steininger $(2010,2003)$ argue that " $[t]$ here may be other factors, such as cheaper labour, lower standards of other environmental policy or the availability of specific physical resources in non-Annex I parties, which make foreign production more profitable." In general, however, the literature on emissions embodied in trade does not investigate the causes of the large and increasing negative BEET of industrialized countries in detail.

But even though it is thus claimed that traditional, production-based climate policy is not the cause of "weak" carbon leakage, Peters and Hertwich (2008b) suggest that pursuing a consumption-based climate-policy can nonetheless reduce leakage. Basically, a consumption-based policy will either price carbon embodied in imports in 
some way or put other restrictions on imported carbon. Thus, if the demand for imports is not completely price-inelastic, "weak" carbon leakage will indeed be reduced by a policy targeting consumption.

But there is a more fundamental problem with an approach that advocates a reduction in "weak" carbon leakage on environmental grounds. As argued in Section 2.3.2, a negative BEET of industrialized countries or a large amount of "weak" carbon leakage is not per se a sign of an environmentally worrying situation. Also in a situation where all negative environmental externalities are internalized, the BEET and "weak" leakage will typically not equal zero. Hence, reducing "weak" carbon leakage - without further qualification - is not a legitimate aim for climate policy. A legitimate aim for climate policy would be to reduce that part of "weak" carbon leakage that is due to (not internalized) environmental externalities. One might assume that Peters and Hertwich actually have only such a reduction in mind. Still, environmental measures that could affect the exports of developing and emerging economies are, as Droege $(2011,1197)$ remarks, "traditionally perceived as potential protectionism" by these countries; and as "there is little trust to build upon," it seems advisable to be precise when advocating such measures in order to avoid political conflicts.

Also note that the notions of "reducing leakage" in the literature on emissions embodied in trade and in the border-adjustment literature are somewhat related concepts, but they are not the same: in the border-adjustment literature, the leakage concept used is "strong" carbon leakage and "reducing leakage" means avoiding an unwanted side-effect that is triggered by the climate policy introduced. In the literature on emissions embodied in trade, on the other hand, the leakage concept employed is "weak" carbon leakage. It refers to an effect not necessarily triggered by climate policy, and thus "reducing leakage" in this case means using environmental policy to stem against trends that probably have completely different causes.

Also, as Peters and Hertwich (2008b) note, the introduction of a consumptionoriented policy will, admittedly, reduce "weak" carbon leakage, i.e. reduce carbon imports by industrialized countries, but carbon leakage will shift to exports instead, i.e. the carbon exports of industrialized countries will grow. Thus, whether a consumptionbased policy will reduce global emissions by more than a production-based one depends on the relative amounts of the reduction of "leakage through imports" compared to the increase in "leakage through exports." Peters and Hertwich, using trade and emissions data, however, establish that there is currently less carbon leakage in exports than in imports (i.e. there are less emissions embodied in the exports of industrialized countries than in their imports; thus, as discussed in Section 6.1, the BEET of industrialized countries is on average negative). "[A]t least in the short term, it is [therefore] likely the majority of emissions embodied in global trade are captured by consumption-based GHG inventories," Peters and Hertwich $(2008 \mathrm{~b}, 57)$ conclude. And from this they also deduce a further argument in favour of a consumption-oriented policy approach: developed countries by following a consumption-based policy "take a greater share of current [global] GHG emissions and consequently emission [reduction] commitments for developing countries are not as important." 
Let us briefly analyze this chain of reasoning. Peters and Hertwich do not specify what exactly they mean by saying that emissions reduction commitments by developing countries are "not as important." But let us assume they have in mind "important" in achieving the aim stated at the outset of their analysis, "a long-term stabilization of greenhouse gas concentrations" (Peters and Hertwich 2008b, 51). Thus, apparently the argument is that under a consumption-based policy the difference in environmental effectiveness between a policy followed by all countries and a policy followed only by industrialized countries is not as large as under a production-based policy. Assuming that the environmental effectiveness of a production- and a consumption-based policy is the same if all countries are included, this statement implies that if only industrialized countries abate, then the consumption-based approach is the environmentally more effective option, i.e. it leads to a larger reduction of global emissions. But can we indeed draw such a conclusion? Actually, this is not possible: the fact that the amount of emissions embodied in imports is larger than the one in exports does not allow us to infer that also the reduction of emissions will be larger if a policy targeting imports is adopted instead of one targeting exports. Basically, the size of the emissions reduction in absolute terms will depend both on the amount of emissions targeted (the size of the emissions base the policy is applied to) and on the effectiveness of the policy in reducing emissions per unit of emissions targeted. The argument discussed by Peters and Hertwich relates only to the amount of emissions targeted - but does not take into account the "per-unit-effectiveness" of the policy. To give an example, including emissions embodied in imports in the scope of the policy will not help to increase emissions reduction, if imports are completely price-inelastic and their amount does not change in response to the policy. This argument will be addressed in more detail in Section 8.4.1.

To summarize, of course the fact that, as Peters and Hertwich (2008a, 1402) put it, much of "Annex B consumption is produced in countries without binding mitigation policies in place" seems worrying at first sight. Still, not all international emission transfers take place because non-Annex B countries have turned into a "pollution haven"; and thus not all of "weak" carbon leakage is a problem that needs to be fought. An economic approach would call for differentiating between "efficient" international carbon transfers and carbon transfers that are triggered by negative environmental externalities. Therefore, we need to draw a subtle distinction: reducing "weak" leakage (i.e. the carbon imports from developing and emerging economies) without any further qualifications cannot be justified as a legitimate aim of environmental policy; applying a carbon price to these imports, on the other hand, can be justified on environmental grounds. In principle, bringing a larger (and increasing) share of global emissions into the scope of climate policy by switching to consumption-based GHG accounting appears to be a very attractive option. But again, we need to pay attention to the fact that expanding the emissions base of a policy does not automatically increase the policy's effectiveness. Only if one assumes that the "per-unit" effectiveness of a consumptionbased policy is not (substantially) lower than that of a production-based one, the arguments given by Peters and Hertwich $(2008 \mathrm{~b}, 57)$ on the "greater share of current 
GHG emissions" covered by a consumption-based policy will suffice to guarantee that a switch to such a policy will indeed be environmentally beneficial on a global level.

\subsubsection{Comparative advantage and technology diffusion}

Apart from the two arguments on "reducing leakage" and "reducing the importance of emissions commitments for developing countries", Peters and Hertwich also give a number of arguments that are actually similar to the ones discussed in the border-tax literature. A third argument is that "consumption-based GHG inventories may shift comparative advantage away from pure economic measures to one that also includes environmental factors" (Peters and Hertwich 2008b, 58). What the authors have in mind is that under a production-based policy the countries that are part of the climate coalition are "punished" for pursuing the policy as their products become more expensive. For the buyer, there is a price incentive to buy the cheaper products from non-coalition countries, even if they are produced with a higher emission-intensity than the products from coalition countries. Under a consumption-based policy, on the other hand, for the consumer (or buyer of intermediate products) in a coalition country, goods containing the same amount of carbon carry the same carbon tax, no matter whether they are produced in the coalition or not, and goods produced with a "cleaner" technology are taxed less and are therefore cheaper. Thus, clean production leads to an "environmental comparative advantage" (Peters and Hertwich 2008b, 58).

This argument is exactly the same as the one used to explain leakage through the competitiveness channel in the literature on policy-induced leakage or to derive the "pollution haven hypothesis" (see Section 4.2): a unilateral production-based climate policy distorts the incentives consumers face, whereas a unilateral consumption-based policy does not punish (but also not favour) "clean" production if judged from the viewpoint of consumers in non-abating countries, and does actually favour "clean" production if judged from the viewpoint of consumers in abating countries. Thus, a consumption-based policy should be environmentally more effective. Peters and Hertwich $(2008 b$, 59) also note that "[a] shift towards 'environmental comparative advantage' may alleviate the competitiveness concerns of some countries" - which is another argument known from the border-tax literature, the argument of "levelling the playing field."

A fourth group of arguments listed by Peters and Hertwich $(2008 \mathrm{~b}, 59)$ relates to technology transfer and "technology diffusion". The authors argue that the introduction of a consumption-based policy might encourage both the governments of industrialized countries to transfer "clean" technologies to developing countries and the private sector to contribute to technology spillover effects. As concerns the role of the private sector, Peters and Hertwich $(2008 b, 59)$ are not very specific: they state that the effect is due to "the shift in comparative advantage" (from pure economic factors to the inclusion of also environmental factors, as argued above) and that under a consumption-based policy "it is important that any migrating industries use the cleanest production technology available" (Peters and Hertwich 2008b, 59). Apparently, they refer to an industry migrating from an industrialized to an emerging economy and taking its production technology with it. Pan et al. (2008, 370), analysing emission flows between the U.S. 
and China between 2001 and 2006, find some evidence of such an effect even under the current production-based policy: the relocation of U.S. production to China "may (...) have improved the efficiency of Chinese industry through a global technique effect, with potential spillovers to other sectors, even if this trend has recently slowed." Thus, the argument of Peters and Hertwich apparently is that such effects may be strengthened by applying a consumption-based instead of a production-based policy. Note, however, that - following the arguments of the "pollution haven" literature - the introduction of a consumption-based policy should actually discourage the industry of industrialized countries from migrating to emerging economies in the first place.

Apart from these effects of a switch of the policy base on the behaviour of the private sector, Peters and Hertwich also suggest that under a consumption-based approach the governments of industrialized countries will contribute to the transfer of technology to non-abating regions. A first route for this technology transfer envisioned by the authors appears to be transfer by means of abatement projects in developing countries: They start by arguing that it makes sense for industrialized countries to abate not only in their own region: "[I]n many cases, the marginal costs of abatement are lower in non-OECD countries." Therefore it is "important that domestic environmental policy considers emissions reduction in foreign regions." But "[c]onsumption-based GHG inventories explicitly encourage emissions abatement in foreign regions due to the reallocation of imports," Peters and Hertwich $(2008 \mathrm{~b}, 59)$ write. They also mention the CDM mechanism of the Kyoto protocol, which also under the current climate policy regime provides incentives to pursue abatement projects in developing countries: "Conceptually, the CDM is naturally embedded in consumption-based GHG inventories instead of being added later as in the Kyoto protocol" (Peters and Hertwich 2008b, 59). Thus, they apparently suggest that a consumption-based policy will contribute to an increase of abatement projects in developing and emerging economies and through this channel also enhance the technology transfer to this countries.

Besides relying on such projects, additionally "it is in the best interest of governments to encourage their trading partners to invest in clean infrastructure, such as cleaner energy facilities," Peters and Hertwich $(2008 \mathrm{~b}, 59)$ reason. The authors however do not explain what they mean by the term "encourage" - is it that the domestic government should pay for such investments of their trading partners or that it should provide them with the necessary technology for free - or do Peters and Hertwich rather think of "persuasion" without any financial incentives? In any case, analysing trade between the U.S. and China, Shui and Harris (2006, 4063) suggest that the "export of US technologies and expertise relating to clean production and energy efficiency to China could be a win-win strategy for both countries": the U.S. could benefit as it improves its trade balance with China and - if a policy that mimics consumption-based accounting like the Kyoto Protocol's CDM is in place - it would also improve its emissions inventory.

If one continues along this line of thought of similarities to the CDM, then this would mean for technology transfer under consumption-based accounting that industrialized countries provide the technology for free. In return, they will be able to 
import less carbon-intensive products, which will improve their emission balance. Still, there remain doubts whether this concept will work in practice as it gives rise to a free rider problem: if one industrialized country supplies "clean" technology to "green" the exports of a trade partner, also all other countries buying goods from this trade partner could profit from being now able to buy "greener" products and thereby lowering their (consumption-based) emissions inventory. Thus, probably no country will come forward to supply the "green" technology.

This argument shows that actually the incentives for technology transfer under a consumption-based policy are a more intricate issue than apparent at first sight. In addition to the effects described by Peters and Hertwich (2008b), there appear to be other forces at work that (at least partly) have countervailing impacts. Therefore, a detailed analysis is needed before one can draw conclusions on the possible effect of a policy switch on the amount of technology transfer.

Finally, not all arguments discussed in the literature favour a consumption-based policy. Pan et al. (2008) point out an advantage of attributing emissions to producers: producers are physically in control of how emissions in production are discharged and therefore have the most information about feasible abatement. A consumer basis, on the other hand, would leave countries "with no direct control over abatement"; but "responsibility is usually best placed with the agent most able to control the outcome" (Pan et al. 2008, 371). This argument seems to apply mostly to an abatement policy that is not based on price-based incentives, but on (perhaps quite indirect) regulation or on voluntary measures. Pan et al., for example, point out that consumers would require information on the emissions embodied in imported products if they were to discriminate between foreign producers. If, on the other hand, a price-based policy system were employed, no such information would be needed - the price signal should feed through the economic system, irrespective of where in the system the policy instrument is applied.

Also, it should be mentioned that not all authors who see advantages in consumption-based emissions accounting advocate a complete switch to a consumptionbased policy. Peters et al. (2011, 5), for example, see "a need for a regular monitoring, verification, and reporting of emission transfers via international trade" - still, they argue, the territorial emissions statistics (and not consumption-based ones) "should remain central to climate policy."

\section{3 "Responsibility" for emissions and the question of justice}

Many authors comparing production-based to consumption-based emissions accounting and policy designs relying on these accounting concepts also attempt to establish which of the two concepts would be "fairer" or "more just" - or whether fairness would actually call for a combination of the two concepts. Thus the questions considered are: How should the costs (or burdens) of emission abatement be distributed between abating (typically: industrialized) and non-abating (typically: developing or emerging) economies? And when an answer to the first question is found: Which emissions accounting concept is better suited to achieve the chosen distribution of burdens? 
Sometimes, the discussion of this topic in the academic literature may appear confusing to economists - and equally to scholars working in others fields like, for example, philosophers. This seems to be due to the fact that authors from quite different academic disciplines are writing in this field, and at times they do not heed some of the principles important to authors writing in a different tradition. There are at least three such "problem zones", which shall be explained briefly at the outset:

\subsubsection{Definitions and basic concepts}

First, many authors use the phrase "responsibility for emissions" as a central term in their argument, for example when posing the question: "Is the producer or the consumer responsible for emissions?" Philosophers, however, typically point to the fact that the word responsibility has a number of completely different meanings in everyday language - and it is actually used in different senses in the discussion on GHG emissions (Steininger et al. 2012): Simplifying a bit, the question above on the responsibility for emissions can mean two completely different things: (i) did the producer or the consumer cause the emissions? - or: (ii) has the producer or the consumer the obligation to pay for the abatement of the emissions? Steininger et al. (2012) point out that one can decide to make the agent who causes emissions also pay for the abatement of the emissions - that, however, is only one of many possibilities of assigning the duty to pay. Thus, in interpreting the discussion on "responsibilities" it helps to be clear about whether the author talks about "causation" or about "obligation to pay" or whether she actually assumes that the "obligation to pay" has to coincide with causation.

Second, there is a difference between the question on whom a tax (or any other policy instrument) is levied and the incidence of the tax (or the other policy instrument): as discussed in Section 2.2.2, if the producer is taxed that does not mean that the producer is also the agent who bears the full tax burden - part or all of the tax burden may be passed on. And equally, if the consumer is taxed that does not mean that she will bear the full tax burden. Tax incidence theory tells us that a tax on a producer and a tax on a consumer actually has equal distributional consequences (in the long run, when all prices have adjusted) as long as the tax base of the two taxes is the same. Many authors writing in the tradition of the literature on emissions embodied in trade, however, never discuss the question of tax incidence. Often, it appears that it is assumed that the agent on whom the tax is levied also bears the tax burden - which, of course, is not correct in general.

Third, as Steininger et al. (2012) stress, when one uses the term policy base one can have in mind two different things - either the tax base (or more general: instrument base - in case one analyzes other policy instruments besides taxes) or the target base. As has been discussed in Section 2.2.1, switching the target base from emissions in production to emissions in consumption has quite different consequences from switching the tax base in a similar manner. Many of the proposals of the literature on emissions embodied in trade on assigning "responsibility for emissions", however, do not differentiate what they are referring to - a change of the target or a change of the tax base. Often, it seems, the authors are actually discussing a switch of just the target base 
- but they then do not analyse the second step that typically will be necessary to achieve the altered target, a corresponding change of the tax base. This omission is of relevance insofar as the change of tax base may have distributional consequences that work in exactly the opposite direction than those of the change in the target base. When reading the following literature review, keep this possible "omission" in mind - and also the two other problems stated above, i.e. that many authors do not specify what exactly they mean by "responsibility" and also do not consider the consequences of tax incidence.

\subsubsection{Attributing "responsibility for emissions" - a literature review}

Eder and Narodoslawsky $(1999,359)$ where among the first authors to employ inputoutput analysis to determine various emissions inventories for a region and then ask the question: "What environmental pressures are a region's industries responsible for?" They determine production-based and consumption-based emissions measures and various combinations thereof, but do not make specific recommendations which ones to use, except for stating that "from an idealistic point of view it is desirable that a region takes total responsibility" (Eder and Narodoslawsky 1999, 373). Such "total responsibility" would involve emissions triggered both by production and by consumption in the region itself and in the rest of the world - and would thus, if applied by all regions worldwide, involve double counting of emissions.

Kondo et al. (1998), also writing in the late 1990s, estimate emissions inventories for Japan and then suggest combining the calculated production- and consumptionmeasure to determine what they call "a more reasonable indicator than the national direct $\mathrm{CO}_{2}$ emissions" (Kondo et al. 1998, 174): the emissions that can be "attributed" to Japan or that Japan is "responsible" for (Kondo et al. 1998, 172). They suggest that such attribution should be based on the benefit principle. This is a principle from the theory of taxation that says that those who benefit most from government expenditure should pay the most taxes. Applied to emissions, the benefit principle would thus say that those who benefit from emissions should be assigned the duty to pay for their abatement. ${ }^{16}$ Kondo et al. actually calculate a measure of such "attributed emissions" for Japan. But they do not attempt to establish possible benefits - they just form a weighted average of production-based and consumption-based emissions with the weights set - without further explanation - at a value of 0.5 .

Ferng (2003) proposes relying on two principles to establish the amount of emissions a country should take the responsibility to reduce: the benefit principle and the concept of ecological deficit. The author motivates the use of the benefit principle by arguing that it "emphasizes the driving forces behind the activities that emit pollutants" (Ferng 2003, 122): production benefit manifests itself in "income generation and consumption benefit in living standards" (Ferng 2003, 124). As opposed to Kondo et al. (1998), when calculating the production-benefit of a specific country, Ferng does

16 This principle is sometimes also termed Beneficiary Pays Principle, see e.g. Steininger et al. (2012). 
not only count the emissions discharged in the territorial production of this country, but also the emissions embodied in imported intermediate products needed to produce the country's territorial production. Consumption benefit is calculated the usual way - as a country's consumption-based emission inventory. Production benefit and consumption benefit are then combined - in the form of a weighted average - to an overall emission measure reflecting the benefit principle. Ferng does not provide a rule for establishing the weights - she argues, they should be determined in international negotiations in such a way as to "reflect the differences among participant countries regarding their economic structure as well as consumption pattern and level." Also, the "basic needs for survival" should be treated "on an equal per capita basis" (Ferng 2003, 131). Then, in a further step, the capacity for emissions assimilation (e.g. the capacity of forests for carbon sequestration) of the country examined should be determined. The difference between the emissions measure according to the benefit principle and the country's capacity for assimilation is termed the country's "over-emissions" or its "ecological deficit". Ferng argues that it is this emissions measure - the "over-emissions" - a country should be responsible to reduce. She claims that this method of calculating a country's responsibility for emissions is more beneficial to developing countries, especially those with large forest areas, than the usual principle of territorial emissions accounting.

Still another method for "assigning the responsibility" for emissions is suggested by Bastianoni et al. $(2004,253)$ : they argue that a producer responsibility principle would not be fair, and that a consumer responsibility principle would not provide producing countries with enough incentives to lower their level of GHG emissions. Consequently, they suggest a principle of shared producer and consumer responsibility, which they term "Carbon Emissions Added" approach. They develop a formula which assigns to each step in the production process (or to each country in the production chain) the emissions it discharges itself plus the emissions embodied in intermediate products it uses. This emissions measure is then normalized by the total emissions of the process. Consumption is treated as the last step of the production process. In that way, producers (or countries) situated at the beginning of the value added chain are made responsible for less emissions than they actually discharge, and producers (or countries) at the end of the value added chain for more emissions.

Lenzen et al. (2007) criticize that the rules for assigning responsibility developed by Kondo et al. (1998) and Ferng (2003) involve double counting of emissions (if applied to all countries), and that the rule developed by Bastianoni et al. (2004) is not invariant to the number of individual steps, into which the production chain is divided. Therefore, Lenzen et al. devise still another method for calculating an emissions measure that attributes emissions to producers and consumers, which does not suffer from the deficiencies criticized. The authors are mainly interested in the "responsibility" of individual producers or consumer, and not in assigning "responsibility" to whole countries. They argue that an organization that controls the production process of a good to a high extent should be assigned a high share of "responsibility" for emissions and vice versa. Control or influence, they suggest, can be approximated by value added. 
They therefore devise the following formula for assigning "responsibility for emissions" to a producer who occupies one step in a longer supply chain of a product: establish the value added in the first step of production as a percentage of the value of the output of this step of production (say, 30 percent). Now use this "percentage value added measure" to split the amount of emissions discharged in this step of production (say, 100t) into two shares - one share equalling the value added measure in percentage terms (30 percent of the emissions discharged, i.e. 30t); this share is attributed to the producer operating the step of production under question. The remainder (70 percent of the emissions discharged, i.e. 70t) is "passed on" to the next step of production. For that step, again the value added in percentage terms is calculated (say, 60 percent). But now the emissions that have to be split using this value added measures do not only include the emissions discharged at this - second - step of the production chain (say, 20t), but also those that have been passed on from the first step (i.e. 70t). Thus, in our example, the emissions attributed to the second production step amount to 60 percent times the sum of $70 t$ and $20 t$, which equals $54 t$. The remainder $-36 t-$ is passed on to the next step of production, etc. With this attribution method, the emissions that are assigned to the consumer are however a kind of "leftover" quantity - as Lenzen et al. (2007, 34-35) put it, "[f]inal consumers (...) are at the end of the supply chain, and receive the remaining remainder."

Andrew and Forgie (2008) show that the approach developed by Lenzen et al. (2007) cannot only be applied to individual producers and products, but also to whole countries: They calculate a production-based, a consumption-based and - using the method of Lenzen et al. - also a "shared" emissions inventory for New Zealand. New Zealand's economy has been founded on the production and export of primary products like meat, dairy products, wool, and wood. The production of these goods discharges not so much $\mathrm{CO}_{2}$, but mostly the GHGs methane and nitrous oxide. The authors find that actually 52 percent of territorial GHG emissions are set free in the production of exports. This high share of emissions embodied in exports, Andrew and Forgie argue, might be a reason for New Zealand to advocate a consumer responsibility perspective in international negotiations - even though, as the authors state, such a perspective will not only have advantages, but also disadvantages. Actually, their argument is a good example of the difference in distributional consequences of changing the target base and changing the tax base: on the one hand, they point out that "passing on the liability to the consumer has the potential to reduce New Zealand's emissions liability" (Andrew and Forgie 2008, 202) - this point refers to the switch of the target base. But the authors continue that "[i]f such a policy resulted in higher prices (...) for goods produced in New Zealand, consumers might well move away from New Zealand products, and this would impact negatively on the economy" - this point apparently refers to other countries either taxing or restricting imports from New Zealand in other ways, i.e. a change in the tax base. Given these potential disadvantages of a "full" switch to consumption-based accounting, Andrew and Forgie suggest that the "middle way" of sharing responsibility between the producer and consumer might balance advantages and disadvantages and might therefore be an option that should be further investigated. 
Rodrigues et al. (2006) develop still another method of assigning responsibility for emissions: they take the average of an agent's consumption-based and her income-based responsibility. Thus their method actually makes use of the third option for attributing emissions mentioned in the introductory paragraphs of this chapter, the concept of "enabled emissions"; it therefore is a concept that actually goes beyond the scope of this discussion of production- and consumption-based emissions accounting. Here, it is mentioned primarily to show that authors in this field have in recent years come up with mathematically ever more sophisticated methods of splitting responsibility - with the aim of constructing rules that fulfil certain criteria: Rodrigues and Domingos (2008), for example, compare the method of Rodrigues et al. (2006) to the one of Lenzen et al. (2007) discussed above; they criticize that when following the rules devised by Lenzen et al., responsibility for emissions decreases with increasing distance in the supply chain; for example, the final consumer would be assigned a larger share of the emissions of a producer who is responsible for the last step in the production chain, say assembling the final product, than of a producer in the beginning of the production chain, say a company extracting raw materials. Rodrigues and Domingos (2008) see this as an unwanted property of the responsibility attribution rule, while Lenzen et al. (2007) constructed their rule exactly in a way to achieve such a property. This demonstrates that there is no unanimity in the field on the question of how to attribute the "responsibility for emissions" to different economic agents.

\subsubsection{Contribution of the research project "RESPONSE"}

The question whether introducing a consumption-based policy orientation would contribute to more just burden sharing in international climate policy was also analysed in the research project "RESPONSE" (of which central sections of this study have also been a part) lead by the Wegener Center for Climate and Global Change of the University of Graz. This section will briefly review the findings of the RESPONSE team, especially those of Lukas Meyer, Dominic Roser, and Luke Tomlinson, three of the philosophers on the team, who worked extensively on the topic of consumptionbased GHG accounting. Steininger et al. $(2012 ; 2014)$ discuss these research results in more detail.

First note that none of the studies reviewed above - with the exception of the more applied analysis of Andrew and Forgie (2008) - distinguishes between the point where a policy instrument is applied - e.g. for a tax, the point of revenue collection - and the incidence of the policy instrument. Thus, when these studies discuss "shared responsibility between consumers and producers", it is often not clear whether the authors intent to construct a "responsibility measure" that should only serve as a tool for providing politicians and consumers with information on the environmental impact of a firm, a region, or a country - or whether the authors also suppose that the burdens of emissions abatement should be shared according to this measure, or whether they think of applying policy instruments to both producers and consumers. At any rate, as Steininger et al. (2012) point out, as tax burdens are passed on, even if one wants to split the burden between producers and consumers, it is usually not necessary to apply the policy instrument to both of them, e.g. to tax both the producer and the consumer: 
The burden of a tax on producers will typically be borne by both producers and consumers, and equally, also the burden of a tax on consumers will typically be borne by both producers and consumers. Thus, Steininger et al. stress an important point neglected by many authors writing in the tradition of the literature on emissions embodied in trade: to assess the distributional consequences of a policy, one has to look at tax incidence (or more broadly: "policy incidence"), and not at the question who delivers the tax money to the authorities. The same reasoning also applies to the incentive effects of a policy - they are also "passed on" through the price mechanism. Thus, arguments like the one of Bastianoni et al. (2004, 255) that assigning the responsibility for GHG emissions to consumers and thus "make final users pay the GHG 'bill' (...) would lower the incentive for developing countries to create cleaner and more efficient production processes" are only valid, if one assumes that final users cannot pass on the burden of the 'GHG bill'.

Steininger et al. $(2012 ; 2014)$ also in another important way depart from the ideas expressed in many of the studies reviewed in this section: they argue that the "responsibility question" - the question whether producers or consumers have caused emissions - should be analysed separately from the "policy base question" - the question whether a tax (or other policy instrument) should be levied on the consumer or the producer. Concerning the "responsibility question", the authors use the concept of "attributive responsibility", which they define as follows: an agent is attributively responsible for emissions if she (i) chooses to (ii) bring about emissions. Point (ii) refers to causation, whereas point (i) limits causal influence to cases where it is voluntary: the agent must knowingly and avoidably cause emissions, the authors specify. One of their central arguments is that both producers and consumers are jointly responsible for emissions in the attributive sense - the consumer chooses to buy a good and thereby drives market demand, whereas it is the producer's choice to produce that good using a process that generates emissions. Further, the authors claim that it is problematic to attempt to determine relative shares of the responsibility for emissions and thus remain sceptical about approaches like those of Bastianoni et al. (2004), Rodrigues et al. (2006), or Lenzen et al. (2007). Referring to Braham and Van Hees (2009), they inter alia state that there is a fundamental theoretical difficulty in determining relative causal shares in any instance of joint causation.

Steininger et al. (2012), however, stress that the result that consumers and producers are jointly responsible for emissions is often not directly relevant for the choice of the policy base. They point out that they thus disagree with the opinion of Lenzen and Murray (2010) and Marques et al. (2012) that climate policy must understand which agent is responsible for causing emissions. They give three reasons for their argument: First, as already mentioned above, the agent who is taxed is not necessarily the one who bears the tax burden - if one wants to split the burden between producers and consumers one can therefore in many practical situations achieve this by taxing either only the producer or only the consumer. Second, there are many principles of justice that do not rely on responsibility: for example, the Ability-to-Pay principle says that nations must pay in proportion to their wealth or some other measure of capacity. If one adopts such a responsibility-insensitive justice principle, thus no 
information on the causation of emissions is required. Third, justifications for adopting responsibility-sensitive principles are not always truly concerned with responsibility. Steininger et al. give the example of the principle of Equal per Capita Emissions: one could favour this principle for pragmatic reasons, for example because it may serve as a simple focal point for negotiations, and not because one is convinced that equality in per-capita emissions is indeed just.

Of course, one may still decide that one wants to follow a responsibility-sensitive justice criterion out of genuine concern for responsibility. Then, when assessing whether a consumption- or a production-based policy is better in achieving this criterion, one should however keep in mind that one should look at the incidence of the policy, and not on the question whether the policy instrument directly applies to production or consumption. Steininger et al. give a schematic outline of how they suggest one should proceed when confronted with a practical choice between policies: First, determine the ideal burden distribution prescribed by the justice-principle favoured. Then, determine the actual burden distribution that would result from either a production- or a consumption-based policy. Here, it is important to assume politically feasible reduction targets and tax rates - which, as the authors remark, are usually not first-best from the perspective of justice. Finally, examine whether the production- or the consumption-based policy variant better resembles the ideal burden distribution.

Steininger et al. (2012) also give an example of how their recommendations for choosing the policy base could be applied. This example shall be briefly outlined here, as Chapter 11 will make use of this scenario. The authors assume that the justice principle favoured is the one enshrined in Article 3.1 of the 1992 UN Climate Convention, the principle of "common but differentiated responsibilities and respective capabilities" (CBDR). This principle has a responsibility-sensitive and a responsibilityinsensitive part (the respective capabilities). Now, if one agrees that industrialized countries currently bear too small a burden, one should choose the policy that increases the burden of industrialized countries. Steininger et al. suggest that, if one looks at the target base only, a switch to a consumption-based policy would probably increase the burden for industrialized countries. But if one also considers a switch of the tax base especially in a situation in which only the industrialized region has a tax on emissions then this result may well be reversed. Still, as the authors stress, unwanted distributional consequences of the policy shift can always be corrected through appropriate policy design: for example, the shift of the policy base could be accompanied by side payments or by adjusting the relative emissions reduction targets of individual countries in such a way as to increase the burdens for those countries that gain from the policy switch.

Summarizing, the central finding of Steininger et al. $(2012 ; 2014)$ is that even though "the debate on consumption-based versus production-based accounting (...) is accompanied by strong moral intuitions" (Steininger et al. 2014, 76), actually none of the two policies is "intrinsically" better than the other from a justice perspective: rather, one should investigate whether a policy switch shifts "burdens from those who currently bear more burdens than justice demands to those who currently bear less than what justice demands of them" (Steininger et al. 2014, 79). And if that cannot be achieved by 
the policy switch in its "pure" form, still the possibility exists to accompany the switch with appropriate side measures.

\subsection{Conclusion}

The literature on emissions embodied in trade has detected long-term trends in international emissions transfers that appear worrying from an environmental perspective. While industrialized countries have on average within the last two decades stabilized their emissions measured according to the production-based accounting principle, the production-based emissions of emerging economies are growing rapidly. These increasing emissions feed an increasing domestic consumption demand in emerging economies, but also - via international trade - a growing consumption demand from industrialized countries. A stabilization (and later reduction) of global GHG emissions will not be possible without the stabilization and later reduction of the production-based emission of emerging economies - thus achieving such a reduction must be a central aim of international climate policy. Such a reduction can however only be accomplished on a large scale if both the emissions that satisfy the domestic consumption demand of emerging economies and the emissions that satisfy the consumption demand of industrialized countries are curbed.

A switch from the current production-based unilateral climate policy of industrialized countries to a consumption-based one would bring at least that part of the emissions of emerging economies into the scope of the policy that satisfies the consumption demand of industrialized economies. Thus such a policy switch seems attractive as a first step towards the aim of stabilizing global GHG emissions. It has been recommended by some authors writing in the field of emissions embodied in trade, for example Peters and Hertwich (2006, 2008a; b). A switch to a consumption-oriented policy will however not only bring the imports of industrialized countries from emerging economies into the scope of the policy, it will also take the exports of industrialized countries to emerging economies out of the scope of the policy. As the arguments in this chapter have shown, the net effect from such a policy switch will not only depend on whether there are more emissions embodied in imports than in exports, but also on the relative effectiveness of the two policies per unit of emissions targeted: actually the product of the emissions targeted and the per unit-effectiveness of the policy must be larger for the imports of industrialized countries than for their exports in order to guarantee that a consumption-based policy indeed leads to a larger reduction in global emissions than a production based one. While the literature on emissions embodied in trade has established that for most industrialized countries the amount of emissions embodied in imports (often by far) exceeds the amount of emissions embodied in exports, this strand of literature has not investigated the relative "per-unit effectiveness" of the two policy variants. The remainder of this study will however repeatedly address this "effectiveness question". Also, the question how a switch of the policy base will affect the "diffusion" or transfer of technology will be taken up again. As this chapter has shown, a number of arguments exist that suggest that technology diffusion might be enhanced by the introduction of a consumption-based policy, but 
there are also arguments pointing into the opposite direction. Overall, the main conclusion on environmental effectiveness that can be drawn from the literature on emissions embodied in trade is quite similar to the one that emerges from the bordertax-adjustment literature: there are some quite convincing arguments that suggest that a consumption-based approach might be more effective; these arguments, however, do not apply under all circumstances - often it is the values of individual economic parameters that decide which policy variant is the more effective one. The task at hand therefore is to identify those situations where a consumption-based policy will indeed be more effective, and those where it will not. The remainder of this study aims to achieve some progress in this direction.

Besides the question of environmental effectiveness, a second major research interest in the literature on emissions embodied in trade has been the goal to devise a "fair" method of assigning what has been termed the "responsibility for emissions". Many authors argue that neither the producer nor the consumer alone can be seen as being responsible for global warming; they therefore have constructed quite complicated schemes that attempt to apportion "responsibility" between producers and consumers. The apportioning rules are based on criteria meant to determine, for example, who "causes" emissions, who "controls" processes that discharge emissions, or who "benefits" from emissions. Applying such rules may be interesting for theoretical reasons; alternatively "responsibility" measures calculated according to these rules may also be used to provide information to politicians, consumers, or the public; this study, however, remains sceptical that such "apportioning schemes" are an appropriate tool for designing practical policies. There are several reasons for this: First, as Steininger et al. (2014) have pointed out, there exist logical difficulties with some of the rules, for example with rules relying on relative causal shares in instances of joint causation. Second, other such rules appear to be tremendously difficult to practically implement - how, for example, can in a global context be accurately determined, who benefited to what extent from emissions? Third, global burden sharing is determined by tax incidence (or the "incidence" of another climate policy instrument), and tax incidence will typically not coincide with the "point of revenue collection". Determining tax incidence in a global context is a difficult econometric task, and combining it with already complex schemes of responsibility attribution will only make the practical implementation of a policy based on it even more complicated. This study - following Steininger et al. (2012; 2014) - therefore suggests keeping the GHG accounting principle used for climate policy rather simple, i.e. to rely on either "pure" production-based or "pure" consumption-based accounting - and not on some complicated scheme attemting to combine the two principles. If the desired global distribution of the burdens of the policy cannot be achieved by either of the two "pure" policies, then "side-measures" (discussed in Chapter 11) should be used to correct the distribution of burdens.

But what is the "desired distribution of burdens" that will guide the following analysis? This paper is not a study on equity, justice, or international burden-sharing rules. No attempt will therefore be made to discuss these issues in depth or to devise any new rules for international burden-sharing. Rather, a "pragmatic approach" will be 
adopted - when developing policy proposals (see Chapter 11) this study will rely on established burden-sharing principles. And in climate policy, there actually is one such widely-accepted principle that has been developed through an international political process - the UNFCCC criterion of "common but differentiated responsibilities and respective capabilities" (CBDR). Note that CBDR is much more comprehensive than the apportioning rules suggested by the literature of emissions embodied in trade: it is generally interpreted to refer not only to current, but also to historic emissions, and apart from the "responsibility" part, it also has a part that refers to the capabilities of individual countries: richer countries shall bear a larger part of the abatement burden, and developing countries shall not be denied growth and poverty eradication (Stern, 2007).

Of course, CBDR is a general principle and does not provide us with an exact formula that assigns burdens to individual countries. For the purpose of this study, employing such a general principle will however suffice. The IPCC $(2007,776)$ argues that industrialized countries should reduce their emissions between 25 and 40 percent until 2020 to limit global warming to the internationally agreed value of $2^{\circ} \mathrm{C}$. Current mitigation pledges fall short of this goal (UNFCCC 2011a; b). Following Steininger et al. (2014), this study therefore assumes that industrialized countries currently bear a smaller burden then required by the principle of CBDR. When assessing policies, a policy that increases the (relative) burden borne by industrialized countries is therefore seen as promoting justice. 
PART II

Theoretical

Analysis 



\section{CHAPTER 7}

\section{Evaluating a Shift to a Consumption-Based Climate Policy - Objectives and Analytical Tools}

This and the following two chapters make up the main analytical part of this study. A production-based policy will be compared to a consumption-based one and assessed according to various criteria: Mostly, as set out in the introduction, this study will concentrate on the criteria of environmental effectiveness and cost-effectiveness, but also the widely-used criterion of carbon leakage and sometimes the politically important criterion of competitiveness will be discussed, and the distributional consequences of switching the policy base will be determined. The discussion will be organized along the four "leakage channels" introduced in Section 4.2 As was argued in that section, these channels also more generally can be seen as transmission channels of the effects of climate policy and are therefore well suited as a structuring tool. Policy transmission in non-energy markets (the "competitiveness channel") and in energy markets (the "fuel market or energy market channel") will be examined by means of an analytical partial equilibrium (PE) model. Policy transmission through income effects (the "income leakage channel") or through technological spillovers, however, does not lend itself to a representation in a simple PE setting - these two channels will therefore be discussed without resorting to a formal presentation. Before starting the detailed analysis, in this chapter first the objectives of the policy comparison are defined, and then the "tool" employed in the analysis of the first two channels is introduced - the analytical PE model just mentioned, a model that comprises two regions and that depicts four regionspecific final goods markets and a global market for fossil fuel. Chapter 8 then uses this model to compare the effects of policy transmission via non-energy markets. Chapter 9 brings in the other three policy transmission channels - the energy market-, the income-, and the technological-spillover-channel. Furthermore, that chapter discusses what will change if we broaden our analysis from a partial-equilibrium to a general-equilibrium setting; and finally, it summarizes the main results of the policy-comparison and asks what these results imply for real-world policy making.

\subsection{Objectives of the theoretical analysis}

The theoretical general equilibrium models discussed in Section 4.1 tell us that the optimal unilateral policy to correct a global externality is in general neither a policy with just production nor one with just consumption as its base, but a policy combining the two approaches. But if we have to confine our choice to introducing either one of the two policies in its "pure" form, this strand of literature does not give us an advice of the kind that one of the two policies would always be the preferred choice. The quantitative border-tax literature discussed in Section 5.2 provides us with many 
examples where the introduction of border measures (that partly achieve a switch to a consumption-orientation of the policy) at least to a certain extent improves the environmental effectiveness of the policy, but there are also examples, where the border measures have little effect, and even some studies showing that border measures lower the environmental effectiveness of the policy. Finally, the literature on emissions embodied in trade produces some quite convincing arguments supporting the view that consumption-based policy approaches are environmentally more effective (see Section 6.2), but our discussion of these arguments has shown that they do not hold under all circumstances. Thus, at least three different strands of literature point to the same conclusion - it is not possible to decide whether a production- or a consumptionoriented policy is more effective in general. Rather, the ranking of the policies in terms of environmental effectiveness depends on the exact design of the policy instruments analyzed, the parameter values assumed, and the specific global policy setting - as for example the question how many countries participate in the abatement policy. Given this observation, this study aims to achieve progress on the question which climate policy setting, which policy design details, and which parameter values make a consumption-based policy the environmental more effective choice (or the more costeffective choice) - and which rather favor the production-based policy variant.

\subsubsection{Analytical approach}

Although so far there do not exist any analytical studies that explicitly examine "consumption-based GHG abatement policy approaches" as such, there are, as we have seen in Chapters 4 to 6 , many studies on related subjects that try to answer questions that are similar to those posed in the previous paragraph. Thus it is necessary to clarify in which way this analysis differs from such related studies.

First, as opposed to much of the CGE literature, this study does not aim to produce precise quantitative estimates of the values certain variables take under specific assumptions. It is rather interested in understanding the basic mechanisms at work in that field of economics. Thus the choice was made to use an analytical, and not a quantitative model as the "tool" for the analysis; a model with only few sectors that depicts economic interdependencies in a rather "stylized" fashion. This simplicity should permit us to gain a clearer view of the main "economic forces" at work, a view not clouded by looking at too many simultaneous effects at the same time.

Second, it had to be decided whether to employ a general or a partial equilibrium model. General equilibrium (GE) models - even simple ones such as some of those discussed in Section 4.1 - depict a number of relationships not present in a partial equilibrium setting: factor supply is limited and therefore factor prices change when demand for factors changes; consumers have budget constraints - therefore price changes also lead to income effects; and there are typically other restrictions imposed such as a zero (or constant) trade surplus/deficit across policy variants. While all of these are desirable characteristics, often - to remain tractable - GE models have a very simple structure as regards their other features. For example, the GE models discussed in Section 4.1 do not comprise a separate fossil fuel market. But, as we know from the quantitative leakage literature, effects that run through the fuel market are often decisive 
for the outcome of an analysis of climate policy. Also, at least in GE models of the Heckscher-Ohlin-Samuelson type, domestic and foreign goods are perfect substitutes. This characteristic however does not allow for a realistic analysis of leakage through the competitiveness channel. In a partial equilibrium analysis, on the other hand, it is easier to model less than perfect substitutability between domestic and foreign goods and to include a separate global fossil fuel market without making the model overly complicated. In this study, therefore a partial equilibrium model is employed. Of course, this approach has all the typical limitations of a PE analysis. But the decision to use a specific model always constitutes a compromise - for the questions of this study the advantages of a PE approach appear to outnumber its disadvantages.

Basically, there are two ways to interpret a PE analysis: it can either (a) represent one individual economic sector - this, for example, is the interpretation adopted by Fischer and Fox (2012), see the discussion of their climate policy model in Section 4.2 or (b) a partial equilibrium model can be seen as a simplified representation of the economy of a whole country or region - Gros (2009), for example, interprets his analysis in this way, see Section 4.1. Of course, (b) is the more problematic approach ignoring income effects or factor price changes will not have too big consequences when just one sector that is small compared to the overall economy is examined. But for an economy as a whole those effects matter and one should thus keep in mind that the results obtained will not always correspond to those of a GE analysis. In the course of the following chapters, both interpretations (a) and (b) will be employed.

Environmental policy in this study will be modeled by the imposition of an emission tax. The different policy variants examined - the production and the consumption-based approach - differ in their tax base (see Chapter 2). Note that, on the other hand, within the framework of the model of this study it is irrelevant where the tax is collected: from the producer, from the consumer, or at the border. As the prices in our model are flexible, the tax burden will be passed on in each of these three cases in exactly the same way. Thus, in our model, it is also irrelevant whether one thinks of the policy being introduced by means of border adjustment measures or by any other scheme of taxation. To give an example, it will be important whether imports are taxed or not (this question relates to the tax base), but it will not be relevant where they are taxed - in the country where they are produced, in the country where they are consumed or at the border (this question only relates to the point of tax revenue collection). In the following, sometimes the terminology of the border tax literature - expressions such as "import tariffs" and "export rebates" - will be used. But this is done only for ease of exposition and in order to allow comparisons to the findings of the border tax literature. It does not imply that the results obtained in the model-based part of this study in any way rely on the use of border measures - any scheme of taxation that applies the same tax base will give the same results.

The PE model developed for this study has two features that distinguishes it from models used in other studies and that shall therefore be briefly explained here. First, as already mentioned, it includes not only final goods markets, but also a global fossil fuel market. Thus the model will allow an examination of the interrelationship between 
effects in the two types of markets - and of the question how a switch to a consumptionbased policy affects policy transmission through the energy market. To the best of the knowledge of the author, currently no studies on climate policy exist that combine goods and fuel markets in this way in a single stylized analytical model. The CGE literature sometimes comments on the effect (or rather: non-effect) of the introduction of border measures on leakage through the energy-market channel - Boeters and Bollen (2012, S181), as mentioned, for example state that "[t]his second channel of leakage cannot systematically be influenced by border measures." But apart from such general statements, no detailed analysis of the impact of a switch to a consumption-orientation on the effectiveness of a policy with the inclusion of energy markets has been conducted. The model developed for this study will allow for such an analysis in a simple, stylized setting and will therefore make it possible to examine whether a switch of the policy-base indeed has no effect through the fuel market.

The second feature of the model that distinguishes it from the approach of other studies is the way the response to the policy by producers in the non-policy region is modeled. As pointed out by Winchester (2011) - see the discussion in Section 5.2.2 many CGE studies treat the import border tariff as if it were not an emission, but an output tax on the exports of the non-policy region (which are the imports of the policy region). Thus, such studies foresee only one possible reaction to the imposition of the tax - a scale-back of these imports. As has already been mentioned in Section 4.3 and will be discussed in more detail in Section 9.4, such a scale-back will not only have undesired distributional consequences for developing countries, it may also hamper environmental effectiveness. Therefore it is important to investigate which alternatives exist to curbing the imports from developing and emerging economies by means of a border import tariff. One such alternative is that producers in the non-policy region, instead of reducing their export production, "green" their production technology - and in that way reduce their tax dues, i.e. not the "scale" of export production, but the "technique" is changed. The model of this study allows for this effect - in the standard scenario the tax imposed is a true emissions tax, and not an export (or import) tax. The producers can react to this tax by changing their input mix - they will use less of the input causing emissions, fossil fuel. This is a simple way to represent the adoption of a cleaner "technology". (Though purists may refrain from terming this the "adoption of a different technology" - actually producers still make use of the same production function, just the point they choose on this function will be a different one.) As discussed in Section 5.2.2, whether producers see the tax as an output tax or an emissions tax will primarily depend on the details of the design of the border measures - for example, on the question how often the embodied carbon measure is updated. With the model of this study the two options can be compared - besides using the "standard" option of a "true" emissions tax one can also analyze what would change if the tax were regarded as an output tax.

A further question that had to be decided in designing the model was whether producers should be allowed to differentiate the production technique across destination markets, i.e. whether it should be possible to produce the export good using an input mix different from that used for producing the goods for domestic consumption. This is 
the option Winchester $(2011,2)$ terms "operating separate production lines for different markets." For this study, this option was adopted. Thus, if a tax on imports from the non-policy region is introduced, only the input mix in the production of these imports will change, but not the input mix in the production of domestically consumed goods in the non-policy region. This option seems to better reflect real-world circumstances than the alternative - allowing for only one production technology (i.e. input mix) in each sector of the non-policy region, no matter whether the good is exported or sold on the home market. Note that for example in China export volumes in recent years accounted for roughly 40 percent of GDP (Pan et al. 2008, 355) and that many factories exist that specialize in export production. Therefore, it does not seem unreasonable to assume that such factories can adopt different production technologies.

The model will be used to analyze policy transmission through the two channels that figure most prominently in the leakage and border-adjustment literature, the competitiveness and the energy market channel. As mentioned above, the other two leakage channels would have been difficult to represent in a partial equilibrium setting; they will therefore be discussed without the use of formal methods.

\subsubsection{Coalition size, parameters, tax design - which factors are decisive?}

As stated in the introductory paragraph of Section 7.1, the main objective of this study is to determine the circumstances under which a consumption-oriented policy would be the environmentally more effective one. The discussion of the quantitative border-tax literature in Section 5.2 has shown that there are actually many factors that influence the relative environmental effectiveness of the two policy variants under question. Not all of these factors will be analyzed here - the research "tool" chosen, the analytical PE model, only permits the examination of certain questions. For example, think of the question whether the inclusion of indirect emissions matters when calculating the carbon content on which the border measures are based. This question cannot be analyzed by the model of this study as there are no intermediate sectors discharging emissions in the model. The same applies to the question whether it suffices to tax carbon-intensive sectors, or whether all sectors should be taxed: the model does not differentiate between sectors according to their carbon-intensity. But for the examination of the influence of a number of other factors the model is well-suited. These factors will be grouped under three headings - the global policy setting, border adjustment design, and technological and demand parameters.

In the analytical part of this study, the global policy setting will be varied only along one dimension, the

- (relative) size of the abating coalition. Coalition size is represented by the value of the output of the coalition (the policy region) compared to the value of global output (i.e. output of the policy region plus the non-policy region).

The options for border adjustment design that will be compared are the following:

- Will adjustments be applied only to imports or both to imports and exports?

- Is the border tax a "true" emission tax - or rather a tax on output exported? 
- Is the border tax based on the true carbon content of the taxed good - or rather on the carbon content of similar goods produced in the policy region?

Finally, also the influence of the following characteristics - described by technological and demand parameters - on the relative effectiveness of the two policies will be examined:

- the "ease" of substituting between different inputs - described by the elasticity of substitution;

- the amount of emissions discharged - described either in absolute figures, or by the emissions rate (i.e. relative to the level of output), or by the emissions intensity (i.e. relative to the value of output), or by the cost share of fossil fuel in production (if additionally the fuel price is factored in);

- the "ease" of substituting domestically produced for foreign produced goods described by the cross-price elasticities of demand for domestic and foreign goods;

- the price-sensitivity of the good examined - described by the own-price elasticity of demand; and

- the question, to which extent global fuel supply can be increased without large extra costs - described by the price elasticity of fuel supply.

In Chapters 8 and 9 the influence of all these factors on the environmental effectiveness (and partly also on the cost-effectiveness) of different variants of climate policy will be assessed. First however, in the remainder of this chapter, the model employed for this analysis will be introduced.

\subsection{Partial equilibrium climate policy model}

The model makes use of the two-region framework introduced in Chapter 2. To keep the analysis as simple as possible, no intermediate but only final goods are manufactured and traded - thus the "simplified setting" for this two-region framework introduced in Section 2.4 applies. Parts of the structure of the model are inspired by the Fischer-and-Fox (2012) model discussed in Sections 4.2 and 5.2.1. That model has, however, been adapted and supplemented to permit an analysis of producer responses induced by climate policy also in the non-policy region. Furthermore, an additional market is included and linked to the goods markets - a global market for (one aggregate type of) fossil fuel. All in all, five markets are represented: in addition to the fossil fuel market there are two final goods markets in each of the two regions. In contrast to some of the models discussed in Section 4.1, the production and demand functions for the final goods are parameterized - though in a fairly general fashion. To start with, supply and demand for these final goods will be described.

\subsubsection{Production}

Home produces goods that can either be consumed domestically (in that case they are denoted by $H$ as in Section 2.1.1) or exported (in that case they are denoted by $X$ ). It is 
assumed that from the viewpoint of the consumer $H$ and $X$ are identical. But producers can - as in the study by Winchester $(2011,6)$ - operate "different production lines for goods shipped to different markets", i.e. for $H$ and $X$. Like in Winchester's study, it will be assumed that in each of these production lines a different input mix may be used. More precisely, the form of the production function will be the same for $H$ and $X$ - we will employ a constant-elasticity-of-substitution (CES) production function with constant returns to scale. But the point chosen on this production function (indicating the input mix) may differ. ${ }^{17}$ In this way, as discussed in Section 7.1.1, our model gives producers the possibility to react rationally to unequal taxation of emissions discharged in the production of exports and those discharged when producing goods for the domestic market: they will emit less in the production of those goods that are more heavily taxed. ${ }^{18}$

The standard interpretation of a production function is to think of it as representing literally just one technology with smooth input substitution possibilities. Here, however, a second - probably more realistic interpretation - will be adopted: the production function is seen as a smooth approximation of a set of distinct technologies using different input combinations. Thus, with this interpretation, a change of the input mix at the same time constitutes a switch to a different technology; and the "ease" of adopting a different technology is specified by the elasticity of substitution of the production function. ${ }^{19}$ Thereby, the choice between different technologies can be represented in a very simple and convenient way.

In the following analysis, the output of the "two production lines" will be referred to as " $\operatorname{good} H$ " and "good $X$ "; one should however keep in mind that the difference between these two "goods" only relates to the market where they are sold (Home or Foreign) and possibly to the input mix used in their production, but not to their technological characteristics.

The CES technology just mentioned - or more accurately: the set of technologies will be employed to produce both $H$ and $X$. The inputs into production are fossil fuel (quantity $E_{H}$ for good $H$ and $E_{X}$ for good $X$ ) as well as a second input $K$ (which can be thought of as a composite of all other inputs required for production). As discussed

17 To allow an analysis of differential taxation this study thus - like the study of Winchester (2011) diverges from an assumption very common in many models that do not focus on the effects of differential taxation - the assumption that goods sharing the same characteristics are always produced using an identical input mix.

18 As a practical example, think of a producer who uses old factories (employing "dirty" technology) to produce for the export market, but new factories (employing "clean" technology) for producing for the home market, when confronted with a policy that taxes emissions from production for domestic consumption only.

${ }^{19}$ For an example where a CES production function is used to describe both substitution between factors for a given technology and switching between technologies (and even the development of new technologies), see Gerlagh and Kuik (2007). 
above, the input mix in the production of $H$ and $X$ may differ; we therefore need to specify the production function for each of the two goods separately:

$$
\begin{gathered}
H\left(E_{H}, K_{H}\right)=\gamma_{1}\left[\alpha_{1} E_{H}^{\rho_{1}}+\left(1-\alpha_{1}\right) K_{H}{ }^{\rho_{1}}\right]^{\frac{1}{\rho_{1}}} \text { and } \\
X\left(E_{X}, K_{X}\right)=\gamma_{1}\left[\alpha_{1} E_{X}^{\rho_{1}}+\left(1-\alpha_{1}\right) K_{X}^{\rho_{1}}\right]^{\frac{1}{\rho_{1}}}, \\
\text { where } \rho_{1}=\frac{\sigma_{1}-1}{\sigma_{1}} .
\end{gathered}
$$

Both production functions are standard CES functions: $\gamma_{1}>0$ is an efficiency parameter, $0<\alpha_{1}<1$ is a distribution parameter, $\sigma_{1}>0$ is the elasticity of substitution, and $\rho_{1}$ is an auxiliary parameter determined by $\sigma_{1}$. The subscript 1 - as in Chapter 2 - signifies that all parameters relate to region Home. One can interpret $H$ and $X$ either as the output of one economic sector (say, the steel industry or the cement industry), or, alternatively, one can see $H$ and $X$ as a stylized representation of the composite output of all sectors of the economy that use (a non-negligible amount of) fossil fuel as an input. Both of these interpretations will be applied in the course of the following analysis.

Next, consider the inputs into production and their prices: It is assumed that the price of input $K$ in Home, $p_{K, 1}>0$, is constant; the analysis focuses on the effects of changes in the price of the other input, fossil fuel. ${ }^{20}$ The market price of fossil fuel is $p_{E}$. Here, no subscript denoting the region is needed as fossil fuel is globally traded and its price is the same in Home and in Foreign. Burning one physical unit of fossil fuel sets free one unit of $\mathrm{CO}_{2}$ emissions. It is assumed that there are no other emissions generated in production (i.e. there are no process emissions); $E_{H}$ and $E_{X}$ therefore also give the overall amount of emissions discharged in production.

The government follows a climate policy by imposing a specific tax $t$ on each unit of emissions. So $t$ is what is usually referred to as the carbon price. But as emissions equal fuel input, $t$ is also equivalent to an input tax on fossil fuel. For the producer the price of using one unit of fossil fuel thus equals the sum of the market price of fossil fuel and the tax, $p_{E}+t$. This sum will be termed the "gross price of fuel".

${ }^{20}$ The partial equilibrium assumption of constant prices for all factors (except fossil fuel) will typically be unproblematic if we study just a single economic sector. If $H$ and $X$ are however interpreted to encompass all sectors using fossil fuel (and thus causing $\mathrm{CO}_{2}$ emissions), these sectors will comprise a substantial share of the overall economy. Thus, the assumption that changes in the output of $H$ and $X$ will have no effect on factor prices will not hold in a strict sense. In that case, one should see partial equilibrium results only as an approximation to the relationships that characterize more complex models. 
Depending on the input prices $\left(p_{E}+t\right)$ and $p_{K}$, producers choose their optimal input mix. This optimal input choice is reflected in the unit cost functions (which can be derived from the production functions). If the tax on emissions is the same for goods $H$ and $X$, the optimal input mix in the production of both goods will also be the same; and therefore the unit costs $c_{H}$ for $H$ and $c_{X}$ for $X$ will be equal. The situation changes, if, for example, only emissions discharged in the production of good $H$ are taxed, but not emissions in the production of good $X$. Then, the optimal input mix in the production of $H$ and $X$ and hence also the unit costs $c_{H}$ and $c_{X}$ will be different. In such a case with a tax only on emissions set free in the production of $H$, unit costs are given by

$$
\begin{aligned}
& c_{H}\left(p_{E}+t, p_{K, 1}\right)=\frac{1}{\gamma_{1}}\left[\alpha_{1}^{\sigma_{1}}\left(p_{E}+t\right)^{1-\sigma_{1}}+\left(1-\alpha_{1}\right)^{\sigma_{1}} p_{K, 1}{ }^{1-\sigma_{1}}\right]^{\frac{1}{1-\sigma_{1}}} \text { and } \\
& c_{X}\left(p_{E}, p_{K, 1}\right)=\frac{1}{\gamma_{1}}\left[\alpha_{1}{ }^{\sigma_{1}} p_{E}{ }^{1-\sigma_{1}}+\left(1-\alpha_{1}\right)^{\sigma_{1}} p_{K, 1}{ }^{1-\sigma_{1}}\right]^{\frac{1}{1-\sigma_{1}}} .
\end{aligned}
$$

Region Foreign produces the goods $F$ and $M$, also employing a CES technology with constant returns to scale in the production of both goods. The technology may, however, differ from the one used in Home; it is characterized by the parameters $\alpha_{2}, \gamma_{2}$, $\rho_{2}$, and $\sigma_{2}$. Also, the input price $p_{K, 2}$ may be different from $p_{K, 1}$ (but the fuel price $p_{E}$ is the same in both regions). The unit cost functions $c_{F}$ and $c_{M}$ can be derived in a similar way as in Home.

\subsubsection{Emissions}

From the cost functions for of each of the goods the conditional input demand for fuel (which equals the "demand" for discharging carbon emissions) can be calculated. For good $H$ it is given by

$$
E_{H}=H \underbrace{\gamma_{1}{ }^{\sigma_{1}-1}\left(\frac{\alpha_{1} c_{H}}{p_{E}+t}\right)^{\sigma_{1}}}_{e_{H}}=H e_{H}
$$

$e_{H}$ is the emissions rate, the "physical counterpart" to the emissions intensity. It gives the amount of emissions discharged in the production of one physical unit of good $H$. Substituting for unit costs in (7.3) yields

$$
E_{H}=H \alpha_{1}{ }^{\sigma_{1}} \frac{1}{\gamma_{1}}\left(p_{E}+t\right)^{-\sigma_{1}}\left[\alpha_{1}^{\sigma_{1}}\left(p_{E}+t\right)^{1-\sigma_{1}}+\left(1-\alpha_{1}\right)^{\sigma_{1}} p_{K, 1}^{1-\sigma_{1}}\right]^{\frac{\sigma_{1}}{1-\sigma_{1}}}
$$


For the other goods, the conditional demand for fuel can be calculated in a similar fashion. Global fuel demand $E$ - and thus the global emissions linked to it - is given by the sum of the fuel demand for the production of the individual goods:

$$
E=E_{H}+E_{X}+E_{M}+E_{F}=H e_{H}+X e_{X}+M e_{M}+F e_{F} .
$$

\subsubsection{Demand and goods market equilibrium}

Each region has a representative consumer. The representative consumer in Home demands goods $H$ and $M$, the one in Foreign goods $X$ and $F$. The demand for each of the four goods is a function of the price of the respective good and the price of the competing good in the same region. For example, demand $h$ for good $H$ is a function $h\left(p_{H}, p_{M}\right) \cdot p_{H}$ is the price of $H$, and $p_{M}$ is the price of $M$. For all goods, constant elasticity of demand functions are assumed:

$$
\begin{aligned}
& h\left(p_{H}, p_{M}\right)=\beta_{h} p_{H}^{\eta_{h H}} p_{M}^{\eta_{h M}}, \quad \text { with } \eta^{h H}=\frac{\partial h}{\partial p_{H}} \frac{p_{H}}{h} \text { and } \eta^{h M}=\frac{\partial h}{\partial p_{M}} \frac{p_{M}}{h} \\
& m\left(p_{H}, p_{M}\right)=\beta_{m} p_{H}^{\eta_{m H}} p_{M}^{\eta_{m M}}, \quad \text { with } \eta^{m H}=\frac{\partial m}{\partial p_{H}} \frac{p_{H}}{m} \text { and } \eta^{m M}=\frac{\partial m}{\partial p_{M}} \frac{p_{M}}{m} \\
& x\left(p_{X}, p_{F}\right)=\beta_{x} p_{X}^{\eta_{x X}} p_{F}^{\eta_{x F}}, \quad \text { with } \eta^{x X}=\frac{\partial x}{\partial p_{X}} \frac{p_{X}}{x} \quad \text { and } \eta^{x F}=\frac{\partial x}{\partial p_{F}} \frac{p_{F}}{x} \\
& f\left(p_{X}, p_{F}\right)=\beta_{f} p_{X}^{\eta_{f X}} p_{F}^{\eta_{f F}}, \quad \text { with } \eta^{f X}=\frac{\partial f}{\partial p_{X}} \frac{p_{X}}{f} \quad \text { and } \eta^{f F}=\frac{\partial f}{\partial p_{F}} \frac{p_{F}}{f}
\end{aligned}
$$

The parameters $\beta_{h}, \beta_{m}, \beta_{x}$, and $\beta_{f}$ are positive. Own-price elasticities are negative, while cross-price elasticities are positive. Thus, the competing goods in each region are gross substitutes. Note that thus - unlike in standard two-good trade models like the Heckscher-Ohlin-Samuelson model - Home and Foreign do not produce the "same" good, i.e. goods that are perfect substitutes. The setting of our model rather resembles the one of the typical CGE model used to analyze climate politics - only that in CGE models the assumption of less than perfect substitutability between domestic and imported products is usually implemented not by directly specifying demand functions for foreign goods, but with the help of Armington (1969) elasticities.

In market equilibrium, $H=h, M=m, X=x$, and $F=f$. Producers face perfect competition; prices will therefore equal the (constant) marginal costs of production, i.e. $p_{H}=c_{H}, p_{M}=c_{M}, p_{X}=c_{X}$, and $p_{F}=c_{F}$. Consider, for example, good $H$ : 


$$
\begin{aligned}
H=h\left(p_{H}, p_{M}\right)=\beta_{h} p_{H}^{\eta_{h H}} p_{M}^{\eta_{h M}}= \\
=\beta_{h}\left(\frac{1}{\gamma_{1}}\right)^{\eta_{h H}}\left(\frac{1}{\gamma_{2}}\right)^{\eta_{h M}}\left[\alpha_{1}^{\sigma_{1}}\left(p_{E}+t\right)^{1-\sigma_{1}}+\left(1-\alpha_{1}\right)^{\sigma_{1}} p_{K, 1}{ }^{1-\sigma_{1}}\right]^{\frac{\eta_{h H}}{1-\sigma_{1}}} \\
\\
{\left[\left(\alpha_{2}\right)^{\sigma_{2}}\left(p_{E}+t\right)^{1-\sigma_{2}}+\left(1-\alpha_{2}\right)^{\sigma_{2}}\left(p_{K, 2}\right)^{1-\sigma_{2}}\right]^{\frac{\eta_{h M}}{1-\sigma_{2}}} . }
\end{aligned}
$$

Supply and demand for the other goods can be derived in a similar way. By plugging (7.7) into (7.4), fuel demand (and the emissions linked to it) for good $H$ can be calculated; and by substituting the result - and analogous results calculated for the other goods - into (7.5), world fuel demand (and thus global emissions) can be obtained.

The part of our model that comprises the markets for the four final goods $H, X, M$, and $F$ has thus been fully specified. The relationship between the parameters and variables is depicted in Figure 7.1. For the moment, assume that the fuel price, $p_{E}$, is exogenously fixed. Then, only the relationships represented by blue arrows are "active": The emissions tax and the fuel price determine emission rates and (unit) production costs. Production costs determine the goods prices. Demand then determines the quantities of the goods produced, and these, along with emissions rates, determine total fuel demand (and the emissions linked to it). Note in particular that the goods prices can be established without knowing the demand functions. This is a consequence of the assumption of constant returns to scale. As we will see in the following chapter, this property of the model greatly simplifies the mathematics required for conducting policy experiments.

The fifth market of our model, the global market for fossil fuel (and thus the relationships depicted by red arrows in Figure 7.1), will only be introduced in Chapter 9. 


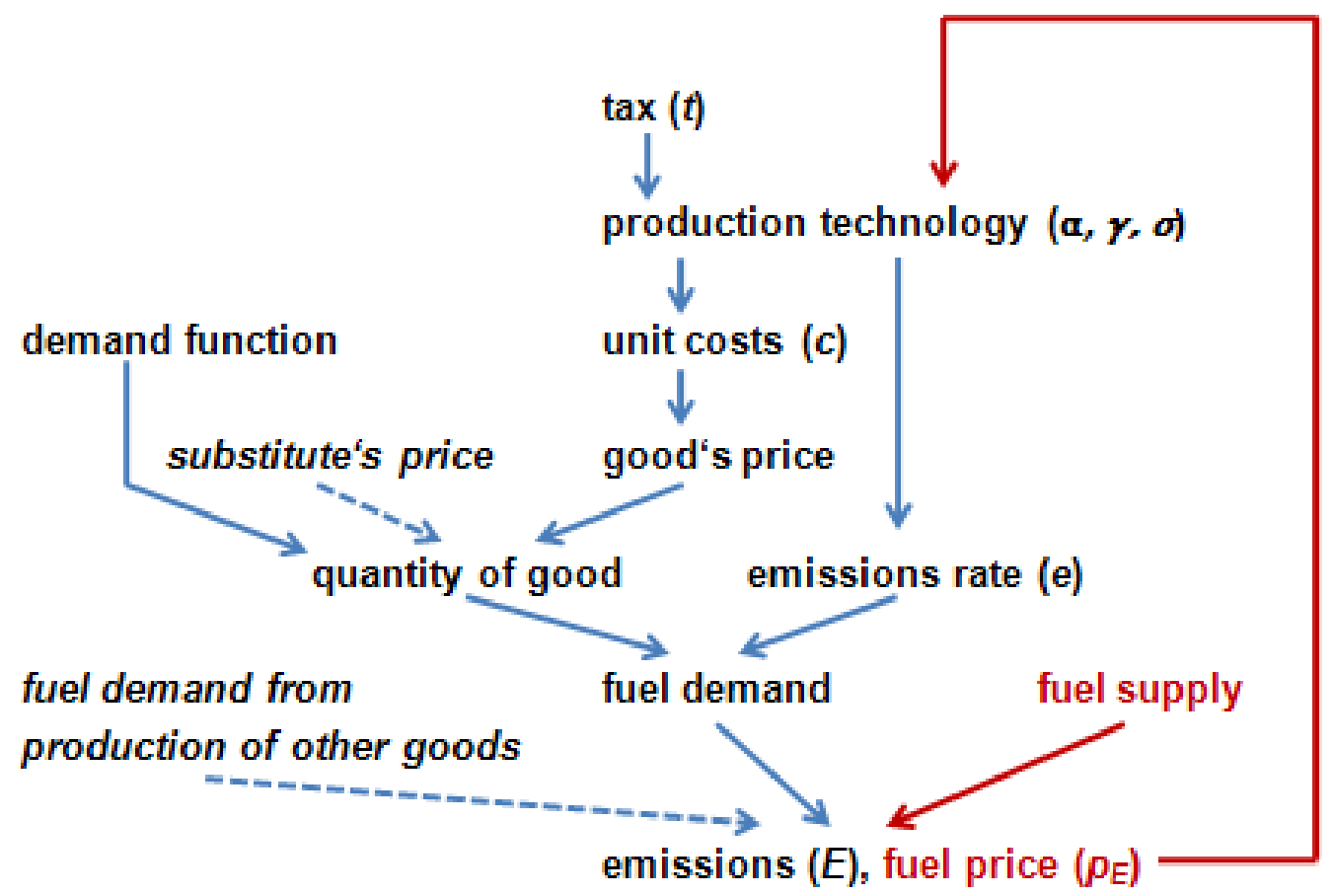

Figure 7.1 Structure of the model

Having determined the prices of the four final goods, one can define another useful measure: the emissions intensity in the production of these goods, i.e. the amount of emissions discharged per value unit of the good. It will be denoted by $i$. For example, for good $H$ the corresponding emissions intensity $i_{H}$ is given by

$$
i_{H}=\frac{E_{H}}{H p_{H}}=\frac{e_{H}}{p_{H}}=\frac{e_{H}}{c_{H}}
$$

The last term in Equation (7.8) follows from the equality of goods prices and unit costs of production. 


\section{CHAPTER 8}

\section{Effects of Policy Transmission via Non-Energy Markets}

This chapter will employ the partial equilibrium model introduced in Section 7.2 to examine the first of the four transmission mechanisms for climate policies introduced in Chapter 4, the transmission channel that works through price changes in non-energy markets. As argued in Chapter 7, the model developed for this study is constructed such that it permits the simultaneous analysis of two transmissions channels - the non-energy market and the energy market channel. Thus, in order to focus on just one of these channels, the other one should be "switched off". In a strict sense, this is not really possible in our model: fossil fuel serves as an input into the production of final "nonenergy market" goods; the two climate policy transmissions channels are therefore intertwined and actually cannot be studied in complete isolation. But it is possible to at least "switch off" effects that stem from the supply side of the fuel market. This approach will be chosen here: it is assumed that the market price for fossil fuel $p_{E}$ remains fixed and thus the amount of fuel used (which equals the amount of emissions discharged) will be determined solely by fuel demand. In terms of Figure 7.1, only the relationships depicted by blue arrows are assumed to be active. Such a setting is actually often employed in the CGE literature on carbon leakage - it allows examining the competitiveness leakage channel alone as by keeping the energy price constant one excludes energy market leakage effects.

In the following, region Home will always be the policy region. It comprises industrialized countries, while region Foreign consists of developing and emerging economies. It is also assumed - in a stylized representation of current circumstances, see Chapter 6 - that the emissions intensity in Home (by far) exceeds the emissions intensity in Foreign. Home implements a climate policy by levying a carbon tax. Thus, the carbon price (the tax) is exogenous and emissions will adjust endogenously. ${ }^{21}$ Three types of policies will be compared: a production-based policy, i.e. a policy that targets emissions discharged in the production of goods $H$ and $X$; a consumption-based policy, i.e. a policy that targets emissions discharged in the production of goods $H$ and $M$; and finally a policy that complements a production-based policy with a border import tax, but not an export rebate, i.e. a policy that targets emissions discharged in the production

21 Alternatively, one could model a cap-and-trade system, where emission quantities are fixed and the carbon price adjusts endogenously. However, in order to keep the model as simple as possible, this alternative will not be pursued here. 
of goods $H, X$, and $M$. As argued in Chapter 3, such a policy - if implemented by means of border measures - might stand greater chances to comply with WTO law than a "full" consumption-based policy. Also, such an "import-tax-only" policy has the appeal that it includes a greater share of global emissions within the scope of the policy than a "pure" production- or consumption-based policy. The three types of policies will be compared for two different scenarios: either (a) the reduction of emissions directly targeted by the policy (i.e. emissions that are part of the tax-base) is the same for the policies being compared, or (b) the carbon price for the policies being compared is the same. Results will be derived for the following criteria: environmental effectiveness (i.e. the reduction of global emissions, see Chapter 2), carbon leakage, competitiveness (measured by the change in net exports, see Chapter 2), and a simple measure of costeffectiveness. Also, the distributional consequences of switching from one policy to the other will be discussed.

\subsection{Policy effects for a single sector}

First, consider the effects of the tax on the emissions discharged in the production of a single good, say good $H$. As the fuel price is fixed, the supply side of the fuel market can be disregarded: fuel use and the emissions linked to it are given directly by the demand relationships (7.3) and (7.4). The effects of the tax will be studied by means of comparative static derivatives. Starting from the equation $E_{H}=H e_{H}$, one obtains ${ }^{22}$

$$
\frac{\partial E_{H}}{\partial t}=\frac{\partial H}{\partial t} e_{H}+H \frac{\partial e_{H}}{\partial t}
$$

As can be seen from (8.1), the tax affects emissions in two ways: first, demand for good $H$ (and thus also supply) may change, and secondly, the emissions rate $e_{H}$ in the production of $H$ may change.

The effect on demand and supply can be calculated by differentiating (7.7) with respect to $t$. Assume for the moment that emissions both in the production of $H$ and of the competing good $M$ are taxed:

$$
\frac{\partial H}{\partial t}=H\left(\eta_{h H} \frac{e_{H}}{c_{H}}+\eta_{h M} \frac{e_{M}}{c_{M}}\right)=H(\underbrace{\eta_{h H} i_{H}}_{<0}+\underbrace{\eta_{h M} i_{M}}_{>0}) .
$$

\footnotetext{
22 In this chapter, $H, E_{H}$, and $e_{H}$ are functions of just one variable, $t$. Nonetheless, the symbol $\partial$ is used instead of $d$ to denote the derivatives, as a second variable, $p_{E}$, will be introduced in Chapter 9. For now, however, $p_{E}$, remains fixed.
} 
As can be seen from the terms in parenthesis, two effects opposing each other influence demand (and production) of $H$ : one effect that works through the own-price of $H$, and a second one that works through the price of the competing good $M$.

The effect that works through the own-price of $H$ is negative as the own-price elasticity $\eta_{h H}$ is negative: the tax raises the gross fuel price. This makes $H$ more expensive, which in turn reduces demand for $H$. This effect is the larger, the larger the absolute value of the own price-elasticity of demand, i.e. the stronger demand reacts to price changes, and the larger the emissions intensity in the production in $H$, i.e. the more important fuel is quantitatively as an input into production and the stronger therefore the impact of a rise of the (gross) fuel price is on the price of good $H$. This effect represents one of the central propagation mechanisms of the model, by which the tax lowers emission.

The second effect, which works through the price of good $M$, which competes in region Home with good $H$, however counteracts this first effect: This second effect is positive as the cross-price elasticity of demand for $\operatorname{good} H, \eta_{h M}$, is positive - the tax raises the gross fuel price, which makes $M$ more expensive and thus shifts demand from $M$ towards $H$. The effect is the larger, the larger the cross-price elasticity of demand for $H$ and the larger the emissions intensity in the production of $M$ (which determines by how much the price of $M$ increases for each unit of increase of the gross fuel price).

Which of the two effects dominates, and whether the tax causes the production of $H$ to increase or to drop, depends on parameter values. If, however, only emissions discharged in the production of $H$ (but not those in the production of $M$ ) are taxed, the tax unambiguously reduces demand for $H$.

It is also instructive to reformulate Equation (8.2) in "elasticity form":

$$
\begin{aligned}
\frac{\partial H}{\partial t}= & H\left(\eta_{h H} \frac{e_{H}}{c_{H}}+\eta_{h M} \frac{e_{M}}{c_{M}}\right)=\frac{H}{p_{E}+t}(\underbrace{\eta_{h H} \theta_{H}}_{<0}+\underbrace{\eta_{h M} \theta_{M}}_{>0}), \\
& \text { where } \theta_{H}=\frac{e_{H}\left(p_{E}+t\right)}{c_{H}}=\frac{\partial c_{H}}{\partial\left(p_{E}+t\right)} \frac{\left(p_{E}+t\right)}{c_{H}}=\varepsilon_{p_{H}, p_{E}+t}, \\
& \text { and } \theta_{M}=\frac{e_{M}\left(p_{E}+t\right)}{c_{M}}=\frac{\partial c_{M}}{\partial\left(p_{E}+t\right)} \frac{\left(p_{E}+t\right)}{c_{M}}=\varepsilon_{p_{M}, p_{E}+t} .
\end{aligned}
$$

To interpret (8.3), consider the expression following the second equality sign in the first line: $\theta_{H}$ is the share of gross fuel costs in overall input costs for $H$, and $\theta_{M}$ the share of gross fuel cost in overall input costs for $M$. As can be seen from the second and third line of (8.3), these cost shares however also give the gross fuel price elasticity of the output price of the respective good, i.e. they show the relative change in output prices caused by the relative change in the gross fuel price due to the introduction of the tax. 
To derive this result, differentiate (7.2) with respect to $\left(p_{E}+t\right)$ and use the equality of unit costs and good prices. Both cost shares, of course, are positive.

Now, consider the term $\eta_{h H} \cdot \theta_{H}$, the product of the own-price elasticity of demand for $H$ and the gross fuel price elasticity of the price of $H$ : it gives the relative change in demand for $H$ triggered by the relative change in the gross fuel price via the change in the price of $H$. This product is negative as the own-price elasticity $\eta_{h H}$ is negative. It also has the form of an elasticity - the elasticity of demand for $H$ with respect to the gross fuel price (via the own-price effect). If we compare Equation (8.3) to (8.2), this elasticity corresponds to what was termed "the first effect" of the tax in (8.2).

In a similar manner, also "the second effect" of the tax from (8.2) corresponds to a term written in elasticity form in Equation (8.3), the term $\eta_{h M} \cdot \theta_{M}$, i.e. the product of the cross-price elasticity of demand for $H$ and the fuel price elasticity of the output price for good $M$. Thus, this term also gives an elasticity of demand for $H$ with respect to the gross fuel price, but now not via the own-price effect, but via the cross-price effect. As $\eta_{h M}>0$, this elasticity is positive. Finally, the first line in Equation (8.3) can be rearranged such that also the left hand side is written in the form of an elasticity. We use the fact that $\partial H / \partial t=\partial H / \partial\left(p_{E}+t\right)$ :

$$
\varepsilon_{H, p_{E}+t}=\frac{\partial H}{\partial t} \frac{\left(p_{E}+t\right)}{H}=\underbrace{\eta_{h H} \theta_{H}}_{<0}+\underbrace{\eta_{h M} \theta_{M}}_{>0} .
$$

Equation (8.4) shows that the elasticity of demand for good $H$ with respect to the gross fuel price is the sum of the two "sub"-elasticities of demand just discussed - one giving the influence via the own-price effect and the other one the influence via the cross-price effect.

Next, consider the effect of the tax on the emissions rate $e_{H}$. Differentiating the expression for $e_{H}$ in (7.4) with respect to $t$ gives

$$
\begin{aligned}
\frac{\partial e_{H}}{\partial t}= & e_{H} \sigma_{1} \frac{e_{H}\left(p_{E}+t\right)-c_{H}}{c_{H}\left(p_{E}+t\right)}=-\frac{e_{H}}{p_{E}+t} \sigma_{1}\left(1-\theta_{H}\right) \\
& \text { with }-\sigma_{1}\left(1-\theta_{H}\right)=\frac{\partial e_{H}}{\partial\left(p_{E}+t\right)} \frac{\left(p_{E}+t\right)}{e_{H}}=\varepsilon_{e_{H}, p_{E}+t}
\end{aligned}
$$

As one would expect, the whole expression $\partial e_{H} / \partial t$ is negative - an increase in the tax will cause the emissions rate to fall: production becomes less carbon intensive, as producers substitute the non-taxed input $K$ for the taxed input fossil fuel. As can be seen by differentiating the expression for $e_{H}$ in (7.4) with respect to $\left(p_{E}+t\right)$, the term $-\sigma_{1}\left(1-\theta_{H}\right)$ represents the gross fuel price elasticity of the emissions rate. Thus, this 
elasticity depends on the elasticity of input substitution $\sigma_{1}$ and on $\left(1-\theta_{H}\right)$, the cost share of input $K$.

Finally, plugging both (8.3) and (8.5) into (8.1) gives the combined effect of the tax on emissions - through both changes in demand for $H$ and changes in the emissions rate $e_{H}: 23$

$$
\frac{\partial E_{H}}{\partial t}=\frac{E_{H}}{p_{E}+t}[\underbrace{\eta_{h H} \theta_{H}}_{<0}+\underbrace{\eta_{h M} \theta_{M}}_{>0} \underbrace{-\sigma_{1}\left(1-\theta_{H}\right)}_{<0}] .
$$

Again, the own-price effect on demand for $H$ and the effect on the emissions intensity lower emissions, while the cross-price effect on demand for $H$ increases emissions. The overall effect may be positive or negative, depending on actual parameter values. If, however, emissions in the production of the competing good $M$ are not taxed, then the tax definitely helps to lower emission in the production of $H$. As before, this equation can also be written in elasticity form:

$$
\varepsilon_{E_{H}, p_{E}+t}=\frac{\partial E_{H}}{\partial t} \frac{p_{E}+t}{E_{H}}=\underbrace{\eta_{h H} \theta_{H}}_{<0}+\underbrace{\eta_{h M} \theta_{M}}_{>0} \underbrace{-\sigma_{1}\left(1-\theta_{H}\right)}_{<0} .
$$

$\varepsilon_{E H, p E+t}$ is the elasticity of emissions with respect to the gross fuel price.

In a similar fashion as with good $H$, the effects of taxing the other final goods $X, M$, and $F$ can be obtained. From (7.5), the impact of the tax on global emissions is given by

$$
\frac{\partial E}{\partial t}=\frac{\partial E_{H}}{\partial t}+\frac{\partial E_{X}}{\partial t}+\frac{\partial E_{M}}{\partial t}+\frac{\partial E_{F}}{\partial t} .
$$

Again, the same relationship can also be expressed using elasticities:

$$
\varepsilon_{E, p_{E}+t}=\frac{E_{H}}{E} \varepsilon_{E_{H}, p_{E}+t}+\frac{E_{X}}{E} \varepsilon_{E_{X}, p_{E}+t}+\frac{E_{M}}{E} \varepsilon_{E_{M}, p_{E}+t}+\frac{E_{F}}{E} \varepsilon_{E_{F}, p_{E}+t}
$$

\footnotetext{
${ }^{23}$ See Allen (1938) for a similar derivation of the effect of price changes on input demand.
} 


\subsection{Production-based policy}

We can now compare a production-based to a consumption-based policy approach. Let us look at the production-based policy first. This policy taxes energy use in the production of $H$ and $X$ at an equal rate. The production costs and thus the prices of both $H$ and $X$ will therefore rise equally; and their emissions rates will fall equally. In Foreign, production costs and thus prices and emissions rates are unaffected by the policy and will therefore remain unchanged.

\subsubsection{Global emission reduction and carbon leakage}

As explained in Chapter 2, the environmental effectiveness of an abatement policy can be defined as depending on the impact of the policy on global emissions. This "impact" (for a marginal increase of the tax) can be calculated using (8.6) - and similar equations for the other three goods - and (8.8):

$$
\begin{aligned}
\frac{\partial E}{\partial t^{P B}}=\frac{1}{p_{E}+t^{P B}} & \{\underbrace{E_{H}\left[\eta_{h H} \theta_{H}-\sigma_{1}\left(1-\theta_{H}\right)\right]}_{<0}+\underbrace{E_{X}\left[\eta_{x X} \theta_{H}-\sigma_{1}\left(1-\theta_{H}\right)\right]}_{<0}+ \\
& +\underbrace{E_{M} \eta_{m H} \theta_{H}}_{>0}+\underbrace{E_{F} \eta_{f X} \theta_{H}}_{>0}\} .
\end{aligned}
$$

The superscript $P B$ of the variable $t$ signifies that production is the policy base. The input cost shares $\theta_{H}$ and $\theta_{X}$ are the same; to simplify, $\theta_{H}$ has therefore been substituted for $\theta_{X}$ in (8.10).

As emissions in the production of $M$ and $F$ are not taxed, there is no cross-price effect on demand for $H$ and $X$; emissions discharged in the policy region are therefore unambiguously reduced. This can be seen in Equation (8.10) from the first two terms inside the curly braces. The policy thus works by lowering the emission rates in the production of $H$ and $X$ and by curbing demand for $H$ and $X$. The third and the fourth term inside the curly braces, however, show that there is a cross-price effect on demand for $M$ and $F$ : As the prices of both $H$ and $X$ rise, consumers in Home as well as in Foreign substitute towards Foreign's production. Thus, emissions in the non-policy region rise - the third and the fourth term in (8.10) represent what we have defined as absolute leakage in Chapter 2. Whether absolute leakage is larger or smaller than the emissions reduction in the policy region - and thus whether the policy helps to reduce global emissions or actually increases them - depends on the actual parameter values of the model. There is nothing inherent in this model to prevent the leakage ratio from exceeding 100 percent.

As can be seen from Equation (8.10), the magnitude of absolute leakage (through the non-energy market channel) is positively related to the following parameters and variables: 
- The emissions associated with foreign production, $E_{M}$ and $E_{F}$. These depend - as can be seen from (7.3) - on the production quantities $M$ and $F$ as well as on the emissions rates $e_{M}$ and $e_{F}$ (which are equal).

- The cost share of fossil fuel in domestic production, $\theta_{H}$. As shown above, this cost share equals the gross fuel price elasticity of the output prices. $\theta_{H}$ depends on the technology of production and the level of the fuel price $p_{E}$ relative to the price of the other input $p_{K}$ (or, decomposing the expressions in a different way, one can also denote $\theta_{H}$ as the product of the emissions intensity $i_{H}$ and the gross fuel price $p_{E}+t$ ).

- The cross-price elasticities $\eta_{m H}$ and $\eta_{f X}$ (i.e. the ease of substituting imports for domestic goods in Home and foreign produced goods for exports in Foreign).

- The level of the fuel price $p_{E}$ (as compared to the level of the carbon price $t$ ).

The leakage ratio can be calculated by dividing the third and fourth term in (8.10) representing absolute leakage - by the first and second term and reversing the sign (see Equation 2.17). Compared to absolute leakage, the leakage ratio $l^{P B}$ thus depends on additional variables and parameters that determine the effectiveness of the climate policy in the policy region. Simplifying and dividing both the numerator and the denominator by $\theta_{H}$, we obtain

$$
\begin{aligned}
& l^{P B}=-\frac{E_{M} \eta_{m H}+E_{F} \eta_{f X}}{E_{H} \eta_{h H}+E_{X} \eta_{x X}-\left(E_{H}+E_{X}\right) \sigma_{1}\left(\frac{1}{\theta_{H}}-1\right)}= \\
& =-\frac{\overbrace{e_{F}\left(M \eta_{m H}+F \eta_{f X}\right)}^{>0}}{\underbrace{e_{H}\left(H \eta_{h H}+X \eta_{x X}\right)}_{<0} \underbrace{-e_{H}(H+X) \sigma_{1}\left(\frac{c_{H}}{e_{H}\left(p_{E}+t\right)}-1\right)}_{<0}} .
\end{aligned}
$$

The second line of (8.11) - although probably looking more complicated at first sight is written such as to facilitate interpretation. It shows that the leakage ratio for a production-based policy is

- positively related to the level of production in the non policy region, i.e. to $M$ and $F$, and negatively related to the level of production in the policy region, i.e. to $H$ and $X$. One also can use these levels of production to construct a simple measure of the "size" of the policy region and the non-policy region. To that end, define "size" as the "economic size" of the respective region, i.e. the level of GDP of the region and assume that the world economy does not produce any other goods except for $H, X, M$, and $F$. Then the relative size $s$ of the policy region - the region Home - expressed as a share of the world economy is given by 


$$
s=\frac{G D P_{1}}{G D P}=\frac{(H+X) p_{H}}{(H+X) p_{H}+(M+F) p_{F}} .
$$

$G D P_{1}$ denotes the GDP of the policy region, and GDP denotes world GDP. The equation makes use of the fact that $p_{X}=p_{H}$ and $p_{M}=p_{F}$. Assume for the moment that all prices are constant. Then one can see from (8.11) that - as expected - the leakage ratio declines with the size of the abating region. Now suppose that we double $H$ and $X$ in Equation (8.11). This halves the value of the leakage ratio. What is the effect on the relative size of the policy region? Let us denote the new size of the policy region resulting from this thought experiment by $\tilde{s}$ :

$$
\tilde{s}=\frac{2(H+X) p_{H}}{2(H+X) p_{H}+(M+F) p_{F}}<2 s
$$

As Equation (8.13) shows, less than doubling the relative size of the policy region will halve the leakage ratio; or, put differently, doubling the relative size of the policy region will reduce the leakage ratio to less than halve its original value. Thus, there is a non-linear relationship between the (relative) size of the abating coalition and the leakage ratio. Such a non-linear relationship has also been reported by some CGE studies - see Section 5.1.2. As Equations (8.11) to (8.13) show, there is however no need for "non-linearities" in the model to produce such a non-linear relationship between the size of the policy region and the leakage ratio - also in a model like ours, which has been "linearized" by obtaining the derivatives of the original equations, this relationship is non-linear: the non-linearity is simply a consequence of the form of the formula for the leakage ratio (in particular of the fact that in that formula absolute leakage is divided not by the global reduction of emissions, but by the reduction in the policy region only).

- The leakage ratio is positively related to the emissions rate in the non-policy region, $e_{F}$; this can immediately be seen from the second line of (8.11). Its relationship to the emissions rate in the policy region, $e_{H}$, is however ambiguous - different effects partly opposing each other are at work: on the one hand, an increase in the emissions rate $e_{H}$ will increase the reduction of emissions by having a stronger effect on the prices of and thus the demand for the taxed goods. On the other hand, whether a higher emissions rate $e_{H}$ is also associated with a stronger reduction in the emissions rate of the taxed goods depends on parameter values: the opposite - a smaller reduction of the emissions rate - is also possible, see Footnote 24 for details. Finally, an increase of the emissions rate $e_{H}$ will raise absolute leakage - this can, for example, be seen from the last two terms of (8.10), which depend on $\theta_{H}$ and thus on $e_{H}$. From Equation (8.11) not all of these effects can be directly seen as the fractions have already been reduced. In Footnote 24 it is however demonstrated that it is the relative 
magnitude of the parameters $\eta_{m H}, \eta_{m H}$, and $\sigma_{1}$ that decides whether the leakage ratio rises or falls with increasing values of the emissions rate $e_{H}{ }^{24}$

- The leakage ratio is negatively related to the ease of substituting other inputs for fossil fuel in production in region Home, i.e. to the magnitude of $\sigma_{1}$.

- The leakage ratio also depends on the price elasticities of demand for the four final goods $H, X, M$, and $F$ : It is negatively related to the absolute value of the own-price elasticities of demand for $H$ and $X$ and positively related to the crossprice elasticites of demand for $M$ and $F$.

${ }^{24}$ First note that $e_{H}$ is an endogenous variable (the value of which is determined within the model) and not an exogenous parameter. Thus when we examine the effects of an "increase in $e_{H}$ " we have to be precise about the way in which this increase is brought about. Here, we assume that $e_{H}$ is changed while at the same time the quantities of goods demanded (and produced) are kept fixed, i.e. $H$ and $X$ are fixed. This implies that also the prices of these goods and thus their unit production $\operatorname{costs} c_{H}$ and $c_{X}$ (which equals $c_{H}$ ) must be fixed. In other words, we are comparing different isoquants (stemming from different production functions) that all represent the same level of output and that are all tangent to the same line of equal unit costs. The points of tangency for these different isoquants differ in their factor employment ratios and thus in their emissions rate $e_{H}$.

First consider the first term in the denominator in the second line of (8.11). We will label it $T_{1}$. It decreases with increasing values of $e_{H}$ :

$$
\frac{\partial T_{1}}{\partial e_{H}}=H \eta_{h H}+X \eta_{x X}<0
$$

Next, look at the second term in the denominator in the second line of (8.11). We will label it $T_{2}$. When differentiating this term with respect to $e_{H}$, remember that $c_{H}$ remains fixed:

$$
\frac{\partial T_{2}}{\partial e_{H}}=(H+X) \sigma_{1}>0
$$

This term decreases with increasing values of $e_{H}$. Considering the sum of both terms, i.e. the whole denominator in the second line of (8.11), we see that it is the relative magnitudes of $\eta_{h H}, \eta_{x X}$, and $\sigma_{1}$ (and of $H$ and $X$ ) that determine whether this sum is increasing or decreasing with increasing values of $e_{H}$ :

$$
\frac{\partial\left(T_{1}+T_{2}\right)}{\partial e_{H}}=H\left(\eta_{h H}+\sigma_{1}\right)+X\left(\eta_{x X}+\sigma_{1}\right)
$$

The sign of this expression will decide whether the leakage ratio increases or decreases with increasing values of $e_{H}$ (differentiate (8.11) with respect to $e_{H}$ applying the quotient rule and the chain rule of differentiation to show this). Thus, parameter values decide whether a higher emissions rate $e_{H}$ in region Home is under production-based policy associated with a larger or a smaller leakage ratio. Loosely speaking, if the price elasticities of demand for the products $H$ and $X$ are large in absolute value compared to the elasticity of input substitution, the leakage ratio will be the smaller the larger the emissions rate in region Home. 


\subsubsection{Effects of a production-based policy on competitiveness}

As a next step in this discussion of the effects of a production-based policy, let us look at its consequences for international competitiveness. In Chapter 2 a simple measure of competitiveness was introduced - the change in net exports $N$, defined as exports $X$ weighted by their price in a situation without climate policy, $\bar{p}_{X}$, minus imports $M$ weighted also by their price in a situation without climate policy, $\bar{p}_{M}$. This measure therefore takes into account changes in physical export and import quantities triggered by the policy, but disregards changes in prices. A detailed explanation why such a measure was chosen was given in Section 2.3.3. For a production-based climate policy it takes the following form:

$$
\frac{\partial N}{\partial t^{P B}}=\frac{\partial X}{\partial t^{P B}} \bar{p}_{X}-\frac{\partial M}{\partial t^{P B}} \bar{p}_{M}=\underbrace{X \bar{p}_{X} \eta_{x X} i_{H}}_{<0}-\underbrace{M \bar{p}_{M} \eta_{m H} i_{H}}_{>0} .
$$

To derive (8.14), equations similar to (8.2) for the goods $X$ and $M$ were used; also, the fact was used that $i_{X}=i_{H}$. The whole equation is negatively signed: exports fall and imports increase due to the introduction of the policy, thus the international competitiveness of region Home decreases. The size of the effect depends on the emission intensity in Home, the own-price elasticity of demand for $X$ (for which good $F$ is substituted in region Foreign) and the cross-price elasticity of demand for $M$ (which is substituted for good $H$ in region Home). The change in net exports for region Foreign is, of course, the exact mirror image of the change in net exports for region Home - for Foreign, net exports (and thus also competitiveness) increase by the same (absolute) amount by which they drop in Home.

\subsection{Consumption-based policy}

This section analyzes a mitigation policy in Home that uses not production, but consumption as the tax base. This means that the tax will be levied on the carbon content of goods $H$ and $M$. It will cause an increase of the prices of the taxed goods, $p_{H}$ and $p_{M}$, and a decline of the emission rates in the production of these goods, $e_{H}$ and $e_{M}{ }^{25}$ The other goods prices, $p_{X}$ and $p_{F}$, and their emissions rates $e_{X}$ and $e_{F}$ remain unchanged.

\subsubsection{Global emission reduction and carbon leakage}

The impact of this consumption-based policy (identified by superscript $C B$ ) on global emissions is given by

\footnotetext{
${ }^{25}$ Here the model of this study diverges from the standard approach followed by many studies that do not explicitly examine the effects of differential taxation - for example the study of Fischer and Fox (2012). As opposed to such studies, this study permits that the climate policy pursued by Home influences production technology and thus the emissions rate $e_{M}$ in Foreign.
} 


$$
\begin{aligned}
\frac{\partial E}{\partial t^{C B}}=\frac{1}{p_{E}+t^{C B}} & \left\{E_{H}[\underbrace{\eta_{h H} \theta_{H}}_{<0}+\underbrace{\eta_{h M} \theta_{M}}_{>0} \underbrace{-\sigma_{1}\left(1-\theta_{H}\right)}_{<0}]+\right. \\
& \left.+E_{M}[\underbrace{\eta_{m H} \theta_{H}}_{>0}+\underbrace{\eta_{m M} \theta_{M}}_{<0} \underbrace{-\sigma_{2}\left(1-\theta_{M}\right)}_{<0}]\right\} .
\end{aligned}
$$

Again, some of the effects of the policy reduce, while others - the cross-price-effects raise global emissions. Without specifying the parameter values, it is however not possible to decide which of these effects dominates for good $H$ and whether therefore overall emissions in the production of good $H$ will rise or fall, i.e. whether the first term inside the curly braces in (8.15) will be positive or negative; and likewise also emissions in the production of good $M$ may rise of fall, i.e. the second term inside the curly braces may also be either positive or negative. But it is possible to draw a definitive conclusion on the sign of the sum of the two terms: using the substitution matrix of the representative consumer of region Home, one can show that the overall impact of the tax on emissions is always negative, i.e. global emissions will definitely fall (see Appendix A to this chapter for a proof). This contrasts with a policy with production as its base, which - as we have seen - may involve leakage ratios of more than 100 percent and thus an increase in global emissions.

From Equation (8.15) we can also see that all effects of the policy pertain to emissions in the production of $H$ and $M$, i.e. to the emissions directly targeted by the policy. The emissions associated with the production of $X$ and $F$, on the other hand, are not affected. This has consequences for carbon leakage: Note that we will measure leakage according to the concept introduced in Chapter 2 for use with consumptionoriented policies, i.e. we define (absolute) leakage as an (unintended) increase in emissions that are not part of the tax-base of the abatement policy and that therefore counteracts the reduction of emissions included in the tax-base - see Equations (2.18) and (2.19). As explained in Chapter 2, we can thereby assess by how much such unwanted "side-effects" lower the global environmental effectiveness of a consumptionoriented policy - which would not be possible if we were to use the "productionoriented" leakage formulas often employed in the border adjustment literature: these do not tell us anything on the effectiveness of consumption-oriented policies in reaching a global abatement target. Now, looking at Equation (8.15), we can see that all effects of the policy occur inside the tax-base. Thus, a consumption-based policy does not cause any carbon leakage in our model. Of course, it is true that the taxed goods are produced in both Home and Foreign, and that therefore emissions measured according to the region's production will also change in Foreign. But here this is not considered leakage, as the policy studied does not focus on production, but on consumption, and we therefore have to establish where goods are consumed, and not where they are produced. Thus, we can state a first central result of our analysis: While carbon leakage 
through the non-energy market transmission channel is positive under a policy with production as its base, it is zero under a policy with consumption as its base. Or, to put it in other words, a production-based abatement policy is hampered by the fact that it triggers an increase in emissions in sectors not directly targeted by the emissions tax; a consumption-based policy is not hampered by such effects. Whether this result implies that a consumption-based policy is environmentally more effective than a productionbased one, will be discussed in Section 8.4. First, however, let us examine to what extent this result depends on the specific assumptions made in the model of this study.

\subsubsection{The role of specific model assumptions}

At first glance, the result that there is no carbon leakage when consumption is the policy base might seem surprising. Should not producers faced with a consumption-based policy try to avoid the tax by concentrating their sales in the low-tax market, i.e. produce more exports and less for the domestic market in Home and vice versa in Foreign, a behavior that would raise emissions outside the policy base, i.e. cause leakage? While it is easy to conceive of such a reaction of producers in a real-world setting, our model does not exhibit such a behavior. This is due to some of the central assumptions of the model, in particular the assumption of constant returns to scale in production and the assumption of input prices remaining constant (in the next chapter, however, we will part with the assumption of a fixed fossil fuel price). These assumptions result in the marginal cost curves being flat; and that, in turn, has the consequence that producers can fully pass on any tax to consumers. Unlike consumers, who adjust their demand to avoid the tax, producers therefore have no profit motive to shift production according to the policy applied. Thus, leakage in this model is caused by consumer preferences, but not by production technology.

Consumers, however, only under a production-based policy have the choice between one product that is affected by the policy and one that is not: for consumers in Home, emissions in the production of good $H$ are taxed, but not those embodied in good $M$; and for consumers in Foreign, emissions embodied in good $X$ are taxed, but not those in $\operatorname{good} F$. If this policy is introduced, consumers will therefore increase their demand of a good that is not part of the tax-base; and that leads to carbon leakage. A consumption-based policy, on the other hand, adds carbon costs to all products demanded by consumers in Home (and does not affect consumers in Foreign at all). Therefore, consumers in Home have no possibility to shift their demand to products not targeted by the policy. Their tax avoidance strategy will only involve substituting between the product with the larger tax burden and the product with the smaller one. But as there is no product that is not taxed at all (that is outside the tax base) in the consumption bundle of consumers in Home, there is no carbon leakage.

Thus, the zero-leakage property of a consumption-based policy rests on some of the assumptions of the model of this study: there must be constant returns to scale in production and the input prices must not change with changing input demand. But how realistic are these assumptions - does our model depict a very specific setting that only seldomly can be found in real-world economies, or is it, on the other hand, a quite reasonable approximation to real-world circumstances? Constant returns to scale are 
actually the typical assumption for describing a competitive industry in long-run equilibrium. The most common theoretical trade models like the Heckscher-OhlinSamuelson model rely on constant returns to scale, and also most CGE models used to analyze climate policies make use of this assumption. Like these CGE models, our model actually combines the assumption of perfect competition in the home market with the assumption of less than perfect competition internationally: goods produced in Home and in Foreign are not the same (but only more or less close substitutes); therefore every country enjoys some monopoly power in international trade. This might be a realistic setting for some sectors, but not for others - many studies find that the carbon-intensive sectors of European economies differ as regards their exposure to international competition and their market structure (Reinaud 2008, Monjon and Quirion 2009, Carbon Trust 2010). Developing an analytical model of markets not characterized by perfect competition is however beyond the scope of this study. As opposed to our model, in models of less than perfectly competitive markets firms would make profits - and that would introduce an additional motive for firms to change their behavior when confronted with an emission tax. Still, the question whether such models would substantially improve our understanding of the effects of climate policy or whether the simpler setting of the model of this study is a "good enough" approximation to real world industry structure, can ultimately only be answered empirically. At any rate, the model of this study can be seen as a first step in developing an analytical framework for the comparison of production- and consumption-based policies - a step that could be followed up at a later stage by devising more sophisticated models that do not rely on perfect competition.

A second simplification in our model is the typical partial equilibrium assumption of constant input prices. As already mentioned, this assumption will not be too far off the empirical facts if the model is interpreted to represent only a single (small) sector of a large economy - but if the model is seen to depict the whole of an economy, then, of course, discrepancies may be substantial. Just like the assumption of constant returns to scale, also the assumption of constant input prices guarantees that the market supply curves for final goods are flat - and that thus the whole tax burden is passed on to consumers. If the assumption of constant input prices is dropped, but the assumption of constant returns to scale is upheld (note that this is the typical setting for most CGE models), then this would result in the following model behavior: the market supply curves for final goods would be upward sloping as an industry that raises production and therefore increases its factor demand drives up the prices of the factors of production, thereby raising unit production costs. If now a tax is introduced, not its entire burden is borne by consumers: the price received by the suppliers of the good falls, but that does not lead to a fall of producer surplus - with constant returns to scale, the owners of the firms make no profits and therefore there is also no producer surplus. Instead, the tax burden is shifted on to the owners of the factors of production - the prices for these factors of production drop. Thus, in this setting the tax burden is shared by consumers and the owners of factors of production. As opposed to a situation where only the consumers bear the tax burden, now there will be carbon leakage: the reduced prices for the factors of production will lead to an increase of demand for these factors 
in those sectors that are not subject to the tax. Production in those sectors - and thus also the emissions associated with production - will rise, i.e. there will be leakage in these sectors. We can conclude that the "zero-leakage property" of a consumption-based policy crucially depends on the assumption of constant input prices. In practical terms, the question whether this "zero-leakage property" is a good approximation to a specific real-world situation is therefore decided by the price-sensitivity of input demand: if input prices hardly react to the drop of demand for inputs triggered by the tax, then indeed there will be very little leakage - and vice versa. For one of the inputs - fossil fuel - this will be studied in more detail in the next chapter: there, the assumption that the fossil fuel price is constant will be dropped.

\subsubsection{Effects of a consumption-based policy on competitiveness}

As for a production-based policy, let us also for a consumption-oriented approach examine the consequences of the introduction of the policy for international competitiveness. Again, we start from an equation similar to (8.2), however this time only for good $M$ :

$$
\frac{\partial N}{\partial t^{C B}}=\frac{\partial X}{\partial t^{C B}} \bar{p}_{X}-\frac{\partial M}{\partial t^{C B}} \bar{p}_{M}=0-M \bar{p}_{M}(\underbrace{\eta_{m M} i_{M}}_{<0}+\underbrace{\eta_{m H} i_{H}}_{>0}) .
$$

First, note that (8.16) is always larger than (8.14). Thus, a consumption-based policy has less of a negative impact on competitiveness for region Home than a productionbased policy - and in many practically relevant situations it will even have a positive impact: More specifically, the sign of (8.16) cannot be determined without knowing the values of the parameters. The typical case, however, will be the following: as we have assumed that the emissions intensity in region Foreign is far higher than the one in Home, i.e. $i_{M}>i_{H}$, and if we additionally suppose that the cross-price elasticity of demand for $M, \eta_{m H}$, is smaller or at least not much larger than the own-price elasticity $\eta_{m M}$ (which also typically is a reasonable assumption), the first term in parenthesis in (8.16) will in absolute value be larger than the second term. In that case, Equation (8.16) will be positive - the introduction of a consumption-based policy will thus enhance the international competitiveness of region Home, the region implementing the policy, and will lower the international competitiveness of region Foreign. This contrasts with the effects of a production-based policy, which - as we have seen - unambiguously lowers competitiveness in Home. The different impacts of the two policy variants on competitiveness might be a further motivation for region Home to support the adoption of a consumption-oriented policy - in addition to possible environmental motivations; but it may also be a motivation for region Foreign to oppose consumption-based policy approaches.

\subsubsection{Border tax design and producer response}

Finally, we can ask what would change in our analysis if producers reacted to the introduction of the tax by adjusting only the "scale" of their production, but not the 
production "technique" employed. There are several possible reasons why the production technique may not be adapted: First, a change of the "technique" may be impossible for technical reasons, for example because no other production technology is available. This may be the case either in region Home or in region Foreign; but under the assumptions of our analysis that Home consists of industrialized countries and Foreign of developing and emerging economies, switching the production technology will typically rather be a problem for Foreign - industrialized countries usually have a greater set of technologies at their disposal than developing countries.

As already mentioned in Chapter 7, a second case where the tax will not trigger a change of the production "technique" is a situation where producers do not have an incentive to adopt a different technology. This, for example, may apply if the tax is not levied according to the true carbon content of the good under question but according to some benchmark or some value of the carbon content that was measured once in the past, but that is not regularly updated. Then producers cannot change their tax dues by changing the carbon content of their production - they therefore perceive the tax rather as an output tax than as an emissions tax (see Sections 5.2.2 and 7.1.1). Again, this is a problem that rather applies to producers in Foreign than in Home: Domestic systems of environmental taxation usually rely on a close monitoring of actual emissions (or at least of fuel input) and thus the tax can immediately be adjusted if the carbon intensity in production changes. When foreign produced goods need to be taxed, and the tax is not determined by a scheme like the "carbon added" system discussed in Chapter 2, it will however often be difficult to establish the true content of embodied carbon of the good under question. The analysis here will therefore concentrate on such a situation where the reaction to the policy is different in Home and in Foreign: in Home producers will react to the tax by changing both the "scale" and the "technique" of their production, while in Foreign they only change the "scale".

In our model, we can represent such a situation by setting the elasticity of input substitution $\sigma_{2}$ equal to zero. As can be seen from the last term of Equation (8.15), this would make the emissions reduction brought about by a given tax rate smaller - and thus the policy environmentally less effective. Competitiveness - as can be seen from Equation (8.16) - is not directly affected by excluding a change of the production "technique" in Foreign. But if the aim of the policy is to reach a given amount of reduction of global emissions, then excluding effects of the policy on the emissions rate in the production of $M$ means that a higher tax is necessary to reach the given reduction target than under a situation where emissions are also reduced through a fall in the emissions rate. And the imposition of a higher tax will - if the policy as argued above leads to an increase in international competitiveness for Home - even amplify this increase in competitiveness for Home, but at the same time also worsen the loss of competitiveness for Foreign. To summarize, the expected loss of competitiveness will already serve as a motivation for Foreign to oppose the introduction of a consumptionoriented policy in a situation where producers in Foreign can react to the tax on their export production by "greening" their production technology; but if they lack the means to make their production more environmentally friendly or if the tax is designed such that such a "greening" of production methods is not immediately rewarded by a 
reduction of tax dues, then the negative effect on competitiveness is even exacerbated and thus there is an even stronger motivation for Foreign to oppose a switch to a consumption-oriented policy.

So far, it was assumed that the carbon coefficient used to calculate the border tax had been obtained by assessing the carbon content of the good that was to be taxed even if that assessment was not repeated regularly and the benchmark thus established therefore remained fixed for long periods of time. The difference between the "true" carbon content of the taxed imports and the benchmark used to calculate the tax will however typically be further exacerbated if the benchmark is based on the carbon content of domestic products similar to the imports under question instead of the actual carbon content of these imports. Such a scheme of taxation may be applied either because it is technically not possible to establish the "true" carbon content of imports, or, alternatively, to increase the chances that the scheme conforms to international trade law (see Chapter 3). Using the notation of our model, under this kind of taxation the gross carbon price producers of imports must pay will not equal $p_{E}+t$, but $p_{E}+\left(i_{H} / i_{M}\right) t$. The reduction of global emissions of such a scheme with a benchmark based on the carbon content of "like" domestic products can be derived following the same steps as in the derivation of Equation (8.15). It is given by

$$
\begin{aligned}
\frac{\partial E}{\partial t^{C B B}}=\frac{1}{p_{E}+t^{C B B}} & \left\{E_{H}[\underbrace{\eta_{h H} \theta_{H}}_{<0}+\underbrace{\eta_{h M} \frac{i_{H}}{i_{M}} \frac{e_{M}\left(p_{E}+t^{C B B}\right)}{c_{M}}}_{>0} \underbrace{-\sigma_{1}\left(1-\theta_{H}\right)}_{<0}]+\right. \\
& \left.+E_{M}[\underbrace{\eta_{m H} \theta_{H}}_{>0}+\underbrace{\eta_{m M} \frac{i_{H}}{i_{M}} \frac{e_{M}\left(p_{E}+t^{C B B}\right)}{c_{M}}}_{<0}]\right\} .
\end{aligned}
$$

Like a consumption-based policy with a tax on imports based on the true carbon content of these imports - see Equation (8.15) - also this benchmark-based policy (identified by the superscript $C B B$ ) will definitely lead to a reduction of global emissions. The proof follows the same line as the one given in Appendix A to this chapter - the only difference is that the own-price elasticity and the cross-price elasticity terms are now multiplied by an additional factor, but this common term can be factored out in Equation (8.A3). Under the assumption that the "true" emissions intensity of imports is larger than that of domestic products, the emission reduction triggered by the benchmark-based policy will however be smaller than that of the "original" policy based on the true carbon content of imports. This can be seen by comparing (8.17) to (8.15). First, note that the last term in brackets in the second line of (8.15) is "missing" from (8.17). This is due to the fact that - as discussed above - a policy based on (unchangeable) benchmarks does not provide an incentive to producers to alter their input mix. Secondly, the second terms in brackets in both lines of (8.17) are both 
smaller in absolute value (both by the same factor) than the respective terms in Equation (8.15). Actually, as demonstrated in Appendix B to this chapter, their sum is negative ${ }^{26}$ and thus also these terms contribute less to the reduction of global emissions under a policy with a border tax based on the carbon content of "like" domestic products than under a policy with a border tax based on the "true" carbon content. This result is intuitively plausible: If the carbon intensity in Home is lower than in Foreign, basing the border tax on imports on this lower carbon intensity means that the tax burden - and thus the environmental effect of the policy - is smaller than if the tax were calculated using the actual carbon intensity of goods produced in Foreign.

\subsection{Policy evaluation in terms of environmental effectiveness}

\subsubsection{Equal reduction of emissions targeted}

The zero-leakage property of a consumption-based policy derived in the previous section immediately implies the following result: If we compare a production-and a consumption-based policy that achieve an equal (absolute) reduction of the emissions directly targeted by the policy (i.e. of the emissions that constitute the tax base scenario (a) from the second paragraph of this chapter), the consumption-based policy is the environmentally more effective one (see also Section 2.3.2 for the background to this result). As an example suppose the EU promises to lower its GHG emissions by 30 percent relative to its 1990 level. This corresponds to approximately $1.7 \mathrm{Gt} \mathrm{CO} 2$ equivalent. As an alternative, the EU could switch to a policy that targets the emissions embodied in the goods consumed on its territory and also promise to reduce them by $1.7 \mathrm{Gt} \mathrm{CO}_{2}$ equivalent (assuming that consumption-based emissions are higher for the EU than production-based ones, the percentage reduction now is lower, say only 25 percent). The result just derived suggests that the consumption-oriented approach is the environmentally more effective one on a global level - as it does not involve carbon leakage, it will lead to a reduction of global emissions of also exactly

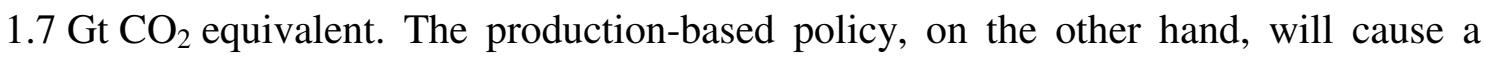
reduction in global emissions of less than the unilaterally promised $1.7 \mathrm{Gt} \mathrm{CO}_{2}$ equivalent - if the leakage ratio were, say, 20 percent, then the global emissions reduction would amount to only $1.36 \mathrm{Gt} \mathrm{CO}_{2}$ equivalent. $^{27}$

26 The sum of two terms discussed in the text is:

$E_{H} \eta_{h M} \frac{i_{H}}{i_{M}} \frac{e_{M}\left(p_{E}+t^{C B B}\right)}{c_{M}}+E_{M} \eta_{m M} \frac{i_{H}}{i_{M}} \frac{e_{M}\left(p_{E}+t^{C B B}\right)}{c_{M}}=\frac{i_{H}}{i_{M}} \frac{e_{M}\left(p_{E}+t^{C B B}\right)}{c_{M}}\left\{H e_{H} \eta_{h M}+M e_{M} \eta_{m M}\right\}$

Appendix B to this chapter demonstrates that the expression put in curly braces is negative. But as the factor of the expression in parenthesis is positive, we can conclude that also the whole expression - the sum of the two terms discussed in the text - is negative.

27 The figures used in this example are chosen for ease of exposition only and should not be considered as exact estimates of real-world data. Note that there is no unanimity in the academic literature on both 
The result just stated, however, does not imply that the consumption-based policy will always be the more cost-effective option (see Section 8.7 for a discussion of costeffectiveness). Also note that to achieve an equal reduction of the emissions that form the tax base one must in general adopt different tax rates (i.e. impose different carbon prices) for the two policies being compared. If one instead compares two policies with equal tax rates (i.e. the same carbon price, scenario (b) from the second paragraph of this chapter), one cannot immediately infer that the consumption-based policy will be the environmentally more effective one.

\subsubsection{Equal tax rate}

In this sub-section, we will look at such a comparison of policies with the same tax rate in more detail. The difference in global emissions reduction between a production- and a consumption-based policy - written in elasticity form - is in this case given by ${ }^{28}$

$$
\begin{aligned}
& \varepsilon_{E, p_{E}+t}^{P B}-\varepsilon_{E, p_{E}+t}^{C B}=\frac{\partial E}{\partial t^{P B}} \frac{p_{E}+t}{E}-\frac{\partial E}{\partial t^{C B}} \frac{p_{E}+t}{E}= \\
&=\underbrace{-\frac{E_{H}}{E} \eta_{h M} \theta_{M}}_{<0}+\underbrace{\frac{E_{X}}{E}\left[\eta_{x X} \theta_{H}-\sigma_{1}\left(1-\theta_{H}\right)\right]}_{<0} \\
& \underbrace{-\frac{E_{M}}{E}\left[\eta_{m M} \theta_{M}-\sigma_{2}\left(1-\theta_{M}\right)\right]}_{>0}+\underbrace{\frac{E_{F}}{E} \eta_{f X} \theta_{H}}_{>0} .
\end{aligned}
$$

If the consumption-based policy is environmentally more effective, the whole expression will be positive. For this to be the case, the two terms in the second line of (8.18) must be small in absolute value and the two terms in the third line must be large. The first term in the second line represents the cross-price effect on demand for good $H$ under the consumption-based policy. This term shows that a consumption-based policy is less effective in reducing emissions in the production of good $H$ than a productionbased one, as the tax on emissions embodied in good $M$ under the consumption-based policy leads to increased demand for good $H$. The second term in the second line represents the reduction in emissions of Home's exports $X$ under the production-based policy. It is large in absolute value if either the share of emissions embodied in exports, $E_{X}$, in overall emissions, $E$, is large; or if $E_{X}$ reacts strongly to the policy - in this case

the difference between production- and consumption-based emission for the EU and the amount of carbon leakage that a unilateral abatement policy of the EU would cause.

${ }^{28}$ To obtain Equation (8.18), it was assumed that the analysis starts from a situation without any previous tax in place. Without this assumption, the simplification that $\theta_{X}$ equals $\theta_{H}$ may not apply. 
the term in brackets is large. The first term in the third line represents the reduction in emissions in Home's imports $M$ under the consumption-based policy. Again, it is large if either the share of emissions embodied in imports, $E_{M}$, in overall emissions, $E$, is large; or if $E_{M}$ reacts strongly to the policy. Finally, the last term represents leakage under the production-based policy (the other leakage term from (8.10), the one relating to $E_{M}$, cancels).

Taken together, the question which policy is more effective cannot be answered without knowing the magnitudes of all the relevant parameters and variables: the amounts of emissions embodied in trade and in non-traded goods, the cost shares of fossil fuel, the elasticities of demand, and the elasticity of substitution between inputs in production. However, a few points warrant a more detailed discussion:

- The magnitude of carbon leakage under a production-based policy is just one of a number of factors that decide whether a consumption-based policy (with the same tax rate as the production-based policy) is indeed environmentally more effective. The other factors relate to the effectiveness of the policies in curbing the emissions that are included within the tax base. Thus, our model-based analysis demonstrates the validity of an argument already made when discussing the concept of policy-induced carbon leakage: when choosing among different policies, one should not rely exclusively on the criterion of "minimum leakage".

- In many empirically relevant situations, $E_{H}$, the amount of emissions embodied in domestically produced goods consumed domestically will be larger than either $E_{M}$ or $E_{X}$ (at least, if the coalition following the climate policy is "large enough", i.e. it consists not just of a few small countries). As can be seen from the first term in the second line of (8.18), a consumption-based policy will however be less effective in reducing emissions in the production of $H$ than a production-based one. This by itself, however, should not be an argument for preferring the production-based policy: the reason why the production-based policy is more effective in reducing $E_{H}$ is that consumers in Home have the possibility to evade the policy by switching to the non-taxed import good $M$, whereby they cause leakage (Pan et al. (2008) term this "abatement through trade"). Thus the larger reduction of $E_{H}$ under the production-based policy represents just a shift of emissions across borders and is not reflected in a larger reduction of emissions also on the global level. Under the consumption-based policy, on the other hand, the cross-price effect on demand for $H$ - the first term in the second line of (8.18) - prevents such an easy evasion of the policy: as also $M$, the good that competes with $H$ in Home, is taxed, demand is shifted from $M$ towards $H$. In that way, the consumption-based policy however also diminishes the reduction of emissions in the production of $H$.

- Peters and Hertwich (2008b) advocate a consumption-based policy on the grounds that - with current trade flows and emissions intensities - it includes a larger share of global emissions than a production-based policy (see the discussion in Section 6.2.2. In terms of the model employed in this study, this means that $E_{M}$ is larger than $E_{X}$. This without doubt is one of the most 
convincing arguments in favor of a consumption-based policy. Nonetheless, by itself this argument cannot guarantee that a consumption-based policy is always environmentally more effective. In particular, for the first term in the third line of (8.18) to be larger than the second term in the second line in absolute value, also the part of the first term in the third line that is in brackets needs to be sufficiently large, i.e. not only should the amount of emissions embodied in imports be large, but imports also need to react sufficiently strong to the policy. And that in turn does not only depend on the emission rate in the production of imports (which is reflected in the input cost share $\theta_{M}$ ), but also on the elasticity of demand for imports, $\eta_{m M}$, and on the elasticity of substitution in region Foreign, $\sigma_{2}$. Thus, the fact that emissions in imports exceed emissions in exports in quantity does not automatically imply that targeting emissions in imports will lead to a larger reduction in global emissions than targeting emissions in exports. Again, the magnitude of the parameters characterizing demand and production technology matters.

- Expanding on the argument from the previous paragraph, the attractiveness of a consumption-based policy rests - apart from its potential to avoid leakage mainly on its effectiveness in reducing emissions in imports. As discussed in Chapter 6, in many industrialized countries these emissions have been growing extraordinarily quickly in recent decades. From the first term in the third line of (8.18) one can see that there are two ways to lower emissions embodied in imports: either the demand for imports is reduced - this option is represented by the term $\eta_{m M} \theta_{M}$ - or emissions in the production of imports are cut - this option is represented by the term $-\sigma_{2}\left(1-\theta_{M}\right)$. As already argued in the previous section, lowering the demand for imports reduces the competitiveness of region Foreign, i.e. of developing and emerging economies. In the next chapter additional reasons will be discussed, why curbing the imports of these countries may not be desirable - reasons relating to the distribution of the burdens of the policy and also to its environmental effectiveness. As will be discussed at various points in the remainder of this study, the second option to reduce emissions in imports, the "greening" of the production technology, does not suffer from such disadvantages. To what extend this option will be chosen, depends on the size of the parameter $\sigma_{2}$, i.e. on the question whether alternative, less carbon-intensive technologies are available in developing and emerging economies and whether the emissions tax is designed such that it rewards the adoption of "clean" technologies by a reduction in tax dues. In the following chapters it will be argued that the answers to these questions are crucial for choosing a climate policy - that only if the policy indeed triggers a "greening" of production methods in developing and emerging economies, a switch to a consumption orientation can be recommended in real-world circumstances.

Recall also from Section 8.3.4 that the effectiveness of a consumption-based policy depends on whether imports are taxed according to their true carbon content or according to some benchmark as for example the carbon content of similar domestic 
products. If we assume that the tax on imports is based on such a benchmark, Equation (8.18) changes to

$$
\begin{aligned}
\varepsilon_{E, p_{E}+t}^{P B}-\varepsilon_{E, p_{E}+t}^{C B B}= & \underbrace{-\frac{E_{H}}{E} \eta_{h M} \frac{i_{H}}{i_{M}} \frac{e_{M}\left(p_{E}+t^{C B B}\right)}{c_{M}}}_{<0}+\underbrace{\frac{E_{X}}{E}\left[\eta_{x X} \theta_{H}-\sigma_{1}\left(1-\theta_{H}\right)\right]}_{<0} \\
& \underbrace{-\frac{E_{M}}{E} \eta_{m M} \frac{i_{H}}{i_{M}} \frac{e_{M}\left(p_{E}+t^{C B B}\right)}{c_{M}}}_{>0}+\underbrace{\frac{E_{F}}{E} \eta_{f X} \theta_{H}}_{>0} .
\end{aligned}
$$

Comparing (8.19) to (8.18) on can see that by basing the import tax on the lower carbon content of domestic products, some of the advantages of a consumption-based relative to a production-based policy are lost. The benchmark-based policy will not lead to "greening" of the production technology in Foreign; and also the demand for carbonintensive imports is reduced by less than in a scenario where the import tax is based on the true amount of emissions embodied in imports.

To summarize the results of this sub-section, for a particular coalition of industrialized countries choosing between a production- and a consumption-based policy with the same carbon price, the consumption-based approach may be the environmentally more effective one under the following circumstances:

- Leakage under a production-based policy is large.

- Emissions embodied in imports (by far) exceed emissions embodied in exports. $^{29}$

- Emissions embodied in imports react strongly to the policy; and emissions discharged in export production do not react strongly to the policy.

- It is possible to base the import tax on the true carbon content of imports - and not on some benchmark.

All these results can be interpreted both as relating either to individual economic sectors of the two regions studied - interpretation (a) from Section 7.1.1 - or to the two regions as a whole - interpretation (b) from Section 7.1.1. Note however that none of the conditions listed above alone suffices to make the consumption-oriented policy the environmentally more effective one. Rather these conditions represent "tendencies" which only if combined appropriately will guarantee a higher environmental efficiency for the consumption-based approach. Finally, remember that these results have been

29 This condition is formulated somewhat imprecisely. For a discussion of parameter restrictions that apply see Footnote 42. 
derived by means of a simplified PE model. Section 9.4 will discuss how far they can be transferred to a general equilibrium setting.

\subsection{Switching the tax base, but not the target base}

The CGE literature on border carbon adjustments (see Chapter 5) examines the introduction of measures that often come reasonable close to a switch to a consumptionbased policy. This strand of literature however typically does not ask the question what the introduction of the border measures would mean for reaching abatement targets that are also formulated in terms of consumption - rather it keeps the institutional background of the analysis unaltered, i.e. countries aim to fulfill abatement targets relating to emissions discharged in production as, for example, stipulated by the UNFCCC system of emissions accounting. Thus, simply put, the border adjustment literature analyses the consequences of switching the tax base (more or less towards a consumption-orientation), but not switching the target base (which is left productionoriented). As the findings of the CGE literature have hugely influenced the political discussion on leakage and appropriate anti-leakage measures, this section will briefly examine how these findings compare to the results produced by the analytical model of this study. One of the central findings of the CGE literature is that the border measures typically reduce carbon leakage - but note that in that strand of literature leakage is calculated for a production-based target, i.e. using formulas (2.16) and (2.17). Thus, this finding from the CGE literature has a different meaning than the results on carbon leakage under a consumption-based policy derived in the previous two sections of this study. However, in this section we will use our model to examine leakage also for production-based targets in order to allow a comparison to the findings of the CGE literature. Apart from making possible such comparisons, the setting of this section changing the tax base, but not the target base - may also be interesting for an additional reason: it facilitates the analysis of a scenario where a country or a group of countries switches to a consumption-orientation in its climate policy (probably motivated by concerns for global emissions), but where the international climate policy framework is not changed. Thus these countries still have to fulfill their obligations under the UNFCCC framework (whether bound by a treaty like the Kyoto Protocol or by voluntary pledges), and these obligations refer to emissions in production. The countries will therefore want to know how they perform according to these production-based targets - even though they now follow a consumption-based policy.

In contrast to the previous sections, we are thus now not interested in the effect of the policy on global emissions, but solely in the effect on the emissions discharged in the production of the country introducing the policy, i.e. the emissions in the production of $H$ and $X$. From (8.15) and (8.18) we see that a consumption-based policy does not reduce emissions in the production of $X$ at all, and also in the reduction of emissions in the production of $H$ it is less effective than a production-based policy: see the first term in the second line of (8.18). Actually, with certain parameter values a consumptionbased policy can effect not a reduction, but even an increase of emissions in the production of $H$ - and therefore also in the production of $H$ and $X$ taken together. For 
this to be the case, the middle term in brackets in the first line of (8.15) must be larger than the first and the third term in absolute value. Then, the sum of all three terms inside the brackets is positive, which means that emissions in the production of $H$ rise.

A typical situation that leads to such effects might look as follows: the emissions rate in Foreign is far larger than the one in Home. Thus, also the tax levied on imports from Foreign will be higher than the one on domestic products. In Home, domestic production and imports both become more expensive, but as the price increase of imports is far higher than the one of domestic production, consumers demand less imports and more domestically produced goods. Production of domestic goods increases; and the additional emissions from this additional production more than outweigh the emissions savings that occur because the tax induces firms to produce the domestic good with a lower emissions rate. Thus, emissions discharged in region Home rise. Such a scenario will not only make Home miss its production-based emissions reduction target, it might also result in Home being heavily criticized by other countries for not taking its due share in international mitigation efforts: Home has introduced a policy that allows its own industry to increase emissions while causing emissions reductions in the industry of other countries.

However, not only the emissions reduction in production in region Home is smaller under a consumption-based than under a production-based policy, the same also holds true for absolute carbon leakage calculated for a production-based mitigation target, i.e. using formula (2.16). As can be seen by comparing Equations (8.10), (8.15), and (8.18), a production-based policy leads to an increase of emissions in sector $F$ while a consumption-based policy does not cause any change of emissions in this sector. And regarding sector $M$, the production-based policy also leads to an increase in emissions, while the consumption-based one leads to a lesser increase or - even more typically - a drop of emissions. ${ }^{30}$ Thus, absolute leakage (measured for a production-based target) is smaller for a consumption-based policy than for a production-based one, and it may also fall below zero, i.e. there may be "negative absolute leakage." But as not only absolute leakage, but also the emissions reduction in region Home is smaller for the consumption-based policy (i.e. the numerator as well as the denominator of Equation 2.17 are smaller), the leakage ratio can be either larger or smaller than that of the production-based policy. Thus, the result so typical for the CGE literature that also the leakage ratio (calculated for a production-based target) is smaller under a consumption-

${ }^{30}$ Under a consumption-based policy, emissions in the production of $M$ and $F$ taken together will fall if emissions in the production of $M$ fall (as the production of $F$ is not affected by a consumption-based policy). From the properties of the substitution matrix of the representative consumer in Home we know (see Appendix A to this chapter) that either the emissions in the production of $H$ or those in the production of $M$ or those in the production of both goods must fall. But as we have assumed that the emissions rate in the production of $M$ is (by far) larger than the one in the production of $H$, it will indeed typically be the emissions in the production of $M$ that fall (although - depending on the actual values of the elasticities of demand - an increase of the emissions in the production of $M$ cannot be excluded). 
oriented policy is not guaranteed within the framework of our model. To ensure it, we have to restrict the range of permissible parameter values: loosely put, if leakage under the production-based approach is large, if the policy is more effective in reducing emissions in imports than in exports; and if not a huge amount of additional emissions in domestic production for domestic consumption is triggered by a switch to a consumption policy base, then the consumption-based approach is likely to be the one with the smaller leakage ratio. But note that the meaning of leakage calculated in this way is difficult to interpret - at any rate it does not have an informative value as regards the global environmental effectiveness of the policy.

Summing up, a consumption-based policy is less effective than a production-based one in reaching a target defined in terms of production-based emissions. It also leads to less absolute leakage (measured with regard to the production-based target), but whether also the leakage ratio is smaller, depends on the specific parameter values.

\subsection{Policy with import tax, but without export rebate}

The CGE literature on border adjustments (see Chapter 5) and the literature on the design of border measures (see Chapter 10) often discuss policies that complement a production-based policy with import border adjustments, but that do not foresee an export rebate. In terms of the model of this study, this corresponds to taxing emissions produced in the sectors $H, X$, and $M$ - only emissions in sector $F$ are not taxed. Thus, such a policy includes a larger share of global emissions than either a "pure" production- or a "pure" consumption-based policy; in a certain sense, it combines the two policies. In the following equations, this policy variant will therefore be labeled by the superscript $P C$ (for production plus consumption). In the text, it will for short be termed "import-tax-only" policy. Note that the analysis will be confined to policies that apply a uniform carbon tax rate (or carbon price) to all sectors included; policy variants that apply different tax rates to production and to consumption such as those studied by Markusen (1975), Hoel (1996), and Gross (2009) - see Section 4.1 - are not examinded here.

\subsubsection{Environmental effectiveness of "import-tax-only" policy}

Let us calculate the impact on global emissions of such a policy targeting three of the four sectors of our model. The derivation is similar to that for the production- and the consumption-based policy: 


$$
\begin{aligned}
& \frac{\partial E}{\partial t^{P C}}=\frac{1}{p_{E}+t^{P C}}\left\{E_{H}[\underbrace{\eta_{h H} \theta_{H}}_{<0}+\underbrace{\eta_{h M} \theta_{M}}_{>0} \underbrace{-\sigma_{1}\left(1-\theta_{H}\right)}_{<0}]+\right. \\
& +\underbrace{E_{X}\left[\eta_{x X} \theta_{H}-\sigma_{1}\left(1-\theta_{H}\right)\right]}_{<0}+ \\
& +E_{M}[\underbrace{\eta_{m H} \theta_{H}}_{>0}+\underbrace{\eta_{m M} \theta_{M}}_{<0} \underbrace{-\sigma_{2}\left(1-\theta_{M}\right)}_{<0}]+ \\
& +\underbrace{E_{F} \eta_{f X} \theta_{H}}_{>0}\}
\end{aligned}
$$

The individual terms of (8.20) combine the terms we already know from the discussion of the production-based and the consumption-based policy. As with the consumptionbased policy, the terms in the first and in the third line taken together are negatively signed; as with the production-based policy, also the terms in the second line of (8.20) are negatively signed. Only the fourth line is positively signed - it represents leakage triggered by the tax on good $X$. The whole of (8.20) is thus negatively signed representing a decrease in global emissions - if the leakage term does not dominate the terms in the first three lines taken together.

Is this policy encompassing three of the four sectors of the model of this study environmentally more effective than either a production- or a consumption-based policy? Again, we can compare the policies for two different scenarios: either we keep the reduction of emissions directly targeted by the policy constant - scenario (a) from the second paragraph of this chapter; or we keep the carbon price constant - this was termed scenario (b). Let us start with scenario (a): the tax base now encompasses the sectors $H, X$, and $M$. The last term of (8.20) represents the only impact of the policy that occurs outside the tax base. We may characterize this impact as "carbon leakage". Note however that in that case the definition of leakage does not conform to the one given in Equations (2.16) to (2.19) - even though the "meaning" of the term "carbon leakage" is still the same: it represents a change in emissions not directly targeted by the abatement policy, which counteracts the aim of the policy. The difference to the definitions from 
Chapter 2 is that now sector $F$ is the only sector not directly targeted by the policy. ${ }^{31}$ As discussed in Section 8.3 and 8.4, for a consumption-based policy our model shows that all effects of the policy occur inside the tax-base and therefore there is no carbon leakage, while for a production-based policy effects counteracting the policy ("leakage") occur in the non-targeted sectors $M$ and $F$. For scenario (a) mentioned above the consumption-based policy is thus clearly the environmentally most effective one, as it does not involve leakage. How do the other two policy variants compare to each other? The production-based policy involves leakage in two sectores ( $M$ and $F$ ); the import-tax-only policy in only one - sector $F$. Let us compare leakge in this sector for the two policy variants: To switch from the production-based variant to the importtax-only variant, one has to add sector $M$ to the tax base. If this leads to a larger reduction of emissions at the original tax rate, ${ }^{32}$ then - in order to keep the reduction of emissions directly targetet by the policy constant - one has to lower the tax rate for the import-tax-only policy. But as leakage is increasing in the tax rate, leakage in sector $F$ will under these consitions be lower for the import-tax-only policy than for the production-based policy. The import-tax-only policy thus ranks second of the three policy variants in terms of environmenatal effectiveness - it causes no leakge in sector $M$ and less leakage than the production-based policy in sector $F$; and third and thus least effective is the production-based policy, which involves leakage in both $M$ and $F$.

As discussed in Section 8.4.1, comparing policies according to scenario (b), i.e. considering policies that apply the same carbon price, is however typically more informative than a comparison according to scenario (a): Let us start such an examination according to scenario (b) by first comparing the import-tax-only policy to a consumption-based approach. Equation (8.21) is written in elasticity form:

$$
\varepsilon_{E, p_{E}+t}^{P C}-\varepsilon_{E, p_{E}+t}^{C B}=\underbrace{\frac{E_{X}}{E}\left[\eta_{x X} \theta_{H}-\sigma_{1}\left(1-\theta_{H}\right)\right]}_{<0}+\underbrace{\frac{E_{F}}{E} \eta_{f X} \theta_{H}}_{>0} .
$$

31 Absolute carbon leakage for an "import-tax-only" policy will be labelled $L^{P C}$, and the leakage ratio will be labelled $l^{P C}$. The two concepts can be defined as follows:

$$
L^{P C}=\Delta E_{F} \quad \text { and } \quad l^{P C}=\frac{\Delta E_{F}}{-\left(\Delta E_{H}+\Delta E_{X}+\Delta E_{M}\right)}
$$

32 Adding a new sector to the policy base will increase the reduction of emissions targeted by the policy if it does not cause counteracting effects in sectors targeted before that are larger than the emissions reduction in the new sector. For a detailed discussion - relating however to global emissions and not just to emissions within the policy base - see the paragraph following Equation (8.22). 
As compared to a "pure" consumption-based policy, the import-tax-only policy additionally brings sector $X$ into the scope of the policy. This involves two terms that bring about a reduction in emissions - the first two terms on the right hand side of (8.21) - but also a "leakage term" that causes an increase in emissions by an increase of demand for the good competing with $X$, good $F$. This can be seen from the last term of (8.21). If the reduction of emissions caused by the tax in sector $X$ is larger in absolute value than the amount of leakage caused by it, then the import-tax-only policy will be environmentally more effective (i.e. will cause a larger reduction in global emissions) than the consumption-based one. In that case, the whole of (8.21) will be negatively signed. A similar comparison can be made for a production-based policy:

$$
\varepsilon_{E, p_{E}+t}^{P C}-\varepsilon_{E, p_{E}+t}^{P B}=\underbrace{\frac{E_{H}}{E} \eta_{h M} \theta_{M}}_{>0}+\underbrace{\frac{E_{M}}{E}\left[\eta_{m M} \theta_{M}-\sigma_{2}\left(1-\theta_{M}\right)\right]}_{<0} .
$$

Now, the import-tax-only policy adds the sector $M$ to the "pure" production-based policy. Again, this involves two emissions reduction terms - the last two terms on the right hand side of (8.22) - and a counteracting term - the first term on the right hand side. In this case, the counteracting term however does not describe "leakage," as the counteracting effect occurs in a sector that is included in the scope of the combined policy, in sector $H$ : it represents a shift in demand from good $M$ to good $H$ caused by the introduction of the tax on emissions embodied in $M$. Again, if the whole equation is negatively signed, then the import-tax-only policy will be the environmentally more effective option. This will always be the case if - as we have assumed - the emissions intensity in the production of the foreign $\operatorname{good} M, i_{M}$, is larger than the emissions intensity in the production of the domestic good $H, i_{H}$. Intuitively, taxing a carbonintensive good should lower emissions even if the tax shifts some of the demand to another good, as this "other" good $-H$ in our case - is produced with a lower carbonintensity. A formal proof is given in Appendix B to this chapter. ${ }^{33}$

Summarizing, the "import-tax-only" policy (if compared for a uniform carbon price across policy variants) leads to a larger reduction in global emissions and is thus

33 Start from Equation (8.22) and disregard the last term (which is negative) for the moment. Simplifying the other two terms on the right hand side and using the relationships $E_{H}=H e_{H}$ and $E_{M}=M e_{M}$, we see that (8.22) will be definitely negative if

$$
H e_{H} \eta_{h M}<-M e_{M} \eta_{m M}
$$

This is the relationship discussed in Appendix B to this chapter. It always holds true if $i_{M}>i_{H}$. Under this condition an import-tax-only policy will therefore be environmentally more effective than a production-based policy. 
environmentally more effective than either a production- or a consumption-based policy under fairly general conditions: the only assumptions required are that leakage in the domestic export sector $X$ is less than 100 percent and that the carbon intensity of imports $M$ is larger than that of domestic production $H$.

\subsubsection{Impact of an "import-tax-only" policy on competitiveness}

The effects on international competitiveness of the introduction of an "import-tax-only" policy will - as in the case of the production- and the consumption-based policy - again be measured by the (marginal) change in net exports $N$ :

$$
\frac{\partial N}{\partial t^{P C}}=\frac{\partial X}{\partial t^{P C}} \bar{p}_{X}-\frac{\partial M}{\partial t^{P C}} \bar{p}_{M}=\underbrace{X \bar{p}_{X} \eta_{x X} i_{H}}_{<0}-M \bar{p}_{M}(\underbrace{\eta_{m M} i_{M}}_{<0}+\underbrace{\eta_{m H} i_{H}}_{>0}) .
$$

From the perspective of region Home, there are two terms in (8.23) that lower its international competitiveness, the first and the last term on the right hand side, and one term that increases its competitiveness, the middle term on the right hand side. Overall without knowing the specific parameters values - it cannot be decided, whether Home's international competitiveness rises or falls: Home's exports are reduced, but - at least for typical parameter values - also Home's imports decline. The "import-tax-only" policy thus occupies the middle ground between policies targeting production and policies targeting consumption - it will neither increase Home's competitiveness as much as a consumption-based policy would (assuming typical parameter values), nor will it decrease Home's competitiveness as much as a production-based policy. And, of course, also for Foreign, which experiences exactly the opposite effects on its competitiveness as Home, the "import tax only" policy strikes a balance between a policy typically perceived as advantageous and one perceived as disadvantageous. Hence, this policy variant might stand a greater chance of being politically acceptable to both industrialized and developing countries than either of the "pure" policy variants.

\subsection{Climate policy costs}

This section examines the costs caused by the different variants of abatement policy compared in this chapter. As Weyant and Hill (1999, xvii) explain, abatement costs measured on the level of a whole economy "reflect the loss of surplus by consumers who are no longer willing to buy" the goods that have become more expensive due to the carbon tax (or other climate policy instrument) and also the loss of "producers who no longer find it profitable to produce" these goods. In our model, producers do not make profits in equilibrium and thus there is no producer surplus; all costs therefore represent the losses of surplus by the representative consumers in the two regions.

For the policy to be economically efficient, its costs have to be outweighed by environmental benefits. We will not attempt to estimate the environmental benefits of different policies - we just assume that they increase with the level of emissions reduction. This assumption will allow us to identify the more cost-effective policy even 
without specifying the size of benefits for the following two scenarios: either we compare two policies which cause the same level of emissions reduction but involve different abatement costs; or we compare two policies with the same abatement costs but different levels of emissions reduction (see Section 2.3.1).

In the following, the term cost thus always refers to costs net of any environmental benefits, i.e. to the "pure" costs of abatement. In our model, these costs are not given by explicit abatement cost functions. Rather, they are represented implicitly by the functions characterizing production and demand. As already discussed, these functions provide for different methods to reduce emissions: seen from the perspective of the consumer, either the "scale" of consumption may be reduced; or the "composition" 34 of consumption may be altered - the relatively "cleaner" good may be substituted for the relatively "dirtier" one; or the "technique" of production of the goods may be changed less of the polluting input fossil fuel may be used. And the possibility to change the "composition" of consumption also allows for what we might term "pseudo-abatement", i.e. shifting emissions to the other region and thereby causing carbon leakage. Of course, this possibility reduces costs per unit of reduced emissions only if these costs are not measured on a global basis, but separately for one of the two regions of the model. We will, however, start our discussion of costs by looking at global cost measures.

\subsubsection{Policy evaluation in terms of cost-effectiveness}

Most economists see cost-effectiveness as a more attractive policy evaluation criterion than environmental effectiveness - see Section 2.3.1. In fact, the comparison of abatement policies with equal tax rates performed in Sections 8.4 and 8.6 can be interpreted as a very simple cost-effectiveness analysis. To see why, note that producers and consumers will choose their level of abatement such that in equilibrium the tax rate (or carbon price) will equal marginal abatement costs. Thus the marginal abatement costs for the policies with equal tax rates are also equal. Now, given that marginal abatement cost are not decreasing with the level of abatement, the more cost-effective policy can easily be identified - it is the one that brings about the greater reduction in global emissions.

Figure 8.1 illustrates how this "simple method of cost-effectiveness analysis" works. Consider first panel (a) - it depicts a method of cost-effectiveness analysis sometimes applied in the CGE literature on border adjustments (see e.g. Boehringer et al. 2012a). The idea is to compare two policies that bring about an equal reduction of

34 Note that this change of the "composition" of consumption is conceptually somewhat different from the term "composition effect" introduced by Grossman and Krueger (1993). These two authors refer to a change of the size of the various sectors that make up a country's production. In the model of this study, each region produces only one good (or has only one "sector") for domestic consumption. Thus, it does not exhibit a "composition effect" in the sense of the concept of Grossman and Krueger. Rather, the only substitution possible for consumers is between domestically produced and imported products. 
emissions. $E_{0}$ is the level of emissions before the introduction of the policy. Emission shall be lowered to $E_{1}$. Policy $A$ with marginal abatement cost curve $M A C_{A}$ requires a tax rate $t_{A}$ to achieve this target; policy $B$ with marginal abatement cost curve $M A C_{B}$ a tax rate $t_{B}$. The tax rate $t_{B}$ and thus the marginal abatement costs of policy $B$ at emissions level $E_{1}$ is lower than $t_{A}$ and thus the marginal abatement costs of policy $A$ at emissions level $E_{1}$. The total costs of the emissions reduction are given by the area under the marginal abatement cost curve between $E_{1}$ and $E_{0}$, i.e. area $C$ for policy $B$ and area $C+D$ for policy $A$. One can see that total costs are smaller for the policy with smaller marginal abatement costs at $E_{1}$, i.e. policy $B$ - marginal abatement costs can therefore serve as an indicator to identify the policy with lower total costs. The argument, of course, rests on the assumption that the marginal abatement cost curves are not decreasing with the level of abatement.

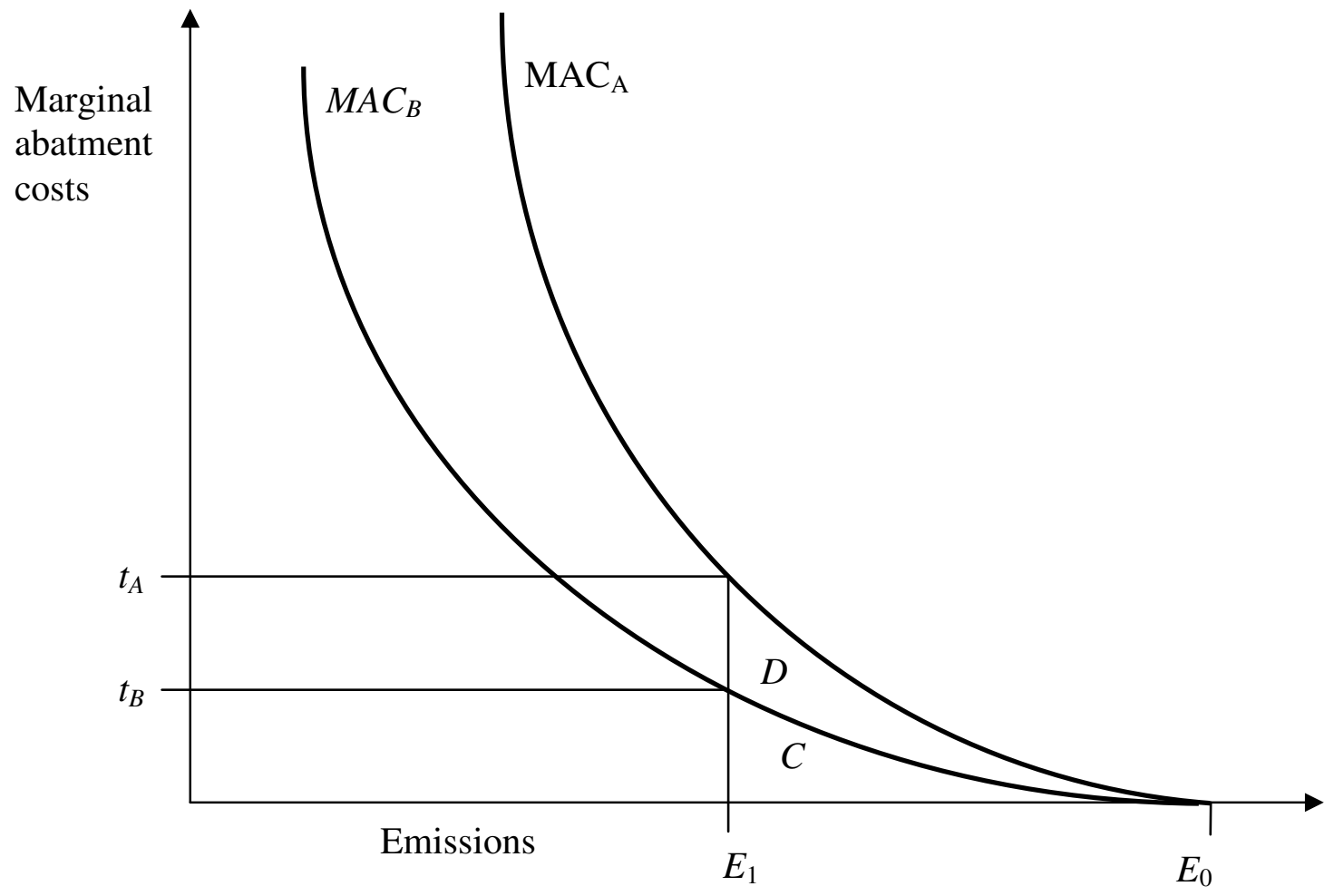

Figure 8.1a Cost-effectiveness of policies causing an equal emissions reduction (see the main text for details)

Now look at Figure 8.1b. This panel shows the kind of policy comparison applied in this study. This time, the two policies are not compared at the point where the emissions reduction is the same for both policies; rather it is assumed, that an equal tax rate $t_{A}$ is introduced for both policies - thereby marginal abatement costs are equalized between the policies. As we already know, with tax rate $t_{A}$ policy $A$ reduces emissions to level $E_{1}$. Additionally, we can see that policy $B$ with this tax rate reduces emissions to level $E_{2}$, which is a larger reduction than that brought about by policy $A$. Thus, now we can identify the policy with the lower total costs (for a given level of emissions 
reductions) by the fact that it is the one that leads to a larger emissions reduction for a given tax rate. Again, the precondition that marginal abatement costs are not decreasing with the level of abatement is essential. For our model this holds true - it is a consequence of the form of the production and demand functions assumed.

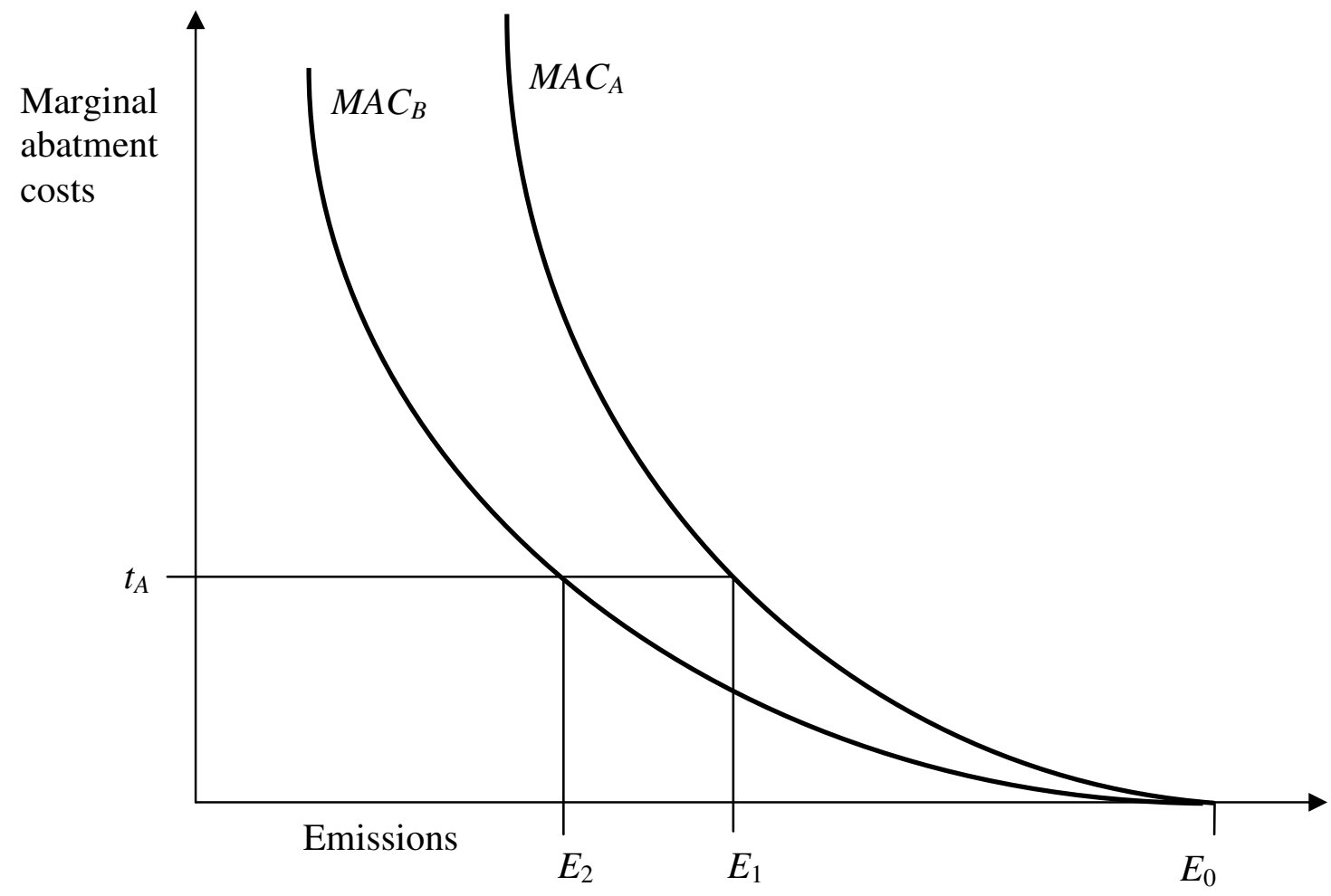

Figure 8.1b Cost-effectiveness of policies with the same tax rate (see the main text for details)

According to these arguments, the comparison of different policies with the same tax rate performed in Sections 8.4 and 8.6 qualifies as such a simple form of costeffectiveness analysis as depicted in Figure $8.1 \mathrm{~b}$ - only that the equal tax rate applied in these sections was an infinitesimal rate. Thus all results stated in Sections 8.4 and 8.6 for environmental effectiveness also hold for cost-effectiveness. ${ }^{35}$

35 One further qualification of such a type of analysis should be mentioned: as, for example, Stern (2007) points out, marginal abatement costs are a only very crude approximation to total or average abatement costs and their use may therefore be misleading. This warning, however, rather applies to studies interested in estimating the actual size of costs incurred by abatement policies. Here, on the other hand, we are not so much interested in quantitative results, but rather in discovering the basic economic relationships characterizing unilateral abatement policies. 
To recap the main results so far, whether a production- or a consumption-based policy applying the same carbon price is environmentally more effective - and as the arguments of this subsection show - thus also more cost-effective depends on the specific values of the parameters in our model. An "import-tax-only" policy, however, is environmentally more effective and therefore more cost-effective than the two other policy variants under fairly general conditions.

At least two objections could be raised against this finding - especially against qualifying the "import-tax-only" policy as more cost-effective than the consumptionbased policy variant: First, will the "import-tax-only" policy not introduce additional distortions by just taxing one of two goods demanded by the same representative consumer - more specifically by driving a wedge between the prices of good $X$ (the emissions embodied in which are taxed) and good $F$ (the emissions embodied in which are not taxed), which are both demanded by the representative consumer in Foreign? The consumption-based policy, on the other hand, does not drive a wedge between goods demanded by the same consumer: Both goods sold in Home are taxed, and both goods sold in Foreign are not taxed. While this argument is correct, it does not automatically render the consumption-based policy the more cost-effective one. First of all, a first-best policy would tax emissions in all four sectors of our model economy. Both the consumption-based and the "import-tax-only" policy are only second best options and both therefore involve distortions - the consumption-based variant by excluding even two sectors from the scope of the policy. Secondly, the inclusion of an additional sector in the scope of the policy enlarges the emissions base the policy is applied to. But with increasing marginal abatement costs it is always cheaper to reduce a large emissions base by a small amount than to reduce a small emissions base by a large amount in order to achieve a given absolute emissions reduction. Thus the policy with the larger emissions base will be the more cost-effective one. This result may be intuitively convincing - it however rests on a precondition: bringing an additional sector into the scope of the policy may have effects on the reduction of emissions in the sectors that were within the scope of the policy before. For example, the inclusion of the additional sector may cause leakage, i.e. a countervailing effect of the policy outside the policy region. Additionally, the additional sector may also induce countervailing effects within the policy region. Thus, to be precise, only if these counteracting effects in other sectors are smaller than the emission reduction in the additional sector, adding this sector indeed increases the cost-effectiveness of the policy. For the model of this study, these conditions are met - see the arguments in Section 8.6.1. But, for example, Steininger et al. (2014), using data from the EMF model comparison study discussed in Section 5.2.3, find that a consumption-based policy is (albeit only a little) more costeffective than an "import-tax-only" policy.

A second argument that might be employed to contest the greater cost-effectiveness of the "import-tax-only" policy is the following: Abatement options in developing countries are far cheaper than abatement options in industrialized countries. To further cost-effectiveness, one should therefore rather reduce more emissions embodied in the imports from developing and emerging economies instead of including the export sector of industrialized countries within the scope of the policy. Thus, a consumption-based 
policy would be the better choice. - This argument may be correct if separate quantitative emissions reduction targets are set for the imports going to industrialized countries and for their exports. But it does not apply to the scenario studied here: if the same tax rate is set for imports and exports, abatement will in both sectors be driven up to the point where marginal abatement costs equal the tax rate. Thus in both sectors the efficient amount of abatement will be chosen. If as argued the abatement of emissions embodied in imports is much cheaper than the abatement of emissions discharged in the production of exports, then most of the emissions reduction will indeed be achieved in the import sector; and in the export sector only those few abatement projects will be realized which have marginal abatement costs lower than the tax rate. But there is no need to completely exclude the export sector from the scope of the policy by pursuing a consumption-based policy variant - the application of a uniform tax rate will guarantee that no abatement will occur in this sector that is not cost-effective.

\subsubsection{Welfare effects of an emission tax}

To be able to attribute global abatement costs to the two regions, these costs have to be determined in more detail. To that end, we have to make the typical assumptions for welfare analysis in partial equilibrium, i.e. all prices except for $p_{H}, p_{X}, p_{M}$, and $p_{F}$ are fixed, there are no income effects on demand for $H, X, M$, and $F$, and utility is linear in all goods except for $H, X, M$, and $F$. The representative consumers of the two regions thus have quasi-linear utility functions. For each of the two representative consumers, utility (net of costs) derived from the consumption of the two goods in her consumption bundle can under these assumption be measured by Marshallian surplus (denoted by $S$ in the following), i.e. by the area below the demand curves for the two goods and above the (constant) market supply curves. The costs of the various abatement policies are then given by the change in Marshallian surplus triggered by the introduction of the policies. Additionally, we also need to be careful to correctly attribute tax revenues. These are fully recycled to consumers and thus on the global level are of no big concern. For each region individually, attribution however matters as it is not necessarily the case that the representative consumer who bears the tax burden is also the one who receives the tax revenues.

In the economic literature, welfare analysis in such a partial equilibrium setting is typically performed for output taxes. The "emissions tax" of our model is however equivalent to an input tax. The main difference is that unlike an output tax it does not only affect prices and quantities demanded and supplied of final goods, but also the choice of inputs in their production - represented in our model by the emissions rate. Therefore, for the analysis of this study the standard "textbook" approach of welfare analysis needs to be adapted to take account of possible welfare effects of the input choice. The method of this study relies on comparative statics and the linear approximation of policy effects. More specifically, there are no cross-effect or 
interaction terms between the two main channels of policy impact, i.e. between the changes in final goods prices triggered by the introduction of the tax and the change in the emissions rate triggered by the introduction of the tax. ${ }^{36}$ This facilitates examining the "price effect" and the emissions-rate effect" separately also in welfare analysis. Only the "price effect" will have consequences for the size of the Marshallian surplus. The change of the emissions rate, on the other hand, will due to the absence of crosseffects not influence the surplus. It will however influence the revenues made through the emissions tax - thus in cases where they are not recycled to the consumer who also bears the tax burden, these revenues need to be correctly accounted for.

Let us start our analysis by first considering a single sector of the model, say the production and consumption of good $H$, and by first looking on the "price effects" - and not the "emissions rate effects." The Marshallian surplus in this sector is given by

$$
S_{H}=u_{H}\left\{h\left(p_{H}(t), p_{M}(t)\right)\right\}-\bar{c}_{H} h\left(p_{H}(t), p_{M}(t)\right) .
$$

$u_{H}$ is the utility derived from the consumption of $H, h$ is - as before - the demand function for good $H$, and $\bar{c}_{H}$ are the unit costs of producing $H$ net of any tax. Equation (8.24) thus assumes that all taxes are recycled to the representative consumer. We can now examine the change of surplus - which, if its algebraic sign is reversed, represents the costs of the policy - for a change of the tax $t$ by one (infinitesimal) unit. For technical reasons, however, it is impossible to perform this type of analysis starting with a zero tax - in this case the introduction of an infinitesimal tax would not show any effect on welfare. Rather, one has to assume a pre-existing tax and then examine the consequences of changing this pre-existing tax by one infinitesimal unit: ${ }^{37}$

${ }^{36}$ For example, in the calculation of the effect of the tax on goods prices, our model uses the "pre-tax" emissions rate. Actually, of course both variables - the goods prices and the emissions rate - change simultaneously when the tax is introduced. A "correct" calculation would therefore, when calculating the effect of the tax on goods prices, use an emissions rate that also reflects the effect of the tax. Such "cross-effects" are however disregarded in an analysis that relies on linear approximation.

37 Mas-Colell et al. $(1995,332)$ provide the following explanation: "[S]tarting from a position without any tax, the first order welfare effect of an infinitesimal tax is zero. Only as the tax rate increases above zero does the marginal effect become strictly negative. This is as it should be: if we start at an (interior) welfare maximum, then a small displacement from the optimum cannot have a first-order effect on welfare." Also in sectors of our model that are not directly targeted by the emissions tax (for example, all sectors in Foreign under a production-based policy pursued by Home), a pre-existing tax must be assumed - otherwise, the cross-price effects in these sectors (responsible, for example, for leakage) would all have zero impact on welfare (Mas-Colell et al. 1995, 349). 


$$
\frac{\partial S_{H}}{\partial t}=\frac{\partial u_{H}}{\partial h}\left[\frac{\partial h}{\partial p_{H}} \frac{\partial p_{H}}{\partial t}+\frac{\partial h}{\partial p_{M}} \frac{\partial p_{M}}{\partial t}\right]-\bar{c}_{H}\left[\frac{\partial h}{\partial p_{H}} \frac{\partial p_{H}}{\partial t}+\frac{\partial h}{\partial p_{M}} \frac{\partial p_{M}}{\partial t}\right]
$$

The two terms inside the brackets give the two effects described in the paragraphs after Equation (8.2): the effect on demand for $H$ working through changes in the own-price of $H$ and the one working trough changes in the cross-price, i.e. the price of competing good $M$. Both terms together equal $\partial H / \partial t$. Additionally, with quasi-linear utility $\partial u_{H} / \partial h=p_{H}$. Using these relationships and simplifying, we obtain

$$
\frac{\partial S_{H}}{\partial t}=\underbrace{\left(p_{H}-\bar{c}_{H}\right)}_{\tilde{t}} \frac{\partial H}{\partial t} .
$$

As before, $t$ represents the input tax on fossil fuel. The difference between the price of good $H, p_{H}$, and its unit production costs, $\bar{c}_{H}$, however, does not equal this input tax $t$; rather it is given by an output tax that is equivalent to input tax $t$. Equivalence shall be defined such that the tax revenue (designated by $T$ ) of $t$ and the output tax - which will be labelled $\tilde{t}-$ be the same. This definition of equivalence can be used to determine the size of the output tax:

$$
T_{H}=E_{H} t=H \tilde{t} \Rightarrow \tilde{t}=\frac{E_{H}}{H} t=e_{H} t
$$

As a next step, substitute (8.27) for $\tilde{t}$ in (8.26) and (8.2) for $\partial H / \partial t$ :

$$
\frac{\partial S_{H}}{\partial t}=e_{H} t \frac{\partial H}{\partial t}=t E_{H}(\underbrace{\eta_{h H} i_{H}}_{<0}+\underbrace{\eta_{h M} i_{M}}_{>0}) .
$$

Equation (8.28) shows that a tax on emissions in the production of good $H$ leads to a reduction of surplus, i.e. it causes positive costs. If however also emissions embodied in $M$ are taxed, the welfare costs accruing in sector $H$ are reduced and may even become negative (note however that a tax on emission in $M$ will cause costs accruing in sector $M$, which are not shown in 8.28). Again, the overall effect depends on parameter values.

Graphically, Equation (8.28) gives what would be termed an infinitesimal change of the area of the "deadweight loss triangle" if the tax were a distortionary tax. The tax, however, is not distortionary; it rather corrects a distortion caused by a negative externality. Therefore, in this case, the triangle under question represents not deadweight loss, but abatement costs - in the sense of a "sacrifice" borne by consumers. 
Next, consider the effect of a change in the tax rate $t$ on the tax revenue $T_{H}=E_{H}(t) t$ in sector $H$ :

$$
\begin{aligned}
\frac{\partial T_{H}}{\partial t}= & \underbrace{\frac{\partial E_{H}}{\partial t} t}_{<0^{*}}+\underbrace{E_{H}}_{>0}=\underbrace{t e_{H} \frac{\partial H}{\partial t}}_{<0^{*}}+\underbrace{t H \frac{\partial e_{H}}{\partial t}}_{<0}+\underbrace{E_{H}}_{>0} . \\
& * \text { assuming no change of tax in competing sector } M
\end{aligned}
$$

An increase of the tax rate by one (infinitesimal) unit on the one hand raises the tax revenue by the number of emissions units taxed, $E_{H}$. On the other hand, the increase of the tax rate causes a drop of emissions by $\partial E_{H} / \partial t$, which lowers the tax revenue by this amount times any previous tax $t$ (assuming that there is not also a change of the tax on competing good $M$ ). For a sufficiently small tax $t$ the overall effect of an increase of the tax on the tax revenue must be positive, but there is a tax level from which onward a further increase in the tax level lowers the tax revenue.

The expression after the second equality sign in (8.29) - using (8.1) - splits the term $\left(\partial E_{H} / \partial t\right) t$ into two parts reflecting the two effects discussed above - the "price effect" (the first term after the second equality sign) and the "emission-rate effect" (the second term after the second equality sign). Let us compare these terms to Equation (8.28), which gives the cost of the policy: These costs equal the first term after the second equality sign of (8.29), i.e. only the part of the reduction of the tax revenue that is due to the "price effect" also constitutes a loss in consumer surplus and therefore qualifies as "abatement cost". The loss in tax revenue due to the "emissions-rate effect", on the other hand, does not influence final goods prices (recall that we have excluded cross-effects) and therefore does not affect the surplus. If it is the same consumer who bears the tax burden and who receives the tax revenues, then this consumer is indifferent to this loss in tax revenue as she is fully reimbursed for any gains or losses in tax revenues because of the recycling of the tax. Or put in other words: the "emissions rate effect" does not influence the size of the "deadweight loss triangle" - which in our case actually is an "abatement cost triangle". In the model of this study thus abatement that changes goods prices causes costs while abatement that changes the emissions rate in production does not cause costs. In part this result is, of course, due to the specifics of the model - the exclusion of second-order effects. Still, there is some practical relevance to this result - it shows that only in a situation where there is no possibility of "abatement by change of technique" abatement costs will be fully passed on to consumers and thus have a direct influence on consumer welfare.

\subsubsection{Distributional impacts of the different policy variants}

The discussion so far has established the "building blocks" which we may now combine to derive the overall effect on costs of a change in the tax for the two representative consumers of the model. We start with a production-based policy and the representative consumer in region Home and use the fact that the expressions for abatement costs and 
tax revenues in the other three sectors of our model are similar to those derived in SubSection 8.7.2 for sector $H$ :

$$
\begin{aligned}
\frac{\partial S_{1}}{\partial t^{P B}} & =\frac{\partial S_{H}}{\partial t^{P B}}+\frac{\partial S_{M}}{\partial t^{P B}}+\frac{\partial T_{X}}{\partial t^{P B}}= \\
& =\underbrace{t E_{H} \eta_{h H} i_{H}}_{<0}+\underbrace{t E_{M} \eta_{m H} i_{H}}_{>0}+\underbrace{t E_{X} \eta_{X X} i_{X}}_{<0} \underbrace{-t E_{X} \sigma_{1} \frac{1-\theta_{X}}{p_{E}+t}}_{<0}+\underbrace{E_{X}}_{>0} .
\end{aligned}
$$

As before, a negative change in surplus $S$ represents a positive (marginal) cost of the policy. The representative consumer in Home consumes goods $H$ and $M$; as can be seen from the first line of (8.30), the tax affects her consumer surplus in these sectors. The second line gives more details: there is a positive cost in sector $H$, as the tax makes good $H$ more expensive (the first term in the second line). The burden of this cost is however alleviated by a "negative cost" in sector $M$ (the second term in the second line) - the consumer can substitute the non-taxed good $M$ for the taxed good $H$, thereby causing carbon leakage. Technically, the cross-price effect on the demand for $M$ shifts out the demand curve for $M$ and thereby enlarges the consumer surplus in this sector. In addition to these effects on consumer surplus, the consumer in Home also receives the revenue from the tax on emissions embodied in good $X$, the export good of region Home - represented by the last term in the first line and the last three terms in the second line of (8.30). Thus we assume that as usual the tax revenue is collected by the country levying the tax, i.e. in this case Home. The welfare burden of the tax is however passed on to the representative consumer in Foreign: good $X$ becomes more expensive, the representative consumer in Foreign therefore looses consumer surplus. Thus, the representative consumer in Home receives the revenues of the tax on $X$ without having to bear an equivalent tax burden - she receives a "transfer" from the representative consumer in Foreign, and this transfer lowers the overall cost of the policy. As argued above, the marginal tax revenue will be positive for not too large values of $t$. The three last terms in the second line of (8.30) represent the three effects on tax revenue discussed above for a tax in sector $H$. Thus for small values of $t$ the last term will dominate the two other terms. Actually, this term may even dominate the whole of (8.30) - the "transfer" from Foreign may be larger than the abatement costs incurred in region Home; and the representative consumer in Home may even experience a gain and not a loss of welfare by the introduction of the abatement policy.

The situation in Foreign is reversed: the representative consumer must bear the abatement cost in sector $X$ and must additionally transfer the tax revenues from $X$ to region Home: 


$$
\begin{aligned}
\frac{\partial S_{2}}{\partial t^{P B}} & =\frac{\partial S_{X}}{\partial t^{P B}}-\frac{\partial T_{X}}{\partial t^{P B}}+\frac{\partial S_{F}}{\partial t^{P B}}= \\
& =\underbrace{t E_{X} \eta_{x X} i_{X}}_{<0} \underbrace{-t E_{X} \eta_{x X} i_{X}}_{>0}+\underbrace{t E_{X} \sigma_{1} \frac{1-\theta_{X}}{p_{E}+t}}_{>0} \underbrace{-E_{X}}_{<0}+\underbrace{t E_{F} \eta_{f X} i_{X}}_{>0}= \\
& =\underbrace{t E_{X} \sigma_{1} \frac{1-\theta_{X}}{p_{E}+t}}_{>0} \underbrace{-E_{X}}_{<0}+\underbrace{t E_{F} \eta_{f X} i_{X}}_{>0} .
\end{aligned}
$$

The first term in the second line represents abatement costs in sector $X$, the following three terms (which are the same as in (8.30), only the signs are reversed) give the tax revenue in $X$, which is transferred to Home. The last term is a "leakage term" which eases the burden of abatement costs in sector $X$ - it represents the increased consumer surplus in sector $F$ due to the cross-price effect triggered by the tax on emissions in $X$. The first two terms in the second line cancel each other, which then gives the third line. For not too large values of $t$, Equation (8.31) is unambiguously negative. ${ }^{38}$ Thus region Foreign is burdened with substantial costs by the pursuit of the climate policy, even though it is region Home, and not Foreign that introduces the policy.

The situation is different for a consumption-based policy:

$$
\begin{aligned}
\frac{\partial S_{1}}{\partial t^{C B}} & =\frac{\partial S_{H}}{\partial t^{P B}}+\frac{\partial S_{M}}{\partial t^{P B}}= \\
& =t E_{H}\left(\eta_{h H} i_{H}+\eta_{h M} i_{M}\right)+t E_{M}\left(\eta_{m H} i_{H}+\eta_{m M} i_{M}\right), \\
\frac{\partial S_{2}}{\partial t^{C B}} & =0 .
\end{aligned}
$$

As can be seen from (8.32) and (8.33), all costs of the policy are borne by the representative consumer in Home - and none by the one in Foreign. This is due to the

\footnotetext{
${ }^{38}$ The sign of (8.31) can be determined as follows: the sum of the first and the last term in the second line must be negative if leakage in sector $X$ does not exceed 100 percent. The second, the third, and the fourth term represent the (change in the) tax revenue, which - as argued above - is positive for not too large values of $t$. But as the signs of these three terms are reversed, their sum is negative and therefore the whole Equation (8.31) is negatively signed.
} 
fact that only goods consumed by the representative consumer in Home are taxed, and that producers can pass on all costs to consumers.

Finally, let us consider an "import-tax-only" policy, first for the representative consumer in Home:

$$
\begin{aligned}
\frac{\partial S_{1}}{\partial t^{P C}}= & \frac{\partial S_{H}}{\partial t^{P C}}+\frac{\partial S_{M}}{\partial t^{P C}}+\frac{\partial T_{X}}{\partial t^{P C}}= \\
= & t E_{H}(\underbrace{\eta_{h H} i_{H}}_{<0}+\underbrace{\eta_{h M} i_{M}}_{>0})+t E_{M}(\underbrace{\eta_{m M} i_{M}}_{<0}+\underbrace{\eta_{m H} i_{H}}_{>0})+ \\
& +\underbrace{t E_{X} \eta_{x X} i_{X}}_{<0} \underbrace{-t E_{X} \sigma_{1} \frac{1-\theta_{X}}{p_{E}+t}}_{<0}+\underbrace{E_{X}}_{>0} .
\end{aligned}
$$

The terms in the second line of (8.34) are the same as those of a consumption-based policy, but in addition there is a transfer of tax revenues from region Foreign (shown in the third line of the equation) as with a production-based policy. Due to this transfer (which, as argued above, is positive for sufficiently small values of $t$ ) the policy will be less costly for Home than a consumption-based policy. If the emissions intensity is higher in Foreign than in Home, costs for Home will however be higher than for a production-based policy - see the proof in Appendix B to this chapter. Still, as with a production-based policy, costs for Home also for the "import-tax-only" policy may be either positive or negative. For region Foreign, on the other hand, nothing changes as compared to a production-based policy, i.e. Equation (8.31) gives the change of surplus also for an "income-tax-only" policy.

The main result of this cost comparison between regions is that the costs of the policy are lower (actually they equal zero) for region Foreign, if Home follows a consumption-based policy than if it follows a production-based or an "import-tax-only" policy. For region Home the outcome is reversed - it would prefer a production-based policy on cost grounds, followed by an "income-tax only policy", with the consumption-based policy ranking third (and last). If we again assume that Foreign consists of developing and emerging economies, these countries are therefore better-off under a consumption-based policy in the setting of our model. This result rests to a great extent on the model characteristic that the tax burden is fully shifted onward to consumers.

By contrast, most CGE models come to the conclusion that a switch to a consumption-based policy actually reduces the welfare of developing and emerging economies - see the discussion in Chapter 5. The assumptions about cost pass-through possibilities are thus essential for the distributional effects of a switch of the policy base. But whatever assumptions better represent real-world circumstances, our model- 
based analysis demonstrates clearly that (i) not only the country that introduces the policy must bear the cost of this policy, and (ii) no "exotic" assumption need to be made to produce a result where a substantial share - or even all - costs are shifted onward across borders; even in a model relying on a fairly standard setting as ours such an outcome is possible.

\subsubsection{Costs vs. competitiveness effects as measures of the "policy burden"}

Finally, the difference between the welfare measures developed in this section and the competitiveness measures discussed in Sections 8.2.2, 8.3.3, and 8.6.2 shall be briefly pointed out. In the model of this study, all costs of the policy are passed on to the consumer. There are no profits in equilibrium and therefore the introduction of the policy does not cause any loss of profits; and the prices of the factors of production stay constant - thus there also is no loss of factor income per unit of factor supplied. Factor employment does change with the introduction of the policy, but as there are no factor rents, this does not have any welfare effect. Thus, the welfare measure of this study is a "consumption-focused" measure. Competitiveness - measured by net export volumes on the other hand is not a welfare measure in a strict sense; however, it is often seen as being related to welfare or policy costs. The idea is that a loss of competitiveness brings about a contraction of the domestic industry at the expense of the foreign one. And this contraction leads to a loss of profits as well as a loss of factor income like, for example, income from wages. Our model, as just argued, is constructed such that actually neither profits are lost nor wages are lowered by the introduction of the policy - but one could argue the following way: if the model were built in a way as to exhibit changes in factor compensation rates and profits, these would be indicated also by a change in the competitiveness measure. One could therefore use competitiveness as a "proxy measure" for welfare changes on the side of firms and suppliers of factors of production; and one could even for our model interpret changes in competitiveness brought about by the introduction of climate policy in such a way - although, in a strict sense, our model does not incorporate such a mechanism. Thus, loosely speaking, one could see the welfare measures discussed in this section as focusing exclusively on welfare derived from the consumption of goods, while the competitiveness measure may be seen as a concept that rather emphasizes welfare from profits and factor income. $^{39}$

39 Of course, in standard welfare analysis ultimately all welfare is derived only from consumption. The distinction here is just drawn to emphasize the two ways how a consumer's welfare can be reduced: either (a) the goods in the consumer's consumption bundle become more expensive and she therefore must reduce the consumption of these goods or (b) her income falls, which also means that she now cannot afford to consume as many goods as before. 


\subsection{Conclusion}

With the help of a small analytical model, this chapter has examined climate policy transmission through the transmission channel most widely discussed in the academic literature and also in the general public - the "non-energy markets" channel, or as it is often called in the carbon leakage literature, "competitiveness channel." Table 8.1 summarizes the main advantages and disadvantages of the three policy variants being compared - a production-based policy, a consumption-based policy, and a policy combining these two approaches termed "income-tax-only" policy. Under the assumption that carbon leakage does not exceed 100 percent, all three policies are suited to contribute to the reduction of global emissions. If the emission intensity in the nonabating region is higher than in the region introducing the policy, the "import-tax-only" policy, however, clearly performs best according to the criterion of global emission reduction and thus environmental effectiveness. According to a simple measure of costeffectiveness, it is also the most cost-effective policy. But the "import-tax-only" policy might be the favored policy variant also for other reasons: on the criteria of "climate policy costs" and "impact on competitiveness" it strikes a balance between the other two policy variants that either benefit the abating or the non-abating countries - in international negotiations it therefore may be seen as a possible compromise solution by both regions.

The production-based policy, on the other hand, obviously performs best if the aim of the policy is not the reduction of global emissions, but just the reduction of the production-based emissions of the abating region, while the consumption-based policy performs best on the criterion of carbon-leakage - in the sense as this criterion is employed in this study, i.e. a consumption-based policy does involve the least (actually: zero) increase of emissions not directly targeted by the policy. As argued at various points in this study, carbon leakage however measures only one aspect of environmental effectiveness - the choice between different policies should therefore be based directly on the criterion of environmental effectiveness and not on the criterion of carbon leakage. For the abating region, a consumption-based policy will also be the one with the most favorable effects on competitiveness (but the reverse holds true for the nonabating region). As concerns climate policy costs, the abating region will however favor a production-best policy. As discussed in Section 6.7, this result does not conform to the findings of most CGE studies. The reason why climate policy costs are so low for the abating region under a production-based policy in the model of this study is that the burden of taxing the abating region's exports is fully passed on to the non-abating region. 
Table 8.1 Comparison of climate policies with different tax bases

\begin{tabular}{|c|c|c|c|c|}
\hline \multicolumn{2}{|l|}{ Criterion } & $\begin{array}{l}\text { Production- } \\
\text { based policy }\end{array}$ & $\begin{array}{l}\text { Consumption- } \\
\text { based policy }\end{array}$ & $\begin{array}{l}\text { "Import-tax- } \\
\text { only" policy }\end{array}$ \\
\hline $\begin{array}{l}\text { Environmental effectiveness } \\
\text { (change of global emissions) }\end{array}$ & $\Delta E$ & $?(-)^{\mathrm{a}}$ & - & $\begin{array}{c}?^{(-)^{\mathrm{a}}} \\
(\text { best })^{\mathrm{a}, \mathrm{b}}\end{array}$ \\
\hline Change of domestic emissions & $\Delta\left(E_{H}+E_{X}\right)$ & -, best & $?$ & $?$ \\
\hline Leakage ratio (PB target) & $l^{P B}$ & + & ? & + \\
\hline $\begin{array}{l}\text { Leakage ratio (effects } \\
\text { outside of tax base) }\end{array}$ & & $\begin{array}{l}\left(l^{P B}\right) \\
+\end{array}$ & $\begin{array}{c}\left(l^{C B}\right) \\
\mathbf{0}, \text { best }\end{array}$ & $\begin{array}{l}\left(l^{P C}\right) \\
+\end{array}$ \\
\hline Competitiveness (of Home) & $\Delta N$ & - & $(+)^{c}$, best & ? \\
\hline $\begin{array}{l}\text { Distributional impact } \\
\text { for region Home }\end{array}$ & $\Delta S_{1}$ & $?(\text { best })^{b}$ & - & $?$ \\
\hline $\begin{array}{l}\text { Distributional impact } \\
\text { for region Foreign }\end{array}$ & $\Delta S_{2}$ & - & $\mathbf{0}$, best & - \\
\hline
\end{tabular}

The impacts of the three policy variants are denoted as follows: a minus sign, [-], signifies that the variable listed as "criterion" is negatively signed, a plus sign, [+], that it is positively signed, a question mark, [?], that the sign depends on the specific parameter values and cannot be determined in general; "best" means that the policy variant thus marked performs better than the other two policy variants in the sense as the criterion is typically used in the policy debate, i.e. "best" marks the policy with the largest global or domestic emission reduction, the smallest leakage ratio, the largest positive effect on competitiveness, and the least costs. If signs are given in parenthesis, e.g. (-) or (best), "mild" additional assumptions are required to derive the result. More specifically:

a holds under the assumption that the leakage ratio is less than 100 percent,

b holds under the assumption that the emissions intensity in Foreign is larger than in Home, and

c holds under the assumption that $\left|\eta_{m M} i_{M}\right|>\eta_{m H} i_{H}$.

If one wants to select a policy according to the criterion of environmental effectiveness, and if the adoption of an "import-tax-only" policy (which, as we have seen, according to this criterion performs better than the other two policy variants) is not possible, one is actually confronted with a difficult choice: the question whether one should opt for a production-based or a consumption-based policy variant cannot be answered in general; the answer depends on the specific values of parameters and variables - and the detailed design of the instrument used to implement the policy. Table 8.2 gives an overview of how the advantages and disadvantages of the two policy variants change with changing parameter values. 
Table 8.2 Parameter values and environmental effectiveness of policy variants

\begin{tabular}{|c|c|c|}
\hline \multicolumn{2}{|c|}{ Parameter or variable } & \multirow{2}{*}{$\begin{array}{c}\begin{array}{c}\text { Policy } \\
\text { variant }\end{array} \\
P B\end{array}$} \\
\hline Coalition size $^{\mathrm{a}}$ & $G D P_{1} / G D P$ & \\
\hline Exports & $X$ & $\boldsymbol{P B}$ \\
\hline Imports & $M$ & $\boldsymbol{C B}$ \\
\hline Emission rate in domestic production & $e_{H}, e_{X}$ & $?$ \\
\hline Emission rate in foreign production & $e_{M}, e_{F}$ & $C B^{b}$ \\
\hline Ease of input substitution in Home & $\sigma_{1}$ & $P B$ \\
\hline Ease of input substitution in Foreign & $\sigma_{2}$ & $\boldsymbol{C B}$ \\
\hline \multirow[t]{4}{*}{ Price-sensitivity of demand } & $\eta_{h H}$ & $=$ \\
\hline & $\eta_{x X}$ & $\boldsymbol{P B}$ \\
\hline & $\eta_{m M}$ & $\boldsymbol{C B}$ \\
\hline & $\eta_{f F}$ & $=$ \\
\hline \multirow{4}{*}{$\begin{array}{l}\text { Ease of substituting foreign for } \\
\text { domestic products and vice versa }\end{array}$} & $\eta_{h M}$ & $P B$ \\
\hline & $\eta_{m H}$ & $=$ \\
\hline & $\eta_{x F}$ & $=$ \\
\hline & $\eta_{f X}$ & $\boldsymbol{C B}$ \\
\hline
\end{tabular}

This table depicts the dependence of the environmental effectiveness of production- and consumptionbased policies on the values of individual parameters and variables. More specifically, the last column lists the policy variant the environmental effectiveness of which increases relatively (as compared to the environmental effectiveness of the alternative policy variant) with increasing values of the parameter or variable given in the first two columns. " $P B$ " means that the production-based policy variant becomes relatively more effective, " $C B$ " means that the consumption-based policy variant becomes relatively more effective, "=" denotes that for this parameter or variable, the choice of policy-base does not influence environmental effectiveness, and "?" means that the question of relative policy effectiveness cannot be decided without knowing the values of some of the other parameters. For example, for the variable "coalition size", which (as can be seen from the second column) is defined by $G D P_{1} / G D P$, the symbol in third column is " $P B$ ". This means that with growing "coalition size," a production-based policy will become environmentally more effective as compared to a consumption-based policy.

a see the main text of this sub-section and Footnote 40 for a precise definition.

${ }^{\mathrm{b}}$ parameter restrictions apply - see the main text of this sub-section and Footnote 42.

The first variable listed in Table 8.2, "coalition size," is defined as the GDP of the abating coalition relative to world GDP. There are actually many ways how one can 
change the coalition's GDP - one therefore has to be precise which variables are altered and which are not. Details are given in a footnote. ${ }^{40}$ The effects of changing some variable or parameter can most easily be traced by examining an equation giving the same information as (8.18), but arranged somewhat differently - it is also given in a footnote. ${ }^{41}$ Table 8.2 shows that with increasing coalition size a production-based policy becomes relatively more effective. This is due to the fact that leakage falls with coalition size (simply, as the economic size of the region where leakage can take place becomes smaller) and that the cross-price effect on demand for domestic good $H$, which makes a consumption-based policy less effective, increases with growing coalition size and thus growing values of $H$ (for a detailed discussion of this effect see Section 8.4.2). A consumption-based policy is therefore especially attractive if the abating coalition is rather small. As concerns exports and imports, the results listed in Table 8.2 are as one would expect: the larger the quantity of exports, the more attractive becomes a production-based policy; and the larger the quantity of imports, the more attractive is a consumption-based approach.

${ }^{40}$ In our model, the ratio of "coalition GDP", i.e. GDP of the region Home, to world GDP can be changed by changing any of the variables $H, X, M$, and $F$, and also by changing the prices of these four goods. But not all of these possible changes actually reflect what we typically have in mind when we talk of "increasing the coalition size". A more or less "realistic" scenario for increasing the coalition size would look as follows: World GDP remains constant; the coalition, however, grows by taking in more and more countries - thus coalition GDP grows and non-coalition GDP falls by the same amount. Also, in real world situations typically the share of exports in a region's production and the share of imports in a region's consumption fall with increasing size of the region. Here, we will represent this thought experiment of changing the coalition size in a simplified form: all prices $\left(p_{H}, p_{X}, p_{M}\right.$, and $\left.p_{F}\right)$ as well as $X$ and $M$ remain constant. Furthermore, we assume that $p_{H}$ equals $p_{F}$. An increase of the coalition size can then be represented by an increase of $H$ and a reduction of $F$ by the same amount.

41 The difference in the reduction of global emissions between a production- and a consumption-based policy is given by

$$
\begin{aligned}
\frac{\partial E}{\partial t^{P B}}-\frac{\partial E}{\partial t^{C B}}=\frac{1}{p_{E}+t} & \{\underbrace{\left\{H e_{H} \eta_{h M} \frac{e_{M}\left(p_{E}+t\right)}{c_{M}}\right.}_{<0}+\underbrace{X e_{H}\left[\eta_{x X} \frac{e_{H}\left(p_{E}+t\right)}{c_{H}}-\sigma_{1}\left(1-\frac{e_{H}\left(p_{E}+t\right)}{c_{H}}\right)\right]}_{<0} \\
& \underbrace{-M e_{M}\left[\eta_{m M} \frac{e_{M}\left(p_{E}+t\right)}{c_{M}}-\sigma_{2}\left(1-\frac{e_{M}\left(p_{E}+t\right)}{c_{M}}\right)\right]}_{>0}+\underbrace{F e_{M} \eta_{f X} \frac{e_{H}\left(p_{E}+t\right)}{c_{H}}}_{>0}\} .
\end{aligned}
$$

Again, to simplify the analysis, it was assumed that there is no previous tax in place (due to this assumption, inter alia, $e_{X}$ equals $e_{H}$ and $e_{F}$ equals $e_{M}$ ). The equation actually gives the same information as Equation (8.18) - only that it is not written in elasticity form and that some of the variables in (8.18) have been further disaggregated. Again, if the whole equation is positive, then a consumption-based policy is the more effective one. To investigate the effects of changes in parameter values, differentiate this equation with respect to the parameter under question. Note, however, that one needs to be careful when examining the effects of changes of endogenous variables - see Footnote 24 for a more detailed discussion. 
Determining the effects of increasing emissions rates on the effectiveness of the two policy variants is a little more complicated. Consider first the emissions rate in region Home, i.e. $e_{H}$ and $e_{X}$. As can be seen from the equation in Footnote 41, increasing this emissions rate has a multitude of different effects: it raises the amount of abatement in the export sector $X$ by curbing demand for $X$ and thus makes a productionbased policy more effective; whether it also contributes to "greening" production in this sector (thereby making a production-based policy even more effective) however depends on the values of other parameters; also the cross-price effect on $H$ under a consumption-based policy gets stronger with increasing values of $e_{H}$, which again makes the production-based approach more effective relative to the consumption-based one. But increasing $e_{H}$ also increases leakage, which, on the other hand, makes the consumption-based policy (which does not involve leakage) the more effective option. Taken together, the question, which policy variant becomes more effective with increasing values of the emission rate in Home, is decided by the specific values of many of the other parameters and can therefore not be answered in general. In Table 8.2 therefore a question mark (?) is entered in the respective field. As concerns the emissions rate in Foreign, i.e. $e_{M}$ and $e_{F}$, however, relatively simple parameter restrictions suffice to guarantee a definite result: if the share of costs of fossil fuel is less than half of the overall production costs of imports, and if the emissions intensity in region Foreign is larger than in Home, then a consumption-based policy becomes relatively more effective with an increase in the emissions rate in Foreign (these are sufficient, but not necessary conditions - depending on the values of the other parameters, in many cases actually far weaker conditions will suffice to guarantee this result). ${ }^{42}$ Thus, under these conditions a very high emissions rate in the non-abating countries may be seen as an argument for adopting a consumption-based policy.

42 To prove this result, assume - like in Footnote 24 - that the quantities of goods demanded and the unit production costs remain fixed while $e_{M}$ is varied. Now differentiate the equation from Footnote $41-$ we will label it $A$ - with respect to $e_{M}$ :

$$
\frac{\partial A}{\partial e_{M}}=\underbrace{-\frac{H e_{H} \eta_{h M}}{c_{M}}}_{T_{1}<0} \underbrace{-\frac{2 M e_{M} \eta_{m M}}{c_{M}}}_{T_{2}>0}+\underbrace{\frac{M \sigma_{2}}{p_{E}+t}}_{T_{3}>0} \underbrace{-\frac{2 M e_{M} \sigma_{2}}{c_{M}}}_{T_{4}<0}+\underbrace{\frac{F \eta_{f X} e_{H}}{c_{H}}}_{T_{5}>0} .
$$

First, consider the first and the second term of the equation, $T_{1}$ and $T_{2}$. Their sum will be $>0$ if $-H e_{H} \eta_{h M}-2 M e_{M} \eta_{m M}>0$. Appendix B to this chapter demonstrates that $H e_{H} \eta_{h M}<-M e_{M} \eta_{m M}$ if $i_{M}>i_{H}$. Thus under this condition also the sum of $T_{1}$ and $T_{2}$ will definitely be positive. Next, look at $T_{3}$ and $T_{4}$. These two terms give the effect on emissions through the change of the emissions rate in the production of imports (the "greening" of imports). By rearranging terms one can see that the sum of $T_{3}$ and $T_{4}$ will be positive if the following condition holds: $1 / 2 c_{M}>e_{M}\left(p_{E}+t\right)$. The fifth term of the equation above, $T_{5}$, will always be positive. Thus we have established two conditions that - if they both hold - guarantee that the whole equation is positive, i.e. that a consumption-based policy becomes relatively more effective with increasing values of the emissions rate in Foreign. These conditions are (i) that the emissions intensity in region Foreign is larger than in Home, and (ii) that the share of costs 
The impact of the ease of input substitution on the relative effectiveness of the two policy variants is as one would expect: the easier input substitution in production in region Home (and thus in the production of Home's exports), the more effective becomes a production-based policy; and the easier input substitution in production in region Foreign (and thus in the production of Home's imports), the more effective becomes a consumption-based policy. The price sensitivity of region Home's domestic product $H$ and region Foreign's domestic product $F$ is irrelevant for the choice of policies - as both policy variants target $H$ and do not target $F$. But the price-sensitivity of imports and exports matters: as expected, an increase of the price sensitivity of imports increases the relative effectiveness of a consumption-based policy, and an increase of the price-sensitivity of exports increases the relative effectiveness of a production-based policy. Also, the ease of switching consumption to the domestic product $H$ in case of an increase of the price of imports is important: the easier such a switch becomes, the less effective is a consumption-based policy - and the relatively more effective therefore a production-based policy. Finally, also the question how readily consumers in Foreign switch their consumption to their domestic products if the price of exports to Foreign rises, is crucial: it governs the size of leakage - with an increasing readiness to switch consumption towards product $F$ the consumption-based policy variant becomes relatively more effective, as it does not involve carbon leakage.

Apart from these parameters and variables, also the design of the taxation scheme is important for the relative effectiveness of the two policies: if the tax on imports is not based on the true carbon content of imports but on an (unchangeable) benchmark, then the incentive to "green" the production of imports is lost - and thus a consumptionbased policy loses some of its attractiveness in terms of environmental effectiveness. If additionally the benchmark has not been calculated using data on the emissions intensity in foreign products, but, for example, is based on the emissions intensity of similar domestic products, then - in case the emissions intensity in Foreign is higher than in Home - the environmental effect of the tax is further reduced. In that case, a policy targeting emissions in imports like a consumption-based policy loses even more of its possible advantages in the reduction of emissions.

of fossil fuel in the production costs of imports is less than half of the overall production costs of imports. Note that these conditions are sufficient but not necessary for obtaining the result just stated. 


\section{Appendix A: Relationships between the price elasticities of demand of the representative consumers of the model}

This appendix demonstrates that a consumption-based policy will always lead to a reduction (and not an increase) in global emissions through the non-energy market policy transmission channel. We start from Equation (8.15). As can be seen, the policy affects emissions discharged in the production of goods $H$ and $M$. Both goods are consumed by only one of the two representative consumers of our model, the representative consumer of region Home.

We will analyze the effect of the introduction of a positive tax. Our aim is to show that this will cause a drop in emissions in the production of $H$ and $M$, i.e. that $\partial E / \partial t^{C B}<0$. The two terms $-\sigma_{1}\left(1-\theta_{H}\right)$ and $-\sigma_{2}\left(1-\theta_{M}\right)$ in $(8.15)$ will always be negative. It therefore suffices to show that the remainder of $(8.15)$ - which we will denote by the letter $V$ - cannot become positive. To this end, we first employ the HicksSlutsky equation in elasticity form to disaggregate the four price elasticities of demand in (8.15) into net substitution and income components:

$$
\begin{aligned}
V=\frac{E_{H}}{p_{E}+t^{C B}} & {\left[\theta_{H}\left(\left.\frac{\partial H}{\partial p_{H}}\right|_{U=\text { const. }} \frac{p_{H}}{H}-H \frac{\partial H}{\partial I} \frac{p_{H}}{H}\right)+\right.} \\
& \left.+\theta_{M}\left(\left.\frac{\partial H}{\partial p_{M}}\right|_{U=\text { const. }} \frac{p_{M}}{H}-M \frac{\partial H}{\partial I} \frac{p_{M}}{H}\right)\right]+ \\
+\frac{E_{M}}{p_{E}+t^{C B}} & {\left[\theta_{H}\left(\left.\frac{\partial M}{\partial p_{H}}\right|_{U=\text { const. }} \frac{p_{H}}{M}-H \frac{\partial M}{\partial I} \frac{p_{H}}{M}\right)+\right.} \\
& \left.+\theta_{M}\left(\left.\frac{\partial M}{\partial p_{M}}\right|_{U=\text { const. }} \frac{p_{M}}{M}-M \frac{\partial M}{\partial I} \frac{p_{M}}{M}\right)\right] .
\end{aligned}
$$

$I$ denotes income (of the representative consumer). As both $H$ and $M$ are normal goods, the income components - the second terms in parentheses in each line - are all negative. Thus they also cause emissions to fall. If we are now able to show that the sum of the other four terms - the net substitution components - cannot become positive, $V$ will definitely be smaller than zero. The net substitution components represent the elasticities of compensated demand (as opposed to the four original elasticities $\eta_{h H}, \eta_{h M}$, $\eta_{m H}$, and $\eta_{m M}$, which are calculated from non-compensated demand). We will now use two results that hold true for compensated demand, if a consumer's expenditure function is twice continuously differentiable: (a) the cross-substitution effects are symmetric: $\partial H /\left.\partial p_{M}\right|_{\mathrm{u}=\mathrm{const}}=\partial M /\left.\partial p_{H}\right|_{\mathrm{u}=\mathrm{const}}$; and (b) the substitution matrix $S=\left[\partial x_{i} /\left.\partial p_{j}\right|_{\mathrm{u}=\text { const. }}\right]$, i.e. the matrix formed from all substitution and cross-substitution terms, is negative semidefinite. From (b) we have: 


$$
\left.\left.\frac{\partial H}{\partial p_{H}}\right|_{U=\text { const. }} \frac{\partial M}{\partial p_{M}}\right|_{U=\text { const. }}-\left.\left.\frac{\partial H}{\partial p_{M}}\right|_{U=\text { const. }} \frac{\partial M}{\partial p_{H}}\right|_{U=\text { const. }} \geq 0 .
$$

(8A.2) can also be written in elasticity form. If we additionally multiply each elasticity by the factor of the respective elasticity in Equation (8A.1), we arrive at a relationship between the changes in emissions caused by the net substitution terms:

$$
\begin{gathered}
\frac{E_{H}}{p_{E}+t^{C B}} \theta_{H}\left(\left.\frac{\partial H}{\partial p_{H}}\right|_{U=\text { const. }} \frac{p_{H}}{H}\right) \frac{E_{M}}{p_{E}+t^{C B}} \theta_{M}\left(\left.\frac{\partial M}{\partial p_{M}}\right|_{U=\text { const. }} \frac{p_{M}}{M}\right) \\
-\frac{E_{H}}{p_{E}+t^{C B}} \theta_{M}\left(\left.\frac{\partial H}{\partial p_{M}}\right|_{U=\text { const. }} \frac{p_{M}}{H}\right) \frac{E_{M}}{p_{E}+t^{C B}} \theta_{H}\left(\left.\frac{\partial M}{\partial p_{H}}\right|_{U=\text { const. }} \frac{p_{H}}{M}\right) \geq 0 .
\end{gathered}
$$

Now consider the two cross-elasticity terms - the second line of (8A.3). We will show that they are equal. By result (a) we can substitute $\partial H /\left.\partial p_{M}\right|_{\mathrm{u}=\text { const. }}$ for $\partial M /\left.\partial p_{H}\right|_{\mathrm{u}=\text { const. in }}$ the second of the two terms. Using (7.3) and (8.3), we also substitute for $E_{H}, E_{M}, \theta_{H}$, and $\theta_{M}$ :

$$
\begin{aligned}
& \frac{e_{H} H}{p_{E}+t^{C B}} \frac{e_{M}\left(p_{E}+t^{C B}\right)}{c_{M}} \frac{p_{M}}{H}\left(\left.\frac{\partial H}{\partial p_{M}}\right|_{U=\text { const. }}\right)= \\
= & \frac{e_{M} M}{p_{E}+t^{C B}} \frac{e_{H}\left(p_{E}+t^{C B}\right)}{c_{H}} \frac{p_{H}}{M}\left(\left.\frac{\partial H}{\partial p_{M}}\right|_{U=\text { const. }}\right) .
\end{aligned}
$$

As can be seen from (8A.4), the two cross-elasticity terms in (8A.3) are indeed equal. (8A.3) is therefore of the form $a b-c^{2} \geq 0$. For $a, b<0$ and $c>0$, this however implies $|a+b|-2 c \geq 0$, and that is exactly what we wanted to show: The sum of the (negative) own-price net elasticity terms is larger or equal in absolute value than the sum of the (positive) cross-price net elasticity terms; the change in emissions triggered by all four net substitution terms taken together is therefore smaller or equal to zero. And as all the other terms in (8.15) and (8A.1) are negative - the income effect terms as well as the terms $-\sigma_{1}\left(1-\theta_{H}\right)$ and $-\sigma_{2}\left(1-\theta_{M}\right)$, the gross fuel price elasticity of the emissions rate the introduction of a positive tax indeed causes a drop in emissions in the production of $H$ and $M$.

In a similar way one can also prove that $\partial E / \partial p_{E}$ and the elasticity $\varepsilon_{E, p E}$ are both strictly smaller than zero - see Equation (9.7): Start by splitting the four goods of the model into two pairs: the pair of goods demanded by the representative consumer in region Home, $H$ and $M$, and the pair of goods demanded by the representative consumer in Foreign, $X$ and $F$. For each pair of goods one can then show separately that a rise of 
the fuel price leads to a drop in emissions. Thus, the overall effect of an increase in the fuel price is a drop in emissions.

\section{Appendix B: Relationships between elasticities following from the Cournot aggregation condition}

In this appendix, a relationship involving elasticities and quantities demanded will be discussed that proves useful at various points in the course of this chapter. Our aim is to derive a condition that guarantees that the following inequality holds true:

$$
H e_{H} \eta_{h M}<-M e_{M} \eta_{m M}
$$

To that end, we will make use of a general relationship between own-price and crossprice elasticities that is usually called "Cournot aggregation condition":

$$
\eta_{i i}=-1-\frac{\sum_{j \neq i} \eta_{j i} s_{j}}{s_{i}}
$$

$\eta_{i i}$ is the own-price elasticity of demand for a good $i, \eta_{j i}$ are the cross-price elasticities of demand of other goods $j$ with respect to the price of good $i$, and $s_{i}$ and $s_{j}$ are the shares of the consumer's expenditure on goods $i$ and $j$, respectively, in the consumer's total expenditure.

Substituting the parameters of our model into this relationship yields

$$
\eta_{m M}=-1-\frac{\eta_{h M} s_{H}}{s_{M}}, \quad \text { where } s_{H}=\frac{H p_{H}}{I} \text { and } s_{M}=\frac{M p_{M}}{I}
$$

$I$ is the income of the representative consumer. Rearranging terms gives

$$
\eta_{h M}=-\left(\eta_{m M}+1\right) \frac{M p_{M}}{H p_{H}}
$$

Now plug this expression into (8B.1) and simplify: 


$$
\begin{gathered}
-H e_{H}\left(\eta_{m M}+1\right) \frac{M p_{M}}{H p_{H}}<-M e_{M} \eta_{m M}, \\
\frac{1}{\eta_{m M}}<\frac{i_{M}}{i_{H}}-1 .
\end{gathered}
$$

To obtain the last inequality, the relationships $i_{H}=e_{H} / p_{H}$ and $i_{M}=e_{M} / p_{M}$ were used. As $\eta_{m M}<0$, the left hand side of the inequality is negative. If $i_{M}>i_{H}$, i.e. if - as we have assumed - the emission intensity in region Foreign is larger than in region Home, the right hand side will be positive and thus the inequality will always hold true. Note that the condition $i_{M}>i_{H}$ is sufficient, but actually not necessary - a weaker condition (with its exact form depending on parameter values) will also suffice to guarantee that inequality (8B.1) holds.

Also note that the assumptions on elasticities used here are somewhat more restrictive than those used in Appendix A to this chapter: When employing the Cournot aggregation condition, we have assumed that no other goods exist except for $H$ that are substitutes (or complements) for $M$. In Appendix A, on the other hand, the proof relies on the properties of the substitution matrix. These apply also to a " $n$-good" case. Thus, even though just the two goods $H$ and $M$ were discussed, the derivation in Appendix A does not exclude a scenario with additional goods besides $H$ and $M$ in the consumption bundle of the representative consumer - goods that may be either substitutes or compliments for $H$ and $M$. 


\section{CHAPTER 9}

\section{Policy Transmission through Energy Markets, Income Effects, and Technological Spillovers}

This chapter continues the comparison of different climate policy variants by concentrating on the other policy transmissions channels introduced in Chapter 4 apart from the "non-energy-market" or "competitiveness" channel, i.e. the energy market channel, the income channel, and the technological-spillovers channel. Even though for the examination of the energy market channel we will again resort to the partial equilibrium model used in the previous two chapters, actually all three transmission mechanisms discussed in this chapter explain effects that affect not just a single sector, but several sectors or even an economy as a whole. Therefore also the question will be posed whether we may have drawn wrong conclusions owing to the simplification made - the adoption of a partial equilibrium setting; and also the consequences of another simplification will be discussed - the use of a two-region instead of a multi-region framework. Finally, this chapter examines which kind of conclusions can be drawn from the analytical part of this study for actual climate policy-making.

\subsection{Policy transmission via energy markets}

The fossil fuel market, the fifth market of the partial equilibrium model employed in this study, is represented as simple as possible. There is just one type of fuel, which is used as an input in the production of all four final goods. Thus, we do not discuss any inter-fuel substitution effects, which are often exhibited by more complex computable equilibrium models (see Burniaux and Oliveira Martins 2012; Boehringer et al. 2010a for recent examples). Again, our aim is to reveal the most basic mechanics of policy transmission. Note, however, that the following discussion must be interpreted to relate to the world as a whole and not just to individual economic sectors - the global fuel market can only be studied by including all sources of fuel demand worldwide. Thus we make use of interpretation (b) from Section 7.1.1.

\subsubsection{The transmission mechanism}

Let the supply of fossil fuel $R$ ( $R$ like resource) be given by a constant-elasticity function:

$$
R=\delta p_{E} \eta_{R}, \quad \text { with } \eta_{R}=\frac{\partial R}{\partial p_{E}} \frac{p_{E}}{R}
$$


$\eta_{R}>0$ is the price elasticity of fuel supply, $\delta$ is a parameter $>0$, and $p_{E}$ is the fuel price, which is the same in both regions as fuel is freely traded.

Global demand for fuel $E$ is the sum of the input demands of the four industries which produce the final goods $H, X, M$, and $F$. The emissions tax affects the fuel market via its impact on these input demands. Thus, as already mentioned in the introduction to Chapter 8 , it is impossible to study the effect of the tax on price and quantity of fuel used by examining the fuel market in isolation - one needs to know how the tax influences production of $H, X, M$, and $F$; this is the point, where policy transmission through non-energy and through energy markets overlaps. In our model, on the demand side for fuel this overlap is actually complete: there is no additional fuel demand by households, and there are no process emissions in the model either - thus also all emissions stem from the fuel demand of the four industries. This fuel demand - and the effect of the tax on it - has already been studied in Chapter 8. Now we add the supply side of the fuel market to the analysis. The fuel price, which has been fixed so far, will now be determined endogenously. We will thereby obtain the combined effects of policy transmission in both non-energy and in energy markets.

In fuel market equilibrium, fuel demand equals fuel supply. As can be seen from (9.1), fuel supply $R$ depends only on $p_{E}$. Fuel demand $E$, on the other hand, depends on both $p_{E}$ and $t-$ see Equations (7.3) to (7.5):

$$
E\left(p_{E}, t\right)=R\left(p_{E}\right)
$$

Taking the total differential of both sides, we have:

$$
\frac{\partial E}{\partial p_{E}} d p_{E}+\frac{\partial E}{\partial t} d t=\frac{d R}{d p_{E}} d p_{E}
$$

From (9.1) and (9.2) we obtain:

$$
\frac{d R}{d p_{E}}=\frac{\eta_{R} E}{p_{E}}
$$

Rearranging terms of (9.3) and plugging in (9.4) yields an expression that gives the effect of the tax on global emissions, i.e. the overall effect of the policy studied: 


$$
\frac{d E}{d t}=\frac{\partial E}{\partial t} \frac{1}{1-\frac{\frac{\partial E}{\frac{\partial p_{E}}{\partial R}}}{\partial p_{E}}}=\frac{\partial E}{\partial t} \frac{1}{1-\frac{1}{\eta_{R}} \underbrace{\frac{p_{E}}{E} \frac{\partial E}{\partial p_{E}}}_{\varepsilon_{E, p_{E}}}} .
$$

On the right side of (9.5), $\partial E$ / $\partial t$, the partial derivative of $E$ with respect to $t$, gives the effect of the tax on global emissions for the case that $d p_{E}$ equals zero, i.e. the pure effect of the non-energy market transmission channel (which has been analyzed in Chapter 8). The overall effect of both channels can therefore also be expressed as follows:

$$
\frac{d E}{d t}=\varphi \frac{\partial E}{\partial t} \quad \text { with } \quad \varphi=\frac{1}{1-\frac{\varepsilon_{E, p_{E}}}{\eta_{R}}}
$$

Equation (9.6) shows that $\varphi$, the effect of the fossil fuel market on global emissions, works as a multiplicative factor on the effect from non-energy markets, $\partial E / \partial t$, in determining the overall effect of the policy, $d E / d t$. This factor $\varphi$ depends on $\eta_{R}$, the price elasticity of fuel supply, and on $\varepsilon_{E, p E}$, the price elasticity of fuel demand (which at the same time is the "demand side" fuel price elasticity of emissions).

Consider now the individual variables and terms of Equations (9.5) and (9.6): $\partial E / \partial t$, the effect of the tax through the non-energy market channel, is given by (8.10) for a production-based and by (8.15) for a consumption-based policy. As discussed in Sections (8.2) and (8.3), for a consumption-based policy $\partial E$ / $\partial t$ will always be negative, whereas for a production-based policy $\partial E / \partial t$ may be either negative or positive - a positive value signifies a leakage ratio of more than 100 percent. Next, $\partial E / \partial p_{E}$, the demand side reaction of emissions to fuel price changes, and the corresponding elasticity $\varepsilon_{E, p E}=\left(\partial E / \partial p_{E}\right)\left(p_{E} / E\right)$, can be obtained using (7.4), (7.5), and (7.7). The derivation is similar to the derivation of the effects of the tax, only now we need to partially differentiate with respect to $p_{E}$ instead of $t$ : 


$$
\begin{aligned}
\varepsilon_{E, p_{E}}=\frac{\partial E}{\partial p_{E}} \frac{p_{E}}{E}= & \frac{E_{H}}{E}\left[\eta_{h H} \theta_{H}+\eta_{h M} \theta_{M}-\sigma_{H}\left(1-\theta_{H}\right)\right]+ \\
& +\frac{E_{X}}{E}\left[\eta_{x X} \theta_{X}+\eta_{x F} \theta_{F}-\sigma_{H}\left(1-\theta_{X}\right)\right]+ \\
& +\frac{E_{M}}{E}\left[\eta_{m H} \theta_{H}+\eta_{m M} \theta_{M}-\sigma_{F}\left(1-\theta_{M}\right)\right]+ \\
& +\frac{E_{F}}{E}\left[\eta_{f X} \theta_{X}+\eta_{f F} \theta_{F}-\sigma_{F}\left(1-\theta_{F}\right)\right] .
\end{aligned}
$$

Note that in (9.7) the input cost shares $\theta_{H}, \theta_{M}$, and $\theta_{X}$ depend on the rate and type (production- or consumption-based) of any previous emissions tax that is already in place when we begin our analysis. If we, however, start our analysis from a situation without any tax, we can evaluate (9.7) at $t=0$. Then $\theta_{H}$ equals $\theta_{X}$, and $\theta_{M}$ equals $\theta_{F}$; and (9.7) can be simplified accordingly.

The individual terms of (9.7) are similar to the terms of (8.10) and (8.15), the equations that describe the effect of the tax on emissions. This is due to the fact that the effect of a change in the fuel price on production costs is similar to the effect of a change in the tax - see Equation (7.2). Therefore, also the propagation mechanism from changes of the fuel price to changes in global emissions is the same as for the tax: the carbon rates in production change and the goods prices change - leading to substitution effects.

As is the case with the equations giving the effects of the tax, also in (9.7) each line contains positive as well as negative terms. Intuitively, one would of course expect that overall the negative effects must be stronger: a higher fuel price should lead to less fuel being used. This is indeed true for the model of this study. It can be proved using the substitution matrix of the representative consumer in Home and in Foreign (see Appendix A to Chapter 8, in particular the last paragraph).

\subsubsection{Energy market effects and global emission reduction}

Knowing the signs of the derivatives and elasticities in (9.5) and (9.6), we can determine whether the fuel market factor $\varphi$ increases or decreases global emissions. As $\varepsilon_{E, p E}<0$ and $1 / \eta_{R}>0$, their product will be $<0$. The denominator in (9.5) and (9.6) will therefore always be greater than one; and the fuel market factor will take a value greater than zero and smaller than one. Thus the sign of $\partial E$ / $\partial t$ will determine whether the fuel price channel increases or decreases global emissions:

- If leakage through the non-energy market channel is less than 100 percent, the fossil fuel market channel will increase global emissions and thus counteract the emissions reduction induced by the introduction of the tax. Still, the overall change in emissions caused by the policy will never become positive. 
To see why note that $\partial E$ / $\partial t$ can only be negative (which means that the policy causes a reduction of global emissions), if leakage through the non-energy market channel is less than 100 percent. As $\varphi$ is positive but smaller than one, by (9.6) $d E / d t$ is negative but smaller in absolute value than $\partial E / \partial t$. Thus the fuel market channel increases global emissions (as compared to the situation with only the competitiveness channel). However, there is a limit to how far global emissions may rise by means of the fuel price effect: Even if $\partial E / \partial p_{E}$ approaches minus infinity, $\varphi$ and thus $d E$ / $d t$ will only approach zero. In that case the policy has no effect on the level of global emissions but it can never have a negative effect as long as leakage through the non-energy market channel is less than 100 percent. A situation where mitigation policy has no effect will, for example, occur if the price elasticity of fuel supply is extremely low: the global amount of fuel used (and thus the level of emissions) will then not depend on the level of the fuel price - it will always remain the same.

- If leakage through the non-energy market channel is more than 100 percent, the fossil fuel market channel will reduce global emissions. Still, the overall change in emissions caused by the policy will never become negative.

The logic runs along similar lines as given above for the opposite case. But the reason for the reduction in global emissions can also be grasped intuitively. Leakage of more than 100 percent through the non-energy market channel means that the policy has not caused a drop, but an increase in fuel use. Therefore, bringing in the fuel market channel by freeing up the price of fuel will allow the fuel price to rise; and that in turn will dampen fuel use and thus emissions.

Finally, from Equations (9.5) and (9.6) one can also see the circumstances under which the fuel market channel will have no effect. These are:

- The initial policy has no effect on global emissions through the non-energy market channel $(\partial E / \partial t=0)$. This can either be the case if carbon intensities and demand do not change as a reaction to the introduction of the policy; or if leakage is 100 percent (i.e. the positive and the negative effects of the policy on global emissions exactly cancel).

- The price elasticity of fuel supply $\eta_{R}$ is very high (to be precise: infinite). Then the introduction of the mitigation policy will not influence the fuel price. The consequences of this scenario are the same as in the case of a "fixed" fuel price (as was assumed in Chapter 8 to study the impact of the competitiveness channel in isolation).

- Fuel price changes are not transmitted to emissions changes $\left(\varepsilon_{E, p E}=0\right)$. This will be the case if carbon intensities and demand do not change as a reaction to fuel price changes.

\subsubsection{Comparing the policy variants in terms of environmental effectiveness}

To compare the overall effects of a production- to those of a consumption-based policy, consider Equation (9.6): the overall policy effect is the product of the effect as transmitted through non-energy markets, $\partial E / \partial t$, and the fuel price factor $\varphi$. As 
discussed in Section 8.4, the effect through non energy-markets - and thus, the term $\partial E$ / $\partial t$ - may differ between the two policies. The fuel market factor $\varphi$ however is the same under both policies (and it is, of course, also the same for the third policy variant discussed in Chapter 8, the "import-tax-only" policy): it depends only on the fuel price elasticities of supply and demand, $\eta_{R}$ and $\varepsilon_{E, p E}$, and these are independent of the choice of policy base. ${ }^{43}$ Thus, differences in the effect of a policy on global emissions (i.e. differences in $d E / d t$ ) are triggered by differences in the effectiveness of policy transmission through the non-energy market channel, but not by differences in the effect of the fossil fuel market. The fuel market only works like a "multiplicative factor" on these initial differences.

This result is also intuitively plausible: as long as there is only one unified global market for fossil fuel, the size of the fuel market effect only depends on the question, by how much the demand for fossil fuel has been reduced by the policy. But it is irrelevant, how and where it was reduced - be it in the production of export goods or goods for domestic use, be it in region Home or in region Foreign.

Note, however, that this equality of the fuel market effect between a productionand a consumption-based policy refers only to global emissions reduction (and thus environmental effectiveness) but does not carry over to carbon leakage. This is due to the fact that the fuel price mechanism affects both the emissions directly targeted by the policy (the tax base) and the emissions that are not part of the tax base. Outside the tax base the drop of the fuel price brought about by the abatement policy causes leakage, whereas concerning those emissions that are part of tax base, it renders the pursuit of the abatement policy more difficult: for a given emissions tax rate, the reduction of emissions will be smaller if we allow for the fuel price effect (i.e. if we do not fix the fuel price); or alternatively for a given emissions reduction target a higher tax rate will be required under a flexible fuel price. But as the tax base is different for a consumption- and a production-based policy, also the split of the fuel price effect into the part that affects the taxed emissions and the part that affects the emissions not taxed will in general not be the same for the two policy variants. Thus, also leakage through the energy market-channel will not be the same for the two policies.

In the following, we will derive a condition for leakage through both channels to be smaller under a consumption- than under a production-based policy. As discussed in

${ }^{43}$ Note that in the study of the effects of the introduction (or change) of an emissions tax, the independence of the price elasticity of fuel demand, $\varepsilon_{E, p E}$, from the choice of policy base also holds if there already is an emissions tax in place. It is true that this previous emissions tax will determine the magnitude of $\varepsilon_{E, p E}$ by its effect on the input cost shares $\theta_{H}, \theta_{M}$, and $\theta_{X}$ - and this magnitude will in general be different for a production- and a consumption-based policy. For the analysis of an infinitesimal change of the emission tax, we however must take this value of $\varepsilon_{E, p E}$, which is predetermined by the previous tax, as given. And this given value enters the calculation of the fuel price factor $\varphi$ in the same way, irrespective of whether the additionally introduced (infinitesimal) tax is production- or consumption-based. 
Section 8.3, leakage through the non-energy market channel is zero under a consumption-based policy. It is therefore always smaller (or equal) to leakage under a production-based policy through the non-energy market channel. As just discussed, the results for leakage through the energy market channel are not as clear-cut. We start our derivation of the combined leakage effect of both policy transmission channels from the two formulas for the leakage ratio given in Chapter 2, Equation 2.17, defining $l^{P B}$, and Equation 2.19, defining $l^{C B}$ :

$$
\left.l^{C B}<l^{P B} \Rightarrow \frac{1-l^{C B}}{1-l^{P B}}>1 \text { (if } l^{P B}<1\right)
$$

We will focus on the case where $l^{P B}<1$, i.e. where the leakage ratio is less than 100 percent, as this case is the empirically more relevant one. Again, we will analyze an infinitesimal change of the tax. Substituting in (9.8) yields

$$
\frac{1-l^{C B}}{1-l^{P B}}=\frac{\frac{d E^{C B}}{d E_{H}^{C B}+d E_{M}^{C B}}}{\frac{d E^{P B}}{d E_{H}^{P B}+d E_{X}^{P B}}}=\frac{\frac{\frac{d E}{d t^{C B}}}{d E_{H}^{C B}+\frac{d E_{M}}{d t^{C B}}}}{\frac{\frac{d E}{d t^{P B}}}{\frac{d E_{H}}{d t^{P B}}+\frac{d E_{X}}{d t^{P B}}}}>1 .
$$

Taking the total differential of $E_{H}\left(t, p_{E}\right)$ and using (9.3), we obtain an expression for the effect of the tax on emissions discharged in the production of $H$. We first assume a production-based policy:

$$
\frac{d E_{H}}{d t^{P B}}=\frac{\partial E_{H}}{\partial p_{E}} \frac{d p_{E}}{d t^{P B}}+\frac{\partial E_{H}}{\partial t^{P B}} \text { with } \frac{d p_{E}}{d t^{P B}}=\frac{\frac{d E}{d t^{P B}}}{\frac{d R}{d p_{E}}-\frac{\partial E}{\partial p_{E}}}
$$

In a similar way, we can proceed to derive expressions for the goods $M$ and $X$, and also expressions giving the effect of a consumption-based policy. Plugging all these expressions into (9.9), rearranging terms and simplifying, we obtain the following condition for the leakage ratio to be smaller under a consumption-based than under a production-based policy: 


$$
\frac{\partial E_{M}}{\partial t^{P B}}+\frac{\partial E_{F}}{\partial t^{P B}}+\frac{d p_{E}}{d t^{P B}}\left(\frac{\partial E_{M}}{\partial p_{E}}-\frac{\partial E_{X}}{\partial p_{E}}\right)>0
$$

The first two terms in (9.11) represent absolute leakage through the non-energy market channel. They are positive. The third term is the difference between the indirect effect of a production-based tax via the fuel price on imports and the indirect effect of a production-based tax via the fuel price on exports. This term may be positive or negative, depending on parameter values. Substituting the respective terms from (8.6), (9.7), and (9.10), we have

$$
\begin{aligned}
l^{C B}<l^{P B} \Leftrightarrow & \frac{1}{p_{E}+t^{P B}}\left\{E_{M} \eta_{m H} \theta_{H}+E_{F} \eta_{f X} \theta_{H}\right\} \\
+ & \frac{\partial E}{\partial t^{P B}} \frac{1}{\eta_{R}-\varepsilon_{E, p_{E}}}\left\{\frac{E_{M}}{E}\left[\eta_{m H} \theta_{H}+\eta_{m M} \theta_{M}-\sigma_{1}\left(1-\theta_{M}\right)\right]\right. \\
& \left.\quad-\frac{E_{X}}{E}\left[\eta_{x X} \theta_{X}+\eta_{x F} \theta_{F}-\sigma_{2}\left(1-\theta_{X}\right)\right]\right\}>0 .
\end{aligned}
$$

Again, the first term in (9.12) is positive; it represents absolute leakage through the nonenergy market channel. The second term - line two and three of (9.12) - on the other hand stems from the leakage effects of the policy in the energy market. As $\partial E / \partial t^{P B}$ is negative for a policy that results in leakage through the non-energy market channel of less than 100 percent, the whole factor of the second term is negative. The part of the second term inside the curly braces may however be either positive or negative. If it is negative, leakage through the energy market channel is larger under a production-based policy. Let us now assume the (probably more typical) case that an increase in the fuel price leads to a drop (and not: an increase) in emissions in the production of both good $M$ and $\operatorname{good} X$. Then, for leakage through the energy market channel to be larger under a production-based policy, the first of the two terms inside the curly braces must be larger in absolute value than the second one, i.e. the impact of a change in the fuel price must be stronger on $E_{M}$ than on $E_{X}$.

If on the other hand the expression inside the curly braces in (9.12) is positive, then leakage through the energy market channel is larger under a consumption-based policy. Still, that does not necessarily imply that also overall leakage through both channels is larger under a consumption-based policy. For that to be case, additionally the second term also needs to be larger in absolute value than the first term in (9.12), which represents leakage through the non-energy market transmission channel. This case can, of course, not be excluded; it however requires a specific combination of parameter values. In general, as can be seen from Equation (9.12), overall leakage through both channels is the smaller for a consumption-based policy as compared to a productionbased policy, 
- the larger is the effect of the non-energy market channel compared to the energy market effect and

- the larger is the amount of emissions embodied in imports, $E_{M}$, compared to emissions embodied in exports, $E_{X}$.

Again, as at various other points in this study, however the following recommendation will be made: as carbon leakage just covers one aspect of environmental effectiveness, the selection of a policy should in most circumstances be based directly on an assessment of the environmental effectiveness of that policy, and not on the amount of carbon leakage it causes.

\subsubsection{Practical implications of the impact of the fuel market on emissions}

Next, we will discuss how far the findings of our model-based analysis on the energy market policy transmission channel conform to some of the central results reported in the CGE literature. We concentrate on two such results:

- "For small abating coalitions leakage through the competitiveness channel is relatively more important, whereas for large abating coalitions leakage through the fuel price channel dominates" (e.g. Burniaux et al. 2010).

In Section 8.2.1 it has already been demonstrated that also with the model of this study leakage through the competitiveness channel drops with coalition size. Here, we therefore only discuss the relationship between coalition size and leakage through the energy market channel. We confine our analysis to a production-based policy with a leakage ratio of less than 100 percent (this conforms to the setting usually studied in the CGE literature). Let us conduct the following thought experiment: We increase the size of the abating coalition by increasing $H$ and at the same time reducing $F$ (see Footnote 40 for the rationale for this approach). At the same time, we keep the reduction of global emissions constant. This has the consequence that also the size of the fuel price effect remains constant. What will change with changing coalition size is thus only the split-up of the fuel price effect between abating and non-abating countries - and thus the amount of carbon leakage. To see how, first note that the tax rate cannot be kept constant. Increasing the coalition size with a constant tax rate would mean increasing emission reduction. Thus as the global reduction of emissions is to stay constant, the tax rate will have to be lowered with increasing coalition size. Observe, however, that in the analysis of this study a change in the tax rate has no effect on the split-up of the fuel price effect between abating and not-abating countries (this is due to the use of comparative static derivatives - the amount of emissions reduction is thus linear in the tax rate). But the increase of the coalition size obviously has an effect on this split up the larger the coalition, the larger the share of the overall fuel price effect that will fall inside the coalition - and thus the smaller the amount of carbon leakage through the energy market channel.

We have thus arrived at a result that seems to contradict the findings of the CGE literature on leakage. A possible resolution of this apparent contradiction is the following: The CGE literature often assumes that ever larger coalitions achieve an ever 
larger reduction of global emissions. Thus the observed increase in carbon leakage with coalition size may actually be due to an increase in the amount of emission reduction an effect that will become even stronger if a nonlinear relationship between fuel demand and fuel price is assumed. In practical terms, this increase in leakage through the energy market channel may of course play a role in political considerations - even if its cause is not the size of the abating coalition per se, but the magnitude of emission reduction.

Let us now look at a second central finding of the CGE literature:

- "The energy market leakage channel cannot be systematically influenced by border measures" (e.g. Boeters and Bollen 2012).

This statement seems to imply that there is no difference in leakage through the energy market leakage channel between a production- and a consumption-based policy. This section has shown, on the contrary, that with the model of this study there may well be such a difference. But recall that the definition of leakage used here for a consumptionbased policy does not conform to the definition employed in the CGE literature - as mentioned, that strand of literature always assesses leakage with the formulas designed for use with production-based policies (Equations 2.16 and 2.17). To allow a comparison, let us therefore also apply these "production leakage formulas" to measure leakage for both policy variants. Using the same formula for both the production- and the consumption-based policy, of course, implies that the tax base used in this formula is the same for both policies. Thus, if the initial amount of emissions reduction through the non-energy market transmission channel is the same for both policies, then the fuel market effect is the same for the two policies and thus also the amount of leakage through the energy market channel will indeed be the same. But the reverse also holds true: if the amount of emissions reduction through the non-energy market channel is not the same for the production- and the consumption-based policy variant, then also leakage through the energy market channel will not be the same. Thus, in the model of this study, if a switch of the tax base can change the effectiveness of a policy as regards its impact via non-energy markets, then - as a direct consequence - also the amount of leakage through the energy market channel will change. In this case it is therefore possible to influence this leakage measure - although the impact cannot be achieved separately, but only in combination with also influencing policy effectiveness via the non-energy market channel. Furthermore, this impact always counteracts any effects achieved in non-energy markets: if, for example, a switch to a consumption basedpolicy helps to bring about a larger reduction of global emissions through its effects in non-energy markets, then the effects in energy markets again "eat away" some of that gain in environmental effectiveness.

In practical terms this implies that if the aim in selecting a policy variant is to pick the variant that is the environmentally most effective one, then one can base one's choice on the performance of this variant in non-energy markets: the variant that is the most effective one there, will - as the fuel market effect reduces the effectiveness of all policy variants by the same percentage - also be the most effective variant if policy effects in both non-energy and energy markets are taken into account. But even if it is thus not possible to influence leakage through the energy market separately from a 
policy's effectiveness in non-energy markets by means of switching the policy base are there other ways to directly affect leakage through the energy market? - Probably not - at least if we limit our discussion to methods that stand a chance of being politically acceptable on a global level. Any such method that is not directly tied to the non-energy market would have to work through the supply side of the global fossil fuel market - with the aim of keeping the fuel price constant just as this was done in the model-based analysis of Chapter 8. But "fixing the fuel price globally" seems to be a project that will not be supported internationally (and the desirability of which is also debateable). This leaves us with the result that it appears to be indeed quite difficult to influence leakage through the energy-market channel by political means.

\subsubsection{Climate policy costs}

In Chapter 8 the impact, which the introduction of different climate policy variants has on welfare via effects in non-energy markets, has been examined analytically. This chapter has added energy markets to the analysis - a similar attempt to analyse welfare effects analytically shall however not be made here: the interplay between the different markets is now already too complex to be suited for a welfare analysis in a partial equilibrium with its limitations on income effects between the different markets. Instead, a few general observations on climate policy costs - and thus welfare effects in a setting including a fossil fuel market will be listed. To begin with, note that the fossil fuel resource must be owned by one of the two regions (or by both) and that the sale of fossil fuel generates resource rents. The introduction of a climate policy then has inter alia the following consequences:

- The region that owns the fossil fuel resource will suffer a welfare loss as the climate policy will curb demand for fuel and will drive down its price, thereby cutting into the rents of the owners of the resource.

- A region that imports fossil fuel, but does not abate will experience a welfare gain as the climate policy drives down the fossil fuel price.

- The tax necessary to achieve a given amount of emission reduction needs to be higher in a scenario where the fuel price is not fixed than in a scenario with a fixed fuel price. The recipients of the tax revenues are therefore better-off in a scenario without a fixed fuel price (at the expense of resource owners).

- Consumers buying the taxed goods are indifferent whether these goods have become more expensive due to a scenario where the net fuel price has remained constant and a (smaller) tax has been imposed on top of the net fuel price, or due to a scenario where the net fuel price has dropped, but instead a larger tax has been imposed - they react only to gross price changes.

Again, as in the case with a fixed fuel price, the distributional consequences of the introduction of a climate policy will to a large degree also depend on the question what share of the abatement costs can be passed on to the other region. 


\subsection{Abatement via income effects and its distributional implications}

The examination of climate policy costs in the previous sub-section has already prepared the field for a discussion of the - after the non-energy market and the energy market channel - third channel of climate policy transmission, the income channel. Put briefly, this channel works as follows: the introduction of an abatement policy affects the prices of goods and the income of the factors of production; as a consequence, consumers can only afford to buy less (in certain cases: more) goods than before and that will have an effect on emissions. In the non-policy region - developing and emerging economies in the setting of this study - this change of the emissions level brought about by the change in income (or more general: change in welfare) is carbon leakage - or, more precisely, carbon leakage through the income channel. The modelbased analysis in Section 8.7 has shown that typically also non-abating countries bear some of the burden of the abatement policy - thus typically they will suffer a welfare loss through the introduction of the policy and will therefore experience "negative leakage", i.e. a drop of emission. More generally, however, not only the non-abating countries, but also the abating countries experience changes in their welfare through the introduction of the policy, and again, that in turn will affect emissions.

All these effects were implicit in the model-based analysis of Chapter 8 and of the first section of this chapter - only that they were analyzed not in general equilibrium setting, which for income changes is usually better suited, but in partial equilibrium. Here the discussion of such income effects is once again taken up, now under the heading of a separate "transmission channel" - the reason being that all issues relating to the global distribution of climate policy costs, i.e. the distribution of the welfare effects caused by climate policy, are extremely disputed in the international political debate and thus a detailed understanding of the issues at stake is required if one wants to contribute to this political debate. This section therefore not only looks on effects on emissions triggered by income changes which were brought about by the policy, i.e. the income channel of policy transmission, but also on these income changes per se, especially on the distribution of these income changes between the two regions. In constrast to the model-based analysis of Chapter 8, we will now not restrict our analysis to a case where all policy costs can be passed on to consumers - thus, the setting is this section is more general than in Chapter 8.

\subsubsection{Distributional effects of climate policy}

In general, every abatement policy at least partly works by making economic agents "poorer" in real terms - abatement costs are real resource costs that have to be borne by some agent (see also the introductory paragraphs of Section 8.7 on the question how to define abatement costs at the level of an entire economy). The costs will be typically split between the two regions - in the extreme, as climate policy also changes the terms of trade, the result of the introduction of the policy may however be that one region experiences a welfare gain and the other one a welfare loss that exceeds the costs of the abatement policy. Thus not only the costs of the policy are "distributed" between the regions, but the policy additionally "redistributes" some of the regions' wealth. Developing and emerging economies are, of course, very sensitive to changes in their 
welfare imposed on them by industrialized countries - and there is a widely-held belief that especially the introduction of border measures, i.e. a form of policy that comes close to a consumption-based approach, will be to their disadvantage (see e.g. Voituriez and Wang 2011 on the Chinese position), while there is little resistance to industrialized countries following a production-based abatement approach. Whether it is indeed true that a consumption-based policy will impose larger costs on developing countries than a production-based one, is a question that can only be answered empirically. Theoretical models can - depending on their structure and the specific parameter values used produce either result (in the model of this study, for example, the costs borne by developing countries are lower, if industrialized countries switch to a consumptionbased policy, see Section 8.7.3). But theoretical models can help to identify the parameters on which the distributional effects of the introduction of a climate policy depend - and these considerations shall, without resorting to a mathematical representation, be briefly discussed here.

Again, as in Sections 8.7 and 9.1.5, think of costs as welfare losses and of the policy being imposed by means of a carbon tax. How the welfare costs of this tax are split depends on (i) which region bears the tax burden, and (ii) which region receives the tax receipts. ${ }^{44}$ The answer to (i) will be determined by what is discussed in the climate policy literature as the "cost pass-through rate" (Neuhoff 2008, Monjon and Quirion 2009): If a tax is imposed on the carbon content of a good a firm produces, this firm will be more or less able to pass on part of the additional cost to consumers, i.e. the price of the taxed good will rise more or less. The cost pass through rate depends inter alia on the structure of the market in which the firm it competes, the degree of international competition which again depends on factors like transport costs and barriers to trade, and the elasticity of demand for the product, its substitutability for other products and the degree of product differentiation - see Reinaud (2008a) for an indepth discussion. If the good is internationally traded, the price increase triggered by the carbon tax also changes the terms of trade. Thus we can analyze the cross-border welfare effects of the policy either by directly assessing how much of the tax burden is borne by consumers and producers in each of the regions. Or, alternatively, we can assess the welfare effects of the changes in the terms-of-trade. These are just two ways of looking at the same effect. As regards the terms of trade, typically, if the export good of a region becomes more expensive, the terms of trade of this region improve and the region will experience a welfare gain. ${ }^{45}$

44 As in Section 8.7, the term welfare refers only to welfare derived from the consumption of goods, but excludes benefits from emissions reductions - for details see the explanation given there.

45 This is a standard result in models of the Heckscher-Ohlin type. It rests on the assumption that the Marshall-Lerner condition is satisfied, i.e. that the sum of the import elasticities of the two regions exceeds unity. Empirically, this condition usually holds in the middle to long run (Artus and Knight 1984). 
Using this framework, we can now proceed to discuss the impact on (welfare) costs of a switch from a production-based to a consumption-based policy. First, note that in the "standard setting" for both policies, the tax receipts accrue to the region introducing the tax, i.e. to industrialized countries. If necessary, this "standard setting" can however be changed by means of policy - this will be discussed in Chapters 10 and 11. Concerning the tax burdens, assume that the policy region is large enough to affect world-market prices. Thus, there is at least some (but we will assume: not complete) cost pass-through. Then the tax burden is shared by both regions, although typically the size of the shares will differ depending on the policy.

To analyze, in which way these shares differ, it is convenient to envisage the switch to a consumption-based policy as being implemented by means of border tax adjustments. ${ }^{46}$ These consist of an import tariff and an export rebate. The import tariff will improve the terms of trade of the region introducing the tariff at the expense of the rest of the world; the export rebate will have the reverse effect. Thus, in the setting of this study, developing and emerging countries gain from the export rebate, but suffer a welfare loss through the import tariff. Which effect dominates will be determined by the cost pass-through rate in the sectors affected by the respective tax or tariff and by the quantity of emissions embodied in the imports and exports of the two regions.

To simplify our discussion, assume that the cost-pass through rate in both regions evenly splits the tax burdens between consumers and producers. Then, it is the amount of carbon embodied in trade that decides which region will gain. Currently, as discussed in Chapter 6, more emissions are embodied in the exports of emerging and developing countries than in their imports. Thus, under the assumption of an even split of the tax burden, the welfare effect of the import tariff will be larger than the welfare effect of the export rebate. The non-policy region therefore suffers a welfare loss due to the introduction of border measures; the policy region, on the other hand, suffers a smaller welfare loss - and might even experience a welfare gain, if the abatement costs are smaller than the terms-of-trade gains. This is the scenario feared by developing countries. But whether it accurately depicts real world welfare effects, depends on the actual magnitude of cost-pass through in the affected sectors. As the model-based analysis of this study has demonstrated, the results just stated are reversed if cost-pass through is complete: developing countries then gain from the introduction of border measures (see Section 8.7.3).

Now consider an "import-tax-only" policy: If we again assume an even split of the tax burden between the two groups of countries, the welfare effect of such a policy is even worse for developing and emerging economies than the welfare effect of a consumption-based policy as the "import-tax-only" policy, of course, does not include

46 The results discussed here also hold if consumption-based accounting is introduced by other means than by border carbon adjustments. The discussion is framed in terms of border adjustments solely for ease of exposition. 
any export rebate. If we assume, on the other hand, complete cost-pass through, then the welfare effect of an "income-tax-only" policy on developing countries is the same as that of a production-based policy.

As already mentioned in Section 8.7.4, producers do not only pass on the costs of climate policy to consumers, but also "in the other direction", to the owners of factors of production. One group that will suffer exceptionally huge losses from the pursuit of climate policy are the owners (or the owning regions) of fossil fuel resources especially if international climate policy does not only impose the relatively small emission reductions being currently discussed, but - in the longer run - the substantial cut-backs on fossil fuel use required to keep global warming below the $2^{\circ}$ threshold. On the other hand, if fossil fuel prices fall due to the pursuit of climate policy, fuel importing countries may experience a welfare gain. ${ }^{47}$ The discussion in Section 9.1 has shown that such welfare effects working through changes in the fuel price are to be expected both under a production- and under a consumption-based policy and that their relative size depends on the effectiveness of the respective policy variant in bringing about emission reductions via policy transmission in non-energy markets. Additionally, for both the production- and for the consumption-based policy variant, the size of the welfare effects also depends on the elasticity of fuel supply (which in turn influences the amount of cost pass-through: if producers are not able to pass on climate policy costs to the factors of production, then the share of costs that they must bear themselves or pass on to consumers is, of course, larger).

Summarizing, the split-up of welfare effects between the abating and the nonabating region depends inter alia on the following factors:

- The relative cost pass-through rates of the affected sectors of both regions.

- The carbon-content of the imports and exports targeted by the policy.

- The net balance between abatement costs and terms-of-trade effects.

- The question whether a region is an importer or an exporter of fossil fuel.

In general, this split-up of welfare effects will not be the same for a production- and a consumption-based policy. A switch to a consumption-based policy will tend to cause welfare losses for developing and emerging economies under the following circumstances:

47 Of course, also the owners of other factors of production may experience changes to their incomes (or to their welfare) due to the pursuit of climate policy - although these effects are most probably not that wide-spread and pronounced as in the case of the owners of oil fields. As examples of groups affected think of the owners of "green" energy resources like hydroelectric power stations, who may experience a welfare gain. Also the demand for capital (and therefore the return on capital) may be affected by climate policy - there actually exist two counteracting effects: demand for capital might fall, if capital is tied to carbon-intensive industries (the size of which should contract due to climate policy), but it might increase if "green" technologies are very capital-intensive. 
- if the export sectors of industrialized countries are able to pass on a large share of the climate policy costs to consumers in developing and emerging economies;

- if on the other hand the export sectors of developing and emerging economies are not able (or only able to a small percentage) to pass on the costs of the border import tariff to consumers (or buyers of intermediate products) in industrialized countries;

- if the carbon content of imports of industrialized countries is larger than the carbon content of their exports;

- if emerging and developing countries are owners of fossil fuel resources (and not importers of fossil fuel).

On this last point, different developing countries fare differently - some are importers, some are exporters of fossil fuels. As concerns carbon intensity, here the typical developing and emerging economy indeed scores worse than most industrialized countries. But cost pass-through rates are quite different for different economic sectors. If, however, cost pass-through rates are generally lower for primary commodities than for manufactured products, and if the share of primary products in emerging economies' exports is larger than that in industrialized countries' exports, then indeed developing and emerging economies would not be able to pass on the burden caused by border taxes to consumers in industrialized countries. But note that from the fact that one plant or even one country is not able to pass on costs, we cannot infer that an entire global industry cannot pass on additional costs: if every plant in that industry all over the world were faced with the same additional costs and were to raise the prices of its products, consumers would not have the possibility to substitute between the products of different plants (or from different regions) and the producers might therefore be able to pass on a larger share of the cost increase than in a situation where just one plant acts alone. In the end, the question whether a switch to a consumption-based policy indeed induces welfare losses for developing and emerging economies can only be answered empirically.

\subsubsection{The income channel of policy transmission}

Just like the question on distributional consequences, also the question whether a production- or a consumption-based policy achieves a larger emissions reduction through the income transmission channel (or under which policy leakage through this channel is larger), cannot be answered without resorting to empirical studies. One might of course argue that as not only the production of emerging economies, but also their consumption is more emission intensive on average (i.e. the amount of embodied emissions per dollar spent is larger in these countries), a larger emission reduction can be achieved by reducing the income of emerging economies than by reducing the income of industrialized countries. But there are several reasons why such a policy of "abatement by impoverishing other countries" actually is a bad option: First, it defies various justice criteria (see Section 6.3) and therefore it is, secondly, a policy that will be difficult to defend politically and the unilateral implementation of which would seriously undermine trust in international climate negotiations. But apart from these 
reasons of justice and political feasibility, as will be argued in Section 9.4, also convincing economic reasons exist why such an approach will not contribute to the environmental effectiveness of a policy. Thus we may conclude that a reduction of welfare is a possible method to reduce emissions and that there is no variant of climate policy that does not reduce the welfare (from consumption) of at least some regions or economic agents. Still, as far as developing countries are concerned, climate policy should aim to avoid as much as possible or even to compensate such income losses. This topic will be discussed in more detail in Chapter 11.

\subsection{Policy transmission through technological spillovers}

Just as the income policy transmission channel, also the technology spillover channel creates "negative leakage" and thus helps to reduce global emissions. It rests on a twostep process: (i) the introduction of carbon pricing creates incentives to develop "green" technology in the sectors included in the tax base; and (ii) these "green" technologies spill over also to sectors not included in the tax base. The size of the overall effect will jointly be determined by (i) and (ii).

Regarding (i), a switch of the tax base from production to consumption excludes the industrialized countries', but includes the developing and emerging economies' exports in the scope of the policy and thus introduces in effect carbon pricing to (part of the economy of) these countries. Whether this will actually trigger the development of "green" technology in developing and emerging economies will however depend on whether these countries have appropriate research facilities at their disposal. One may suspect that at least in many developing countries this will not be the case; and thus, without additional support from industrialized nations, the desired technological innovations in developing countries may not materialize.

Regarding (ii), the spillovers, it can however be expected that these will be enhanced by a switch to consumption-orientation of the policy. This is due to the fact that under a consumption-based policy there will not only be "inter-regional" (i.e. from industrialized to developing countries), but also "intra-regional" spillovers, e.g. from the export sector to the domestic production sector in developing economies; and barriers to "intra-regional" or even "intra-country" spillovers can be expected to be lower than barriers to spillovers across regions.

To summarize, a brief analysis of the technology spillovers channel suggests the following: A switch to a consumption-based policy will at least enhance step (ii) of transmissions process - it will fasten the spread of clean technology throughout developing and emerging economies once this technology has been introduced to one sector there. Still, there remain doubts about its effects on step (i).

\subsection{Limitations to an analysis relying on simplified models}

The results on policy transmission via non-energy and energy markets - see Chapter 8 and the first section of this chapter - were all obtained in a partial equilibrium setting. Some authors have criticized that such simplified settings will not accurately depict the 
response of developing and emerging economies to the imposition of border adjustments. For example, Houser et al. (2008) and Jakob and Marschinski (2013) point out that countries targeted by border tariffs on their exports might react with import substitution (see Section 4.3). When presenting their study, Jakob and Marschinski argued that this effect may be that strong that the introduction of border tariffs may not only have no positive effect on the global climate, but might actually harm it (Endres, 2012). But, currently still little is known about the actual size of this effect - it is not represented in partial equilibrium models, and one might suspect that it is also not accurately depicted in CGE models as import substitution on a larger scale would require a substantial change of the structure of an economy. As will be discussed in Chapter 11, it may however be possible to avoid such an effect by designing a switch of the policy base in a way that avoids or compensates income losses of developing countries.

Another reason why simplified models may not accurately predict the response of developing countries to a switch of the policy base is that such models usually do not depict the many ways in which producers can avoid or circumvent the border tax. Think, for example, of the following setting: firms in developing and emerging economies do not all employ the same technology, but actually plants in these countries produce with different carbon-intensities. If now a tax on carbon embodied in the exports of these countries is introduced, then the "cleanest" producers will concentrate their sales in export markets. Some of the modern plants in emerging economies producing with low-carbon technology may be able to compete with factories in industrialized countries on an equal footing. The "dirty" producers, on the other hand, may channel their sales into their home market. The tax thus does not have any effect on the carbon-intensity of production in emerging economies - it just redirects the sales of individual plants in these countries.

Also at the international level, the border tax can be avoided by a redirection of trade flows. Houser et al. (2008) give the following example: the U.S. imposes a border tax on carbon embodied in Chinese steel, but not on carbon embodied in Japanese steel (for example, because Japan producers with a cleaner technology). This makes Japanese steel more competitive in the U.S. market compared to Chinese steel. Japan could therefore redirect steel originally produced for the domestic market to the U.S., and Japanese domestic steel demand could be satisfied with imports from China. The effect of the border tax therefore is just a diversion of Chinese steel exports - but again the tax does not change the carbon-intensity in Chinese plants and thus also has no effect on the quantity of global emissions. Of course, such effects involving the redirection of trade flows cannot be detected if one relies on models with only two regions. In the example above, the effect could be avoided if also Japan introduced a climate policy comparable to that of the U.S. Basically, a redirection of trade-flows can occur in all situations in which not all "low-carbon-countries" join the abating coalition. Thus, this effect is primarily a problem for small regions forging ahead with their climate policy. 


\subsection{Conclusions}

The analysis of policy transmission via non-energy markets in Chapter 8 has shown that an "import-tax-only" policy is environmentally more effective than either a pure production- or a pure consumption-based policy under fairly general assumption, but that the question whether a production- or a consumption-based policy is more effective depends on the specific values of the model parameters and on details of policy design. This chapter has added the other three policy transmission channels to the analysis - the energy market, the income, and the technology spillovers channel - and it has discussed some shortcomings of an analysis relying on sectoral two-region models. This changes the core results of our analysis in the following way:

- The effects of policy transmission via energy markets do not change the ranking of the different policy variants in terms of environmental effectiveness - they lower the effectiveness of all variants by the same percentage. If, however, the elasiticity of fuel supply is very low (and the fuel supply curve therefore virtually vertical), none of the policies will be effective in reducing global emissions.

- In general, all policy variants affect the welfare of both abating and non-abating countries. The "import-tax-only" policy variant reduces the welfare of developing and emerging economies by more (or at least: not less) than the other two variants. The question whether a production- or a consumption-based policy has a larger effect on the welfare of developing countries however depends on the specific values of the model parameters. But in general, the better exporters in industrialized countries are able to pass on the additional costs imposed by carbon taxes to consumers in developing and emerging economies, and the less exporters in emerging and developing economies are able to pass on the costs imposed by the import tariff to consumers in industrialized countries, the larger the burden in terms of lost welfare that emerging and developing economies have to bear.

- "Abatement by inducing income losses" is a form of climate policy that should be applied only with great care - especially if targeted at developing and emerging economies. It contradicts justice criteria; and additionally doubts exist whether it is a form of abatement that actually works: reducing the income of developing and emerging economies may induce import substitution in these countries and may thus - as these countries produce with higher emission intensity - actually increase global emissions.

- A consumption-based policy orientation (and equally: an "import-tax-onlypolicy") may enhance the spread of "green" technology. But there remain doubts whether it also enhances the development of "green" technology.

- The introduction of a tax on imports from developing and emerging economies will induce "tax avoidance strategies" in these countries - and these strategies also lessen the effect the tax has on emission reduction. One such strategy is the re-routing of international trade flows. It can theoretically be counteracted by 
including all "low-carbon countries" in the abating coalition. Another such strategy works if the emissions intensity of different plants is emerging economies different. Then the low-carbon plants can concentrate on exports, while the "high-carbon" plants produce for the domestic market. Again, the emission reduction effect of the tax is reduced - and there is virtually no practicable method that can prevent the use of such a "tax avoidance strategy."

The results of this chapter and the previous one will be taken up again in Chapter 11 to guide the development of proposals on policy design. 
PART III

\section{Implementing}

Consumption-Based

Policy Approaches 



\section{CHAPTER 10}

\section{Design Options for Consumption-Based Policy Approaches - a Literature Review}

This chapter and the following one form the third - and last - part of this study. Building on the results of the analytical chapters of this study as well as on some findings of the quantitative border adjustment literature, this part will discuss whether in "real-world" situations a consumption based-policy can be implemented that is environmentally more effective than the current production-based approaches. The previous chapters have shown that this is not a question that can be answered with "yes" or "no" - rather the answer depends on quite specific details of the situation being studied and the design of the policy instruments. This chapter will review the literature on criteria for the design of such instruments and present some design proposals made in recent years. Chapter 11 then discusses the consequences for policy design that follow from the findings of this study.

In Chapter 2, two different methods for the practical implementation of a consumption-based policy orientation have been introduced: a "carbon added" system and border tax adjustments. Setting up a "carbon added" system would take many years and require the cooperation of all - or at least most - countries of the world. Following the initial suggestions of such a system by Droege et al. (2009), its possible realization has so far not been further discussed. As concerns border tax adjustments, there however already exist some detailed proposals how such a system could be designed. Most of them actually do not envision a "full" switch to consumption-based emissions accounting; rather, these proposals demonstrate how difficult in practical terms such a "full" switch would be. Efficiency, of course, would require that the border tax adjustments mimic the domestic system of carbon pricing as close as possible (at least in certain respects - see Section 4.1) and thus indeed represent a switch to consumptionbased accounting. But in designing a border adjustment system for the "real world", besides environmental effectiveness or cost-effectiveness there are at least three other criteria that count: (i) the system should stand a reasonable chance to conform to WTO rules - at least if it is supposed to be introduced without first signing an international agreement that changes trade law; (ii) its implementation should be practicable, i.e. its administrative complexity and cost and the information and monitoring requirements should not be prohibitive; and (iii) it should be politically acceptable also to countries that are not part of the abatement coalition - thus, distributional consequences as well as criteria such as the moral justification for the measures or procedural fairness must be considered. Additionally, as Stern (2007) points out, the proposed system should also be "perceived as fair", as political acceptability is ultimately determined rather by the question how politicians and the general public of affected countries see the policy than 
by the question whether it meets some abstract justice criteria (some authors list further criteria, see e.g. Droege 2009; 2011b; Cosbey et al. 2012). Point (i) has been examined in Chapter 3; point (ii) will be discussed in the second section of this chapter: in that section four detailed proposals for a border tax design will be presented; and for three of these proposals the practicability of the scheme was a guiding principle. Point (iii) - the political challenges of the introduction of border measures - so far has not been discussed in detail in this study. For the practical implementation of border measures it however is an extremely important point. It will therefore be examined at some length in the first section of this chapter.

\subsection{Making border carbon adjustments politically acceptable}

The current international political climate does not favour the introduction of border adjustments. In industrialized countries, such adjustments have in recent years mostly been discussed as either a "stick" to encourage other countries to pursue a more ambitious climate policy or as a measure to address fears about a loss of competitiveness. Only rarely they were seen as a means to further environmental objectives. In developing countries and emerging economies, on the other hand, the possible introduction of border measures by industrialized countries is considered unfair protectionism and feared as a threat to the export industry and, more general, to the export-based growth strategy of many emerging economies.

Many authors discussing the practical challenges of an introduction of border measures therefore argue that in order make such an introduction possible, first the suspicion and mistrust of developing countries must be addressed: "Developed countries need to abandon rhetoric about trade protection to force other countries to do more, and focus instead on legitimate goals associated with ensuring that their own policies do not create unreasonable disadvantage," Grubb $(2011,1056)$ demands. And Neuhoff and Ismer $(2008,5)$, summarizing the results of an expert workshop on border adjustments, recommend an international process to "create confidence among developing countries that a border adjustment which discriminates against their producers will not be applied." But what are "legitimate goals"? Is a border adjustment system possible that does not "discriminate against the producers" of developing countries? And - is it possible to design a system of border measures from which both developed and developing countries benefit, i.e. to create a win-win situation?

\subsubsection{Objectives of border adjustments and their legitimacy}

There seems to be some consensus in the academic discussion that reducing carbon leakage definitely qualifies as an acceptable or "legitimate" objective for the use of border measures - but protecting the domestic industry or applying economic pressure to other countries in general does not (see e.g. Neuhoff and Ismer 2008, Grubb 2011, Cosbey et al. 2012). The difference between these possible objectives is that only reducing leakage is clearly an environmental goal - it will improve the environmental effectiveness of the current international climate regime (the caveats discussed in Section 8.4.2, of course, apply). As such, reducing leakage should be in the interest of 
all countries and does not only promote the narrow national interests of the coalition planning to introduce the border measures - for the non-abating countries "reducing leakage" therefore should be acceptable as a morally legitimate goal.

Grubb (2011), however, advocates adopting a pragmatic approach also towards policies meant to support competitiveness: he argues that countries opposed to border measures need to "acknowledge the truth that no politician is going to impose a carbon price on a sector that can make a politically credible threat to migrate." Therefore, the alternative to border measures is not to have such sectors not protected at all. Rather, they are typically protected by being exempted from carbon pricing, for example by receiving emissions allowances for free. But that is obviously environmentally less effective than the application of border measures: an exemption from carbon pricing means that the sector in question is nowhere in the world subject to an abatement policy - not in the abating countries, and of course also not in the non-abating countries. With a domestic abatement policy coupled with border adjustments, on the other hand, at least the production for domestic use in the abating countries and the imports of the abating countries are covered by the policy. Grubb $(2011,1052)$ points out the quantitative dimension of this problem: "To start the journey towards deep emission reductions by exempting sectors that account for about a third of global emissions is not a very promising way to solve the climate problem." To sum up, if one accepts that the competitiveness of certain sectors will always be protected, then one should prefer a protection by means of border measures to one by means of exemptions, as border measures are the environmentally more effective method.

Grubb (2011) presents also a second argument for border carbon adjustments that in his view is supported by both environmental and competitiveness concerns: if the industry of a region feels well protected, it will be much easier for this region to commit to a more stringent abatement policy. Introducing border adjustments therefore will allow climate coalitions to unilaterally forge ahead with an ambitious policy. The EU, for example, could raise its emissions reduction target for 2020 from 20 to 30 percent, if the EU industry did not fear a loss of competitiveness, Grubb asserts. This argument is debatable - as we have seen in Section 5.2.1, studies comparing border adjustments to free allocation of emission allowances typically conclude that border adjustments are better at preventing leakage, but that free allocation of allowances is better at preserving competitiveness. The reason is that free allowances also exempt production for the domestic market from the abatement policy; in contrast, border adjustments do not. Which system will be preferred by the domestic industry, however actually depends on the details of the system. The EU ETS, for example, does not grant a complete exemption for industries at risk of leakage from emission pricing; thus, it may well be the case that some firms or sectors prefer border adjustments to exemptions.

Not all authors agree with Grubb (2011) that preserving competitiveness - if it improves the domestic acceptability of a stringent climate policy - is a legitimate motivation for border adjustments. Cosbey et al. (2012) warn that some sectors that would migrate from industrialized to emerging economies due to global trends even without any climate policy might use the "competitiveness argument" to seek protection 
from these global trends; and also that preventing the loss of competitiveness is not a valid argument for breaching world trade law. Still, even Cosbey et al. concede that few real world policies fulfil only one motivation. And Neuhoff and Ismer $(2008,4)$ remark that "focusing on leakage (...) addresses relevant competitiveness concerns, without opening discussion on wider competitiveness concerns that are by and large unrelated to carbon pricing." Thus, there seems to be agreement that there is nothing wrong with addressing competitiveness concerns as long as this unambiguously goes together with a reduction of carbon leakage, i.e. with addressing environmental concerns.

Of course, one could also argue that using border tax adjustments as a "stick" to force other countries into signing an international climate agreement is a policy that is in the end motivated by environmental concerns. Nonetheless, the academic literature mostly disapproves of this option: it "may create negative repercussions that undermine international cooperation on climate policy" (Neuhoff and Ismer 2008, 4), it is probably in conflict with the UNFCCC principle of "common but differentiated responsibility", and it "could open the door to sanction-like actions" (Cosbey et al. 2012, 9), i.e. a policy where the threatened measures by far exceed the levels of border measures that could be justified by carbon leakage. Droege $(2011 b, 1196)$ explicitly stresses the importance of "a clear commitment that any border measure is linked to the underlying GHG emissions that cross the border." Thus, while politicians often see border measures as a means to protect competitiveness or to pressure other countries to reduce their emissions (see Section 3.1), in the academic discussion there is some reluctance to accept any motivation for border adjustments as legitimate that is not clearly linked to the environmental effectiveness of the policy.

\subsubsection{Border carbon adjustments as a win-win scenario?}

The introduction of border carbon adjustments changes relative prices and therefore creates winners and losers: individuals, economic sectors, and whole countries. The international climate negotiations are conducted at the level of countries - still, not necessarily will the positions of all governments at these negotiations reflect whether a country as a whole is a winner or a loser: Quite often, some social groups within a country are better at making their voice heard. For example, if industrialized countries introduce border adjustments for their trade with China, this will typically benefit consumers in China, but hurt the Chinese export industry. While the position of the Chinese export industry is well-known globally, one hears only little of the position of the Chinese consumer. The same holds true for most industrialized countries: the discussion on border carbon adjustment is dominated by the views of industry representatives. Thus, by listening to the public discussion on border measures, one might gain a wrong impression on who the winners are and who the losers. Rather, a detailed economic analysis is called for to establish the distributional consequences of border adjustments.

Sections 8.7.2, 8.7.3, 9.1.5, and 9.2.1 have examined the distributional consequences of the introduction of border measures: the import tariff burdens the export industry of the non-abating countries and the consumers of the abating countries, while the export rebate benefits the export industry of the abating countries and the 
consumers of the non-abating countries. Additionally, the import tariff generates revenues, which can be distributed, but the export rebate requires government funds, which must be raised. Finally, if the policy reduces global emissions and thus slows climate change, all countries will benefit from this effect. Apart from these comparative-static impacts, the redistribution of income between sectors and countries might also trigger dynamic effects. Countries like China that follow an export-based growth strategy probably expect that additional income accruing to export-oriented sectors will benefit the whole economy and increase the overall growth rate; but such dynamic effects are beyond the scope of this analysis. Taking all effects together, as we have seen in Section 9.2.1, it cannot be established in general, which group of countries will win, and which will lose (or whether both will win) - this depends on the specific parameter values and therefore is an empirical question. However, only if developing and emerging economies can be assured that they will not be among the losers of the proposed scheme, they will be willing to politically accept the introduction of border measures. Thus it is crucial to determine under which circumstances not only the countries that plan to introduce the border policy, but all countries benefit.

Grubb (2011) argues that in general the demand for basic commodities is not very price-sensitive, so that producers would be able to pass on the great majority of cost associated with border adjustments to final consumers. That would imply that above all consumers in the carbon-pricing region would face additional costs, whereas consumers in non-abating countries would be relieved of some costs. This is exactly the result also produced by the partial equilibrium model employed in Chapters 7 to 9 of this analysis. Still, as we have seen in Section 5.2.3, most simulation models give exactly the opposite result - it is the non-abating, i.e. the emerging and developing countries in most studies that bear most of the burden of a climate policy with border measures. The model of Dong and Whalley (2009), which does not fit into this general picture, can however provide us with a clue how a border adjustment policy that produces welfare gains for developing countries needs to look like: the import tariff should not be to high (it is set at the carbon-intensity of the importing, and not of the exporting country in the model of Dong and Whalley), and there should be an export rebate. If - as favoured by many experts and politicians - a border policy without an export rebate is introduced, then however a welfare gain for non-abating countries indeed seems unlikely - at least if one does not count welfare gains from a slowing of global warming.

The discussion so far has however neglected the fact that it is possible to redistribute income between the abating and the non-abating countries. If a policy with border adjustments is indeed more cost-effective than one without such adjustments, then the introduction of the adjustments produces a net welfare gain. Thus it is - at least theoretically - possible to attain a situation where both groups of countries are betteroff. In many cases, also funds will easily be available that can be used for such redistributive purposes: the import tariff raises revenue - and if the policy consists only of an import tariff or if the revenues from the import tariff are larger than the funds needed to finance the export rebate, then this revenue can be disbursed. So far it was assumed that it would always be disbursed in the country that introduces the border measures, i.e. in the scenarios discussed here in industrialized countries. But that need 
not be the case: some authors have suggested channelling this money to developing countries, e.g. Grubb (2011) or Springmann (2013). By contrast, Clarke (2010) proposes a different scheme where border measures rather work as a fall-back option for countries that do not want to join a global cap-and-trade system in emissions allowances. Still, also Clarke stresses that developing and emerging economies would have to be compensated for introducing carbon pricing.

\subsubsection{Export taxes - a feasible alternative to import tariffs?}

A possible alternative to a carbon import tariff is discussed by Droege et al. (2009) and Wang and Voituriez (2009): an export tax charged by countries that are not part of the abating coalition. Theoretically, such an export tax levied by exporting countries could exactly resemble and therefore replace an import tariff levied by importing countries. The only difference between the two measures would be that the tax revenues immediately accrue to the exporting country, i.e. to developing and emerging economies in the scenario studied here. Thus, they would not need to be redistributed from the abating to the non-abating countries as in the case of an import tariff. The option of an export tax might also be politically attractive to developing and emerging economies as they would maintain full control over the tax revenues. Mueller and Sharma (2005) argue that the idea of an introduction of such taxes might even unlock the stuck international climate negotiations.

Actually, China has already some experience with both export taxes on some products and a reduction of VAT refunds on others (Droege et al. 2009, Wang and Voituriez 2009). In the last decade, China levied export taxes between 5 and 25 percent on sectors such as iron and steel, aluminium, copper and several other non-ferrous metals. The tax rate was not dependent on the carbon content of the commodities taxed, and thus the export tax was not a carbon tax (or a carbon border adjustment) in a strict sense. Still, it was mostly energy- and carbon-intensive products that were taxed; and it was the goal of the Chinese policy to reduce the export of goods that use large amounts of energy or natural resources as inputs (however, this was done to avoid domestic shortages, and not so much for environmental reasons). Wang and Voituriez (2009) convert the Chinese export tax rates into $\mathrm{CO}_{2}$-based rates to determine the $\mathrm{CO}_{2}$ price implicit in theses rates. They find that in the years 2006 to 2008 the implicit $\mathrm{CO}_{2} \operatorname{tax}$ on Chinese steel was between $€ 30$ and $€ 43$ per ton of $\mathrm{CO}_{2}$, for aluminium it amounted to $€ 18$ to $€ 26$, and for cement $€ 2.5$ to $€ 3.5$. Thus, for steel and aluminium the implicit border carbon tax was in the range of the carbon price of the EU ETS - for these two products the Chinese export tax system performed no worse, and probably even better, than a (theoretic) border carbon adjustment system the EU might have designed. For cement, however, the Chinese tax did not offer the protection the EU might have hoped for. Still, these calculations show that an export tax system might be an alternative to a carbon import tariff. Wang and Voituriez (2009), however, note that China often changes her export taxes - sometimes on a yearly basis. To make them a reliable climate policy tool, instead a long-term commitment would be required. 


\subsubsection{Compensating developing countries for income losses}

Whichever policy tool is employed - be it export taxes or carbon import adjustments one important question is whether the amounts raised would suffice to compensate developing and emerging economies for the possible welfare losses they would experience if border adjustments were introduced. Grubb (2011) performs simple calculations based on recent trade figures to determine the prospective revenues that can be raised by import measures. He assumes that the border adjustments are based on direct emissions only and the use of best available technology (BAT) at a carbon price of $€ 15$ to $€ 30$ per tonne of $\mathrm{CO}_{2}$. From trade in cement, the EU could thereby raise $€ 0.5-$ 1 billion per year; and from steel trade $€ 2-4$ billion per year. If the whole OECD region were to apply border measures, the possible revenues for cement and steel taken together would amount to $€ 3.5-€ 5$ billion per year for a carbon price of $€ 15$, or roughly double that amount for a $€ 30$ carbon price. If more commodities were included in the carbon pricing scheme, of course, the revenues would be higher. Grubb (2011) suggests that these revenues could be counted towards the pledges of industrialized countries to contribute to international climate finance. In that way, two problems of international climate policy could be solved at the same time: the problem of competitiveness and leakage on the one hand, and on the other hand the problem how to raise enough funds for international climate finance. At the UNFCCC climate conference in Copenhagen, developed countries have committed to the objective of providing US\$ 100 per year by 2020 for mitigation and adaptation in developing countries (Copenhagen Accord, UNFCCC 2010, codified one year later in Cancun: UNFCCC 2011d). According to Grubb (2011, 1054), compared to this promise of US\$ 100 , the amount that can be raised through border adjustments is thus "a modest, but (...) far from trivial contribution." The question, whether the revenues from the border measures suffice to compensate developing countries for the possible welfare losses the application of the measures bring about, can however not be answered by an analysis like the one just discussed: Grubb does not determine the effects of the different policies on welfare.

This is however done by Springmann (2013), who conducts a more complicated model-based analysis of border carbon adjustments. Springmann also assumes that the revenues from the border measures are not channelled into the general budget of developing and emerging economies, but specifically spent on mitigation and adaptation projects. The effects of this policy are simulated by a two-step procedure: the impact of clean development investments on emissions in non-Annex I countries is represented by bottom-up abatement cost curves, whereas the macroeconomic effects of these investments and the carbon tariffs are captured by a CGE model. Results are obtained for an emission reduction of 11 percent in Annex I countries. This leads to a carbon price of $\$ 15$ per tonne $\mathrm{CO}_{2}$. The border adjustments are applied for imports only and are based on direct and indirect emissions discharged in the country of origin of the imports plus emissions from the transport of these goods. The main findings are that the carbon tariff yields revenues of about $\$ 9.8$ billion. Investing this sum in mitigation and adaptation projects in non-Annex I countries reduces emissions in these countries by about 11 percent. Carbon leakage thus turns negative - the combination of climate 
policy in Annex I countries coupled with border tariffs and an investment of the proceeds of these tariffs in non-Annex I countries triggers an emission reduction in nonAnnex I countries that is of about the same (relative) size as the original emissions reduction in Annex I countries. As concerns welfare, the revenues of the border measures however do not suffice to compensate developing and emerging countries for the welfare losses the introduction of border adjustments brings for them - these countries thus would be better off with an abatement policy of the Annex I countries without border adjustment and without clean development spending. Springmann (2013, 33 ) concludes that "[o]n the political level, this calls into question whether combining carbon tariffs with clean development financing would be enough to make China and other developing countries reconsider their general opposition to carbon tariffs."

As discussed above, the question whether developing countries indeed suffer welfare losses through border carbon adjustment and if so, how big these losses are, has however not been finally resolved - the results depend on the model employed. Thus findings that challenge the conclusions of Springmann (2013) cannot be excluded. The EMF model-comparison study reviewed above (see Section 5.2.3) finds that channelling the tariff revenues to exporting countries cannot fully offset the adverse welfare effects of the introduction of the border measures on non-abating countries, but it can at least markedly reduce them (Boehringer et al. 2012a). Steininger et al. (2014) use the data produced by the EMF study, but compare a somewhat different scenario: as opposed to the original EMF setting, not all of Annex I countries except Russia abate, but only the EU pursues a unilateral abatement policy; and the border adjustments include only an import tariff, but no export rebate. Then, the welfare costs of the policy are the same for non-Annex 1 countries in a scenario without border carbon adjustments and in one with border carbon adjustments if the tariff revenues go to the exporting countries. And the Rest-of-Annex I countries (i.e. the Annex I countries except for the EU countries, which pursue the climate policy) are even better-off in the setting with border measures and the tariff revenues going to the exporting countries than in the scenario without border measures. Thus, in this scenario the introduction of border measures has produced a result where no group of countries is worse-off and some are even better-off. But even if the revenues from the border tariffs do not suffice to compensate non-abating countries - as long as the policy with border adjustments is more cost-effective than a policy without such adjustments, there must be countries that experience welfare gains by the introduction of the policy. These countries are therefore in a position to pay the necessary compensation. Of course, if this compensation cannot be paid from the revenues of the border measures, but must be drawn from the general budget, the decision to grant it will be politically sensitive; in a real-world setting it is therefore by no means assured that an agreement on the payment of such compensation to developing countries can indeed be found.

Grubb (2011) however lists additional reasons why the introduction of border measures should be in the interest of both abating and non-abating countries. He stresses that when comparing scenarios with and without border measures one should be realistic about the typical characteristics of a scenario without border adjustments. As already mentioned in Section 10.1.1, countries tend to protect leakage-exposed sectors 
even if they do not implement border measures. Thus, the real-world scenario without border adjustments usually has many sectors exempted from carbon pricing by means of free allocation of emissions allowances. This fact, Grubb argues, should make the introduction of border measures even more attractive to both abating and non-abating countries: "Developing countries do not benefit in any way from the current situation, in which countries adopting carbon prices have to exempt large swathes of industrial production from paying it, for fear of carbon leakage," Grubb $(2011,1056)$ states. And in industrialised countries, replacing free permit allocation with border measures means that the government will be able to raise substantial additional funds. Even if the revenues from the border tariffs are passed on to developing countries, the governments of industrialized countries will still receive the revenues from auctioning emissions permits in sectors that have been exempted from carbon pricing before. Thus, there might be advantages to both groups of countries over and above those reported in typical CGE studies. Note, however, that as opposed to the governments of industrialized countries, the industry in industrialized countries might not welcome the replacement of free allowance allocation by border measures - free allowance allocation means also an exemption from carbon pricing for products going to the domestic market, border adjustments, on the other hand, do not exempt these products.

Finally, as our discussion has shown, there are different ways how to channel the revenues from border adjustments to developing countries: the revenues may go directly into the general budget of these countries - and these countries may then be free to decide how to use them; or the revenues go to these countries, but are earmarked for mitigation and adaptation projects (like in the proposal of Springmann (2013) discussed above); or, alternatively, the revenues may also be contributed to internationally administered climate funds. These funds then - according to certain criteria - decide how to disburse the money. It may thus be the case that some developing countries receive more of these funds than they have contributed in the form of border taxes paid, and others receive less. Naturally, developing countries would rather decide themselves what to do with the border tax revenues - this is one reason why many of these countries might prefer export taxes to border import tariffs; but, on the other hand, many industrialized countries may not be comfortable with completely relinquishing the control over the use of these funds.

To summarize this brief discussion on the distributional effects of border adjustments, creating a situation from which all countries benefit, will in many practically relevant cases require that the proceeds of the import tariff are assigned to non-abating countries, and it might in some cases require an international redistribution of income that goes even further. The practical challenge for countries planning to introduce border adjustments thus is how to win political approval of such redistribution measures.

\subsubsection{A multilateral approach to the introduction of border adjustments}

If a border adjustment scheme is designed such that it stands a good chance not to contradict international trade law, it could theoretically be implemented unilaterally. Also, both the bills introduced in the U.S. in the House of Representative and in the 
Senate in 2009 (which, in the end, did not become law) and the EU ETS directive (see Section 3.1) include provisions for the unilateral application of border measures. Nonetheless, the recent academic literature mostly advises against such a unilateral approach (e.g. Neuhoff and Ismer 2008; Droege et al. 2009; 2011b; Quirion 2010). Rather, Droege $(2011 b$, 1197) calls for an "open exchange with the trade partners affected", and Neuhoff and Ismer (2008) recommend formal or at least informal international coordination and cooperation. The aim of such an approach is, of course, to win the trust of developing and emerging countries, which see any kind of trade measures with deep suspicion. Specifically, international cooperation should prevent the hijacking of border measures by unilateral interests (Droege et al. 2009) and seek "to limit and possible harmonise their use to a narrowly defined and therefore more widely acceptable scale and scope" (Neuhoff and Ismer 2008, 3). In that way, the goodwill of developing countries for the negotiations of a wider climate deal should be maintained and "unnecessary trade wars" avoided (Droege et al. 2009, 64). All these proposals to hear the opinion of affected countries or - even better - to negotiate with them the measures to be implemented are sometimes subsumed under the criterion of "procedural fairness."

In addition to these political arguments for international cooperation, for certain forms of border adjustments there are also legal requirements to seek international consultations: for example, any use of trade rule exemptions under Article XX of the GATT requires prior negotiations. Also, for the inclusion of indirect emissions like those from electricity generation an international agreement might seem advisable, as the legal status of an adjustment for indirect emissions is unclear (Droege et al. 2009).

Neuhoff and Ismer (2008) recommend that cooperation be sought in the form an international convention, which could determine which form of border adjustment is allowed: the convention could for example draw up a list of products for which adjustments are possible, it could decide whether the adjustments should only apply to imports or also to exports, or how the carbon content of the goods in question is determined: if it is based on a benchmark like BAT, then, for example, one would need to establish how BAT is to be defined. Also, it should be agreed how different forms of climate policies in different countries should be compared, and under which circumstances a country would qualify for being exempted from the border measures.

Neuhoff and Ismer (2008) apparently prefer that this international coordination involves a formal rather than an informal approach. Formal coordination could be accomplished by signing a separate agreement on border carbon adjustment or by using the WTO or the UNFCCC framework. Informal coordination, on the other hand, could result in agreeing on guidelines for border measures. Even though these guidelines would not carry formal legal weight, Neuhoff and Ismer argue, they might nonetheless be quite effective: a country that follows the guidelines might, for example, have much better chances to have its border regime accepted by the WTO.

In case a country decides to proceed with border adjustments even though it has not gained international approval of its policy, Cosbey et al. (2012) recommend that the country should still adhere to some rules of good governance: it should notify trade 
partners at an early stage of its plans and should give them the possibility to comment and discuss the planned regime. There should also be enough lead time so that exporting countries and firms can adjust their policies. Furthermore, all calculations of, for example, carbon intensities or benchmarks should be transparent; and exporting firms or countries should also be able to appeal these calculations.

\subsection{Border adjustment design proposals}

In the following, four different detailed design options for border carbon adjustments will be reviewed: proposals by Ismer and Neuhoff (2007; 2009), by Monjon and Quirion (2010), by Cosbey et al. (2012), and by Gros et al. (2010). All four - more or less - attempt to balance the different criteria listed in the first paragraphs of this chapter: conformity with WTO law, practical feasibility, and political acceptability. As concerns the objective of the border measures, the authors of all four proposals see them above all as an instrument to improve the environmental effectiveness of the policy and not to address concerns of the domestic industry about a loss of competitiveness or to apply political pressure to countries that have not signed international climate treaties. Cosbey et al. (2012) explicitly state that preventing leakage is the only motivation they recommend to be used as a justification for border adjustments as it is ultimately an environmental motivation.

\subsubsection{The proposal of Ismer and Neuhoff}

Ismer and Neuhoff $(2007,237)$ argue that border adjustments can be both "feasible and compatible with World Trade Organization (WTO) constraints." The main points of their proposal are as follows:

- Border adjustments should be applied to both imports and exports.

- They should include all products - however, not according to the "true" carbon content of the product.

- Instead, the quantities of basic materials utilized in the production of each product should be identified. Ismer and Neuhoff suggest that producers should be obliged to specify these quantities just like food producers in many countries are obliged to specify the ingredients of food products such as fat, protein, or sugar. The border tax or rebate should be calculated by multiplying the quantities of these basic materials by emission coefficients determined for each of these basic materials and then adding up the resulting products.

- The emission coefficients should be based on the best available technology (BAT) on a global scale. To qualify as BAT, a technology should be commercialized and already be employed with a certain market share.

- In this way, one BAT for each class of basic materials should be determined; if different production processes are available to produce this material, these differences should be disregarded - only the least carbon-intensive process qualifies as BAT. 
- Electric energy input should be treated differently than other inputs: the tax or rebate should match the electricity price change that is caused by carbon pricing in the policy region (it is thus determined by the $\mathrm{CO}_{2}$ intensity of the marginal generation technology).

Ismer and Neuhoff motivate their choice of exactly this design with the following arguments: in practice, it is not possible to exactly determine the carbon content of each and every product - therefore, one has to use a "proxy" such as the carbon content of basic materials embedded in the examined product. As the production of basic materials usually is the most carbon-intensive part of the whole production process, in this way a large share of the "truly" embedded carbon will be accounted for. Assessing the carbon content of basic materials according to BAT, of course, typically underestimates the "true" carbon content; still, as Ismer and Neuhoff argue, only by using BAT the nondiscrimination rules of the GATT can be fulfilled - and thus conflicts with international trade law will be avoided. Relying on product-specific, and not on process specific border adjustments serves the following purpose: For imports, in this way cost-intensive monitoring of foreign production processes and also problems with WTO law can be avoided; for exports, on the other hand, one can avoid creating unwanted incentives: if export rebates were based on process-specific carbon coefficients, products produced by "dirty" processes would be rerouted into exports as they receive higher export rebates and the incentive to switch to a "clean" production process would be lost. Finally, concerning the input of electricity, basing the border adjustment on BAT would result in a zero adjustment, as renewable energy can be produced with (almost) zero emissions. Thus, if an adjustment for emissions from electricity is desired, a different calculation method has to be chosen.

\subsubsection{The proposal of Monjon and Quirion}

As opposed to Ismer and Neuhoff (2007; 2009), Monjon and Quirion (2010) do not present a general design proposal for border carbon adjustments, but one tailored specifically to the EU ETS. Monjon and Quirion (2010, 5205) "find no reason to conclude that [such adjustments] would be unmanageable." Their detailed proposal is as follows:

- An adjustment for imports and exports is more efficient, but one limited to imports "may be seen as satisfactory" (Monjon an Quirion 2010, 5202).

- Only basic materials need to be included, but not consumer products.

- The adjustment both for imports and exports should be based on BAT (to be more specific: on the product specific benchmarks the European Commission has elaborated for the sectors that receive free emissions allowances)

- If indirect emissions (from electricity generation) are included, the adjustment could be based either on the national average emissions in electricity production of the exporting country or on the marginal emissions factor from the exporting country (this is a method employed for many CDM projects). 
- The adjustment should not take the form of a tax or a monetary rebate, but of a requirement to surrender emissions allowances for imports and of a rebate on the amount of allowances a domestic emitter has to surrender for exports. Also, the obligation for imports should apply immediately when the imported product is registered at the border, not four months after the end of the year as for domestic emitters.

There are many elements in the proposal of Monjon and Quirion that try to keep the design simple and easily manageable, for example the idea to use BAT benchmarks that are already currently calculated by the EU or the limitation of the border adjustments to a small number of basic products. As concerns setting the benchmarks according to BAT and not according to average or actual emissions of the product examined, Monjon and Quirion (2010) argue that information on actual emissions or on average emissions in the exporting country is typically not easily available. One however needs an emission measure that is simple to calculate, and the benchmarks the European Commission defines for the EU ETS might be an ideal choice. These benchmarks only cover direct emissions - thus, if one aims to also include indirect emissions, a different method of calculation for indirect emissions must be devised. On the question of effectiveness of basing the adjustments of BAT, Monjon and Quirion cite a study of Demailly and Monjon (2008) of the world cement industry. This study finds that even though in the cement industry the emissions of production with BAT amount to only 80 percent of average emissions, border adjustments based on BAT are almost as successful in preventing leakage as border adjustments based on actual technology. From this result, Monjon and Quirion conclude that an approach using BAT should suffice. Also, citing their own sectoral leakage study (Monjon and Quirion 2009), the authors argue that the overall leakage ratio of the sectors cement, steel, and aluminium taken together will become almost nil with a border adjustment that is applied to imports only - for the EU as a whole thus a border adjustment without an export rebate "may be seen as satisfactory" (Monjon and Quirion 2010, 5202) if the introduction of export rebates causes legal problems. For certain sectors, for example the steel sector, however exports from the EU are usually higher than imports - thus for these sectors "having the full [border tax adjustment] would be important."

The other simplification - applying the adjustments only to basic commodities - is motivated as follows: According to Monjon and Quirion, there are only few products for which the risk of carbon leakage is really high. By limiting the adjustments to just these products, the authors argue, the EU could not only lessen the administrative burden, but also show good faith that the aim of the adjustments is indeed an improvement in environmental effectiveness - and it could also confine industry lobbying to just a few sectors. Monjon and Quirion also discuss whether limiting the adjustments to basic commodities would shift carbon leakage to downstream products. For example, taxing imports of steel, but not of cars at the EU border might incentivize producers to shift manufacturing of cars outside the EU and then import the cars to the EU. Houser et al. (2008) and Weber and Peters (2009) note that, for example, the U.S. imports more steel embedded in final goods than in the form of basic steel products. Monjon and Quirion however argue that these figures do not per se imply that leakage 
will be shifted to final goods. Citing calculations by the French Energy and Environment Agency (ADEME 2007), the authors ascertain that at a $\mathrm{CO}_{2}$ price of $€ 30$ 50 the emissions embodied in a car amount to no more than $€ 48-80$ - which is negligible compared to the price of a car. For most final products, the extra cost due to the carbon import tariff is similarly small compared to the total cost of the product; therefore, Monjon and Quririon argue, carbon pricing and carbon border adjustments targeting basic commodities cannot be expected to cause a substantial diversion of trade in final products or carbon leakage via such an effect.

Finally, Monjon and Quirion recommend not tax-based, but allowance-based border adjustments. The motivation is to ensure a more similar treatment of European and non-European firms. The allowances should, however, be handed in immediately when a product is registered at the border - in this way, the authors argue, fraud can be avoided. Monjon and Quirion do, however, not elaborate on the question whether the allowances for imports should be drawn from the same pool as the allowances for domestic production or whether there should be additional "import allowances." As Neuhoff and Ismer (2008) point out, if importers obtain their allowances from the same pool and thereby reduce the number of allowances available for domestic producers, the "production cap" of the system is effectively transformed into a "consumption cap."

\subsubsection{The proposal of Cosbey et al.}

More recently, also Cosbey et al. (2012) have elaborated a proposal for the design of border carbon adjustments (BCA). This proposal does not refer to any specific country; it is kept in general terms. Compared to Ismer and Neuhoff $(2007 ; 2009)$ and Monjon and Quirion (2010), the authors are more cautious about the possible benefits of border adjustments: they state that border adjustments are "at best a fall-back measure in the event of collective failure at the international level to define appropriate levels of national action. At worst BCA can be a coercive, divisive and highly imperfect policy tool with serious methodological challenges" (Cosbey et al. 2012, 3). The main points of the proposal are as follows:

- Adjustments for imports, but not for exports.

- Rather narrow coverage of sectors: to qualify, a sector must be both GHGintensive and trade-intensive (these criteria are fulfilled only by some basic commodities sectors, but not by consumer goods sectors).

- Only direct emissions plus indirect emissions from electricity production should be included.

- The adjustment for direct emissions should be based on the average emissions intensity of the country introducing the border measures. Additionally, producers should be given the option to prove that they produce with a lower emissions intensity.

- The adjustments should in general be product-specific. Only in a few cases process-specific adjustments are called for. 
- Indirect emissions stemming from electricity production should, however, be adjusted based on the average emissions intensity in the electricity production of the exporting country.

- Exemptions from the border measures should be granted to countries adhering to a multilateral climate agreement to which the implementing state is also party and to least-developed countries (LDCs) and low-income countries (LICs). Exemptions or rate reductions should also be granted to countries (and sectors) following an effective national (price-based) climate policy.

- The revenues from the import adjustments should either be directly refunded to the exporting country or used to subsidize clean technology transfer, contributed to internationally administered climate funds, or used in other ways that benefit developing countries.

The proposal does not include export rebates because the authors on the one hand consider them vulnerable to legal challenges; on the other hand, a border adjustment system that grants exemptions could easily be circumvented if it also applies export rebates. The problem is the following: Assume a trade partner who is not a member of the climate coalition has introduced a comparable cap-and-trade system. Clearly, trade with this country should be granted an exemption from both the import tariff and the export rebate. But any country-specific exemption referring to exports can be bypassed: Domestic exporters who want to claim the export rebate can export their products first to a third country and then have them sold on to the country to which the exemption applies. Cosbey et al. argue that there is no feasible way to avoid such an outcome.

The decision of Cosbey et al. to recommend a rather narrow coverage of sectors is based on the following arguments: while a broad coverage would probably be somewhat more effective in preventing leakage, one also has to weigh the benefits of including additional sectors against the administrative costs. Also, including sectors with comparatively low risk of leakage might lead to conflicts with trade law, as other countries may claim that the border adjustment in these sectors is not motivated by environmental objectives. Thirdly, including manufactured goods or other goods that have long and complex supply chains might make the border adjustment system vulnerable to trans-shipment with the aim to escape the border measures. Such problems with trans-shipment can occur if a system of border measures has exemptions or rate reductions for certain countries - then there is always an incentive to route a product through an exempt country along its supply chain to avoid paying the border tax, even if hardly any value is added to the product in the exempt country. For basic commodities, in contrast, it is usually easy to determine the country of origin. Like Monjon and Quirion (2010), also Cosbey et al. $(2012,13)$ emphasize that "even if only the highemitting highly traded sectors are covered (there are relatively few of them), the regime will deliver almost all of its potential benefits in terms of reducing leakage."

Another dimension of the proposed border adjustment system is the question how the carbon content of the taxed products should be assessed. In contrast to Ismer and Neuhoff (2007) and Monjon and Quirion (2010), Cosbey et al. (2012) do not 
recommend to use BAT to assess direct emissions, but to base the benchmarks on the average emissions intensity in the country implementing the border measures (note: not the country targeted by the measures!). They acknowledge that a BAT benchmark would be the least likely to be successfully challenged under WTO law, but it would also be the least effective at preventing leakage. Using the average emissions intensity in the exporting country or even the emissions intensity from "worst practice" as a benchmark, on the other hand, would be more effective, but also involve a higher risk of violating trade law and of being circumvented by "creative" trans-shipment. A "worst practice" benchmark, Cosbey et al. state, might due to the high level of adjustment charges involved also run counter the spirit of CBDR. Thus, every option involves trade-offs. Cosbey et al. regard setting the benchmark for direct emissions at the average emissions intensity of the country implementing the border measures as a reasonable compromise between the different objectives mentioned. They argue that direct emissions tend to be roughly similar for energy-intensive and trade-exposed sectors globally and that therefore they are amenable to applying one international standard regardless of the country of production: also with such a uniform standard they would still offer strong protection against leakage. Note that this claim contradicts the findings of Bednar-Friedl et al. (2012b; see Section 5.2.2 a discussion), who point out huge international differences in process emissions.

Furthermore, Cosbey et al. argue, that as a general rule benchmarks should be product-specific, and not process-specific. Process-specific benchmarks have disadvantages such as setting wrong incentives and potentially being not in conformity with trade law (these were discussed above). For certain products like steel, however, the application of multiple benchmarks seems nonetheless warranted: steel can be made from iron ore using a process relying on a blast furnace, or from scrap steel using an electric arc furnace. Emissions of the second process are far lower than those of the first one; its use is however limited by the availability of scrap steel. Cosbey et al. argue that therefore a separate benchmark should be set for steel produced by blast furnaces.

In addition to applying a benchmark for direct emissions, Cosbey et al. also suggest giving producers the possibility to provide third-party verified data on the carbon intensity of their production. If they can prove in this way that their production is "cleaner" than the one that defines the benchmark, their import border adjustment should be reduced accordingly. This, the authors argue, would provide producers with the incentives to improve their production processes, and it would increase the odds that the scheme conforms to WTO law. Still, for firms producing at above-benchmark GHG intensities, there is no incentive to improve their performance.

For indirect emissions that stem from energy production (mostly electricity production), Cosbey et al. suggest employing a different benchmark: the average emissions intensity from the exporting country. The reason is that in electricity production huge differences exist between individual countries in their national energymix and therefore their national GHG intensity. For these emissions, it is therefore important to apply a country-specific standard: that improves the effectiveness against leakage and sets the right incentives. Still, Cosbey et al. $(2012,16)$ conclude that such a 
hybrid system of different benchmarks for direct and indirect emissions "would still face GATT MFN problems, but other things being equal would probably be more defensible than a pure exporting country benchmark." Finally, indirect emissions that do not stem from energy production, i.e. emissions embodied in other inputs to production, should not be covered by border adjustments, Cosbey et al. argue: calculations would be to complex, and furthermore, these emissions do not amount to a significant share of total emissions.

As concerns the exemptions and tariff rate reductions listed above, they are motivated either by the objective of environmental effectiveness: countries that apply a comparable cap-and-trade system, should not be "punished" by having their exports taxed twice - once in the country itself and a second time at the border. Or they are motivated by the UNFCCC principle of CBDR - this for example applies to the exemptions for LDCs and LICs. Neuhoff and Ismer $(2008,5)$ remark, however, that "such exemptions risk pollution havens that are unlikely to benefit any party." They instead recommend supporting developing countries in other ways. The proposal of Cosbey et al. (2012) actually also envisions such other forms of support: the revenues from the import tariff should be used in a way that benefits developing countries. Additionally, channelling the tariff proceeds to developing countries also prevents the implementing countries to manipulate the terms of the border adjustments in order to improve domestic welfare; and it increases the chances that the measures will be accepted by the WTO as it demonstrates that they have been introduced for environmental reasons.

\subsubsection{The proposal of Gros et al.}

The fourth design proposal for border carbon adjustment discussed here, the one of Gros et al. (2010), differs in a fundamental way from the three schemes just reviewed it is the only proposal that suggests including all imports and basing the border measures on the "true" carbon content of the product in question, and not on some benchmark. In detail, Gros et al. suggest the following border adjustment system to supplement the EU ETS:

- The adjustments (in form of a tax) should be applied to imports, but not to exports.

- All imports should be included - not just imports from carbon-intensive sectors.

- The border tax should be based on the carbon content of the import. The relevant figures can either be determined by the importer (using internationally accepted methodologies) or it will be established by the authorities of the country introducing the border measures using an international standard such as ISO 14067.

- The tax rate should be set equal to the difference of the EU price of carbon and the foreign price of carbon.

- Revenues from the tax should feed a fund that will ease the transition of energyintensive industries and invest in new technologies. 
The decision not to rebate exports is motivated by the objective to make the whole scheme WTO-compliant. Excluding exports makes the border measure less protectionist, and that increases the chances that the measures are compatible with world trade law, Gros et al. argue.

Another central point is that all imports - and not just those from carbon-intensive sectors - are included in the scheme. The authors regard this point as crucial: if, for example, only the imports from ETS-covered sectors were taxed at the border, "the efficiency of the carbon border tax would be reduced dramatically in terms of its impact on global welfare," Gros et al. state $(2010,49)$. The reason, they argue, is that carbon pricing in ETS sectors does not only raise the prices of commodities from these sectors, but also the prices of all goods that use commodities from ETS sectors as inputs.

In a similar vein, Gros et al. contend that basing the border adjustments on the "true" carbon content of a product, and not on some benchmark, is also critical for the efficiency of the border scheme. That means that the adjustments are "process-specific" instead of "product-specific", i.e. "like" products in the sense of GATT Article III are treated differently, which is prohibited by the GATT (see Section 3.2 for details). In order to keep the border measures nonetheless in compliance with WTO law, therefore GATT Article XX, the "general exception clause" has to be invoked. This in turn requires a proof that the policy indeed helps to achieve an environmental objective. But that, Gros et al. (2010) argue, can be unambiguously proved - Gros (2009) shows in a simple one-sector partial equilibrium model that augmenting a system of domestic carbon taxation with a tariff on the carbon content of imported goods increases global welfare and lowers global emissions (see Section 4.1 for a discussion of this model).

A question of practical relevance is how the carbon content of manufactured products that have passed through a long international value added chain should be assessed. Gros et al. suggest that either the importer could provide information on the carbon footprint of the imported good - in that case she would have to employ a internationally accepted methodology. Or, alternatively, the EU could establish the carbon content of the good in question - also using some globally accepted standard. The authors suggest employing for example ISO 14067, an international standard for determining the carbon footprint of a product. Gros et al. $(2010,56)$ remark that "although calculating the carbon content of thousands of products from several different countries may seem a daunting job, one could argue that it should be no more complicated than, for example, obtaining a CE marking ${ }^{48}$ to enter the EU market."

As concerns the use of the tax revenues, Gros et al. suggest that they should feed a fund that finances climate-related industry restructuring and research. It is, however, not 48 The CE marking certifies that a product has met EU consumer safety, health, and environmental
requirements. 
clear whether this proposal refers only to projects in non-abating countries or to such projects in general.

\subsubsection{Relying on benchmarks and taxing only basic commodities}

To conclude this comparison of detailed design proposals for border adjustment systems, a few common point shall be highlighted: there seems to be a majority opinion that, as Droege et al. $(2009,64)$ put it, "a general adjustment for all imports from regions outside a carbon pricing zone, based on the carbon footprint, is neither manageable nor useful as final goods often carry a large source of inputs for which carbon emissions could not be traced back." Rather, the adjustments should concentrate on just a few sectors and be based on benchmarks. Only Gros et al. (2010) disagree: they stress that in that way much of the efficiency and incentive effects of the border scheme would be lost. Still, it is not clear whether the scheme of Gros et al. with its complicated embedded carbon assessments can indeed practically be implemented. Furthermore, taxing imports at their true carbon content would imply substantial tax rates - for example, for imports from China, the average border tax would amount to 89 percent of the value of the products at a carbon price of $€ 25-30$, Gros et al. calculate. This, however, is probably an amount that would trigger retaliatory measures by China. 



\title{
CHAPTER 11
}

\section{Consumption-Based Climate Policy in Practice: Abatement Potentials Difficult to Exploit}

\begin{abstract}
As stated repeatedly throughout this study, there exist apparently convincing arguments supporting the view that by switching to a consumption-orientation, industrialized countries can improve the effectiveness of unilateral climate policy: with current worldwide production and trade patterns, a consumption-based policy would include a larger share of global emissions than a production-based one; it would bring part of the industry of developing and emerging economies into the scope of the policy - sectors which should offer abatement options that are cheaper than those in industrialized countries; and finally, a consumption-based policy would avoid (or at least: reduce) leakage through the competitiveness channel and probably enhance the spread of "green" technology in developing and emerging economies, thereby perhaps even creating "negative" leakage. The analytical part of this study has however shown that these arguments do not apply in all circumstances and that additionally great care has to be devoted to the details of the design of the policy instrument - otherwise a switch of the policy-base might well achieve results directly opposed to the original intentions.

Drawing on the results of the analytical chapters of this study, on findings of the quantitative border adjustment literature, and on arguments from the discussion of the policy design proposals reviewed in Chapter 10, this chapter aims to answer the following question: under which circumstances will a consumption-based approach not just in the idealized setting of an analytical model, but also under real-world circumstances increase the global environmental effectiveness (and the costeffectiveness) of a unilateral climate policy pursued by (a group of) industrialized countries, and how must the policy instrument be designed to achieve that objective. We start by defining in more detail the aims the policy should pursue.
\end{abstract}

\subsection{Criteria for assessing policy variants}

This study has primarily concentrated on environmental effectiveness and costeffectiveness. The discussion of the previous chapter has however shown that a policy, in order to stand a chance of being actually implemented in a "real-world" situation, must fulfill a few more requirements. Accordingly, the policy proposals to be developed in this chapter should meet the following criteria: they should promote environmental effectiveness (or - if quantifiable - even better: cost-effectiveness), should not impose more economic burdens on emerging and developing countries than the current international climate policy regime, should be perceived as fair, should stand a reasonable chance to conform to WTO rules, and their implementation should be practicable. 
This study has not attempted a detailed discussion of justice criteria. Instead we rely on the widely accepted UNFCCC criterion of "common but differentiated responsibilities and respective capabilities" and additionally assume that currently industrialized countries bear a smaller burden than required by this principle (the rationale for this approach is given in the last two paragraphs of Section 6.4). This motivates the requirement that the policy should not increase the burdens on developing and emerging economies. The additional criterion of "perceived fairness" has been briefly discussed in the introductory paragraphs of Chapter 10 - simply put, it requires that the policy to be introduced not only conforms to some abstract justice criteria, but is also perceived as beeing "fair" by the politicians and the general public of the affected countries. Here, the criterion of "perceived fairness" is assumed to also include "procedural fairness" (see Section 10.1.5), i.e. "fairness" is not only determined by the policy as such, but also by the way it is implemented. WTO rules applying to border adjustments have been discussed in Section 3.2.; and the practicability of various schemes of border measures was inter alia the topic of Section 10.2.

Note that "preserving competitiveness" is not listed as a criterion. The reason is that the WTO accepts only environmental criteria as motivation for the introduction of border measures (see Section 3.2) and that it is hard to find a moral justification for promoting the competitiveness of one group of countries at the expense of others. Thus, basing a policy on the argument that it "preserves competiveness" will in all likelihood not meet the criterion of "perceived fairness". Note however that a consumption-based policy - and also an "income-tax-only" policy - promotes the competitiveness of the abating coalition. Thus, even if the switch of the policy base is not motivated by it, its effect on competitiveness may be regarded as a welcome positive "side-effect."

From the criteria listed above two requirements can immediately be deduced that the climate policy design should fulfill: First, it should not lead to a reduction of the income (or: of the welfare) of developing and emerging economies as compared to a production-based policy. This follows from the "justice criterion" of not imposing additional burdens on this group of countries. It is however also a requirement called for by economic arguments in order to guarantee that the measures introduced indeed promote the environmental effectiveness of the policy: as argued in Section 9.4, if a loss of income of developing and emerging economies triggers import substitution in these countries, the environmental effect of the policy may actually not be a reduction, but an increase of global emissions. In case it is not possible to reformulate the policy design such that it does not cause income losses of developing countries, these losses may also be compensated by direct payments to this group of countries.

The argument on income losses immediately brings us to the second requirement regarding policy design that follows from the criteria listed above: as explained in Chapters 7 and 8, in every economic sector there exist (at least) two ways to reduce emissions: either the output of the sector is reduced, or the production technology is altered so as to lessen the emissions per unit of output. But as the reduction of output leads to a reduction of income, for the imports from developing and emerging economies this method of abatement should be avoided as far as possible as it may lead 
to import substitution, which - as dicussed above - may have negative effects on the environment. Thus the aim of the policy should be not to curb the exports of developing and emerging economies, but to "green" them. This however requires that this group of countries (i) possesses the necessary production technologies and that (ii) the policy is designed such that it incentivizes a switch to a "green" production technology. These two points will be taken up in Section 11.3.

\subsection{Conditions favoring the effectiveness of consumption approaches}

The discussion of Chapters 8 and 9 has shown that a switch to a consumption-based policy should be an - on environmental grounds - promising option if the abating coalition meets the following criteria: the coalition is small relative to the world economy and it produces with a markedly lower carbon intensity than its trade partners; available technological abatement options in domestic production have largely already been implemented and additional abatement in domestic production seems difficult (in terms of the model of Chapters 7 to 9: the elasticity of input substitution in Home is small); the demand for the coalition's exports is not very price sensitive - therefore taxing these exports will not trigger a large reduction of emissions; but on the other hand demand in non-abating countries for their domestic production is highly sensitive to cross-price effects and a taxation of the exports of the abating coalition would therefore cause carbon leakage. The demand of the abating coalition for imports, in contrast, is price-sensitive and a tax on imports would therefore have a powerful effect on global emissions.

This characterization of "the ideal candidate" country (or group of countries) for a switch to a consumption-based policy however is not valid without qualifications: as we have seen in Chapter 9, even though a policy switch is more attractive for small abating coalitions at first sight, such small coalitions run the risk that the countries the exports of which are taxed simply avoid the tax (and thus also the environmental effects of the tax) by redirecting trade flows. Additionally, also a large effect of the tax on the amount of imports from non-abating countries is favorable for the environment only at first sight - if it triggers import substitution in the non-abating countries, it may, as described in the previous section, actually have a detrimental effect on the environment. These arguments demonstrate that the design of a consumption-based policy that indeed achieves its intended aims is not a trivial task. In the following, four policy design features will be discussed that should help to accomplish that goal.

\subsection{Designing an effective and just consumption-based policy}

\subsubsection{The use of tax revenues}

The revenues of the tax on imports of the abating countries should be allocated to nonabating countries, i.e. to developing and emerging economies. - This policy design recommendation is motivated by the following arguments: 
- Justice: the costs of the policy for developing and emerging economies are reduced as compared to the "standard" option, where the countries that levy the tax also receive the tax revenues.

- Environmental effectiveness: the environmentally detrimental feed-back of income losses of developing and emerging economies caused by import substitution is avoided (see Section 11.1).

- Compatibility with WTO rules: distributing tax revenues to non-abating countries may be seen as a proof that the policy measure really pursues environmental objectives, and not the aim to lower the costs of abatement incurred by abating countries.

Allocating the revenues of the import tax to non-abating countries clearly increases their welfare as opposed to an option where the abating countries receive this revenue - it however need not be the case that this measure fully reimburses non-abating countries for the cost of the policy. This is basically a question of tax incidence, i.e. it depends on which share of the climate policy costs is borne by developing and emerging countries. Different CGE studies give different answers to this question: Springmann (2013) - see Section 10.1.4 - finds that the revenues of border measures will not suffice to compensate developing and emerging countries for the welfare losses the introduction of the measures causes. Steininger et al. (2014) - using data from the EMF model comparison study discussed in Sections 5.2.3 and 5.2.4 - on the other hand find that for a unilateral climate policy of the EU the welfare costs of a production-based policy and a policy with an import tariff, but no export rebate are virtually equal.

Note that if a policy also includes an export rebate, then this rebate is typically funded out of the revenues from the import tariff. In that case, the funds that can be distributed to developing and emerging economies are therefore less than under a policy with only an import tariff. On the other hand, granting an export rebate directly increases the welfare of non-abating countries.

To sum up, the proposal to channel tariff proceeds to developing and emerging economies should serve the aim to avoid welfare losses of this group of countries due to the switch of the policy base - it is however not guaranteed that this measure suffices to fully reimburse these countries for the cost of the policy. If not, additional reimbursement payments are an option - it is however unclear whether there is the political will in industrialized countries to finance such payments.

Additionally, it has to be decided in which way the revenues from the import tariff are disbursed to developing and emerging economies: shall they be handed directly to the governments of these countries, or be spent on mitigation projects in these countries and technology transfer to them; or be channelled through internationally administered climate funds. Although the last two options give industrialized countries more control over the use of the funds and will therefore probably be favoured by these countries, note that spending the funds on abatement projects may in the eyes of developing and emerging economies not qualify as a compensation for the costs of the policy - and, depending on how exactly the funds are allocated, it may also not avoid the 
environmentally detrimental feedbacks due to import substitution in developing and emerging economies. As an alternative to imposing import tariffs the revenues from which are then returned to developing countries, the introduction of an export tax by these countries may be agreed upon (see Section 10.1.3). In that case, developing and emerging economies maintain the full control over the tax revenues.

\subsubsection{Technology transfer}

The transfer of "green" technology to developing and emerging economies should be fostered. - This policy design recommendation serves the following aims:

- To enhance environmental effectiveness by enhancing possibilities for cheap mitigation in developing and emerging economies: Many of these economies cannot be expected to have access to advanced "green" technologies. Thus the often cited "low-cost abatement opportunities in developing countries" might be only be exploitable by industrialized countries investing in developing countries, e.g. through mechanisms like the Kyoto Protocol's CDM. But for developing countries themselves they may not exist. This, however, can be changed by transferring the required technologies to these countries. Note also that if developing and emerging economies cannot react to an emission tax on their exports by changing their production technology (and thus alleviating the tax burden), then the tax will fully feed into the prices of their exports causing a reduction in demand for these products and thus also a reduction of the income of developing and emerging economies - which leads to the effects already discussed in the previous subsection. Therefore technology transfer also helps:

- To avoid the environmentally detrimental feed-back of income losses due to import substitution by developing and emerging economies; and:

- To promote justice - by avoiding income losses in developing and emerging economies and by transferring additional income in the form of patents on "green" technology to these countries.

- To boost the technology spillover leakage channel: the introduction of "green" technology in the export sectors of developing and emerging economies enables a spillover of this technology also to the sectors in these economies producing for the home market, thereby bringing about "negative leakage", i.e. an additional reduction of global emissions.

- To lower the risk that the WTO compatibility of the measures will be challenged: Technology transfer is a form of income transfer to developing and emerging economies. It can thus be seen as a proof of the "good will" of the countries implementing the policy not to discriminate against the countries affected by the policy.

Summarizing, technology transfer contributes both to the environmental effectiveness (and cost-effectiveness) of a consumption-based policy and to justice in burden sharing. 


\subsubsection{No export rebate?}

The introduction of an export rebate can be regarded as optional. With current production, emission, and trade patterns most effects of a consumption-based policy stem from the import tariff. - Actually, there are a number of arguments that favor a policy without an export rebate (an "import-tax-only" policy) over the variant with the rebate. The reasons are the following:

- The share of global emissions covered is larger than under a "pure" productionor consumption-based policy. For a given carbon price, therefore the global emissions reduction is larger than for the two "pure" policy variants (this statement only holds with some qualifications - see Sections 8.6.1 and 8.7.1). This promotes the environmental effectiveness of the policy.

- Cost effectiveness: in the model used in this study the "import tax-only" policy is also the most cost-effective variant. However, this result does not hold in general (see the discussion in Section 8.7.1): Steininger et al. (2014) - using the data of the EMF model comparison study discussed in Sections 5.2.3 and 5.2.4for example find that for a unilateral climate policy of the European Union granting a rebate on exports improves the cost-effectiveness of the policy. The difference is however "negligible", the authors state. Thus, even if costeffectiveness cannot be used as an argument for adopting an "import-tax-only" policy, it also is not a strong argument against the adoption of this policy variant.

- A policy without an export rebate stands a greater chance to be compatible to WTO regulations (see Section 3.2).

- It also furthers "perceived justice": Industrialized countries do not ask measures from developing and emerging economies (the taxation of exports) they are not prepared to implement themselves. Industrialized countries may actually be seen as taking on a "leadership role" by taxing the emissions of their exports.

- For political reasons, it might be the policy variant preferred by countries affected, i.e. emerging and developing economies. The export rebate imposes additional burdens on producers in these countries as they face increased competition due to the reduced prices of the exports of industrialized countries. On the other hand, the price reduction on exports from industrialized countries benefits consumers in developing and emerging economies buying these goods. In trade models of the Heckscher-Ohlin type the benefit to consumers always dominates the costs to producers - overall, developing and emerging economies thus benefit from the introduction of an export rebate and should therefore actually favor it. And the criterion of "not imposing additional burdens" on these countries also calls for the adoption of a policy including an export rebate. Still, developing and emerging economies often oppose export rebates - the reason probably being that producers in these countries are better in making their voices heard in the political process than consumers. 
The export industry of industrialized countries will, of course, argue for the introduction of export rebates - but, as discussed above, "maintaining competitiveness" is not a criterion that will here be used to assess the desirability of a policy.

\subsubsection{Incentives to "green" production}

The policy instrument should be designed such as to incentivize the adoption of lowcarbon production technologies by developing and emerging economies. - The incentives of an environmental tax work the following way: if the economic agent affected by the tax reacts in the way intended by the policy, her tax burden is alleviated. Correctly set incentives should further:

- Justice: the income losses of developing and emerging economies caused by the introduction of the policy are reduced if they are able to alleviate their tax burden by "greening" their production technology.

- Environmental effectiveness: reduced income losses also avoid the negative feed-back on environmental effectiveness due to import substitution (discussed above). If the incentives are "right," abatement in the export sector of developing and emerging economies is achieved less by reducing the "scale" of production, but rather by changing the "technique" of production.

Of course, incentives only have an effect if the producers affected by the tax can indeed change the tax burden by changing their production technology. That requires that the production technology - or the carbon content of the produced goods - of each and every producer taxed is permanently assessed. In contrast, a policy relying on benchmarks will not provide any incentives to "green" production in developing and emerging economies.

\subsection{Policy implementation in the short run: border adjustments}

In Section 2.2.3 two schemes to undertake a switch to a consumption-based policy orientation were introduced: border carbon adjustments and a "carbon added" system. Of these, realistically only border adjustments can be introduced within a relatively short time-frame: as opposed to a "carbon added" scheme, they do not require creating a global system of emission monitoring, and they also do not require a detailed international agreement on how the scheme will be implemented - but, as we will see shortly, if the aim of the measures is to improve environmental effectiveness, they, too, cannot be imposed without at least some international cooperation.

An inspection of the four design recommendations made in the previous section shows that a switch to a consumption-based policy cannot be achieved without a strong political commitment of industrialized countries and without the willingness of these countries to impose partly costly and controversial measures also upon their own industry and consumers. Border adjustments are by no means a "quick fix" to problems the introduction of a stringent climate policy might cause to the domestic industry (as some politicians and industry representatives seem to hope - see Chapter 3) - at least if 
the border measures are meant not only to further competitiveness, but also to improve the global environmental effectiveness of the policy.

Let us examine the possible problems of implementing the four recommendations one by one: Returning the revenues from border taxes to developing and emerging economies may not be popular in industrialized countries - nonetheless, it might be one of the less controversial proposals. The governments of industrialized countries will still be able to raise more funds than under a policy without border adjustments: The adjustments typically replace the free allocation of emission permits to substantial parts of the domestic industry, thus permitting the governments to obtain additional revenues from auctioning these permits. A promising alternative to the imposition of an import tariff might also be an agreement with countries affected by the tariff on an export tax. Such a tax, introduced by developing and emerging economies, achieves effects similar to an import tariff, but might be more acceptable to these countries.

The next proposal, a large-scale transfer of technology to developing and emerging economies, may be more difficult to implement: It affects patents held by private companies - and these companies will most likely resist giving up patent rights or at least ask for compensation. Also, the availability of state-of-the-art technology to emerging economies will immediately affect the relative competitiveness between producers in these countries and those in industrialized nations. Thus, even though it may not seem a very demanding proposal at first sight, the transfer of "green" technology could actually prove to be one of the most controversial parts of the whole scheme.

The third proposal, the idea to implement border measures consisting only of an import tariff, but not including an export rebate, will of course be protested by the domestic export industry. Especially if the export industry is protected by the free allocation of emission permits prior to the introduction of border measures, the switch to border measures without an export rebate will definitely be to the disadvantage of this industry.

But the most complicated proposal as concerns its practical implementation may be the fourth one: the design of a border adjustment scheme that provides incentives to "green" production in developing and emerging economies. Of the four policy designs discussed in Section 10.2 all except for the one of Gros et al. (2010) suggest schemes that rely on benchmarks - and these, as discussed above, will not provide incentives for a change of the production technology. Basically, we are faced with a trade-off between the practicability of a scheme and its environmental effectiveness: benchmark-based systems are easy to implement, but not very effective as concerns emission reduction. This contention is substantiated by results from the quantitative border tax literature: the EMF model comparison study discussed in Sections 5.2.3 and 5.2.4 finds that "the scope for global cost savings [by means of border adjustments] is small" (Boehringer et al. 2012a, S97); and one of the reasons for this finding given by the authors is exactly the use of benchmarks: "import tariffs applied to the industry-average of embodied carbon do not incentivize polluters in unregulated countries to adopt less emissionintensive production techniques" (Boehringer et al. 2012a, S102). The alternative, 
determining the amount of embodied carbon for each and every product that crosses the border, will set the desired incentives, but on the other hand it may be prohibitively complicated, costly, and time-consuming. Actually, with today's long and complex value added chains, which often extend through several countries, there is little hope that embodied carbon can be established at the border without the help of the producer (or rather: producers) of the product being assessed. The assertion of Gros et al. (2010) that such calculations of the carbon content of products should not be too complicated appears overly optimistic.

To nonetheless facilitate an assessment of the carbon content of goods "at the border," the classes of goods covered by the border measures may be limited to primary products. For these, the supply chain is typically shorter and their carbon content can therefore be more easily established. Covering only such products is exactly what is recommended by many studies (see e.g. Droege 2009, Monjon and Quirion 2010, Cosbey et al. 2012). As the discussion in Section 10.2 has shown, there is however no unanimity in the literature on how effective such a scheme including only primary products would be. Gros et al. (2010) argue that limiting the coverage of products would dramatically reduce the efficiency of the border measures. Weber and Peters (2009) estimate that in the U.S. the emissions embodied in primary products such as steel, cement, or paper represent only a small share of the total of emissions embodied in imports (27 percent or less). Following these arguments, a border tax that is "manageable" in terms of its administrative complexity will not achieve much in terms of additional emission reduction. The opposite view is however held by Monjon and Quirion (2010) - see Section 10.2.2: they contend that carbon pricing for manufactured products would in constrast to carbon pricing for primary commodities only lead to a small increase in the cost of products targeted in percentage terms. Such a small cost increase, they argue, would neither cause substantial trade distortions nor large carbon leakages; thus, not including manufactured products in a border adjustment scheme would not have a large effect on its effectivenss. To summarize the discussion of this paragraph, views on the effectiveness of a border tax scheme covering only primary products diverge. But as such a scheme appears to be the only option that can easily be implemented in the short run, we are left with few alternatives. Still, it is not absolutely clear whether confining the border adjustment to primary commodities will indeed solve the problems with the practicability of the scheme - it may well be the case that even with this limited set of products it may not be possible to accurately establish their carbon content without any help of the producers of theses goods.

A possible way out of this dilemma is proposed by Cosbey et al. (2012): the combination of benchmarks with a possibility for producers to prove that they produce with a lower carbon-intensity than assumed by the benchmark (and to have the border tax on their products then calculated using this proven lower carbon-intensity). Thus, the scheme of Cosbey et al. provides an incentive for producers to themselves supply information on the carbon content of their products. But note that also this proposal envisages border taxes only for primary commodities - with manufactured goods the incentive to reveal the carbon content of goods actually may not work: such goods are 
typically produced using many intermediate products as inputs, the carbon content of which usually cannot accurately be established by the manufacturer of the final product.

A question of central importance for such a scheme is the level of the benchmark. Cosbey et al., as discussed in Section 10.2.3, suggest setting it (for direct emissions) at the average carbon intensity of the country implementing the border measures. If this country - as assumed in this study - employs a relatively "clean" production technology, the incentive effect of the benchmark combined with the possibility to prove better performance will however be limited: firms producing with a carbonintensity higher than the benchmark - under our assumptions the majority of firms will in most cases prefer to have their products assessed according to the benchmark to the alternative of trying to perform even better than the benchmark and then have their tax dues reduced. Cosbey et al., however, do not recommend the use of a higher benchmark as this might, as the claim, be in conflict with WTO rules and contradict the UNFCCC principle of CBDR. Their proposal therefore may be a reasonable compromise if the aim of the border measures is just to prevent carbon leakage (as assumed by Cosbey et al. as the goal of the measures), which, as argued above, can be achieved by raising the price and thus curbing demand for the exports of developing and emerging economies. But the aim here is not to curb the demand for these exports, but to provide incentives to "green" the production technology in emerging economies and to achieve this, benchmarks set at the carbon-intensity of the implementing country may not suffice.

An alternative might be to use the emissions intensity from "worst practice" as a benchmark - also combined with the possibility for producers to prove that they perform better. That would provide an incentive for a greater number of producers to "green" their production technology and then indeed present such a proof. But as this idea - as Cosbey et al. point out - is in conflict with GATT provisions, its implementation would need the signing of an agreement between the countries introducing the measures and those affected. Thus, some level of international cooperation is required. And to induce developing and emerging economies to accept such a scheme, industrialized countries most probably will have to be very generous as concerns other details of the planned policy. Also note that for a firm it is a costly procedure to supply the data to prove the emissions-intensity of its production (and thereby get its tax dues reduced). For larger enterprises it may be worthwhile to undergo that procedure, but for small- and medium-sized producers the costs may be prohibitive. Thus, for these producers, again the incentive to adopt low-carbon production technology is lost.

Let us finally discuss the effects of a tax scheme that does not reward producers in developing and emerging economies for adopting a less carbon-intensive technology by lowering their tax dues. In that case, the tax will not have a "technique effect," but just a "composition" and a "scale effect" (see Section 4.2 for a definition of these terms). The model employed in this study does not allow for an analysis of the composition effect. But, in general, the composition effect of a border tax should lower global emissions: less carbon intensive sectors in developing and emerging economies will grow at the 
expense of more carbon intensive sectors. Still, as not for all carbon-intensive products close substitutes exist that are less carbon-intensive, an abatement strategy that relies exclusively on the composition effect has its limits.

As regards the scale effect, its negative consequences for the income of developing and emerging economies (and the possible feedbacks leading to an increase in emissions - see Section 11.1) can, as discussed above, be avoided by channelling the revenues of the border tax (and possibly additional funds) to these countries. More precisely, to what extent negative feedbacks can be avoided and to what extend the border tax actually contributes to emission reductions, will of course depend on how exactly the revenues of the tax are spent in developing and emerging economies. As argued in Section 9.4, these revenues should be used such as to avoid import substitution. Other possibilities may, however, exist to spend these proceeds that further enhance the reduction of emissions: the tax revenues may, for example, be directly used to finance mitigation projects - as in the study by Springman (2013) discussed in Section 10.1.4. Such a strategy could be combined with a transfer of "green" technology from industrialized to developing and emerging economies. Additionally, firms making use of such projects to "green" their production technology could be granted an exemption or a reduction of the border tax as an additional incentive to take part in such a scheme. Again, however, some level of cooperation between industrialized countries and developing and emerging economies will be required in order to implement such a complex strategy.

Finally, note that in case producers are not able to reduce the burden imposed by the border tax by adopting a less carbon-intensive production technology, this increases the incentives to avoid or circumvent the tax. As discussed in Section 9.4, firms can, for example, reroute their exports to third countries. In that case, the border tax would not contribute to global emission reduction. To sum up, if a border adjustment policy does not help to "green" production in developing and emerging economies - either by providing the "right" incentives or through a more complex scheme involving the dirct funding of abatement projects - its environmental impact will be at best limited and at worst negative. Still, also a border tax scheme that is environmentally not effective may help to protect the competitiveness of the industry of abating countries. From this discussion of border adjustment design options the can be implemented in the short run we can therefore draw the following conclusions:

- Border carbon adjustments introduced without any agreement with affected countries may help to preserve the competitiveness of the industry in abating countries. They will however typically only have a small effect on the global environmental effectiveness or the cost-effectiveness of the abatement policyand at worst even a negative effect. An introduction of such adjustments on environmental grounds can therefore not be recommended in general. - For practicability reasons, border adjustments in such a situation will typically be based on benchmarks for the carbon content of certain product classes. The problem with such a form of adjustments is that there is virtually no way to design them such that they incentivize the adoption of a less polluting 
production technology in developing and emerging economies. Thus their main impact will be a reduction of imports from these countries - which is an unwanted effect both for reasons of justice and on economic grounds. If such adjustments are introduced to protect the competitiveness of the domestic industry, note that due to their limited environmental effect it will be difficult to defend their WTO compatibility. In case such a form of border adjustments is nonetheless introduced for political reasons, the scheme should at least provide for the distribution of the tariff revenues to affected countries to minimize impacts that contradict just burden sharing and that might have negative environmental consequences.

- Cooperation with affected countries might allow the design of a border adjustment scheme that improves the global environmental effectiveness and the cost-effectivenss of a unilateral abatement policy. Still, if such cooperation is possible, it should also be examined whether there are alternative policy approaches that perform better in terms of environmental effectiveness. - The aim in negotiations with affected countries should be to design a scheme that provides incentives for producers in those countries to adopt a less carbonintensive production technology. One possibility is the introduction of a "worst practice" benchmark combined with the possibility for producers to prove that they perform better. Additionally, technology transfer and the disbursement of tax revenues to non-abating countries should be agreed. Alternatively, a simple benchmark could be combined with a scheme that channels border tax revenues into abatement projects which affect the production technology in countries that are not part of the climate coalition. Again, the policy would have to provide for technology transfer. Whichever of the two options is chosen, for reasons of practicability the scheme will typically only cover primary commodities. Depending on demand and production paramenters, such a scheme may improve the environmental effectiveness and cost-effectiveness of a unilateral abatement policy. Still, the suggested schemes are no "full border adjustments" and the effectiveness improvements that can be achieved will therefore typically fall short of what models would predict for "full adjustments". Both schemes suggested require the cooperation of non-abating countries. If, however, global cooperation at such a level proves to be possible, industrialized and developing countries should also study alternative options for a joint implementation of climate policy. Sectoral agreements for carbon-intensive industries might be one possibility - an option that, depending on design details, can be at least as effective as border measures, but that is internationally far less controversial.

\subsection{Policy implementation in the long run: carbon added scheme}

In the long run, instead of carbon border adjustments, a "carbon added" scheme as discussed in Section 2.2.3 can be introduced. Such a scheme would require (almost) global cooperation in determining emissions at all steps of production. The great advantage of the "carbon added" proposal is that it should provide accurate data on the 
carbon content of every product. If a carbon tax (or other policy instrument) is applied according to this carbon content, it therefore provides the right incentives to lower the carbon content. We can therefore draw the following conclusion:

The environmental effectiveness (and cost-effectiveness) of a unilateral climate policy pursued by (a group of) industrialized nations may - depending on parameter values - be improved through a switch to a consumption-orientation based on carbon accounting by means of a "carbon added" scheme. The decisive parameters are: elasticities of demand, parameters defining the production technology, emissions intensities and trade and production volumes in abating and non-abating countries. Such a switch of policy-base should also be accompanied by technology transfer to nonabating nations. Carbon taxes on the exports of developing and emerging economies under such a scheme will typically be directly collected by these countries - if not, i.e. if instead they are collected in the form of border tariffs, then the revenues from these tariffs should be disbursed to the countries where the taxed goods were produced.

As opposed to a policy switch carried out in the short-run without any cooperation of developing and emerging economies, thus - provided parameter values are as required - the introduction of a consumption-based policy based on a "carbon added" emissions accounting scheme can be recommended on environmental grounds. Of course, the objective in the long run should be the adoption of a "first-best" climate policy, i.e. a policy that includes the production of all countries and that applies only a single carbon price to all carbon dioxide emissions. A consumption-based policy (or probably better: an "income-tax-only" policy) adopted by industrialized countries may however constitute an intermediate step on the way to a policy that includes all global emissions. Provided industrialized countries offer an attractive "policy package" to developing and emerging economies, these countries might have some reason to first have a stringent climate policy applied to their export industry, before it is applied to their entire economy. As Houser et al. (2008) note, in China, for example, exporting firms are often the best in class. For these firms, it will therefore be easier to comply with a climate policy than for many firms concentrating only on the domestic market.

An issue that also relates to the long-run, but that is of quite a different nature would be a change of the international climate policy architecture to a system that does not rely on emission reduction targets, but on carbon budgets for individual countries (which could be based on equitable per-capita rights to emit into the atmosphere). As mentioned in Section 1.2, such carbon budgets could be defined in terms of consumption-based emissions. But note that the introduction of such a system is a change of the target base, and not of the tax base. Thus it is not directly related to the main research questions of this study. Nonetheless, a change of the target base might in many countries lead to the adoption of a tax base matching this target base, i.e. a tax base that is consumption-oriented, too. The difference to the setting examined in this study is that this system would bring all countries into the scope of the policy. Countries that have a larger carbon budget then they want to spend - in most instances developing countries - under these circumstances have an incentive to sell their "rights to emit". Therefore, a global carbon market should develop, which means that there will be only 
a single global carbon price. Different carbon prices in different countries and the inefficiencies related to these differences - the point of departure of this study - will not be an issue anymore. Of course, the introduction of such a new climate policy architecture will have effects of the welfare of individual countries. But a major policy architecture change can only be introduced by means of an international agreement. The distributional effects of this change will thus be part of the negotiations leading to this agreement - and not an effect that one country (or a group of countries) can impose unilaterally on others as is the case with border measures.

\subsection{Conclusions}

The exports of developing and emerging economies are characterized by what one might call "large abatement potentials." They contain a substantial share of global emissions in the form of embodied emissions (see Chapter 6), and the marginal abatement costs in developing and emerging economies are often close to zero. Still, for industrialized countries proceeding unilaterally it is not easy to exploit this potential. A switch to a consumption-based policy orientation appears to be a promising option only at first sight: In reality, the design of a policy that taps this potential by providing the right incentives and not causing adverse effects is a tremendously difficult task. This study finds that it cannot be accomplished without at least some level of cooperation by developing and emerging economies. Thus, the idea that if developing and emerging economies are not willing to cooperate (or if industrialized countries are not willing to make the necessary compromises to incentivize them to cooperate), industrialized countries may just as well proceed unilaterally and nonetheless - through a consumption-based policy - bring about a reduction of emissions in non-abating countries, has turned out to be an illusion. Still, there is room for a possible adoption of consumption-based approaches as a means to increase the environmental effectiveness of climate policy - but not in the form of measures unilaterally imposed by industrialized countries, but as a scheme mutually agreed between those countries introducing the measures and those affected by them. 


\section{CHAPTER 12}

\section{Conclusion}

Numerous studies suggest that to have a realistic chance to keep global warming below the internationally agreed $2^{\circ}$ limit, GHG emission will have to peak before 2020 (for a recent study on this issue see e.g. UNEP 2013). Thus, huge abatement efforts within the next years are called for. The prospects that an international agreement on a globally coordinated GHG abatement strategy will enter into force within this decade are however bleak. Countries or coalitions of countries willing to address the problem of climate change therefore have to rely on unilateral action. Naturally, there is an interest in designing such unilateral strategies as effective as possible. One option suggested to increase the effectiveness of unilateral policies is a switch from the current system of a production-based to a consumption-based policy orientation. Such a policy does not target the emissions discharged on the territory of the country that abates, but the emissions embodied in the goods it consumes. This study has analyzed whether such an approach pursued by all (or a group of) industrialized countries can indeed help to increase policy effectiveness - defined in terms of environmental effectiveness, costeffectiveness, and carbon leakage. First, the findings of different - and so far separate strands of the literature on this subject were reviewed. Then - using a stylized analytical model - the effects of a production- and a consumption-based policy were examined and compared. Finally, the question was discussed, whether - and if so, how - a consumption-based policy could be designed for a "real-world" situation that is more effective than a comparable production-based approach.

A switch to a consumption-based orientation in effect extends the reach of the policy beyond the borders of the abating coalition, as it brings the export production of countries not participating in the coalition into the scope of the policy. In the academic literature, a number of arguments can be found that suggest that such a switch implemented by industrialized countries might increase the effectiveness of unilateral policy approaches. In the introduction to this study, four such arguments were presented. A closer examination throughout the course of this study has however revealed that - although all of the arguments appear convincing at first sight - actually none of them can guarantee that a consumption-based policy is indeed more effective than a production-based one. Specifically, the four arguments and the findings relating to them are as follows:

- "With current worldwide production and trade patterns, a consumption-based policy by industrialized countries includes a larger share of global emissions than a production-based policy; under the assumption that abatement costs increase in the level of abatement, it therefore is the more cost-effective option."

- This study finds that it does not suffice to compare the quantities of emissions 
included in the scope of the two policy variants; rather, also the effectiveness of the policy per unit of emissions in bringing about reductions to these emissions has to be considered. In particular, a switch to a consumption-based policy takes the export sector of industrialized countries out of the scope of the policy, but brings imports from developing and emerging economies into the scope. If these economies do not possess low-carbon technologies, they cannot react to the policy by "greening" their production. Thus, either the policy has little effect on imports from these countries, or - potentially even worse from the viewpoint of environmental effectiveness - the exports from developing and emerging economies will not be "greened", but curbed. This however means an income loss for these countries. Due to limits on the size of their trade deficits, these countries might be forced to also reduce imports from industrialized countries and substitute domestic products for these imports. These domestic products will however typically be produced with a higher carbon intensity. In that case, the policy does not cause a drop, but an increase in emissions in developing and emerging economies. Thus, the validity of the first of the four arguments cannot be guaranteed.

- "Abatement costs in some developing and emerging economies are effectively zero. A consumption-based policy could make use of this low-cost abatement potential by bringing the export sector of these economies into the scope of the policy." - The objections against the validity of this argument are similar to some of those against the first argument: The low-cost abatement opportunities in emerging economies can only be exploited by firms that posses the required technology (e.g. firms from industrialized countries via the Kyoto Protocol's CDM). Many firms in developing and emerging economies however may not posses these technologies.

- "The introduction of a consumption-based policy reduces carbon leakage through the competitiveness channel." - This argument may - depending on demand and market structures - actually apply in a sector-wise analysis. Still, two objections can be raised: First, the policy with less leakage is not automatically the environmentally more effective one. To assess environmental effectiveness, one must also compare the effects of the policy in the policy region, and not only consider leakage. Second, in general equilibrium a negative feedback effect on environmental effectiveness due to import substitution in developing and emerging economies (discussed above) may occur.

- "Protecting the competitiveness of the domestic industry by means of a consumption-based approach may allow governments to pursue a more ambitious climate policy." - The problem with this argument is that if the other three arguments do not hold, then a consumption-based approach may not increase the environmental effectiveness of an abatement policy. Thus, the only effect of the policy is actually to protect the domestic industry. Such a policy however can (and most probably will) be challenged in the WTO. 
Thus, this study has shown that some of the most convincing arguments in support of the adoption of a consumption-based approach actually do not hold in general. This, of course, does not imply that they never hold. Nonetheless, this finding clearly has the consequence that it cannot be assumed that a switch to a consumption-orientation will necessarily improve the effectiveness of a policy. Rather, the relative effectiveness of consumption-based approaches depends on a number of parameters and policy design details. This study has identified the following relationships determining the effectiveness of the introduction of a consumption-oriented policy and its impacts on competitiveness and the distribution of policy costs (without loss of generality, it is in some of the arguments assumed that the policy instrument is an emission tax):

- The model-based analysis shows that certain circumstances and parameter values exist that are conducive to the effectiveness of a consumption- as compared to a production-based policy. These are: the abating coalition is small relative to the size of the world economy; it produces with a relatively low carbon-intensity; technological abatement opportunities have already been largely exhausted; the demand for the abating countries' exports is not very price-sensitive, but on the other hand the demand for the non-abating countries domestic products is highly sensitive to cross price effects triggered by the abating countries' exports. Non abating countries, in contrast, produce with a high carbon-intensity, but posses the technology to reduce it.

- However - partly in contradiction to the previous point - small abating coalitions are confronted with the risk that the effectiveness of a consumptionbased policy is undermined by a redirection of trade flows.

- In the model of this study, a policy without an import border adjustment (which includes a larger share of global emissions than either a production- or a consumption-based policy) is more effective than either of the other policy variants. This finding, however, contrasts with some result from CGE models.

- The effects of policy transmission via energy markets do not change the ranking of the different policy variants in terms of environmental effectiveness - they lower the effectiveness of all variants by the same percentage.

- A consumption-based policy may further technological spillovers to sectors in developing and emerging economies producing for their home market. However, the export industry of these countries would have to be first supported by technology transfer from industrialized nations.

- To be able to use carbon leakage as an indicator for policy effectiveness also for consumption-based policies, its definition must be adjusted as compared to the definition valid for production-based policies. This study however recommends being cautious with using carbon leakage as an effectiveness indicator when comparing policies - switching the policy-base typically also alters the effectiveness of the policy within the policy region. Thus the policy variant with the smallest leakage ratio is not necessarily the environmentally most effective one. 
- For the abating region, a consumption-based policy will be the one with the most favorable effects on competitiveness (but the reverse holds true for the nonabating region).

- Both a production- and a consumption-based policy will typically cause costs to abating as well as to non-abating countries. The split of costs between the two groups of countries depends on the quantities of emissions embodied in imports and exports, on the cost pass-through rates (i.e. the question how much of the burden of an emissions tax is passed on), and on the question whether a country is a fuel importer or exporter. While most CGE studies come to the result that a switch to a consumption-based policy causes welfare losses for developing and emerging countries, the model of this study demonstrates that - under the assumption of high cost-pass through rates - also the opposite result is possible.

Making use of these findings, this study has developed a number of recommendations for the practical design of a consumption-based policy. To be politically and practically feasible, a policy design proposal must however fulfil more criteria than just enhancing the effectiveness of the policy. In this study it was assumed that additionally a switch of the policy-orientation should not increase the burdens of the policy on developing and emerging economies, should meet the criterion of "perceived fairness," should stand a reasonable chance to conform to WTO rules, and be practicable. This led to the formulation of the following recommendations:

- The revenues of the tax on imports of the abating countries should be allocated to non-abating countries, i.e. to developing and emerging economies.

- The transfer of "green" technology to developing and emerging economies should be fostered.

- The introduction of an export rebate can be regarded as optional. With current production, emission, and trade patterns most effects of a consumption-based policy stem from the import tariff.

- The policy instrument should be designed such as to incentivize the adoption of low-carbon production technologies by developing and emerging economies.

In the literature two methods to change the policy base to a consumption orientation are discussed: border carbon adjustments and a so-called "carbon added" scheme. Border carbon adjustments start with a production-based emissions accounting system, but levy a tariff on carbon embodied in imports and grant a rebate on emissions taxes paid for carbon embodied in exports. Such adjustments could be introduced relatively quickly; however, the design of a border adjustment scheme that fulfills the fourth of the policy design proposal above appears to be practically infeasible if the countries targeted by the scheme do not cooperate in its implementation: to impose a correct border tax on imports, one needs information on the emissions discharged at every step of production of a good - a virtual impossibility with today's long value added chains that often extend through several countries. If, as is often suggested, instead of the correct carbon content a benchmark is used to determine the border tax, the incentive effect of the tax will be lost: the exporter cannot lower her tax dues by "greening" her production 
technology. One of the central arguments of this study is that if the incentive effect of the tax is lost, also the environmental effectiveness of the policy will be reduced. In the extreme the policy may not lower, but even raise global emissions as it will curb - and not "green" - the exports of developing and emerging economies and may thus, as described above, trigger import substitution with all its negative effects for the environment. To summarize, there may be some specific cases where the introduction of a consumption-based policy orientation by means of border carbon adjustments improves the effectiveness of a unilateral policy even if cooperation with the countries affected by the scheme proves impossible. In general, however, such an approach cannot be regarded as an effective method to enhance the environmental effectiveness and/or cost-effectiveness of a unilateral abatement strategy and is therefore not recommended in this study.

If cooperation with countries affected by a border carbon adjustment scheme can be agreed, it may however be possible to design the scheme such that it improves the environmental and/or cost-effectiveness of a unilateral abatement policy. For that to be the case, the scheme should help to lower the carbon-intensity in production in developing and emerging economies. This can be achieved by either agreeing with affected countries on a scheme that provides appropriate incentive effects, for example by combining a "worst practice" benchmark with the possibility for producers to prove that they perform better (such a scheme would contradict WTO rules and can therefore not be introduced unilaterally). Alternatively, the scheme could influence the carbonintensity in affected countries not via incentives, but through a direct commitment of affected countries to implement "green" technology in export production. Such "green" technology projects in affected countries could be financed from the revenues of the border measures. Both these shemes are however not "full border carbon adjustments" therefore the gains in environmental and/or cost-effectivenes that could possibly be achieved by their implementation will typically be smaller than those predicted by theoretical models for "full adjustments." Also, as these possible gains in effectiveness additionally depend on demand, production, and trade parameters as discussed above, no general conclusion on their size can be drawn. Therefore, every proposed border carbon adjustment scheme must be assessed individually to determine whether - and if so, by how much - it improves the environmental and/or cost-effectiveness of a unilateral abatement policy. Also, if cooperation with affected countries is possible, other methods to improve climate policy effectiveness that also rely on a certain level of cooperation - for example agreements that "level the playing field" only for certain sectors - may be feasible, too. The use of border carbon adjustments in such a situation thus can only be recommended if the proposed scheme indeed improves environmental and/or cost-effectiveness (and also meets the other criteria for practical and political fesability listed above) and also compares favorable to other methods that enhance policy effectiveness.

In the long run, the policy base could however be switched not by border adjustments, but by a "carbon added" scheme - a system that, just like a value added tax records value added at every step of production, would record all emissions discharged in the course of the production of a good. Thus, information on carbon embodied in 
every good would be readily available, and correct taxation preserving the intended incentive effects should be possible. The system could therefore be used to introduce a consumption-based policy that may - if all other conditions on parameter values discussed above are fulfilled - indeed increase policy effectiveness. The introduction of such a scheme would, however, require the cooperation of (nearly) all countries in the world. Its possible realization therefore is a long-term project.

This study has started with the obvservation that the share of emissions embodied in the exports of emerging economies is large and growing, and abatement costs in many of these countries are indeed still low. However it was found that - if implemented unilaterally - a switch to a consumption-based policy by industrialized countries is not an appropriate approach to exploit this "abatement potential." Introducing border carbon adjustments for other reasons than to further environmental effectiveness - for example, to protect the competitiveness of the industry of abating countries or to apply political pressure to countries not wanting to join an abating coalition can however not be recommended - it may poison the climate of the international climate negotiations and prevent any progress on a global abatement treaty. The situation is different if it is assumed that cooperation with affected countries is possible - then, the environmental effectiveness of the policy may indeed be enhanced by a switch to a consumption-based approach. But assuming international cooperation means that one actually not anymore analyses methods to improve "unilateral" abatement policies, but an - albeit limited - multilateral approach to climate policy. The level of international cooperation required is still quite low if the aim is just to introduce an environmentally "meaningful" border adjustment scheme in the short run, but it is already substantial if one wants to establish a "carbon added" scheme in the longer run. Consumption-based approaches to climate policy should therefore be best discussed not as an additional "tool" of unilateral climate policy, but rather as a possible intermediate step on the way from unilateral to full multilateral approaches to mitigation. For developing and emerging economies it may make sense to follow such a step-wise approach i.e.to first have a stringent climate policy applied to their export industry, before it is applied to their entire economy. Thus there is indeed a place for consumption-based approaches in international climate policy - however not as a unilaterally imposed, but as a multilaterally agreed measure to improve the environmental and/or cost-effectiveness of global abatement efforts. 


\section{References}

ADEME (2007). Guide des facteurs d'émissions, Bilan Carbone: Entreprises et Collectivités, Version 5. Agence de l'Environnement Mission Interministérielle et de la Maîtrise de l'Energie, Paris. Available at: <http://www.energies-davenir.com/bibliothequeea/production_energie_reseau_alimentation/bilan_carbone_guide_facteurs_emissions_ V5.pdf $>$ [Accessed on 2 November 2013].

Ahmad, N. and A. Wyckoff (2003). Carbon dioxide emissions embodied in international trade of goods. OECD Science, Technology and Industry Working Papers, 2003/15. Organisation for Economic Co-operation and Development, Paris.

Aichele, R., and G. Felbermayr (2012). Kyoto and the Carbon Content of Trade. Journal of Environmental Economics and Management, 63: 336-354.

Alexeeva-Talebi, V., N. Anger and A. Löschel (2010). Alleviating Adverse Implications of EU Climate Policy on Competitiveness: The Case for Border Tax Adjustments or the Clean Development Mechanism? In: V. Ghosal, Reforming Rules and Regulations. CESifo Seminar Series, The MIT Press, Boston.

Alexeeva-Talebi, V., C. Boehringer, U. Moslener (2007). Climate and Competitiveness: an Economic Impact Assessment of EU Leadership in Emission Control Policies. Centre for European Economic Research (ZEW), Mannheim.

Allen, R. G. D. (1938). Mathematical Analysis for Economists. St. Martin's Press, New York.

Andrew, R. and V. Forgie (2008). A three-perspective view of greenhouse gas emission responsibilities in New Zealand. Ecological Economics, 68: 194-204.

Antimiani, A., V. Costantini, C. Martini, L. Salvatici, M.C. Tommasino (2013). Assessing alternative solutions to carbon leakage. Energy Economics, 36: 299-311.

Armington, P.S. (1969). A theory of demand for products distinguished by place of production. IMF Staff Paper 16 (1): 159-178. International Monetary Fund, Washington, D.C.

Artus, J. R., M. D. Knight (1984). Issues in the Assessment of the Exchange Rate of Industrial Countries. IMF Occasional Papers, 29. International Monetary Fund, Washington, D.C.

Babiker, M.H. (2005). Climate change policy, market structure, and market leakage. Journal of International Economics, 65: 421-445.

Babiker, M.H. and T.F. Rutherford (2005). The economic effects of border measures in subglobal climate agreements. Energy Journal, 26(4): 99-126.

Barker, T., S. Junankan, H. Pollitt, P. Summerton (2007). Carbon leakage from unilateral enviromental tax reforms in Europe, 1995-2005. Energy Policy, 35: 6281-6292.

Barrett, S. (1998). Political Economy of the Kyoto Protocol. Oxford Review of Economic Policy, 14(4): 20-39.

Barrett, S. and R. Stavins (2003). Increasing participation and compliance in International climate change agreements. International Environmental Agreements: Politcs, Law, and Economics, 3 (4): 349-376. 
Bastianoni, S., F. M. Pulselli, E. Tiezzi (2004). The problem of assigning responsibility for greenhouse gas emissions. Ecological Economics, 49: 253-257.

Bednar-Friedl, B., V. Kulmer, T. Schinko (2012a). The effectiveness of anti-leakage policies in the European Union: results for Austria. Empirica, 39(2): 233-260.

Bednar-Friedl, B., T. Schinko, K.W. Steininger (2012b). The relevance of process emissions for carbon leakage: A comparison of unilateral climate policy options with and without border carbon adjustment. Energy Economics, 34, Supplement 2: S168-S180.

Bernard, A. and M. Vielle (2009). Assessment of European Union transition scenarios with a special focus on the issue of carbon leakage. Energy Economics, 31:S274-S284.

Boehringer, C., E. Balistreri, T. Rutherford (2012a). The role of border carbon adjustment in unilateral climate policy: Overview of an Energy Modelling Forum study (EMF29), Energy Economics, 34, Supplement 2: S97-S110.

Boehringer, C., B. Bye, T. Faehn, K. E. Rosendahl (2012b). Alternative designs for tariffs on embodied carbon: A global cost-effectiveness analysis. Energy Economics, 34: 143-153.

Boehringer, C., J. Carbone, T. Rutherford (2011). Embodied carbon tariffs. NBER Working Paper 17376. National Bureau of Economic Research, Cambridge, MA.

Boehringer, C., M. Ferris, T.F. Rutherford (1998). Alternative $\mathrm{CO}_{2}$ abatement strategies for the European Union. In: J.B. Braden, S. Proost (Eds.), Climate Change, Transport and Environmental Policy. Edward Elgar Publishing, Northampton, MA.

Boehringer, C., C. Fischer, K. E. Rosendahl (2010a). The Global Effects of Subglobal Climate Policies. The B.E. Journal of Economic Analysis \& Policy, 10 (2), (Symposium), Article 13.

Boehringer, C., A. Lange, T. Rutherford (2010b). Optimal emission pricing in the presence of international spill-overs: decomposing leakage and terms-of-trade motives. NBER Working Paper 15899. National Bureau of Economic Research, Cambridge, MA.

Boeters, S. and J. Bollen (2012). Fossil fuel supply, leakage and the effectiveness of border measures in climate policy. Energy Economics, 34: S181-S189.

Boston Consulting Group (2008). Assessment of the Impact of the 2013-2020 ETS Proposal on the European Cement Industry: Final Project Report - Executive Summary.

November. Available at:

$<$ http://www.flacema.org/flacema/images/stories/Articulos_MA/bcg20assessment_im pact202013-2020.pdf> [Accessed on 2 November 2013].

Braham, M. and M. van Hees (2009). Degrees of Causation. Erkenntnis, 71: 323-344.

Brewer, T.L. (2010). Trade policies and climate change policies: a rapidly expanding joint agenda. The World Economy, 33 (6): 799-809.

Burniaux J.M., J. Chateau, R. Duval (2010). Is there a case for carbon-based border tax adjustment? An applied general equilibrium analysis. OECD Economics Department Working Paper, No. 794. Organisation for Economic Co-operation and Development, Paris.

Burniaux, J.-M., J. Oliveira Martins (2012). Carbon leakages: a general equilibrium view. Economic Theory, 49: 473-495. 
Carbon Trust (2010), Tackling carbon leakage - Sector-specific solutions for a world of unequal carbon prices. Report CTC 767. The Carbon Trust, London. Available at: $<$ http://www.carbontrust.com/media/84908/ctc767-tackling-carbon-leakage.pdf> [Accessed on 25 September 2013].

Clapp, C. (2010). Levelling the Playing Field in a Fragmented Carbon Market: Do CarbonBased Border Tax Adjustments Work? Climate Science and Policy. Available at: $<$ http://www.climatescienceandpolicy.eu/2010/09/levelling-the-playing-field-in-afragmented-carbon-market-do-carbon-based-border-tax-adjustments-work/> [Accessed on March 7, 2011].

Clarke, H. (2010). Carbon Leakages, Consumption-based Carbon Taxes and International Climate Change Agreements. Economic Papers, 29 (2): 156-168.

Copeland, B. R. and M. S. Taylor (1994). North-South trade and the environment. Quarterly Journal of Economics, 109: 755-787.

Cosbey, A., S. Droege, C. Fischer, J. Reinaud, J. Stephenson, L. Weischer, P. Wooders (2012). A Guide for the Concerned: Guidance on the elaboration and implementation of border carbon adjustment. Policy report 03 (November). Entwined, Stockholm. Available at: <http://www.iisd.org/pdf/2012/bca_guidance.pdf > [Accessed on April 3, 2013].

Davis, S.J., K. Caldeira (2010). Consumption-based accounting of $\mathrm{CO}_{2}$ emissions. Proceedings of the National Academy of Science of the United States, 107: 5687-5692.

Davis, S.J., G.P. Peters, K. Caldeira (2011). The supply chain of $\mathrm{CO}_{2}$ emissions. Proceedings of the National Academy of Sciences of the United States, 108: 18554-18559.

Demailly, D. and P. Quirion (2008). Leakage from Climate Policies and Border Tax Adjustment: Lessons from a Geographic Model of the Cement Industry. In: R. Guesnerie and H. Tulkens, Eds., The Design of Climate Policy, papers from a Summer Institute held in Venice. CESifo Seminar Series, The MIT Press, Boston.

Demailly, D. and P. Quirion (2006). $\mathrm{CO}_{2}$ abatement, competitiveness and leakage in the European cement industry under the EU ETS: grandfathering vs. output-based allocation. Climate Policy, 6(1): 93-113.

Dong, Y. and J. Whalley (2009). How Large Are the Impacts of Carbon Motivated Border Tax Adjustments? NBER Working Paper 15613. National Bureau of Economic Research, Cambridge, MA.

Droege, S. (2011). Using border measures to address carbon flows. Climate Policy 11: 11911201.

Droege, S. and S. Cooper (2010). Tackling leakage in a world of unequal carbon prices $-A$ study for the Greens/EFA Group. Climate Strategies, Cambridge.

Droege, S., H. van Asselt, T. Brewer, M. Grubb, R. Ismer, Y. Kameyama, M. Mehling, S. Monjon, K. Neuhoff, P. Quirion, K. Schumacher, L. Mohr, W. Suwala, Y. Takamura, T. Voituriez, X. Wang (2009). Tackling leakage in a world of unequal carbon prices. Report. Climate Strategies, Cambridge.

Economist (2011). Greenhouse gases: The cost of trade - Rich countries are outsourcing carbon-dioxide emissions. The Economist online (Apr 26 $\left.{ }^{\text {th }}, 17: 30\right)$. Available at: $<$ http://www.economist.com/blogs/dailychart/2011/04/greenhouse_gases $>$ [Accessed on September 7, 2013]. 
Edenhofer, O., B. Knopf, G. Luderer (2010). From Utopia to Common Sense: The Climate Mitigation Challenge. In: E. Cerda and X. Labandeira, Eds., Climate Change Policies: Global Challenges and Future Prospects. Edward Elgar Publishing, Cheltenham.

Eder, P. and M. Narodoslawsky (1999). What environmental pressures are a region's industries responsible for? A method of analysis with descriptive indices and inputoutput models. Ecological Economics, 29: 359-374.

Endres, A. (2012). Klimazölle können der Umwelt schaden. Zeit online, September 24. Available at: <http://www.zeit.de/wirtschaft/2012-09/klima-zoelle-pik> [Accessed on 22 August 2013].

European Parliament and the Council of the EU (2009). Directive 2009/29/EC of the European Parliament and of the Council of 23 April 2009 amending Directive 2003/87/EC so as to improve and extend the greenhouse gas emission allowance trading scheme of the Community. Official Journal of the European Union, L 140, 5 June 2009: 63-86.

Felder, S. and T.F. Rutherford (1993). Unilateral Action and Carbon Leakage: The Consequences of International Trade in Oil and Basic Materials. Journal of Environmental Economics and Management, 25: 162-176.

Ferng, J.-J. (2003). Allocating the responsibility of CO2 over-emissions from the perspectives of benefit principle and ecological deficit. Ecological Economics, 46: 121-141.

Fischer, C., A. K. Fox (2012). Comparing Policies to Combat Emissions Leakage: Border Carbon Adjustments versus Rebates. Journal of Environmental Economics and Management 64 (2), 199-216.

Gerlagh, R. and O. Kuik (2007). Carbon Leakage with International Technology Spillovers. FEEM Nota Di Lavoro 33.2007. Fondazione Eni Enrico Mattei, Venice.

Graichen, V., K. Schumacher, F. C. Matthes, L. Mohr, V. Duscha, J. Schleich, J. Diekmann (2008). Impacts of the EU Emissions Trading Scheme on the industrial competitiveness in Germany. Research Report 370741501 (Climate Change 10/8), Umweltbundesamt, Dessau.

Gros, D. (2009). Global Welfare Implications of Carbon Border Taxes. CEPS Working Document No. 315/July. Center for European Policy Studies, Brussels.

Gros, D., C. Egenhofer, N. Fujiwara, A. Georgiev, S. S. Guerin (2010), Climate Change and Trade: Taxing carbon at the border? CEPS Paperbacks. Center for European Policy Studies, Brussels.

Gros, D. and C. Egenhofer (2011). The case for taxing carbon at the border. Climate Policy 11(5): 1262-1268.

Grossman, G.M. (1980). BTA: Do They Distort Trade? Journal of International Economics, 10: $117-128$.

Grossman G.M. and A.B. Krueger (1991). Environmental impacts of a North American free trade agreement. NBER Working Paper No. 3914. National Bureau of Economic Research, Cambridge, MA.

Grubb, M.J. (2011). International climate finance from border carbon cost levelling. Climate Policy, 11(3): 1050-1057.

Hertwich, E.G. and G.P. Peters (2009): Carbon footprint of nations: a global, trade-linked analysis. Environmental Science and Technology, 43: 6414-6420. 
Hoel, M. (1996). Should a carbon tax be differentiated across sectors? Journal of Public Economics 59, 17-32.

Hoerner, J. and F. Muller (1996). Carbon Taxes for Climate Protection in a Competitive World. Paper prepared for the Swiss Federal Office for Foreign Economic Affairs. Environmental Tax Program of the Center for Global Change, University of Maryland, College Park.

Hollinger, P. (2009). Sarkozy calls for carbon tax on imports. Financial Times online, September 10, 7:00 pm. Available at: <http://www.ft.com/cms/s/0/a5fb6084-9e3211de-b0aa-00144feabdc0.html\#axzz2eOwKsycc> [Accessed on 9 September 2013].

Hourcade, J.C., D. Demailly, K. Neuhoff, M. Sato, M. Grubb, F. Matthes, and V. Graichen (2008). Differentiation and Dynamics of EU-ETS Industrial Competitiveness Impacts: Final Report. Climate Strategies, Cambridge.

Houser, T., R. Bradley, B. Childs, J. Werksman, R. Heilmayr (2008). Leveling the Carbon Playing Field. Peterson Institute for International Economics/World Resources Institute, Washington DC.

IPCC (1997). Revised 1996 IPCC Guidelines for National Greenhouse Gas Inventories: Volumes 1, 2 and 3. J.T. Houghton, L.G. Meira Filho, B. Lim, K. Tréanton, I. Mamaty, Y. Bonduki, D.J. Griggs, and B.A. Callander, Eds.; Intergovernmental Panel on Climate Change (IPCC), IPCC/OECD/IEA, Paris, France.

IPCC (2007). Climate Change 2007: Mitigation of Climate Change. Contribution of Working Group III to the Fourth Assessment Report of the Intergovernmental Panel on Climate Change. B. Metz, O.R. Davidson, P. R. Bosch, R. Dave, L. A. Meyer (eds.). Cambridge University Press, Cambridge, UK/New York.

IPCC (2013) Summary for Policymakers. In: Climate Change 2013: The Physical Science Basis. Contribution of Working Group I to the Fifth Assessment Report of the Intergovernmental Panel on Climate Change. Stocker, T.F., D. Qin, G.-K. Plattner, M. Tignor, S. K. Allen, J. Boschung, A. Nauels, Y. Xia, V. Bex and P.M. Midgley (eds.). Cambridge University Press. Cambridge, UK/New York.

Ismer, R., and K. Neuhoff (2007). Border tax adjustment: a feasible way to support stringent emission trading. European Journal of Law and Economics, 24: 137-164.

Ismer, R., and K. Neuhoff (2009). Border Tax Adjustment: A Feasible way to Address Nonparticipation in Emission Trading. Cambridge Working Papers in Economics, CWPE 0409. University of Cambridge.

Jaffe, A.B., S.R. Peterson, P.R. Portney, R. Stavins (1995). Environmental regulation and the competitiveness of U.S. manufacturing. Journal of Economic Literature, March, 33(1), 132-163.

Jakob, M., R. Marschinski (2013). Interpreting trade-related CO2 emission transfers. Nature Climate Change, 3 (1): 19-23.

Karp, L. (2012). Carbon Leakage in General and Partial Equilibrium. University of California, Berkeley.

Karp, L. (2011). The Environment and Trade. Annual Review of Resource Economics, 3: 397417.

Kerry-Lieberman (2010), American Power Act. Draft U.S. Senate bill. Available at: $<$ http://www.c2es.org/docUploads/APAbill.pdf> [Accessed on September 25, 2013]. 
Khor, M. and H. Jhamtani (2009). India, G77 Propose Text Against Trade Protection in Copenhagen Draft. South Bulletin, Issue 40 (September 10). Available at: $<$ https://www.dropbox.com/sh/ak9e8qp573hagbx/oJUvJVQJQS/SB 40_The Rise of Climate Protectionism/SB 40.pdf $>$ [Accessed on September 12, 2013].

Kondo, Y., Y. Moriguchi, H. Shimizu (1998). $\mathrm{CO}_{2}$ Emissions in Japan: Influences of Imports and Exports. Applied Energy, 59 (2-3): 163-174.

Krugman, P. (2009). Climate, trade, Obama. The New York Times, June 29. Available at: <http://krugman.blogs.nytimes.com/2009/06/29/climate-trade-obama/?_r=0> [Accessed on September 25, 2013].

Kuik, O., M. Hofkes (2010). Border adjustment for European emissions trading: competitiveness and carbon leakage. Energy Policy, 38(4): 1741-1748.

Lenzen, M., L.-L. Pade, J. Munksgaard, (2004). $\mathrm{CO}_{2}$ multipliers in multi-region input-output models. Economic Systems Research, 16: 391-412.

Lenzen, M., J. Murray, F. Sack, T. Wiedmann (2007). Shared producer and consumer responsibility - Theory and practice. Ecological Economics, 61: 27-42.

Lenzen, M. and J. Murray (2010). Conceptualising environmental responsibility. Ecological Economics, 70: 261-270.

Lininger, C. (2013). Consumption Based Approaches in International Climate Policy: An Analytical Evaluation of the Implications for Cost-Effectiveness, Carbon Leakage, and the International Income Distribution. Graz Economics Papers 2013-03, University of Graz.

Lockwood, B. and J.Whalley (2008). Carbon Motivated Border Tax Adjustments: Old Wine in Green Bottles? NBER Working Paper No. 14025. National Bureau of Economic Research, Cambridge, MA.

Manders, T., P. Veenendaal (2008). Border tax adjustments and the EU-ETS: a quantitative assessment. CPB document No 171, October. CPB Netherlands Bureau for Economic Policy Analysis, The Hague. Available at: <http://www.cpb.nl/sites/default/files/ publicaties/download/border-tax-adjustment-and-eu-ets-quantitative-assessment.pdf> [Accessed on May 20, 2011].

Markusen, J. R. (1975). International externalities and optimal tax stuctures, Journal of International Economics, 5: 15-29.

Marques, A., J. Rodrigues, M. Lenzen and T. Domingos (2012). Income-based environmental responsibility. Ecological Economics, 84: 57-65.

Mas-Colell, A., M.D. Whinston and J.R. Green (1995). Microeconomic Theory. Oxford University Press.

Mattoo, A., A. Subramanian, D. van der Mensbrugghe and J. He (2009). Reconciling Climate Change and Trade Policy. World Bank Policy Research Working Paper No. 5123. World Bank, Washington D.C.

McKibbin, W. J., P. J. Wilcoxen (2009). The economic and environmental effects of border tax adjustments for climate policy. CAMA working paper 9/2009. Center for Applied Macroeconomic Analysis, The Australian National University.

Miltner, A. and R. Salmons (2007). An assessment of the impacts of environmental tax reforms on the competitiveness of selected industrial sectors. Competitiveness Effects of Environmental Tax Reforms - COMETR, Final report to the European Commission. 
Monjon, S. and P. Quirion (2009). Assesing leakage in the EU ETS: Results from the CASE II model. Climate Strategies Working Paper, Cambridge, UK.

Monjon, S. and P. Quirion (2010). How to design a border adjustment for the European Union emissions trading system? Energy Policy, 98(9): 5199-5207.

Monjon, S. and P. Quirion (2011). Addressing leakage in the EU ETS: Border adjustment or output-based allocation? Ecological Economics, 70: 1957-1971.

Mueller, B. and A.Sharma (2005). Trade tactic could unlock climate negotiations.

SciDev.Net. Available at: <http://www.scidev.net/global/climate-

change/opinion/trade-tactic-could-unlock-climate-negotiations.html> [Accessed on May 1, 2013].

Munksgaard, J. and K. Pedersen (2001). CO2 accounts for open economies: producer or consumer responsibility? Energy Policy 21: 327-334.

Muñoz, P., K. W. Steininger (2010). Austria's CO2 responsibility and the carbon content of its international trade. Ecological Economics, 69(10): 2003-2019.

Nakano, S., A. Okamura, N. Sakurai, M. Suzuki, I. Tojo, N. Yamano (2009). The Measurement of $\mathrm{CO} 2$ Embodiments in International Trade: Evidence from the Harmonised Input-Output and Bilateral Trade Database. OECD Science, Technology and Industry Working Papers, 2009/3. Organisation for Economic Co-operation and Development, Paris.

Neuhoff, K. (2008): Tackling Carbon. How to Price Carbon for Climate Policy. University of Cambridge. Available at: <http://www.eprg.group.cam.ac.uk/wp-content/uploads/ 2009/03/tackling-carbon_final_3009082.pdf> [Accessed on November 15, 2013].

Neuhoff, K. and R. Ismer (2008). International cooperation to limit the use of border adjustment. Workshop Summary. Climate Strategies workshop, Cambridge. Available at: <http://www.eprg.group.cam.ac.uk/wp-content/uploads/2008/11/ba-workshopreport_nov-6-2008.pdf> [Accessed on November 15, 2013].

OECD (2009). The Economics of Climate Change Mitigation: Policies and Options for Global Action Beyond 2012. Paris.

Pan, J., J. Phillips, Y. Chen (2008). China's balance of emissions embodied in trade: approaches to measurement and allocating international responsibility. Oxford Review of Economic Policy, 24 (2): 354-376.

Pauwelyn, J. ( 2007). U.S. Federal Climate Policy and Competitiveness Concerns: The Limits and Options of International Trade Law. Working Paper 07-02. Nicholas Institute for Environmental Policy Solutions, Duke University, Durham, NC.

Peters, G. P. (2008). From production-based to consumption-based national emissions inventories, Ecological Economics 65: 13-23

Peters, G. P. and E. G. Hertwich (2006). Pollution embodied in trade: the Norwegian case. Global Environmental Change, 16: 379-387.

Peters, G.P., E.G. Hertwich (2008a). CO2 embodied in international trade with implications for global climate policy. Environmental Science and Technology, 42(5): 1401-1407.

Peters,G.P., E.G. Hertwich (2008b). Post-Kyoto greenhouse gas inventories: Production versus consumption. Climatic Change, 86(1-2): 51-66. 
Peters, G.P., J.C. Minx, C.L. Weber, O. Edenhofer (2011). Growth in emission transfers via international trade from 1990 to 2008. Proceedings of the National Academy of Science of the United States, 108(21): 8903-8908.

Peterson, E.B. and J. Schleich (2007). Economic and environmental effects of border tax adjustments. Working Paper sustainability and innovation No. S1/2007. Fraunhofer Institute for Systems and Innovation Research (ISI), Karlsruhe.

Quirion, P. (2010). Competitiveness and Leakage. In: E. Cerda and X. Labandeira (eds.), Climate Change Policies: Global Challenges and Future Prospects, Edward Elgar Publishing, Cheltenham.

Reinaud, J. (2008a). Issues Behind Competitiveness and Carbon Leakage - Focus on Heavy Industry. IEA Information Paper, International Energy Agency/OECD, Paris.

Reinaud, J. (2008b). Climate Policy and Carbon Leakage - Impacts of the European Emissions Trading Scheme on Aluminium. IEA Information Paper, IEA/OECD, Paris.

Rodrigues, J., T. Domingos, S. Giljum, F. Schneider (2006). Designing an indicator of environmental responsibility. Ecological Economics, 59: 256-266.

Rodrigues, J. and T. Domingos (2008). Consumer and producer environmental responsibility: comparing two approaches. Ecological Economics, 66: 533-546.

Sampson, G. (1998). WTO Rules and Climate Change: The Need for Policy Coherence. In: W.B. Chambers, Ed., Global Climate Governance: Inter-linkages between the Kyoto Protocol and Other Multilateral Regimes. United Nations University Press, Tokio.

Shui, B. and R. Harriss (2006). The role of $\mathrm{CO}_{2}$ embodiment in US-China trade. Energy Policy, 34: 4063-4068.

Springmann, M. (2013). Carbon tariffs for financing clean development. ClimatePolicy, 13 (1), 20-42.

Steininger, K., C. Lininger, S. Droege, D. Roser, L. Tomlinson (2012). Towards a Just and Cost-Effective Climate Policy: On the Relevance and Implications of Deciding between a Production versus Consumption Based Approach. Graz Economic Papers 12-06.

Steininger, K.W., C. Lininger, S. Droege, D. Roser, L. Tomlinson, L. Meyer (2014). Justice and cost effectiveness of consumption-based versus production-based approaches in the case of unilateral climate policies, Global Environmental Change, 24: 75-87.

Stern, N. (2007). The Economics of Climate Change - The Stern Review. Cambridge University Press.

Stiglitz, J. E. (2007). Making Globalization Work. Paperback edition. W.W. Norton \& Co, New York.

UNEP (2013). The Emissions Gap Report 2013. United Nations Environment Programme (UNEP), Nairobi.

UNFCCC (1992). United Nations Framework Convention on Climate Change. United Nations, New York.

UNFCCC (1998a). Kyoto Protocol to the Framework Convention on Climate Change. United Nations, New York.

UNFCCC (1998b). Decision 2/CP.3. Methodological issues related to the Kyoto Protocol. FCCC/CP/1997/7/Add.1. United Nations Framework Convention on Climate Change, Bonn. 
UNFCCC (2010). Decision 2/CP.15. Copenhagen Accord. FCCC/CP/2009/11/Add.1. United Nations Framework Convention on Climate Change, Bonn.

UNFCCC (2011a). Compilation of economy-wide emission reduction targets to be implemented $b$ Parties included in Annex I to the Convention.

FCCC/SB/2011/INF.1/Rev.1. United Nations Framework Convention on Climate Change, Bonn.

UNFCCC (2011b). Compilation of information on nationally appropriate mitigation actions to be implemented by Parties not included in Annex I to the Convention. FCCC/AWGLCA/2011/INF.1. United Nations Framework Convention on Climate Change, Bonn.

UNFCCC (2011c). Decision 1/CP.17. Establishment of an Ad Hoc Working Group on the Durban Platform for Enhanced Action. FCCC/CP/2011/9/Add.1. United Nations Framework Convention on Climate Change, Bonn.

UNFCCC (2011d). Decision 1/CP.16.The Cancun Agreements: Outcome of the work of the Ad Hoc Working Group on Long-term Cooperative Action under the Convention. FCCC/CP/2010/7/Add.1. United Nations Framework Convention on Climate Change, Bonn.

UNFCCC (2012). Decision 2/CP.18. Advancing the Durban Platform. FCCC/CP/2012/8/Add.1. United Nations Framework Convention on Climate Change, Bonn.

UNFCCC (2013). Decision -/CP.19 (Advance unedited version). Further advancing the Durban Platform. United Nations Framework Convention on Climate Change, Bonn.

Van Asselt, H., and F. Biermann (2007). European Emissions Trading and the International Competitiveness of Energy-intensive Industries: a Legal and Political Evaluation of Possible Supporting Measures. Energy Policy, 35: 497-506.

Van Asselt, H., and T. Brewer (2010). Addressing competitiveness and leakage concerns in climate policy: An analysis of border adjustment measures in the US and the EU. Energy Policy, 38: 42-51.

Venmans, F. (2012). A literature-based multi-criteria evaluation of the EU ETS. Renewable and Sustainable Energy Reviews, 16(8): 5493-5510.

Voituriez, T., X. Wang (2011). Getting the carbon price right through climate border measures: a Chinese perspective. Climate Policy, 11: 1257-1261.

Wang, X., and T. Voituriez (2009). Can Unilateral Trade Measures Significantly Reduce Leakage and Competitiveness Pressures on EU-ETS-Constrained Industries? The case of China export taxes and VAT rebates. Working Paper. Climate Strategies, Cambridge, UK.

Waxman-Markey (2009). The American Clean Energy and Security Act (H.R. 2454). U.S. House, $111^{\text {th }}$ Congress, $1^{\text {st }}$ Session. Available at: <http://www.opencongress.org/ bill/111-h2454/text> [Accessed on September 22, 2013].

WBGU (2009), German Advisory council on Global Change. Solving the climate dilemma: The budget approach. Special Report, Berlin.

Weber, C.L., and G.P. Peters (2009).Climate change policy and international trade: Policy considerations in the US. Energy Policy, 37: 432-440

Weyant, J. P., J. N. Hill (1999). The Costs of the Kyoto Protocol: A Multi-model Evaluation, Introduction and Overview. The Energy Journal (Special Issue). 
White House (2001). President Bush Discusses Global Climate Change. [press release] 11 June 2001. Available at: <http://georgewbush-whitehouse.archives.gov/news/releases/ 2001/06/20010611-2.html> [Accessed on September 22, 2013].

Wiedmann, Thomas (2009). A review of recent multi-region input-output models used for consumption-based emission and resource accounting, Ecological Economics, 69: 211-222.

Wiedmann, T., M. Lenzen, K. Turner, J. Barrett (2007). Examining the global environmental impact of regional consumption activities - part 2: review of input-output models for the assessment of environmental impacts embodied in trade. Ecological Economics, 61(1): 15-26.

Winchester, N. (2011). The impact of border carbon adjustments under alternative producer responses. Report No. 192, MIT Joint Program on the Science and Policy of Global Change, Massachusetts Institute of Technology, Boston.

World Bank (2007). International Trade and Climate change - Economic, Legal, and Institutional Perspectives. The World Bank, Washington, DC.

World Resources Institute (2010). U.S. Climate Action in 2009-2010. WRI fact sheet (September). Available at: <http://pdf.wri.org/factsheets/ factsheet_us_climate_action_in_2009-2010.pdf> [Accessed on September 9, 2013].

WTO/UNEP (2009). Trade and Climate Change. Report by the United Nations Environment Programme and the World Trade Organization, World Trade Organization Publications, Geneva.

Wyckoff, A. W. and J. M. Roop (1994). The embodiment of carbon in imports of manufactured products: implications for international agreements on greenhouse gas emissions. Energy Policy, 22: 187-194. 